\title{
IDENTIFICACIÓN DE BIOMARCADORES EPIGENÉTICOS EN LA ENFERMEDAD DE ALZHEIMER
}

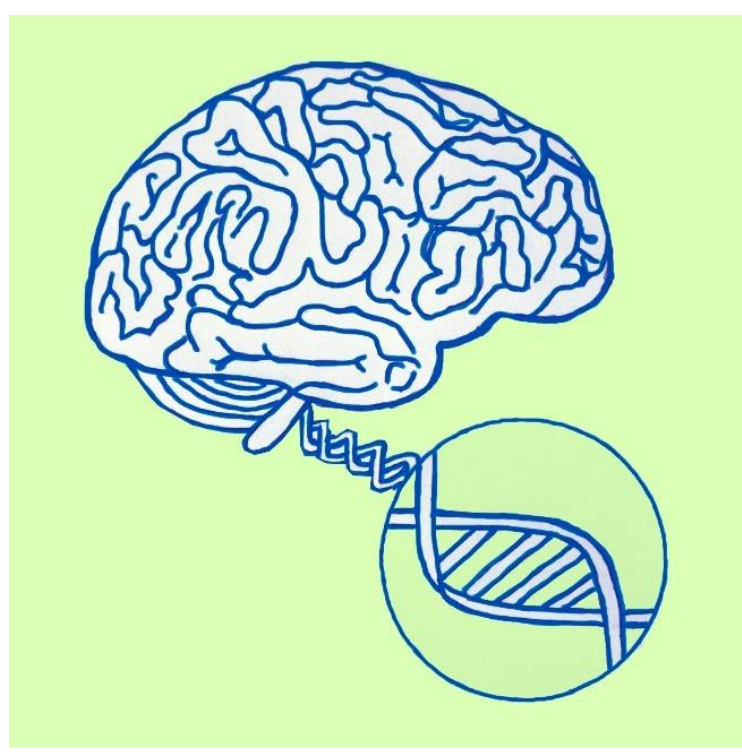

DOCTORANDA:

- Miren Altuna Azkargorta

\section{DIRECTORA DE TESIS:}

- Maite Mendioroz Iriarte

\section{TUTOR DE LA TESIS DOCTORAL:}

- Gregorio Tiberio López
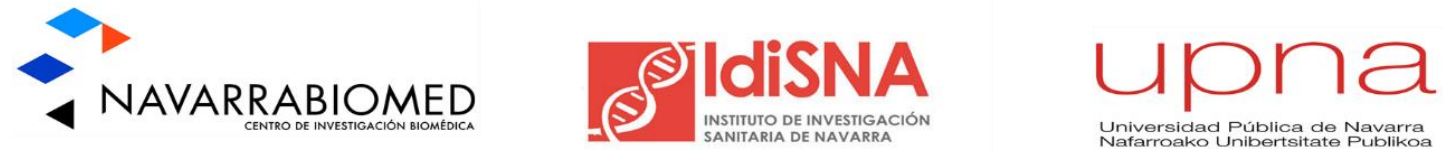

Escuela de Doctorado de la Universidad Pública de Navarra Doctorado en Ciencias de la Salud 


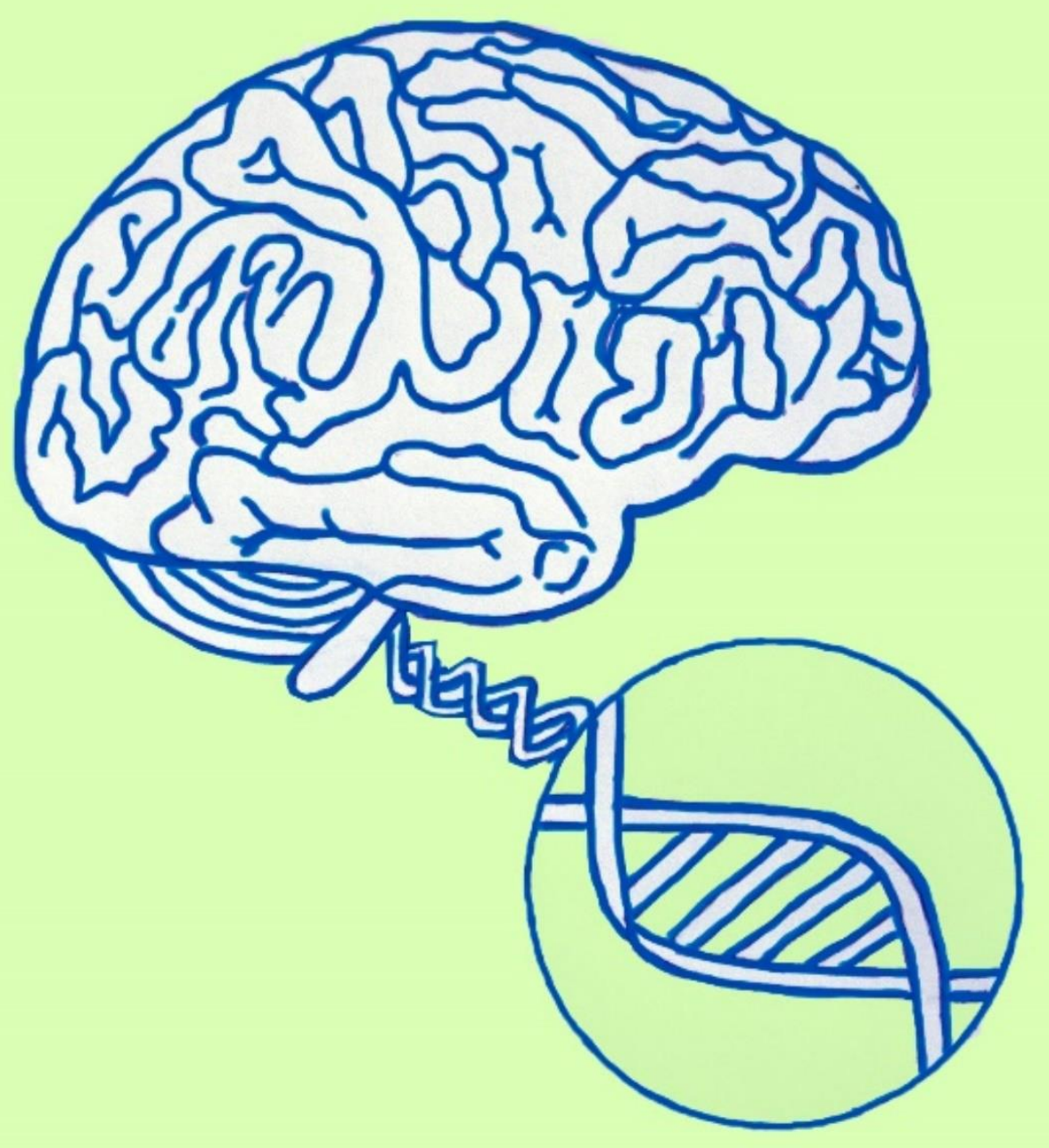

\section{IDENTIFICACIÓN DE BIOMARCADORES} EPIGENÉTICOS EN LA ENFERMEDAD DE ALZHEIMER

Doctoranda: Miren Altuna Azkargorta.

Directora Tesis: Maite Mendioroz Iriarte. 


\section{AGRADECIMIENTOS:}

Este proyecto no hubiese sido posible sin la inestimable entrega y dedicación de Maite Mendioroz. Ella ha sido y siempre será una de mis grandes referentes a nivel profesional. Le agradeceré eternamente su contribución en mi formación como neuróloga asistencial pero especialmente su confianza desde el principio en mis capacidades investigadoras. Gracias Maite por tu labor como guía académica e investigadora en este proyecto y en otros que hemos compartido, y por tu cercanía, amabilidad pero sobre todo por brindarme tu amistad.

Gracias también a todo el servicio de neurología del Complejo Hospitalario de Navarra por todo su apoyo.

También y no menos importante, gracias a los de casa por estar siempre a mi lado, especialmente a mis padres (Itziar y Jesus), apoyándome en cada momento y en cada proyecto que he emprendido en mi vida.

Por último, muchas gracias a los pacientes y familiares, y a los voluntarios que han colaborado de forma altruista con el Biobanco de Tejidos Neurológicos del Sistema Navarro de Salud. Gracias también a todo el equipo investigador del grupo de neuroepigenética de Navarrabiomed y a todos los trabajadores del Biobanco. 


\section{PRÓLOGO:}

La enfermedad de Alzheimer es uno de los mayores retos sanitarios, sociales y económicos del siglo XXI.

En la actualidad y a pesar de los grandes esfuerzos realizados no se ha llegado a conocer y entender por completo la patogenia de la enfermedad. La comprensión de la misma no sólo es esencial para el desarrollo de terapias eficaces, sino también para establecer un diagnóstico lo más temprano posible. Se cree que la escasa eficacia de los tratamientos ensayados hasta la fecha se debe, al menos en parte, a la instauración tardía de los mismos por la demora que existe en el diagnóstico.

En los últimos años se ha producido una revolución en la práctica clínica de las demencias con la llegada de los biomarcadores diagnósticos para la enfermedad de Alzheimer, permitiendo no sólo una mayor celeridad, sino también una mayor certeza diagnóstica. Dichos biomarcadores (tanto de líquido cefalorraquídeo como de neuroimagen estructural como funcional), de innegable utilidad no sólo investigadora sino también asistencial, tienen lamentablemente sus restricciones por su excesivo coste y/o su naturaleza invasiva.

Por ello en la actualidad se está investigando en la identificación de biomarcadores más accesibles para su uso en la práctica clínica habitual. Entre ellos destacan los esfuerzos para la identificación de biomarcadores plasmáticos. Es un área de investigación en auge, muy prometedora, pero con resultados en ocasiones contradictorios que obligan a un análisis exhaustivo y crítico del trabajo científico publicado.

Entre las distintas estrategias empleadas para la identificación de biomarcadores más accesibles y que ayuden a comprender la patogenia subyacente a la enfermedad de Alzheimer destaca especialmente la epigenética.

La epigenética resulta de gran interés ya que estudia la regulación de la expresión génica sin modificar la secuencia del ADN. Dichos mecanismos regulatorios son parcialmente 
heredables, pero también modificables por exposición a múltiples factores ambientales. En este sentido, al tratarse la enfermedad de Alzheimer de una enfermedad multifactorial de base fisiopatológica compleja donde se ha identificado la contribución tanto de factores de riesgo genéticos como ambientales, la epigenética podría aportar un nuevo e interesante enfoque. La identificación de alteraciones en la regulación de mecanismos epigenéticos podría no sólo tener utilidad como potencial biomarcador diagnóstico e incluso pronóstico, sino que también podría ser útil para la mejor comprensión de la enfermedad, y por otro lado, para el desarrollo de futuros tratamientos. Incluso se podría intentar valorar si las diferencias objetivadas en los mecanismos epigenéticos entre pacientes con enfermedad de Alzheimer y controles podrían a su vez tener impacto directo en el curso clínico de la enfermedad.

Las alteraciones epigenéticas ya se emplean como dianas terapéuticas con resultados prometedores en otras enfermedades con gran impacto sanitario, social y económico como es el cáncer. Por ello se cree que la epigenética abre una nueva vía de investigación para obtener un mayor conocimiento de la enfermedad, permitir la identificación de potenciales biomarcadores diagnósticos y/o pronósticos, y para el desarrollo de terapias tanto modificadoras de la enfermedad como sintomáticas (en el caso de que existiera correlato entre el desarrollo de algunos síntomas y las alteraciones en el patrón de regulación epigenética).

En resumen, el disponer de mejores herramientas diagnósticas y una mayor comprensión de la enfermedad permitirá avanzar en una de las grandes batallas de la sociedad del siglo XXI: la lucha contra la enfermedad de Alzheimer. En este sentido, la epigenética puede ser una herramienta prometedora más para resultar victoriosos.

Finalmente, y con el objetivo de ahondar en los conocimientos actuales sobre biomarcadores sanguíneos para el diagnóstico de la enfermedad de Alzheimer y para ejemplificar las variaciones epigenéticas identificadas en la misma se presenta este trabajo mediante el formato de compendio de artículos. Se presentan un artículo de revisión que ejerce en cierta medida la función de introducción y dos trabajos de investigación originales. 


\section{ÍNDICE:}

1. INTRODUCCIÓN: CONOCIMIENTO PREVIO. (páginas 9-54).

1.1. Enfermedad de Alzheimer: conceptos básicos. (páginas 10-17).

1.1.1. Definiendo el deterioro cognitivo leve y la demencia. (página 11).

1.1.2. Síndrome clínico típico. (páginas 11-12).

1.1.3. Continuum de la enfermedad de Alzheimer. (páginas 12-17).

1.1.3.1. Enfermedad de Alzheimer preclínica. (páginas 13-16).

1.1.3.2. Enfermedad de Alzheimer prodrómica. (página 17).

1.1.3.3. Enfermedad de Alzheimer establecida. (página 17).

1.2. Epidemiología. (páginas 18-21).

1.2.1. Incidencia y prevalencia de la enfermedad de Alzheimer. (páginas 18-19).

1.2.2. Mortalidad asociada a la enfermedad de Alzheimer. (página 20).

1.2.3. Coste económico de la enfermedad de Alzheimer. (página 21).

1.3. Patogenia de la enfermedad de Alzheimer (páginas 22-48).

1.3.1. Factores del riesgo para el desarrollo de la enfermedad de Alzheimer. (páginas 23-33).

1.3.1.1. Principales factores de riesgo genéticos. (páginas 23-28).

1.3.1.2. Factores genéticos protectores para el desarrollo de la enfermedad de Alzheimer. (páginas 29).

1.3.1.3. Principales factores de riesgo no genéticos o ambientales de la enfermedad de Alzheimer. (páginas 29-32).

1.3.1.4. Factores ambientales protectores para el desarrollo de la enfermedad de Alzheimer. (páginas 32-33).

1.3.2. Hipótesis patogénicas de la enfermedad de Alzheimer. (páginas 33-41).

1.3.3. Neuroepigenética. (páginas 41-48). 
1.3.3.1. Estudios de metilación del $A D N$ en la enfermedad de Alzheimer. (páginas 45-48).

1.4. Diagnóstico de la enfermedad de Alzheimer. (páginas 49-54).

1.4.1. Relevancia del diagnóstico precoz. (páginas 49-53).

1.4.2. Proceso de identificación de nuevos biomarcadores. (página 5354).

2. INTRODUCCIÓN: PROBLEMA A INVESTIGAR y OBJETIVOS DE LA INVESTIGACIÓN (páginas 55-58).

2.1. Hipótesis. (página 58).

2.2. Objetivos. (página 58).

3. MÉTODOS Y RESULTADOS: (páginas 59-139).

3.1. Artículo $\mathrm{n}$ 오: Biomarcadores sanguíneos en la enfermedad de Alzheimer (páginas 61-74).

3.2. Artículo $\mathrm{n}$-2: DNA methylation signature of human hippocampus in Alzheimer's disease is linked to neurogenesis (páginas 75-116).

3.3. Artículo $\mathrm{n} 03$ : PLD3 epigenetic changes in the hippocampus of Alzheimer's disease (páginas 117-139)

4. DISCUSIÓN. (páginas 140-154).

5. LIMITACIONES. (páginas 155-158).

6. FUTUROS PROYECTOS DE INVESTIGACIÓN. (páginas 159-162). 
7. CONCLUSIONES. (páginas 163-165).

8. ÍNDICE DE ABREVIATURAS (páginas 166-171).

9. BIBLIOGRAFÍA. (páginas 172-199).

10. ANEXOS. (páginas 200-251).

10.1. Artículo $\mathrm{n}$ 1: Biomarcadores sanguíneos en la enfermedad de Alzheimer (páginas 201-208).

10.2. Artículo $\mathrm{n}-2$ : DNA methylation signature of human hippocampus in Alzheimer's disease is linked to neurogenesis (páginas 209-236).

10.3. Artículo n-3: PLD3 epigenetic changes in the hippocampus of Alzheimer's disease (páginas 237-251). 


\section{INTRODUCCIÓN: CONOCIMIENTO PREVIO.}

\subsection{ENFERMEDAD DE ALZHEIMER. CONCEPTOS BÁSICOS}

La enfermedad de Alzheimer (EA), descrita por primera vez por el patólogo y psiquiatra alemán Alois Alzheimer en 1906, es una enfermedad neurodegenerativa de curso progresivo, crónico e irreversible. La EA es la primera causa de demencia, responsable del $50-75 \%$ del total de los casos, y la enfermedad neurodegenerativa más frecuente. Es a su vez, la primera causa de demencia relacionada con la edad, siendo la propia edad el principal factor de riesgo para su desarrollo. Entre los 65 y 95 años cada 5 años se duplica la incidencia y la prevalencia de EA (1-9).

A pesar de su gran prevalencia y consecuente impacto socioeconómico, se dispone de escasas herramientas diagnósticas y terapéuticas en la actualidad. El diagnóstico de confirmación de demencia debida a EA exige la realización de estudio anatomopatológico postmortem, según los últimos criterios vigentes (10), siendo el diagnóstico en vida de posible o probable.

Los cambios anatomopatológicos definitorios de EA en el cerebro de sujetos afectos aparecen al menos 20 años antes del inicio de los síntomas (11-14), existiendo por tanto un largo período preclínico (carente de síntomas). Aspecto muy relevante ya que el diagnóstico clínico de EA (cuando los síntomas ya se han instaurado) implica obligatoriamente la existencia de cambios crónicos de larga data, probablemente de carácter irreversible. Por tanto, no es sorprendente que cada vez se comparta más la idea de que el diagnóstico temprano de la EA implique el diagnóstico en la fase preclínica (presencia de cambios anatomopatológicos definitorios de EA en ausencia de síntomas) y no en la fase prodrómica o fase de deterioro cognitivo leve. 


\subsubsection{Definiendo Deterioro Cognitivo Leve y Demencia:}

El diagnóstico de demencia exige la existencia de un deterioro cognitivo y/o de síntomas neuropsiquiátricos que interfieren en la capacidad de rendimiento laboral y/o en actividades de la vida diaria; y conllevan un claro empeoramiento con respecto al rendimiento/funcionalidad previa del individuo. El deterioro cognitivo debe ser objetivable mediante anamnesis y/o estudio neuropsicológico; y debe afectar al menos a dos dominios cognitivos diferentes (empeoramiento de la memoria episódica, de las funciones ejecutivas, de las funciones visuoespaciales, del lenguaje y/o cambios en la personalidad o comportamiento) (10).

Si dicho deterioro cognitivo no impacta significativamente en las actividades diarias de la persona recibe el nombre de deterioro cognitivo leve; mientras que se trata de una demencia si dicho deterioro cognitivo impacta en la capacidad del sujeto para afrontar las actividades diarias. Cuando dicho deterioro cognitivo leve es atribuible a la base fisiopatológica de EA recibirá el nombre de EA prodrómica $(15,16)$. Gracias a la mejoría en los métodos diagnósticos tras la introducción de los biomarcadores, en la actualidad cada vez se diagnostican más casos de EA en fase prodrómica.

\subsubsection{Síndrome clínico típico:}

La forma más frecuente de presentación, y denominada por tanto síndrome clínico típico de EA, es la forma amnésica. Se caracteriza por déficits precoces y prominentes en la memoria episódica de carácter progresivo, con niveles variables de alteración en las funciones ejecutivas, lenguaje y disfunción visuoespacial. La alteración en la memoria episódica a su vez suele presentar un claro gradiente temporal con mayor afectación de los recuerdos recientes y con relativa preservación de la memoria episódica remota. No obstante, y aunque el déficit amnésico con gradiente temporal es lo que caracteriza al síndrome clínico típico de EA, no se trata de un déficit aislado 
amnésico, sino que suele tratarse de un deterioro cognitivo multidominio de predominio amnésico.

Se han descrito otras formas de presentación no amnésicas o no típicas de EA como son la alteración primaria y predominante del lenguaje en forma de afasia primaria progresiva (sobre todo la variante logopénica) y la atrofia cortical posterior. La recurrencia de dichas variantes clínicas de presentación es mucho menor y más aún cuando la EA es de inicio tardío, en mayores de 65 años, lo que representa la inmensa mayoría de los casos. Es muy frecuente a su vez la demora en el diagnóstico en estos casos que debutan con sintomatología atípica (17).

\subsubsection{Continuum de la enfermedad de Alzheimer:}

Siguiendo las recomendaciones de la National Institute on Aging and the Alzheimer's Association (NIA/AA) publicadas en el año 2011 existen distintas formas diagnósticas de EA: EA probable (basada en criterios clínicos), EA posible (basada en criterios clínicos) o EA probable o posible con evidencia de proceso fisiopatológico de EA (10).

En la actualidad la EA se considera un continuum entre la existencia de cambios anatomopatológicos definitorios (presencia de depósito anómalo extracelular de amiloide y de ovillos neurofibrilares intracelulares compuestos de proteína tau) y:

- de la fisiopatología de la enfermedad sin repercusión clínica (el estadio preclínico a su vez es fruto de múltiples subprocesos que acontecen de forma secuencial, con ciertos rasgos distintivos entre las formas de EA autosómica dominante y EA esporádica),

- el deterioro cognitivo leve en relación a EA probable,

- y la demencia por EA probable. 
EAAUTOSÓMICA DOMINANTE
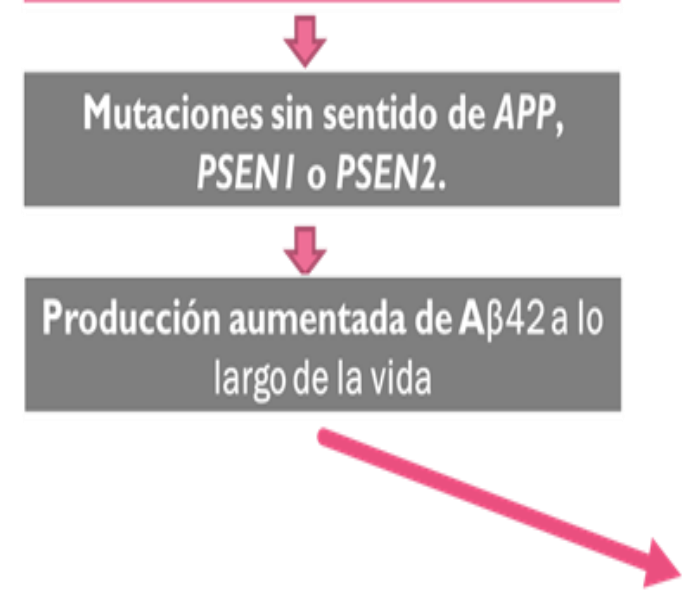

EA ESPORÁDICA

\section{Alteración eliminación $A \beta$}

Incremento de niveles de $\mathrm{A} \beta 42$

19 Acumulación y oligomerización de A $\beta 42$ en sistema límbico y cortezas asociativas.

20 Daño sináptico inicial.

30 Formación de placas difusas por depósito de oligómeros de $A \beta 42$.

4ํㅡㄹ Respuesta inflamatoria por activación astrocitariay de la microglia.

50 Daño de la homeostasis de iones y daño oxidativo.

60 Alteración de quinasas y fosfatasas que favorece formación de ovillos neurofibrilares.

70 Disfunción neuronal y sináptica extensa + déficit neurotransmisores.

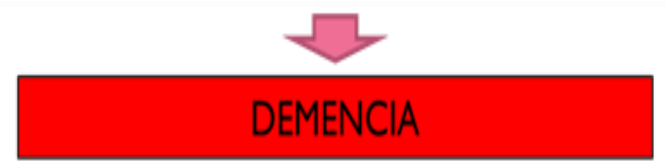

Figura 1: Adaptado de Lane C.A. et al. European Journal of Neurology 2018 (18). La figura describe de forma esquemática los procesos fisiopatológicos implicados en las distintas formas de EA: tanto la EA esporádica (la forma más frecuente) como en la EA de inicio temprano y herencia mendeliana autosómica dominante.

1.1.3.1. EA preclínica: Se inicia con el depósito anómalo de material amiloide cerebral, años o incluso décadas antes del inicio de los primeros síntomas. Los péptidos de $\beta$ amiloide $(A \beta)$ que se depositan de forma anómala tienen su origen en la proteína precursora de a miloide $(A P P)$. Dicha proteína puede degradarse siguiendo la vía no 
amiloidogénica (acción predominante de $\alpha$-secretasas cuyo producto final es la creación de fragmentos solubles no patógenicos de $A \beta$ ) o siguiendo la vía amiloidogénica (acción predominante de $\beta$-secretasas, cuyo producto son péptidos $A \beta$ insolubles que se pueden depositar a nivel extracelular, que pueden formar polímeros o agregarse hasta formar placas de amiloide).

En las fases iniciales existe un acúmulo de oligómeros de $A \beta$ extracelular que repercute negativamente en la función sináptica y neuronal, sin afectar a la supervivencia neuronal. No obstante, los péptidos $A \beta$ tienen tendencia a formar polímeros, siendo los polímeros $A \beta 40$ (acúmulo sobre todo en placas difusas y en las paredes de los vasos sanguíneos cerebrales, relacionados con el desarrollo de angiopatía amiloide) y A $A 42$ (componente más importante de las placas de amiloide maduras), con efecto neurotóxico conocido, los más directamente vinculados con la patogenia de EA.

Se ha postulado que, como consecuencia del efecto neurotóxico de $A \beta$, se produce el fenómeno de degeneración neurofibrilar reflejada a nivel intracelular por la presencia de ovillos neurofibrilares compuestos por proteína tau hiperfosforilada.

Todos estos cambios que acontecen de forma secuencial en la fisiopatología de la EA también tienen reflejo directo en el comportamiento dinámico de los biomarcadores diagnósticos de la enfermedad utilizados en la práctica clínica actual, creando un modelo dinámico ampliamente aceptado. Primero acontecería el descenso de $A \beta 42$, la forma más fibrogénica del material amiloide, en líquido cefalorraquídeo (hasta 20 años antes del inicio de los síntomas), seguido de la captación de trazadores de PET (tomografía por emisión de positrones) amiloide, a continuación la aparición de biomarcadores de daño neuronal (detección de incremento de niveles de proteína tau hasta 15 años antes del inicio de los síntomas), a posteriori se podría detectar hipometabolismo parietotemporal bilateral en PET de fluorodesoxiglucosa (FDG) y/o adelgazamiento cortical en resonancia magnética craneal $(\mathrm{RMc})(12,19)$ y finalmente la manifestación clínica. 

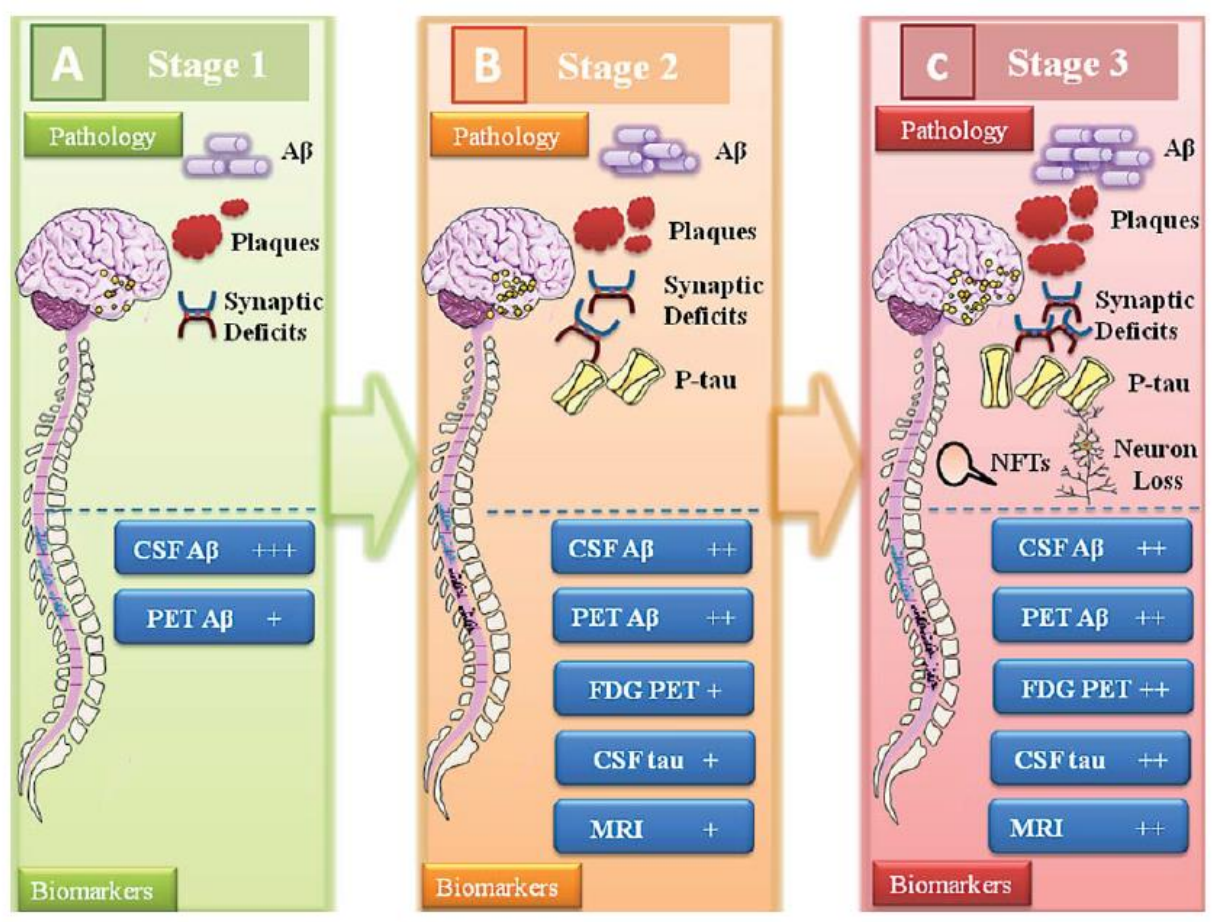

Figura 2: Procedente del artículo de Tan et al. del año 2014 (20) que muestra los cambios evolutivos que acontecen ya en la fase preclínica de la $E A$, dentro de esta fase se postula que primero aparecen cambios de amiloidosis cerebral, a posteriori daño sináptico y neurodegeneración inicial que finalmente evoluciona a una neurodegeneración instaurada. Todos estos cambios se producen años antes de comenzar con los síntomas de deterioro cognitivo y tienen correlato con los distintos biomarcadores diagnósticos disponibles en el momento actual.

Esta fase preclínica es importante para poder prevenir o enlentecer la evolución a fases sintomáticas y para poder identificar otros biomarcadores que puedan actuar además como dianas terapéuticas en un futuro.

Los biomarcadores que reflejan el proceso fisiopatogénico de la EA, tanto la $\beta$ amiloidosis (en este caso niveles de $A \beta 42$ en líquido cefalorraquídeo y/o positividad para PET amiloide) como los que reflejan daño neuronal y neurodegeneración (en este caso niveles de tau-total y tau-fosforilada en líquido cefalorraquídeo o la presencia de un 
patrón de hipometabolismo sugestivo de EA en PET-FDG cerebral) de aplicabilidad en la práctica clínica reciben el nombre de biomarcadores core (21).

Los cambios en los biomarcadores core de líquido cefalorraquídeo (LCR) detectados años-décadas antes del inicio de los síntomas son congruentes con los hallazgos postmortem anatomatológicos de EA $(14,22)$.

El International Working Group (IMG) describe dos tipos de EA preclínica: presintomática y asintomática a riesgo de desarrollar EA. El término EA presintomática se debería emplear en los casos de EA genéticamente determinada (minoría de los casos). En cambio, el diagnóstico de asintomático a riesgo de desarrollar EA exige ausencia de síntomas y la presencia de al menos uno de los biomarcadores core de EA.

Incluso dentro del grupo de asintomáticos a riesgo de desarrollar EA se ha postulado la existencia de 2 fases diferentes según la NIA/AA: fase 1 correspondiente a la existencia in vivo de evidencia de amiloidosis mediante análisis de LCR o PET; y fase 2 correspondiente a la existencia de evidencia in vivo no sólo de amiloidosis sino también de neurodegeneración (12).

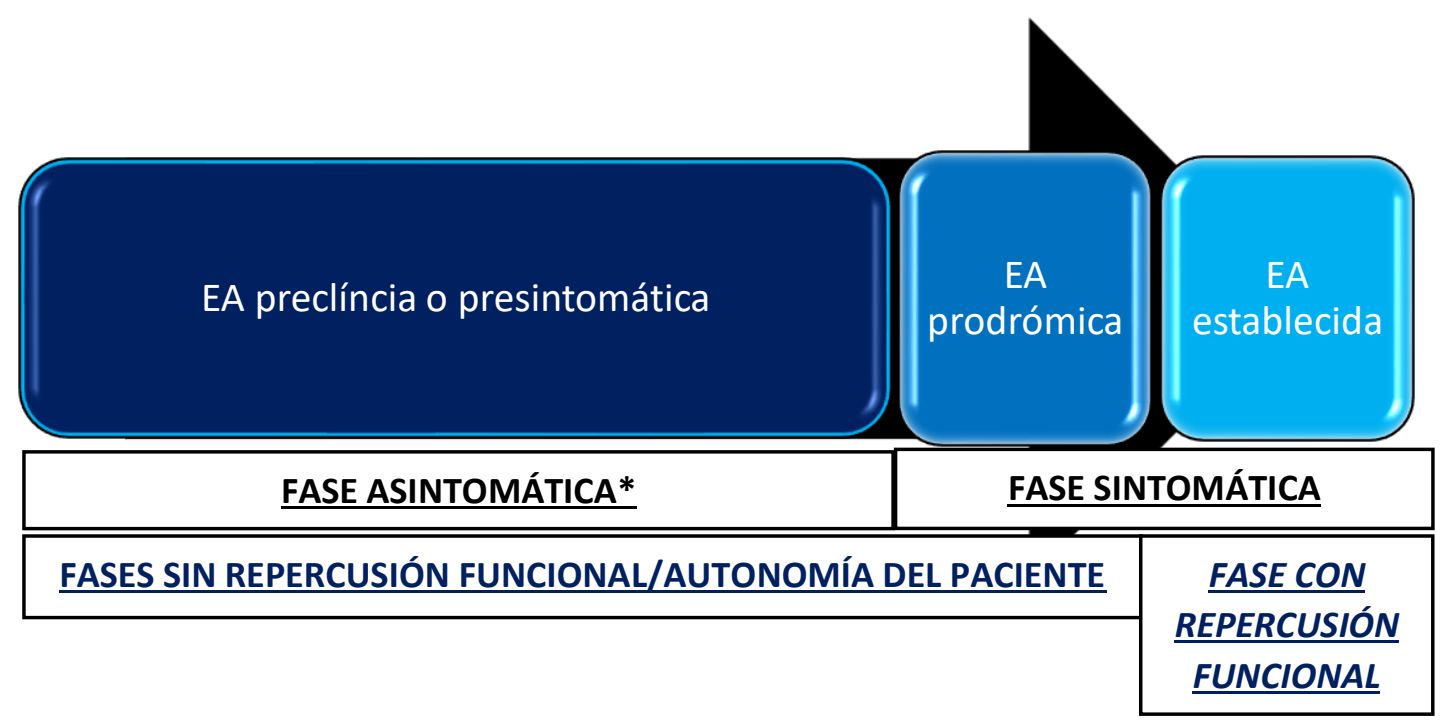

Figura 3: Muestra de forma esquemática el continuum de la EA donde la fase preclínica o presintomática es la más larga y lo que distingue la EA prodrómica de la EA establecida es la aparición de la repercusión funcional del deterioro cognitivo. 
1.1.3.2. EA prodrómica: También conocida como deterioro cognitivo leve por EA. El individuo presenta un deterioro cognitivo objetivable pero sin repercusión en su autonomía y/o funcionalidad. Para establecer el diagnóstico de EA prodrómica además de constatar la existencia de un deterioro cognitivo leve es necesario disponer de resultados de biomarcadores core que apoyen la existencia de un proceso fisiopatogénico subyacente de EA.

1.1.3.3. EA establecida o demencia por EA: deterioro cognitivo con repercusión significativa en la funcionalidad y en la autonomía del paciente que permite establecer el diagnóstico de demencia, siendo dicho deterioro cognitivo atribuible a EA. 


\subsection{EPIDEMIOLOGÍA:}

\subsubsection{Incidencia y prevalencia de la enfermedad de Alzheimer:}

La EA es una enfermedad relacionada con la edad y, por tanto, no sorprende que el envejecimiento poblacional experimentado a nivel mundial en las últimas décadas haya conllevado el incremento en su incidencia y prevalencia.

Según los datos de la Organización Mundial de la Salud (OMS) en el año 2000 sólo un 6,8\% de la población tenía 65 o más años, mientras que para el año 2050 se espera que hasta un 16,2\% de la población los tenga. Para el año 2050 se prevé llegar a diagnosticar hasta 1 millón de casos nuevos de EA al año $(23,24)$. Además del incremento de la incidencia vinculada al envejecimiento poblacional, como consecuencia de la mejoría en el cuidado de los pacientes afectos e incremento de su esperanza de vida también aumentará la prevalencia. A nivel mundial en el año 2006 se estimaba que 26,6 millones de personas estaban afectadas de EA. Mientras que en el año 2016 sólo en Estados Unidos había 5,4 millones de personas afectas de EA, de los cuales 5,2 millones tenían 65 o más años (17).

La incidencia actual en los países de la Unión Europea es de 11,08 casos por 1000 habitantes y año (25). En la población estadounidense entre los 65-74 años la incidencia es de 2 casos por 1000 personas-año y a partir de 85 años la incidencia se incrementa hasta 37 casos por 1000 personas-año.

La prevalencia de EA tiene un incremento exponencial con la edad a partir de los 65 años. De hecho, se duplica la prevalencia cada 5 años a partir de los 65 años (18). La prevalencia de EA en Estados Unidos es de 1 cada 9 individuos con una edad igual o superior a 65 años mientras que se incrementa hasta 1 de cada 3 individuos a la edad de 85 años. En Europa se estima que un 0,97\% de la población entre 65 y 74 años, un $7,7 \%$ de entre 75 y 84 años y un 22,5\% de los mayores de 85 años tienen la enfermedad. Hasta un $81 \%$ de los individuos afectos de EA tiene 75 o más años. Según algunos datos, 
hasta un 40\% de los individuos entre 90 y 94 años estarían afectos de EA. Los datos de la población española son superponibles a la europea con una prevalencia estimada de $7,7 \%$ a la edad de 70 años $(17,24,26,27)$.

Se espera un incremento de prevalencia de EA hasta del $87 \%$ en los países europeos. Según algunas predicciones, en el año 2050 se calcula que habrá 106,8 millones de personas afectas en todo el mundo, de los cuales 16,51 millones se localizarán en los países de la Unión Europea (25).

La prevalencia de EA en el sexo femenino es más alta que en el sexo masculino (16). Se estima que 2 de cada 3 casos de EA en Estados Unidos acontecen en mujeres. Entre las distintas causas que se han descrito para justificar el incremento de prevalencia entre las mujeres destaca la mayor esperanza de vida del género femenino. Otra de las hipótesis derivadas del estudio Framingham sugiere que la mortalidad por patología cardiovascular en edades medias de la vida es mayor en la población masculina y que por tanto los varones mayores de 65 años que han sobrevivido tendrían mejor control de factores de riesgo cardiovasculares y por tanto, menor riesgo de desarrollar EA. A su vez existen estudios que apoyan que el riesgo de desarrollar EA en caso de tener el alelo E4 de apolipoproteína E4 (factor de riesgo genético más relevante) es mayor en la población femenina que en la masculina, sobre todo entre los 65 y 74 años, y también en relación a cambios hormonales (estrógenos) (17). A su vez se cree que otro de los motivos pueda ser un menor nivel educacional de las mujeres con respecto a los hombres dado que se ha identificado que un menor nivel educacional puede a su vez incrementar el riesgo para el desarrollo de EA (16).

También se han descrito diferencias raciales en Estados Unidos en la prevalencia de EA, siendo la prevalencia de EA más alta en el caso de la población hispana y de la afroamericana. Se cree que en parte es debido a la mayor prevalencia de factores de riesgo cardiovascular y a un menor nivel educacional en estos grupos poblacionales (28). 


\subsubsection{Mortalidad asociada a la enfermedad de Alzheimer:}

La EA no sólo tiene un impacto negativo y significativo en la calidad de vida de los pacientes, sino que a su vez es la sexta causa de muerte en la población general y la quinta en pacientes mayores de 65 años en Estados Unidos. En España, en el año 2013, la EA fue declarada como la séptima causa de muerte, la primera entre las demencias (27), siendo a su vez una causa importante de dependencia y por tanto de consumo de recursos sociales a nivel poblacional en el momento actual.

No obstante, es difícil establecer el número de muertes exactas inducidas por EA por la forma en la que se recoge dicho dato en los certificados de fallecimiento. Según el registro de mortalidad de Gales e Inglaterra, en el $11,6 \%$ de los casos, la EA era la principal causa de muerte (18). Lo que es indudable es que el número de fallecimientos por EA se está incrementando, mientras que se reducen los atribuidos a otras causas como la cardiopatía isquémica, gracias a campañas de prevención a nivel poblacional realizadas en el área de la patología cardiovascular en los últimos años (16).

Se calcula que la esperanza de vida de las personas mayores de 65 años diagnosticadas de EA es de 4-8 años, aunque existe una gran variabilidad existiendo casos con una supervivencia mayor de 20 años. La edad al diagnóstico, la asociación con comorbilidad significativa y/o la gravedad de la enfermedad al diagnóstico influyen claramente en la esperanza de vida. A menor edad en el momento del diagnóstico, menor probabilidad de comorbilidad significativa asociada y posible mayor esperanza de vida y por tanto, mayor probabilidad de que la enfermedad progrese hasta fases avanzadas de la misma. Si el diagnóstico es a la edad de 65 años la mediana de supervivencia es de 9 años frente a 3 años si el diagnóstico es a los 90 años. Cabe destacar que la esperanza de vida de los varones, con mayor riesgo potencial de patología cardiovascular asociada, es a día de hoy menor que en el caso de las mujeres. A su vez se debe señalar que el diagnóstico de la EA se realiza a edades más tempranas en el sexo femenino $(16,24,26,29)$. 


\subsubsection{Coste económico de la enfermedad de Alzheimer:}

La EA junto con otras demencias neurodegenerativas es una de las patologías crónicas que más coste económico conlleva para las arcas públicas y también para la economía individual y/o familiar.

A medida que el deterioro cognitivo progresa el paciente sufre una merma irreversible en su autonomía funcional. Cada vez precisa de mayor apoyo sociosanitario, con mayor requerimiento de consultas médicas especializadas, más visitas a urgencias y más ingresos hospitalarios; pero también de más ayudas domésticas y/o de institucionalización en residencias adaptadas.

En el año 2016 el coste directo, entendido como el gasto médico y en recursos sociales, estimado de EA en la población estadounidense era de 236 billlones de dólares y se cree que dicho coste ascenderá hasta 1 trillón de dólares para el año 2050 (30).

Por todo ello se considera que tras el cáncer y la enfermedad coronaria la EA es la tercera patología más costosa para las arcas estadounidenses (se presupone que el impacto en las arcas europeas, con cobertura sociosanitaria más extensa a nivel poblacional que la estadounidense, es al menos similar) y dado el incremento de prevalencia estimada tendrá incluso mayor impacto en un futuro (24).

Los costes de la enfermedad dependen de la severidad y del estadio de la enfermedad y también del lugar de residencia del paciente. Se estima que el $75 \%$ del coste ocurre en las fases avanzadas de la enfermedad en relación con un mayor requerimiento de institucionalización. 


\subsection{PATOGENIA DE LA ENFERMEDAD DE ALZHEIMER:}

La patogenia de la EA, enfermedad neurodegenerativa más frecuente, sigue sin poderse esclarecer del todo en la actualidad a pesar de que desde el año 1906 se conocen, gracias a Alois Alzheimer, los hallazgos anatomopatológicos postmortem definitorios de EA: la presencia de placas extracelulares de beta-amiloide $(A \beta)$, en el parénquima cerebral y en los vasos sanguíneos, en este caso responsables de angiopatía amiloide, y de ovillos neurofibrilares intraneuronales compuestos por agregados de proteína tau hiperfosforilada. Se postula que ambos tipos de agregados tienen efecto neurotóxico produciendo una alteración irreversible del funcionamiento neuronal $y$, finalmente, destrucción del tejido nervioso (31).

A su vez se debe señalar que se constata la existencia de copatología en el estudio postmortem de entre $1 / 3$ a $1 / 2$ de pacientes diagnosticados de EA detectándose la presencia de otros agregados proteicos, como los cuerpos de Lewy (sinucleinopatía), o lesiones vasculares, entre otros. La presencia de copatología en las necropsias se ha asociado tanto a una mayor probabilidad como a una mayor celeridad en la progresión del deterioro cognitivo al grado de demencia, empeorando de forma significativa el pronóstico funcional e incluso vital de los pacientes (32).

En la actualidad se considera a la EA, salvo los raros casos de EA de inicio precoz con herencia mendeliana autosómica dominante donde se conoce la existencia de una mutación patogénica causal de la misma, como una enfermedad multifactorial de patogenia desconocida con indudable contribución de múltiples factores de riesgo (FR) genéticos y ambientales. Se debe señalar a su vez que el estudio de los FR ambientales ha adquirido especial relevancia en los últimos años por su potencial carácter reversible; y mediante la mejoría de las técnicas disponibles se ha avanzado también en el reconocimiento de los FR genéticos; siendo ahora uno de los grandes retos planteados la identificación de la naturaleza de la interacción entre ambos tipos de FR. 


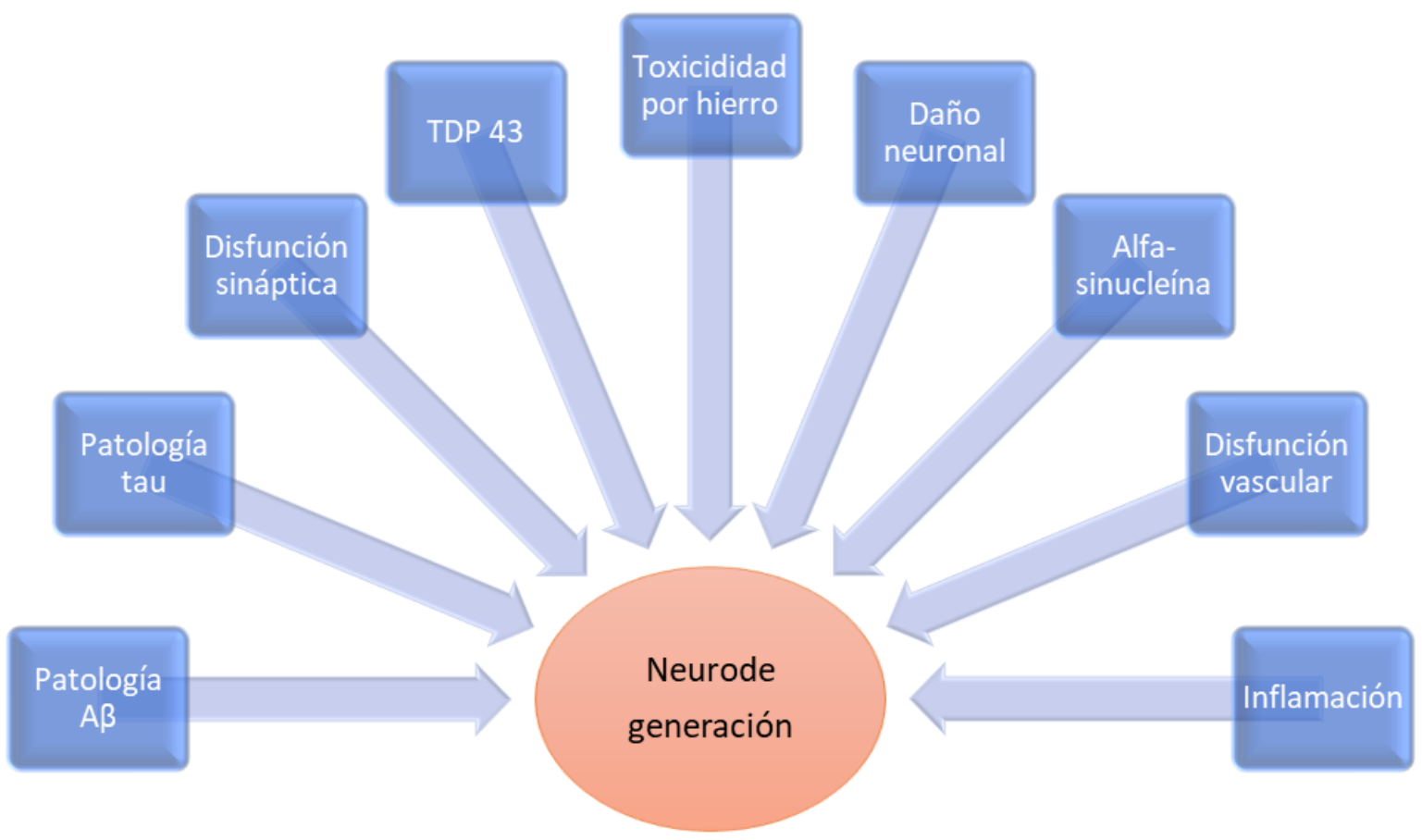

Figura 4 adaptada de Molinuevo et al. 2018 (33) pretende ilustrar la gran complejidad del proceso de neurodegeneración (considerado como el proceso mejor vinculado con la aparición de síntomas de deterioro cognitivo) que acontece en contexto de la EA. A su vez cada uno de los procesos o eventos descritos en dicha figura pueden tener múltiples causas y/o desencadenantes.

\subsubsection{Factores de riesgo para el desarrollo de EA:}

\subsubsection{Principales factores de riesgo genéticos:}

La contribución genética es indudable y en la actualidad se cree que la EA (a excepción de los pocos casos de EA genéticamente determinados) es una enfermedad de herencia no mendeliana, probablemente asociada a FR genéticos polimórficos. Se ha llegado a afirmar que el $70 \%$ del riesgo del desarrollo de EA por parte del individuo se puede atribuir a la presencia de FR genéticos (18). Ello viene apoyado por el hecho de que, tras la edad avanzada, el hecho de tener antecedentes familiares de primer grado de EA aumenta de forma significativa el riesgo de desarrollar EA y por los estudios de heredabilidad realizados con gemelos $(34,35)$. 
Por tanto, se puede afirmar que la probabilidad de desarrollar EA está influenciada por distintos factores de riesgo genéticos, que incluyen mutaciones causales con una penetrancia casi completa (muy infrecuentes) y diversos polimorfismos genéticos que modulan en distinto grado la probabilidad de desarrollar EA (frecuentes) (7).

Los casos de EA monogénica autosómica dominante (mutaciones en APP, PSEN1 y PSEN2; con una penetrancia casi completa) suponen menos del $1 \%$ de todos los casos de EA y debutan a edades tempranas: 30-75 años (36).

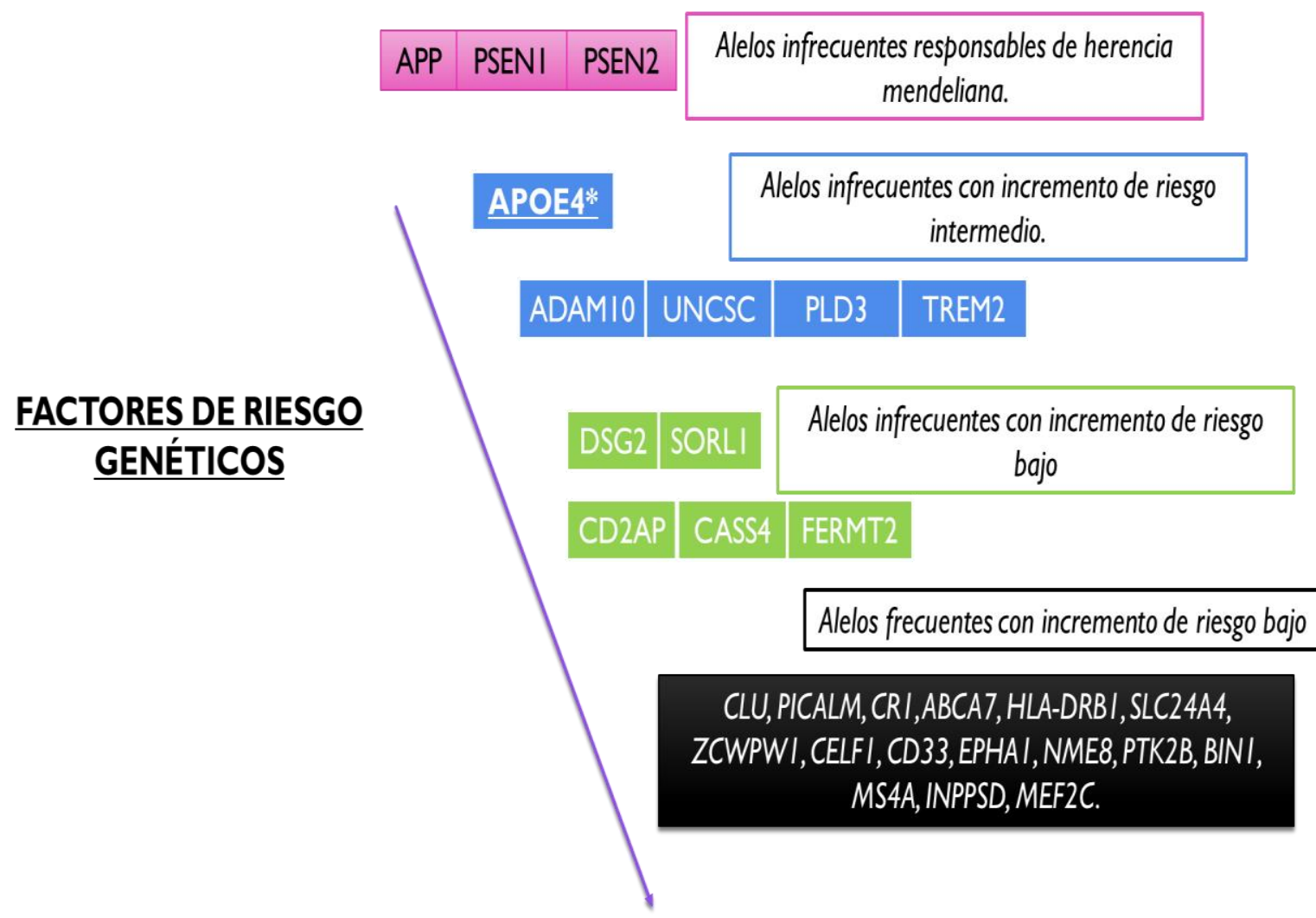

Figura 5: Adaptada del artículo Alzheimer's disease de Lane, CA et al. publicado en European Journal of Neurology en el año 2018 (18) que pretende reflejar la gran complejidad de la heredabilidad genética de la EA. Cabe señalar que *APOE4 es un alelo infrecuente pero que su incremento de riesgo es superior al resto de los genes especificados en la figura en color azul. 
Se conoce que la EA de inicio tardío (en mayores de 65 años) es una enfermedad genéticamente compleja pero donde la heredabilidad estimada oscila entre 60 y $80 \%$ aproximadamente. El factor de riesgo genético más importante es el genotipo de la apolipoproteína $\mathrm{E}(A P O E)$, que codifica para el principal transportador de colesterol del cerebro. El gen APOE tiene 3 alelos posibles: E2 tiene una frecuencia poblacional de $8,4 \%$ frente a $77,9 \%$ de E3 y de E4 de 13,7\%. La presencia del alelo APOE E4 incrementa el riesgo de desarrollar EA con una odds ratio de 4 para heterocigotos y una odds ratio entre 8 y 12 para homocigotos comparando con los homocigotos para E3. La presencia de un alelo APOE E4 reduce aproximadamente en 10 años la edad de inicio de los síntomas (17). En cambio, la presencia de APOE E2/E2 y E3/E3 reduce el riesgo de desarrollar EA con una odds ratio de 0,5 y 0,7 , respetivamente.

APOE E4 contribuye al incremento de riego de EA mediante distintos mecanismos que incluyen mayor agregación de polipéptidos de beta-amiloide y una menor degradación de los mismos, incremento de la fosforilación de tau, disminución del metabolismo de glucosa, e incremento de la disfunción mitocondrial y vascular, entre otros.

En la práctica clínica no se considera indicado el genotipado de APOE, a pesar de que es bien conocido que la presencia del alelo APOE E4 supone un factor de riesgo para el desarrollo de la EA, pero no tiene un valor diagnóstico ni predictivo de por sí (17).

Además de $A P O E$, se han identificado más de 20 genes de riesgo mediante estudios de asociación genómica masiva (GWAS) cuyas variantes poco comunes $(<1 \%)$ o comunes $(>1 \%)$ pueden conllevar un incremento de riesgo de desarrollar EA de inicio tardío. Estos genes tienen su rol en el metabolismo lipídico, sistema inmune innato y en la endocitosis, en la vía amiloide y metabolismo de proteína tau, entre otras vías. El efecto de cada uno de estos genes es menor (claramente inferior al efecto de la APOE) y carece de claro significado predictivo clínico.

Dado que el impacto de cada uno de estos FR genéticos es muy discreto se ha planteado el uso de escalas de riesgo poligénicas para la EA. La finalidad varía entre las distintas 
escalas publicadas pudiendo ser: la identificación del fenotipo clínico de la EA, el riesgo de progresión desde el estadio de deterioro cognitivo leve al de demencia, la relación con el grosor cortical y el volumen del hipocampo, la utilidad de los biomarcadores core de líquido cefalorraquídeo y de los biomarcadores plasmáticos de inflamación, entre otros $(37,38)$. Ninguna de ellas se ha instaurado para su uso en la práctica clínica. Existen diferentes dificultades para su instauración práctica como el hecho de que los FR genéticos de la EA detectadas por GWAS hasta la fecha sólo explicarían el 30\% de la heredabilidad, y obviarían la innegable contribución de otros factores de riesgo, entre ellos los ambientales, cuya presencia no valoran estas escalas de riesgo.

Como ya se ha señalado, mediante aproximación de GWAS se han detectado múltiples genes como posibles factores de riesgo para el desarrollo de EA siendo en general su efecto leve-moderado. En este sentido destacan, entre otros, 20 polimorfismos de un único nucléotico (SNPS) localizados en la región no codificante de PICALM (phosphatidylinositol-binding clathrin assembly protein). PICALM, ampliamente expresada por las células endoteliales de la barrera hematoencefálica (BHE), está implicada en la endocitosis, en la internalización de receptores celulares y en el tráfico intracelular de proteínas endocitadas incluyendo $A \beta$. En este sentido además existen datos que apoyan que la expresión de PICALM está reducida en la BHE de pacientes afectos de EA y que ello se correlaciona con niveles más altos de $A \beta$, con los estadios de Braak \& Braak y con el grado de deterioro cognitivo. En roedores con déficit de PICALM se ha descrito a su vez un incremento de depósito de $A \beta$ de forma temprana $(39,40)$.

Varios SNPs (entre ellos el SNP rs9349407, reportado en varios estudios de población caucásica) del gen CD2AP (CD2 associated protein), expresado ubicuamente pero de forma más abundante en células inmunes, epiteliales y neuronas, también han sido descritos como FR genéticos para el desarrollo de EA de inicio tardío (40). Al CD2AP se le han atribuido distintas funciones en la formación de la sinapsis, en la endocitosis, en el tráfico de vesículas, también en el procesamiento de la $A P P$ y en la integridad de la BHE, ya que se expresa abundantemente en las células endoteliales de la microvasculatura cerebral. Su hipofunción se ha asociado a una mayor producción de 
$A \beta$; a una mayor neurotoxicidad mediada por proteína tau y también a una mayor afectación de la integridad de la BHE $(41,42)$. Se ha descrito una reducción de la expresión de mRNA de CD2AP en muestras de sangre periférica de pacientes con EA de inicio tardío (40). Es interesante señalar que SNPs tanto de CD2AP como de PICALM han sido identificados no sólo como FR genéticos para EA sino también para la demencia vascular, lo cual podría apoyar aún más que su papel patogénico podría estar vinculado a la disfunción de la BHE ya ampliamente descrita en la EA (40).

Un SNP de la Clusterina (CLU), también conocida como apolipoproteína J, identificado vía GWAS se ha vinculado con el riesgo de desarrollar EA esporádica. En concreto el alelo C del SNP rs11136000 incrementaría el riesgo de EA mientras que el alelo T lo reduciría en hasta un $16 \%$. Se cree que CLU podría estar implicada en la patogenia de la EA por su acción sobre el transporte de lípidos, su rol en la inflamación y directamente en la agregación y la eliminación de agregados de $A \beta$. Se conoce que la eliminación vía BHE de $A \beta 42$ se favorece por su unión a la clusterina (39).

Además de genes implicados en la función vascular, también se han identificado vía GWAS polimorfismos en genes relacionados con la homeostasis del calcio. Es el caso del SNP rs2986017 de CALHM1 (calcium homeostasis modulator 1), expresado tanto a nivel de la membrana celular como en el retículo endoplasmático, que disminuye el flujo de calcio intracelular y como consecuencia de ello tiene un impacto en el metabolismo vía $\alpha$-secretasas de la $A P P$, incrementando la cantidad de $A \beta$ (43).

Polimorfismos identificados vía GWAS en el gen CR1 (complement component receptor 1) se han asociado al incremento de riesgo de EA. CR1 es el receptor de la proteína del complemento $\mathrm{C} 3 \mathrm{~b}$. El $\mathrm{A} \beta 42$ circulante es eliminado por su adhesión al CR1 de la superficie eritrocitaria mediada por C3b. Una menor actividad de la vía del complemento C3, descrita en modelos animales, favorecería un acúmulo excesivo de beta-amiloide, lo cual a su vez tendría efecto neurotóxico e induciría la muerte neuronal (36).

También se han detectados polimorfismos en el gen de BIN1 (bridging integrator 1) vía GWAS que incrementarían el riesgo de padecer EA de inicio tardío. BIN1 estaría 
implicada en funciones tales como la apoptosis, la inflamación y/o la homeostasis de calcio. Se ha postulado también que podría tener efecto directo sobre el metabolismo de APP. Se ha constatado incremento de la expresión del mismo en cerebros de pacientes con EA respecto a controles $(40,44)$. Todas estas variantes, denominadas comunes por tener una prevalencia de su alelo mayor del 1\% en la población, tienen un efecto leve en el incremento de riesgo de la EA. En cambio, sí se ha constatado mediante el empleo de técnicas de secuenciación masiva o NGS (next generation sequencing), la presencia de variantes raras (frecuencia $<1 \%$ ) en determinados genes que suponen un incremento de riesgo significativo para el desarrollo de la EA (17)(45). Algunos de los genes descritos por el momento son los siguientes: phospholiphase D3 (PLD3) y Triggering receptor expressed on myeloid cells 2 (TREM2) $(46,47)$.

El gen TREM2 codifica para un receptor de la microglía implicado en la eliminación de A $\beta$. TREM2 reconoce lipoproteínas incluyendo $A P O E$, fosfolípidos y células apoptóticas y está implicada en la función de fagocitosis de la microglía. Además de su función en la eliminación de beta-amiloide se cree que TREM2 es la vía de respuesta de la microglía ante el daño producido por la patología tau $(48,49)$.

En el año 2014 Cruchaga et al. identificaron que variantes infrecuentes del gen PLD3 incrementaban de forma significativa el riesgo de presentar EA de inicio tardío. PLD3 se expresa ampliamente en el cerebro humano incluyendo hipocampo, corteza frontal y entorrinal, regiones cerebrales especialmente vulnerables a los cambios antomopatológicos definitorios de la EA. Se conoce que PLD3 codifica para una fosfolipasa que puede estar implicada en el procesamiento de APP. Se ha postulado que la disminución de la expresión de PLD3 se asociaría a un incremento de los niveles extracelulares de $A \beta 42$ y $A \beta 40(40,47)$. 


\subsubsection{Factores genéticos protectores para el desarrollo de EA:}

En los últimos años también se han identificado factores genéticos protectores que disminuyen de forma significativa la probabilidad de desarrollar EA. Entre estos factores destaca la mutación codificante $A 673 T$ del gen $A P P$. Se estima que existe una reducción de hasta el $40 \%$ del riesgo de desarrollar EA en los que presentan esta mutación e incluso se ha descrito en su presencia una reducción significativa del riesgo de desarrollar deterioro cognitivo no causada por la EA en la población mayor de 65 años. Se cree que el efecto beneficioso se debe a la alteración del procesamiento de la $A P P$, reduciendo su procesamiento por la vía amiloidogénica mediada por $\beta$-secretasas (50).

Resulta interesante también el papel protector otorgado al alelo E2 de $A P O E$, asociado a la disminución del riesgo de desarrollar EA. La presencia tanto en heterocigosis, pero más aún en homocigosis, para el alelo E2 de APOE se ha asociado a la presencia de menor cantidad de depósito extracelular de $A \beta$, menor cantidad de ovillos neurofibrilares y a una menor pérdida del volumen del hipocampo comparado con los portadores de los otros alelos (51).

Por último, se ha descrito que el alelo G del SNP rs72824905 en el gen PLCG2, que participa en la señalización del sistema inmune, disminuye de forma significativa el riesgo de padecer EA y se asocia a un incremento de la longevidad (52). En conjunto, los estudios de asociación a nivel genético han resultado especialmente útiles para comprender mejor la patogenia de la EA mediante la identificación de diferentes vías biológicas implicadas en el incremento o disminución de riesgo de EA (53).

\subsubsection{Principales factores de riesgo NO genéticos o ambientales de la EA:}

Entre los factores de riesgo no genéticos para el desarrollo de EA se han propuesto múltiples factores de riesgo cardiovascular: 


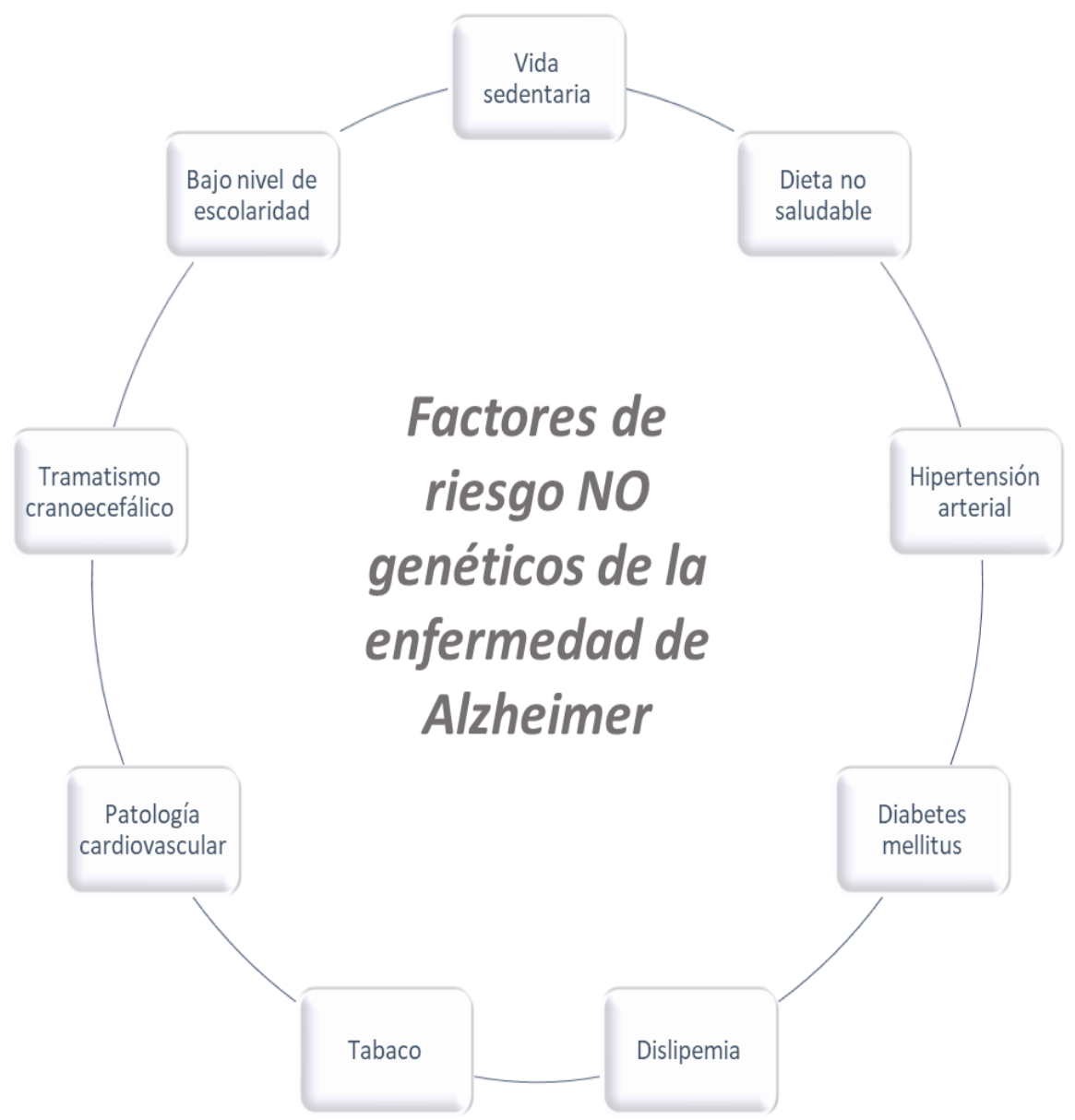

Figura 6 que esquemáticamente ilustra los principales factores de riesgo no genéticos y modificables asociados a la enfermedad de Alzheimer.

- La glucemia basal alterada en ayunas y la diabetes mellitus tipo 2 incrementarían el riesgo de desarrollo de EA por distintos mecanismos, entre ellos por la alteración de la regulación de la insulina implicada a su vez en la eliminación de $A \beta$ y/o el estrés oxidativo y/o la disfunción de la BHE.

- La hiperlipemia y la obesidad especialmente si están presentes en edades medias de la vida conllevarían un incremento de riesgo.

- El consumo de tabaco en edades medias y avanzadas de la vida incrementa el riesgo de desarrollar todo tipo de demencias, no sólo la demencia vascular, sino también la EA. Se ha postulado que podría existir una asociación entre cantidad de tabaco fumada y la cantidad de $A \beta$ extracelular acumulada. Se cree que el 
estrés oxidativo inducido por el tabaco podría favorecer el desarrollo de la resistencia a la insulina y esto a su vez acarrear la aceleración de la ateroesclerosis, factor de riesgo conocido para el desarrollo de EA. A su vez el tabaco induce daño hipóxico directo y aumenta la probabilidad de otros factores de riesgo cardiovasculares como diabetes mellitus tipo 2 y la hipertensión arterial, reconocidos factores de riesgo por sí mismos para el desarrollo de la EA (54).

- La hipertensión arterial (HTA), sobre todo si está presente en edades medias de la vida, también se relaciona con incremento de riesgo de desarrollar EA. La HTA reduce a nivel regional el flujo sanguíneo cerebral y es bien conocido que disminuye la reactividad vascular cerebral. Además, la HTA incrementa el riesgo de ateroesclerosis en arterias cerebrales, aumenta el riesgo de daño de la microvasculatura, de lesiones de la sustancia blanca, de sufrir ictus isquémico, y de hemorragia intracerebral en presencia de angiopatía amiloide cerebral (presente hasta en un $80 \%$ de los casos de EA). A su vez, se ha constatado en modelos animales que la HTA induce disfunción de la BHE, propicia el depósito extracelular de $A \beta$, y facilita a su vez el desarrollo de disfunción neurovascular y la neurodegeneración inducida directamente por $A \beta(39,48,55,56)$.

- La hiperhomocisteinemia además de ser un factor de riesgo para el desarrollo de daño de la microvasculatura cerebral y de ictus isquémico, también se considera un factor de riesgo para el desarrollo de la EA. Se cree que el incremento de riesgo está asociado al daño cerebrovascular, a la disfunción endotelial, al estrés oxidativo y a la desmetilación inducida por los niveles incrementados de homocisteína (39).

No se conoce si los factores de riesgo cardiovascular contribuyen a la presentación clínica de la EA por favorecer que exista daño vascular cerebral y/o si el propio daño vascular inducido por la presencia de dichos FR favorece la aparición de los hallazgos anatomopatológicos definitorios de EA (18). 
Además de los factores de riesgo cardiovasculares también se han identificado otros que incrementan la probabilidad de padecer EA como es el antecedente de daño cerebral inducido por traumatismo craneoencefálico (TCE), en cuyo caso uno de los mecanismos planteados para el incremento del riesgo es la hipotética disfunción de la BHE y de la unión neurovascular, que a su vez favorecería el depósito extracelular de $A \beta$.

En los últimos años existe evidencia creciente para apoyar que la estructura del sueño también puede impactar significativamente en el riesgo de desarrollar la EA. Existen múltiples publicaciones sobre la asociación de síndrome Apnea Hipopnea del Sueño (SAHS) y el riesgo de desarrollar EA. Se sabe que el SAHS favorece la fragmentación del sueño, la hipoxia intermitente, induce estrés oxidativo y contribuye a facilitar el depósito extracelular de $A \beta(57,58)$.

Se han descrito otros múltiples factores de riesgo, algunos de ellos relacionados con la contaminación ambiental y la exposición a nanopartículas, exposición a distintas drogas (incluso la exposición puntual) que podrían favorecer la disfunción vascular cerebral y de la BHE, etc.

A su vez es bien conocido y ya se ha mencionado con anterioridad que el antecedente familiar de EA esporádica en un familiar de primer grado incrementa de forma significativa el riesgo de sufrir EA. Se considera que este incremento del riesgo puede deberse no sólo a la existencia de factores de riesgo genéticos compartidos sino que también a la exposición de similares factores de riesgo ambientales (28).

\subsubsection{Factores ambientales protectores para el desarrollo de EA:}

En los últimos años se han identificado distintos factores protectores que reducen la probabilidad tanto del desarrollo como de la presentación clínica de la EA. Entre ellos destacan:

- La presencia de una mayor reserva cognitiva asociada a un mayor nivel educativo, el disponer de una mayor red de amistades o relaciones sociales, el 
tener mayor adherencia a aficiones variadas o el mantenerse activo intelectualmente y/o físicamente. A mayor nivel educativo y en función de la exigencia de la actividad laboral menor sería el riesgo de desarrollar los síntomas de la EA.

- La realización de ejercicio físico regular también reduce de forma significativa (según algunos estudios en hasta un 45\%) la probabilidad de la EA. Dicho decremento de riesgo va más allá del beneficio en el control de los factores de riesgo cardiovascular y/o sobre su potencial beneficio sobre la regulación del flujo cerebral. Se ha postulado que favorece la liberación de factores neurotróficos, y potencialmente la neurogénesis y la plasticidad sináptica.

- Una dieta equilibrada pobre en grasas saturadas y rica en antioxidantes, como es el caso de la dieta mediterránea también podría reducir el riesgo de presentar la enfermedad.

- Se ha postulado también que el tratamiento hormonal sustitutorio con estrógenos y la administración de vitamina D (en caso de niveles deficitarios) podría tener efecto beneficioso sobre las funciones cognitivas en personas de edad avanzada, aunque existen resultados contradictorios en la actualidad (59).

\subsubsection{Hipótesis patogénicas de la enfermedad de Alzheimer:}

Existen distintas teorías patogénicas para explicar el desarrollo de la EA. Hasta el momento la más ampliamente estudiada y aceptada es la hipótesis amiloidogénica aunque existen otras hipótesis alternativas, mejor dicho complementarias, como la colinérgica, la inflamatoria, la de contribución vascular, etc. La hipótesis de la cascada amiloide sostiene que la producción de $A \beta$ sería responsable de la disfunción y de la muerte neuronal, neurodegeneración y finalmente del desarrollo de demencia. No obstante existe suficiente evidencia para afirmar que el efecto tóxico de los oligómeros de $A \beta$ sería mucho más precoz que el depósito de placas extracelulares de $A \beta$ que correspondería a fases más tardías de la enfermedad $(27,31)$. 
Dicha teoría defiende que el depósito de $A \beta$ se produciría como consecuencia de un procesamiento anómalo de la proteína precursora de amiloide $(A P P)$, codificada por un gen ubicado en el cromosoma 21. En condiciones normales la APP se escinde mediante la acción de las enzimas beta y gamma-secretasas y la región $\mathrm{N}$-terminal es liberada a nivel extracelular, donde es rápidamente degradada o eliminada. Pero en personas de edad avanzada y en el contexto de la EA la capacidad de degradar y eliminar $A \beta$ se reduce y por consiguiente, los péptidos de $A \beta$ se pueden acumular. $A$ nivel intracelular $A \beta$ induce disfunción del retículo endoplasmático y de las mitocondrias, e impacta negativamente en la regulación de la homeostasis de calcio y de lípidos (60). A partir de la APP se forman dos péptidos, conocidos como $A \beta 40$ y $A \beta 42$, con 40 y 42 residuos de aminoácidos, que son los principales componentes de los agregados de $A \beta$. El incremento de los niveles de $A \beta 42$ o del ratio de $A \beta 42 / A \beta 40$ induce la formación de amiloide fibrilar y finalmente de agregados extracelulares en forma de placas seniles.

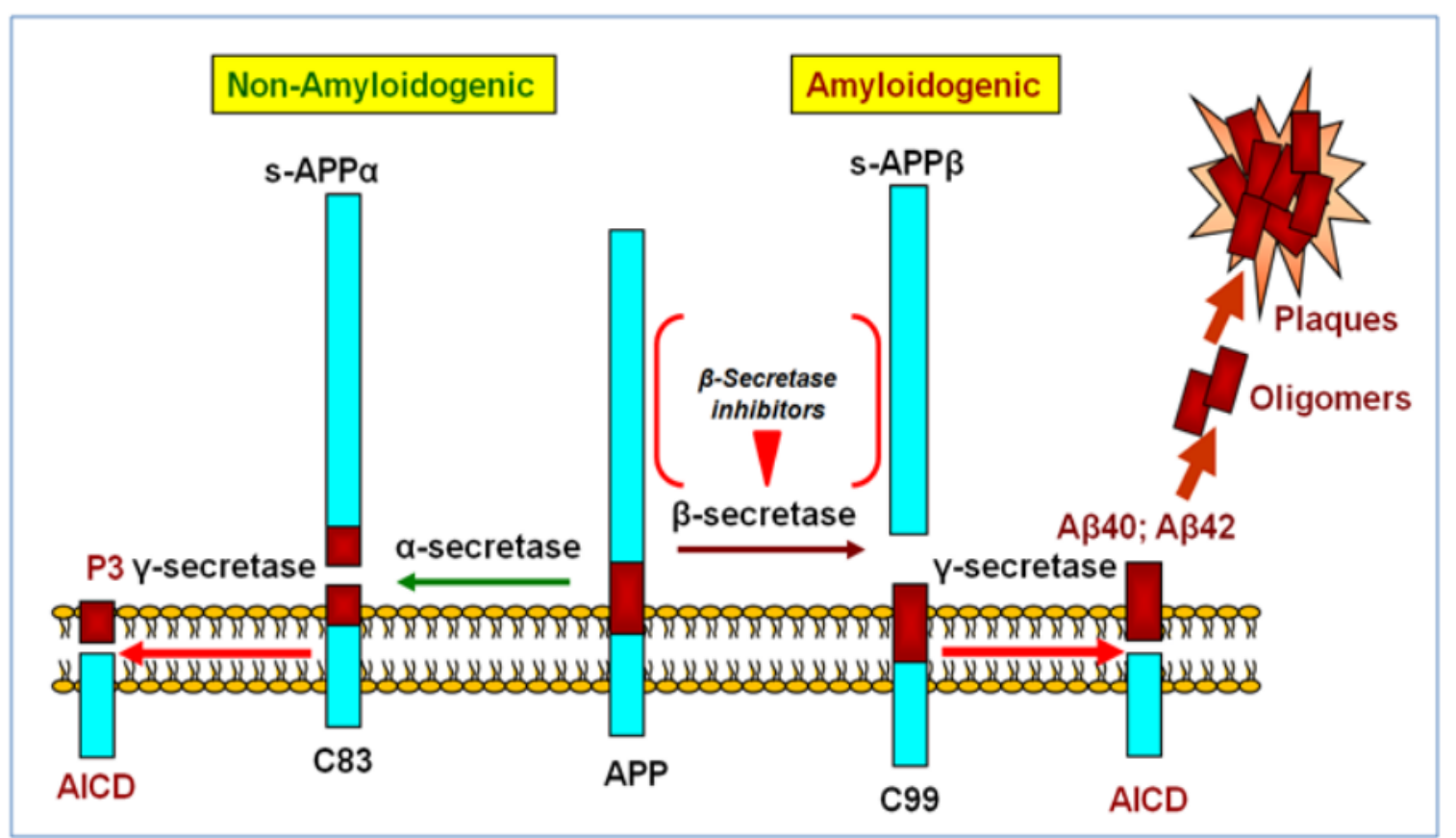

Figura 7 procedente de www.discoverymedicine.com que pretende reflejar de forma esquemática la hipótesis amiloidogénica. 
Las formas oligoméricas solubles de $A \beta 42$ son las que se consideran actualmente las formas más tóxicas y las que mejor se correlacionan con el déficit cognitivo y la disfunción sináptica. Es ampliamente conocido que $A \beta 42$ induce daño oxidativo y promueve la hiperfosforilación de la proteína tau, lo que a su vez tiene efecto tóxico sobre la sinapsis (concepto de sinaptotoxicidad) y el empeoramiento de la función mitocondrial y finalmente sobre la muerte neuronal y la neurodegeneración $(31,49)$.

La existencia de mutaciones en el gen $A P P$, localizado en el cromosoma 21, responsables de alguno de los casos de EA familiar de inicio precoz, al igual que el riesgo incrementado de desarrollar EA de forma precoz en sujetos con síndrome de Down, portadores de tres copias del gen APP, apoyarían la hipótesis amiloidogénica. También las mutaciones patogénicas localizadas en la región de acción de beta y gamma secretasas, que inducen un incremento de producción y/o un cambio en la ratio de la formación de $A \beta 42$, irían a favor de esta hipótesis.

Además, el patrón dinámico constatado en el LCR dentro del continuum de la EA también apoya el papel inicial y central del amiloide. El descenso de $A \beta 42$ acontecería antes que el incremento de tau-total y tau-fosforilada. Al igual que la positividad de los ligandos de amiloide en el PET sería más precoz que los ligandos de tau (19).

En cambio el fracaso de las terapias anti-amiloide, la existencia de depósito de amiloide cerebral en personas sin clínica de EA, la no correlación entre depósito de amiloide e inicio de los síntomas y grado de atrofia medido por técnicas volumétricas de neuroimagen estructural, sugiere que la neurodegeneración y la pérdida neuronal, y el depósito de amiloide podrían ser fenómenos independientes $(8,49)$.

Como se ha referido con anterioridad, la EA se define a nivel anatomopatológico, además de por la presencia de acúmulos de beta-amiloide extracelular, por la presencia de ovillos neurofibrilares intracelulares compuestos por proteína tau hiperfosforilada. La proteína tau es una proteína asociada a los microtúbulos codificada por el gen MAPT, localizado en el cromosoma 17. Hasta el momento, se conoce que seis isoformas diferentes de proteína tau se expresan en el cerebro humano adulto, incluyendo 
isoformas de tau de $3(3 R)$ y 4 repeticiones (4R). Estas repeticiones hacen referencia a la exclusión o inclusión del exón 10 del gen MAPT en la isoforma expresada y, en situaciones de normalidad, se encuentran en el cerebro en un ratio 1:1. La hipótesis patogénica de tau apoya que el evento esencial en el desarrollo de EA es el depósito de la proteína asociada a los microtúbulos, crucial para la formación y mantenimiento del citoesqueleto, la proteína tau, con la posterior formación de ovillos neurofibrilares. Esta teoría defiende que la proteína tau juega un papel importante en la patogenia de la enfermedad incluso desde estadios precoces de la enfermedad, habiéndose descrito su papel en la instauración precoz de daño sináptico, incluso antes de la producción de ovillos neurofibrilares y/o de que se produzca la neurodegeneración (32). La tau hiperfosforilada produce un daño celular mediante agravio en el sistema de transporte, el sistema del citoesqueleto, la señalización y la integridad mitocondrial $(49,61)$.

Los estadios de la patología tau evaluados por la escala Braak y Braak (escala anatomopatológica empleada para el diagnóstico gold-standard de la EA) confirman que la propagación temporal y espacial de los agregados de tau hiperfosforilada tienen una muy buena correlación con la aparición de los síntomas, mucho mejor que con la patología amiloide. En los últimos años y en la misma línea se ha objetivado muy buena correlación entre la evolución clínica y el PET con ligandos específicos para la proteína tau.

También se conoce que en la EA existe evidencia creciente de alteración en los niveles de quinasas y fosfatasas, como la GSK3 $\beta$ (Glycogen synthase kinase 3 beta), implicada en el proceso de fosforilación de la proteína tau (32).

Por otro lado, la hipótesis vascular de la EA se basa en el hecho de que la disfunción vascular podría tener un efecto en el desarrollo de la enfermedad. Se ha descrito la existencia de disfunción de la unión neurovascular y la BHE en múltiples enfermedades neurodegenerativas incluyendo en la EA. En circunstancias normales el flujo sanguíneo cerebral está estrictamente regulado, ya que pequeños cambios en él pueden inducir la muerte neuronal en cuestión de escasos minutos. Como consecuencia de la disfunción 
de la unión neurovascular y de la BHE descrita en la EA se cree que se reduce la eliminación de moléculas neurotóxicas; y que ello induce un desequilibrio en el aporte de nutrientes y de energía; que a su vez conlleva el desarrollo de alteraciones en la expresión de factores de crecimiento, componentes de la matriz extracelular y receptores vasculares; pudiendo todo ello favorecer la instauración de daño sináptico y disfunción neuronal irreversible (39).

Existe evidencia creciente de que la disfunción vascular descrita en la EA podría a su vez influir en la amiloidogénesis teniendo tanto impacto en la capacidad de eliminación de $A \beta$ como en su excesiva producción.

Apoyarían dicha hipótesis numerosos artículos científicos publicados durante los últimos años que demuestran la asociación existente entre la presencia de alguno o de varios de los factores de riesgo cardiovascular en edades medias de la vida y el posterior desarrollo de la EA. También se ha demostrado que el riesgo de EA es mayor en presencia de ateroesclerosis y se ha constatado que los factores de riesgo cardiovasculares y los genéticos con impacto en la función cerebrovascular (p.ej: PICALM, CLUSTERINA, etc.) pueden superponerse para incrementar el riesgo de la EA (27). De hecho hasta un $80 \%$ de las autopsias de los casos de EA han demostrado la coexistencia de patología vascular cerebral, y se conoce que su presencia acelera la progresión del deterioro cognitivo asociado a EA y, como consecuencia de ello, también se adelanta la edad de diagnóstico de la misma $(45,57)$. 

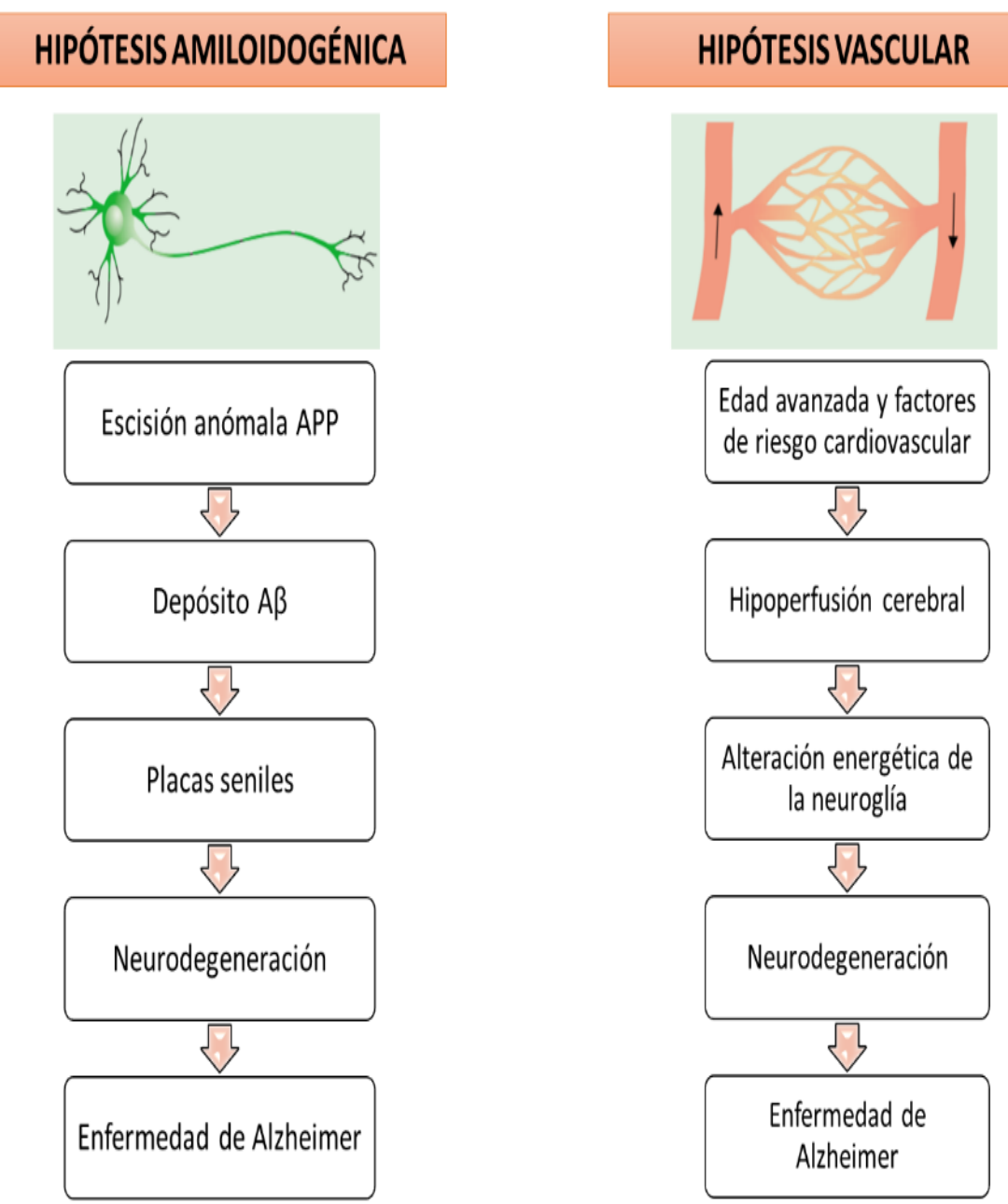

Se presenta esta figura 8 adaptada del trabajo De la Torre et al. del año 2004 (62) que refleja de forma esquemática las ideas básicas de la teoría amiloidogénica explicada con anterioridad y de la teoría vascular en la que se va a ahondar a continuación.

Otra hipótesis patogénica que cada vez adquiere mayor relevancia es la hipótesis de la neuroinmunomodulación. La microglía tiene múltiples funciones en el cerebro sano como son el mantenimiento de las sinapsis, la neurogénesis, la regulación de funciones cognitivas y la vigilancia inmunológica entre otras (63). Al igual que la microglía los astrocitos también tienen un indudable rol en el mantenimiento de la función y de la estructura cerebral, como en la plasticidad sináptica, transmisión de señales o la integridad de la BHE (64). 
El envejecimiento, principal factor de riesgo para desarrollo de EA, conlleva un deterioro de la función del sistema inmune denominado fenómeno de inmunosenescencia que también afecta al sistema nervioso central (SNC). Se ha identificado una expresión génica diferente de varios genes relacionados con la respuesta inmune en distintas regiones del cerebro asociado a la edad, siendo dichos cambios más evidentes en los casos confirmados de EA. Dichas modificaciones en la expresión génica también se acompañan de modificaciones proteicas y fenotípicas de la microglía. Como consecuencia de ello se cree que en los cerebros ancianos existe un exceso de mediadores inflamatorios que inducen una respuesta incrementada pero ineficiente por parte de la microglía ante estímulos inflamatorios repetidos (65).

Dicha teoría sugiere que el inicio de la EA es consecuencia de la reacción de la microglía a distintas agresiones neuronales o a oligómeros de tau. La reacción conllevaría la liberación del Factor Nuclear Kappa Beta (NFKß), sobreproducción de citocinas proinflamatorias y como consecuencia la unión de las mismas a sus receptores celulares. Ello induciría la activación de proteín-quinasas como la CDK5 y la glicógeno sintetasa quinasa beta 3 (GSK3 $\beta$ ) que promueve la hiperfosforilación de la proteína tau y su posterior agregación con efecto neurotóxico. Los propios oligómeros y polímeros de tau liberados de la degradación neuronal ayudarían a perpetuar el ciclo (66).

También es interesante el hecho de que se ha demostrado la existencia de alteración de la integridad de la BHE con la edad, agravada en casos de EA y que precedería al desarrollo de atrofia hipocampal y al deterioro cognitivo, permitiendo el paso de células y moléculas inflamatorias sistémicas en fases precoces de la EA (65). Dicha alteración de BHE por otro lado también podría contribuir a la potencial identificación de biomarcadores plasmáticos que reflejan la patología del SNC, y que bien podrían tener utilidad diagnóstica y/o pronóstica en la práctica clínica.

Mientras tanto la hipótesis colinérgica se basa en la existencia de una deficiencia en el córtex cerebral de la enzima colina acetiltransferasa, en la menor síntesis y menor captación de la acetilcolina y en el hecho de que el grado de extensión del defecto colinérgico tiene relación con la severidad de los síntomas de la EA. Dicha teoría motivó 
el desarrollo de inhibidores de la acetilcolinesterasa como tratamiento sintomático, aprobado en la actualidad, con utilidad en la práctica clínica para la EA. A pesar de que existe evidencia de la afectación de otros neurotransmisores en la EA como son la dopamina, noradrenalina e histamina, cabe destacar que la afectación colinérgica parece ser la más precoz.

De hecho, se ha detectado existencia de degeneración neurofibrilar de forma muy precoz en las neuronas colinérgicas del núcleo basal de Meynert en personas con diagnóstico de EA y se cree que la disminución del número de receptores colinérgicos nicotínicos y muscarínicos a nivel de terminales colinérgicas presinápticas tendría relación con el grado de deterioro cognitivo. A su vez existe evidencia in vitro de que los agregados de $A \beta$ inhiben la neurotransmisión colinérgica $(61,67)$.

También se debe señalar que la desregulación de la homeostasis del calcio es otra de las teorías patogénicas propuesta para la EA. El calcio (Ca) es el segundo mensajero del organismo, siendo sus concentraciones extracelulares superiores a las intracelulares. El Ca es un mensajero intracelular ubicuo necesario para regular la función de múltiples proteínas incluyendo los canales iónicos y múltiples receptores. Por ello no es sorprendente que la alteración en la homeostasis de Ca impacte en la supervivencia celular y en concreto en la muerte neuronal tanto por la vía de la necrosis como por la de la apoptosis, y también impacte en la función sináptica.

Es conocido que $A \beta 42$ interacciona con canales de $C a$ específicos provocando su apertura y por lo tanto una alteración en la homeostasis de calcio. Como consecuencia del incremento de calcio intracelular se produce daño sináptico (sinaptotoxicidad) y provoca la muerte de la neurona. A su vez, el propio incremento intracelular de calcio induce la hiperactivación de las quinasas encargadas de fosforilar a la proteína tau. La hiperfosforilación de tau la desensambla de los microtúbulos induciendo la desestabilización de los mismos y el bloqueo en la conducción axonal. 
Existe también evidencia vía estudios de GWAS de que polimorfismos en genes implicados en la homeostasis intracelular de calcio podrían ser factores de riesgo genéticos para el desarrollo de EA $(9,43,68)$.

Otra de las teorías patogénicas que ha adquirido relevancia en los últimos años, aunque sigue siendo muy controvertida, es la hipótesis de la enfermedad por doble-prion. Dicha hipótesis defiende que las formas fibrilares de la proteína $A \beta$ y de la proteína tau, previas a la formación de las placas seniles y de los ovillos neurofibrilares, serían las que actuarían como las formas patógenas de la enfermedad y tendrían capacidad para propagarse de forma anómala (69).

En resumen, la EA es una enfermedad multifactorial con gran complejidad $y$ heterogeneidad genética. El mismo fenotipo puede ser inducido por alteraciones en distintos genes y los polimorfismos o mutaciones en un mismo gen pueden inducir el desarrollo de fenotipos diferentes (12).

Sin embargo, menos del $1 \%$ de los casos de EA se explican por mutaciones en el gen de la proteína precursora de amiloide $(A P P)$ y los genes de las proteínas preselinina 1 (PSEN1) y preselinina 2 (PSEN2) (70). Por todo ello se considera que es una enfermedad multifactorial, que implica factores genéticos y ambientales tales como: la edad, presencia de alelo E4 de gen APOE, historia familiar de EA (71), presencia de factores de riesgo cardiovascular, menor nivel educativo, menor actividad social e intelectual y traumatismo cráneo-encefálico moderado o severo, entre otros (72).

\subsubsection{Neuroepigenética:}

Una disciplina que combina el efecto de los factores ambientales y genéticos en la expresión de los fenotipos y el desarrollo de las enfermedades es la epigenética. La epigenética estudia los mecanismos de la regulación de la expresión génica sin modificar la secuencia de ADN; regulación heredable y también modificable por diversos factores ambientales (73). 
Los mecanismos epigenéticos regulan la expresión génica de las funciones fisiológicas como la diferenciación y el desarrollo celular. También son mecanismos cruciales para modular la expresión génica ante agresiones externas o cambios biológicos internos.

Un aspecto interesante es que la modificación en la expresión de los genes que acontece gracias a la regulación epigenética permite que células con un número limitado de genes se puedan diferenciar en distintos tipos celulares. Además, la epigenética posibilita que individuos con la misma base genética presenten fenotipos, e incluso enfermedades diferentes, como es el caso de los hermanos gemelos.

Existen diferentes mecanismos epigenéticos, siendo el más ampliamente estudiado la metilación del ADN. La metilación del ADN es una modificación bioquímica que consiste en la adición de un grupo metilo a la posición $5^{\prime}$ de una citosina formando la 5metilcitosina $(5 \mathrm{mC})$. Esta metilación ocurre preferentemente en las citosinas que van seguidas de una guanina, lo que conocemos como dinucleótidos $\mathrm{CpG}$. Los dinucleótidos CpG no están distribuidos al azar en el genoma sino que se agrupan en determinadas regiones conocidas como islas $\mathrm{CpG}$. Cuando un fragmento del $\mathrm{ADN}$ tiene una proporción de dinucleótidos CpG mayor del 50-60\% se considera que es una isla CpG. La metilación del ADN es un proceso relativamente estable y se origina y se mantiene por la acción de las ADN metiltransferasas (DNMT): DNMT1 contribuye a mantener el estado de metilación durante la replicación celular; mientras que DNMT3a y DNMT3b son responsables de la metilación durante la embriogénesis y de la metilación de novo. Las proteínas de unión de las islas CpG metiladas $(M B D)$ pueden ayudar también a regular el estado de metilación. 

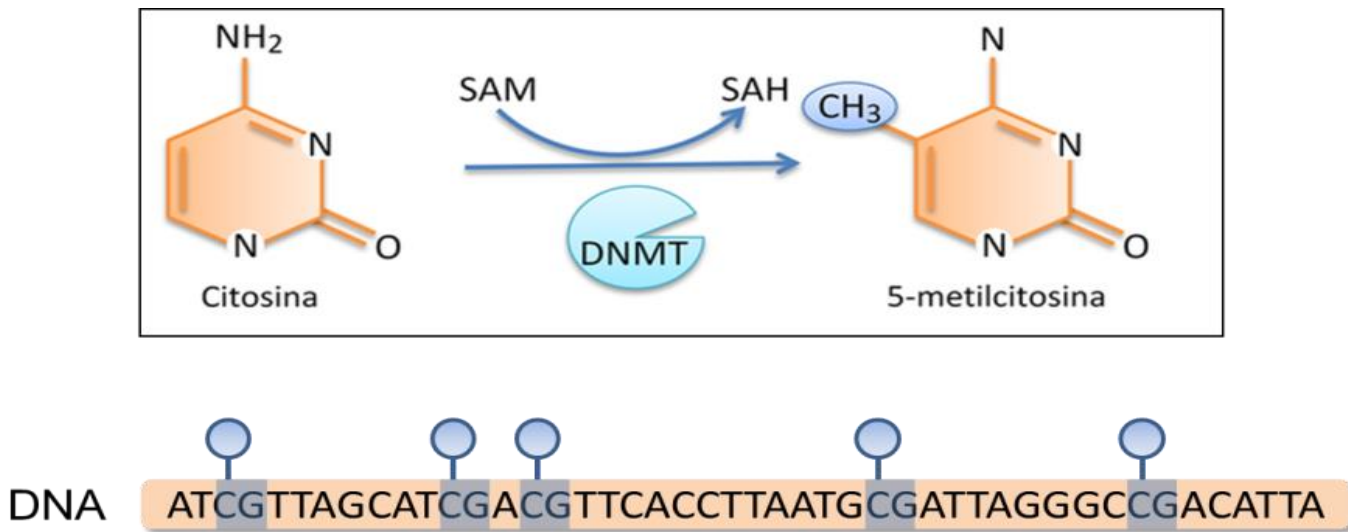

\section{Dinucleótidos CpG}

Figura 9 modificada con respecto a la original procedente de https:// geneticmolecularunlar.wikispaces.com/

La acción de las DNMT y la consiguiente metilación del ADN ocurre en una de las siguientes localizaciones: 1- metilación de las islas CpG localizadas en las regiones promotoras de los genes, 2- metilación de las islas CpG localizadas en el cuerpo del gen, 3- metilación de regiones intergénicas; y la 4- metilación de las secuencias repetitivas. Las islas CpG son especialmente abundantes en las regiones promotoras, dando lugar a cambios estructurales de la cromatina. Se estima que hasta el $60-70 \%$ de los genes humanos presentan regiones promotoras asociadas a islas CpG. Las regiones metiladas conllevan imposibilidad de acceso a los factores de transcripción y por tanto inhiben la transcripción del gen; en cambio, el estado de hipometilación permitiría la expresión del gen. La 5 metilcitosina también se une a las $M B D$ dificultando la expresión génica (74). La metilación del ADN modifica la estructura de la cromatina. El ADN no metilado tiene estructura de eucromatina y permite a los factores de transcripción la unión a las regiones correspondientes. 

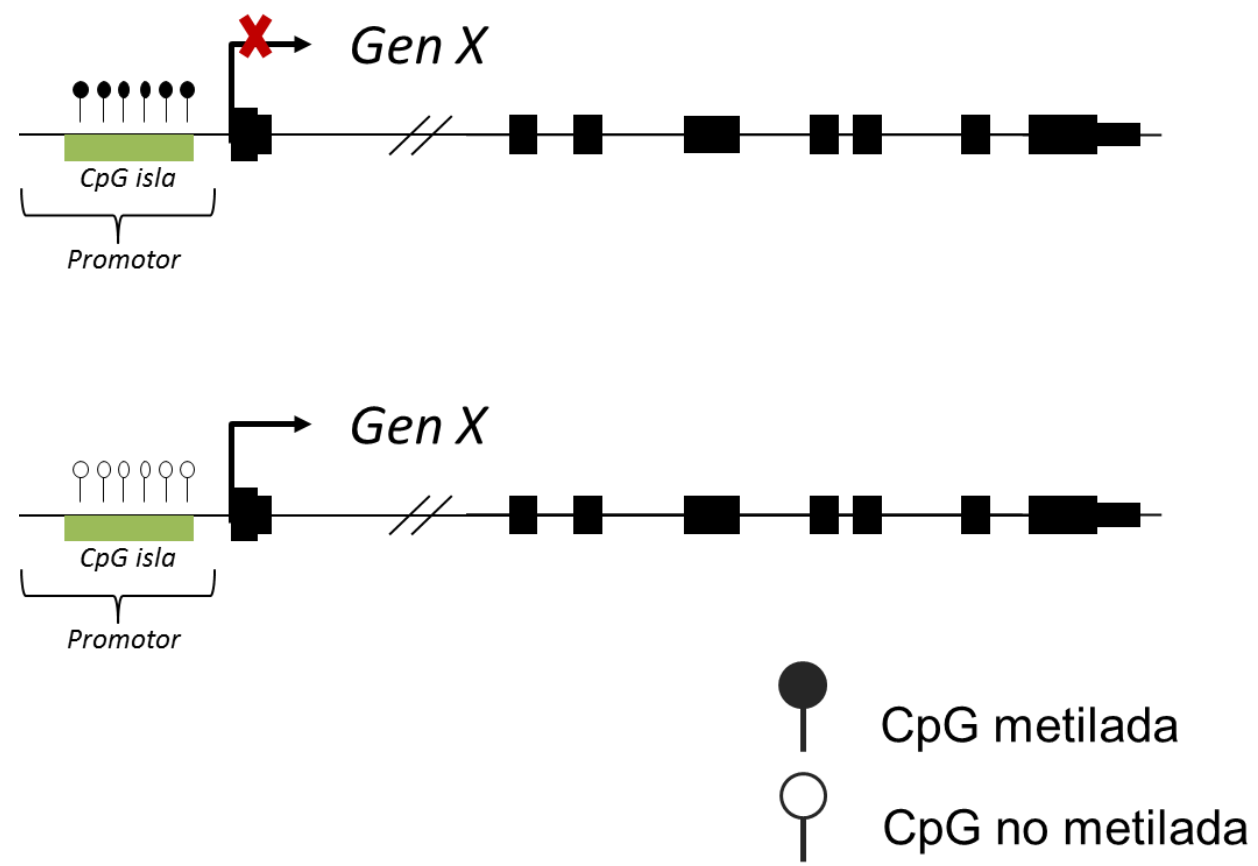

Figura 10 modificada del artículo Mendioroz et al. 2014 (75).

La metilación del ADN, al igual que el resto de los mecanismos epigenéticos, es un proceso esencial para el normal desarrollo y proliferación celular y para el mantenimiento de la integridad del genoma. Por todo ello, tiene gran relevancia en la fase del desarrollo del SNC, estando implicado en el desarrollo neuronal, diferenciación neuronal y también por su implicación en la neurogénesis en el adulto.

Aunque la metilación del ADN es un mecanismo epigenético relativamente estable, que se hereda en las células hijas obtenidas mediante mitosis, varios factores ambientales a los que nos exponemos a lo largo de la vida pueden inducir cambios en el epigenoma. Además, existen claros cambios en el patrón de metilación del ADN en relación a la edad (se ha descrito la existencia de pérdida de metilación con la edad aunque sobre todo en regiones promotoras no reguladas por islas $(\mathrm{pG})$; considerándose un buen marcador de envejecimiento tisular, incluyendo el envejecimiento del SNC (76).

El estudio de la metilación del ADN entre diferentes condiciones, como la salud y la enfermedad, permite establecer diferencias en la metilación en regiones concretas del 
genoma asociadas a dichas condiciones (marcas de metilación). Estas diferencias se conocen como metilación diferencial.

El estudio de la metilación diferencial se puede realizar mediante distintas aproximaciones de investigación:

1- Aproximación mediante gen candidato (estudiando loci seleccionados a priori) o

2- Aproximación de genoma completo (Genome-wide) (estudiando el metiloma global del genoma, sin apriorismos).

\subsubsection{Estudios de metilación del ADN en la enfermedad de Alzheimer:}

La metilación del ADN se ha demostrado alterada en múltiples enfermedades complejas, entre ellas en la EA.

Se han identificado, mediante la aproximación de molécula candidata, genes biológicamente relevantes para la EA diferencialmente metilados en cerebros de pacientes con EA con respecto a controles. Un resumen de los genes que han mostrado metilación diferencial en estrategias de gen candidato en la EA se muestra continuación. 


\begin{tabular}{|c|c|c|c|c|c|}
\hline Gen & Proteína & $\begin{array}{l}\text { Número } \\
\text { MIM }\end{array}$ & $\begin{array}{l}\text { Metilación } \\
\text { diferencial }\end{array}$ & Tejido & Referencias \\
\hline APOE & Apolipoproteína $\mathrm{E}$ & $* 104760$ & $\begin{array}{l}\text { Promotor hipermetilado } \\
\text { en la EA }\end{array}$ & $\begin{array}{l}\text { Córtex frontal y } \\
\text { linfocitos } \\
\text { periféricos }\end{array}$ & Wang et al. 2008 \\
\hline APP & Proteína precursora del amiloide & $* 104760$ & $\begin{array}{l}\text { Promotor hipometilado } \\
\text { en la EA }\end{array}$ & Tejido cerebral & West et al. 1995 \\
\hline APP & Proteína precursora del amiloide & $* 104760$ & Sin cambios & $\begin{array}{l}\text { Córtex parietal; } \\
\text { Córtex frontal e } \\
\text { hipocampo }\end{array}$ & $\begin{array}{l}\text { Yoshikai et al. I990; } \\
\text { Barrachina et al. } \\
2009\end{array}$ \\
\hline MAPT & Proteína tau & $* 157 \mid 40$ & Sin cambios & $\begin{array}{l}\text { Córtex frontal e } \\
\text { hipocampo }\end{array}$ & $\begin{array}{l}\text { Barrachina et al. } \\
2009\end{array}$ \\
\hline MTHFR & Metilenetetrahidrofolato reductasa & $* 607093$ & $\begin{array}{l}\text { Cuerpo del gen } \\
\text { hipermetilado en la EA }\end{array}$ & $\begin{array}{l}\text { Córtex frontal y } \\
\text { linfocitos } \\
\text { periféricos }\end{array}$ & Wang et al. 2008 \\
\hline PSENI & Preselinina I & $* 104311$ & Sin cambios & $\begin{array}{l}\text { Córtex frontal e } \\
\text { hipocampo }\end{array}$ & $\begin{array}{l}\text { Barrachina et al. } \\
2009\end{array}$ \\
\hline PSENI & Preselininal & $* 104311$ & $\begin{array}{l}\text { Promotor hipometilado } \\
\text { en la EA }\end{array}$ & $\begin{array}{l}\text { Córtex frontal y } \\
\text { linfocitos } \\
\text { periféricos }\end{array}$ & Wang et al. 2008 \\
\hline rDNA & $\begin{array}{l}\text { Genes ribosamales (rRNA) } \\
\text { nucleolares }\end{array}$ & & $\begin{array}{l}\text { Promotor hipermetilado } \\
\text { en la EA }\end{array}$ & Córtex parietal & Pietrzak et al. 20II \\
\hline SIOOA2 & Proteína S100-A2 & $* 176993$ & $\begin{array}{l}\text { Promotor hipometilado } \\
\text { en la EA }\end{array}$ & Córtex temporal & $\begin{array}{l}\text { Siegmund et al. } \\
2007\end{array}$ \\
\hline SORBS3 & Vinexina & *610795 & $\begin{array}{l}\text { Promotor hipermetilado } \\
\text { en la EA }\end{array}$ & Córtex temporal & $\begin{array}{l}\text { Siegumnd et al. } \\
2007\end{array}$ \\
\hline TERT & Transcriptasa reversa & $* 187270$ & $\begin{array}{l}\text { Promotor hipermetilado } \\
\text { en la } E A\end{array}$ & $\begin{array}{l}\text { Linfocitos } \\
\text { periféricos }\end{array}$ & Silva et al. 2008 \\
\hline TREM2 & $\begin{array}{l}\text { Triggering receptor expressed on } \\
\text { myeloid cells } 2\end{array}$ & *605086 & $\begin{array}{l}\text { Promotor hipermetilado } \\
\text { en la EA }\end{array}$ & Hipocampo & Celarain et al. 2016 \\
\hline CRTCI & $\begin{array}{l}\text { Creb-regulated transcription } \\
\text { coactivator I }\end{array}$ & *607536 & $\begin{array}{l}\text { Promotor hipometilado } \\
\text { en la EA }\end{array}$ & Hipocampo & $\begin{array}{l}\text { Mendioroz et al. } \\
2016\end{array}$ \\
\hline
\end{tabular}

Tabla 1 modificada del artículo Mendioroz et al. 2014 (75).

Por otro lado, empleando las aproximaciones Genome-wide, recientemente se han descrito genes diferencialmente metilados en varias regiones cerebrales de pacientes con EA. La aplicación de tecnologías -ómicas al estudio de la metilación del ADN en muestras postmortem de cerebros con EA ha sido de enorme utilidad en este campo. 
Los primeros ensayos, realizados en la plataforma 27K Methylation Array de Illumina (Illumina Inc,, San Diego, CA, USA) en el año 2012, ofrecieron resultados modestos pero se mostraron útiles para identificar nuevos genes relacionados con la EA, como TMEM59 (77) o la fosfatasa DUSP22, que participa en la fosforilación de la proteína tau y regula la vía CREB, esencial en las sinapsis (78). Posteriormente, la irrupción de una plataforma de mayor potencia y resolución, Ilumina Infinium HumanMethylation450K arrays (Illumina Inc, San Diego, CA, USA), que analiza hasta 485.000 CpGs a lo largo de todo el genoma, ha permitido encontrar genes diferencialmente metilados, incluyendo algunos genes que previamente habían sido identificados como factores de riesgo para el desarrollo de EA como son ABCA7 o BIN1 (amphiphysin II) (79). Resulta relevante el hecho de que un importante número de dichas diferencias están presentes desde fases precoces de la enfermedad y en individuos asintomáticos, lo que apoyaría su papel patogénico y su potencial utilidad como biomarcadores tempranos de la enfermedad (80). Cabe resaltar que la asociación de BIN1 y $A B C A 7$ se ha replicado por otros autores en una cohorte independiente (81). Además, Lunnon et al. lograron identificar una región hipermetilada en el gen ANK1 cuyos niveles de metilación se correlacionaban con la carga de los cambios neuropatológicos de la EA (79). Se puede encontrar una revisión exhaustiva de los genes con metilación diferencial en el cerebro de la EA en la revisión realizada por Sánchez-Mut y Gräff (82).

Hasta el momento, se han realizado estudios de metilación mediante aproximación Genome-wide en distintas regiones cerebrales tales como córtex prefrontal, frontal, neocórtex temporal superior y córtex entorrinal. En las regiones estudiadas se ha constatado un predominio de la ganancia de metilación en pacientes con respecto a controles. Sin embargo, otras zonas relevantes en el inicio de la EA, como el hipocampo o el cíngulo, no se han estudiado mediante estas tecnologías.

El epigenoma de la EA está siendo estudiado en la actualidad, pero todavía hay mucho por aprender. Su mejor conocimiento podría ayudar a descifrar la fisiopatogenia de la enfermedad y también permitir la posible identificación de biomarcadores diagnósticos de la enfermedad $(83,84)$. En la misma línea, mediante el estudio de metilación 
utilizando la estrategia de gen candidato se han identificado diferencias en el patrón de metilación de APOE, con potencial efecto sobre la patogenia de la EA, accesible a ser monitorizada en células sanguíneas como linfocitos, y poder ser un biomarcador relevante para EA. Por otro lado, los niveles de metilación en la región promotora de los genes COASFY y SPINT1 también se podrían considerar como potenciales biomarcadores diagnósticos de EA (85). 


\subsection{DIAGNÓSTICO DE LA ENFERMEDAD DE ALZHEIMER:}

En la actualidad el diagnóstico definitivo de EA, según las recomendaciones de la National Institute on Aging and the Alzheimer's Association (NIA/AA), sigue exigiendo la realización de estudio anatomopatológico postmortem (10). En vida se puede obtener el diagnóstico en grado de certeza bien posible o probable.

La anamnesis dirigida, apoyada preferiblemente en la evaluación neuropsicológica reglada, sigue siendo la herramienta diagnóstica más ampliamente empleada para establecer el diagnóstico de deterioro cognitivo y para establecer la sospecha etiológica de que dicho deterioro cognitivo pueda deberse a una EA. Se recomienda el despistaje de causas tratables de deterioro cognitivo como de alteraciones analíticas incluyendo los déficits vitamínicos o las alteraciones de la función tiroidea; y/o la existencia de lesiones estructurales como hematomas subdurales, estando indicada la realización de una prueba de neuroimagen para su descarte (tomografía craneal o preferiblemente $\mathrm{RMc})$.

Siguiendo esta estrategia diagnóstica, aplicada hasta hace unos años, era complicado establecer el diagnóstico de EA en fases sintomáticas iniciales o fase prodrómica y por ello en muchas ocasiones se demoraba el diagnóstico hasta que el deterioro cognitivo hubiese progresado hasta el estadio de demencia. Esto sobre todo acontecía en las presentaciones atípicas de la enfermedad y/o en el caso de antecedente de patología psiquiátrica o toma crónica de psicofármacos.

\subsubsection{Relevancia del diagnóstico precoz:}

Con la información disponible en la actualidad, se estima que los procesos neurodegenerativos pueden iniciarse hasta 20-30 años antes del inicio de los síntomas (86). La detección precoz de EA en etapas presintomáticas ofrecería una gran oportunidad para establecer tratamientos potencialmente modificadores de la 
enfermedad de forma precoz, hipotéticamente de manera previa a la instauración del daño sináptico y del desarrollo del extenso daño neuronal. Se cree que el fracaso de los tratamientos ensayados hasta la fecha, al menos en parte, se debe a la instauración tardía de los mismos, cuando el daño neuronal ya se ha producido y es irreversible. Uno de los grandes retos asistenciales por tanto sería poder diagnosticar a los pacientes afectos de forma precoz (en fases sintomáticas iniciales) para que se puedan beneficiar de un posible tratamiento modificador de la enfermedad.

Con la finalidad de establecer un diagnóstico precoz de EA en los últimos años se ha postulado el empleo de biomarcadores, tanto de líquido cefalorraquídeo (LCR) como de neuroimagen tanto estructural (RM) como funcional (PET). Otra forma de clasificar los biomarcadores empleados en la práctica clínica es en función de su vinculación con la patofisiología de la enfermedad: 1- relacionados con el acúmulo de amiloide, 2- con la patología tau, y 3-relacionados con la neurodegeneración (87).

Los biomarcadores core para el diagnóstico de EA en LCR son: A $\beta 42$ que refleja el depósito cortical de amiloide; tau total (t-tau) que se relaciona con la intensidad o grado de neurodegeneración y la tau fosforilada ( $p$-tau) que se correlaciona con los ovillos neurofibrilares. La combinación de estos biomarcadores (descenso de los niveles de A 342 combinado con incremento de los niveles de tau-total y tau-fosforilada) tiene una sensibilidad y especificidad próxima al $85-90 \%$ para el diagnóstico de EA cuando se aplican en la fase de deterioro cognitivo leve. En ausencia de síntomas de enfermedad la presencia de biomarcadores core positivos (fase preclínica) se considera que aumenta el riesgo de presentación clínica de la EA. Pero esto no implica que obligatoriamente el sujeto vaya a desarrollar los síntomas, sino que tiene un riesgo incrementado.

En la práctica clínica se debe tener en cuenta que su mayor utilidad radica en su alto valor predictivo negativo, ya que la normalidad de dichos valores permite excluir con alto grado de certeza el diagnóstico de EA $(19,48)$.

Tanto los niveles reducidos de A 342 en LCR como la unión del ligando de amiloide en el PET cerebral son biomarcadores directos de presencia de amiloidosis cerebral. Los 
marcadores directos de amiloidosis son considerados como específicos para la EA, aunque si bien es cierto que un número no desdeñable de pacientes con diagnóstico confirmado de enfermedad por cuerpos de Lewy pueden presentar alteraciones en el patrón de biomarcadores de amiloidosis en LCR dada la frecuencia de la coexistencia de ambas patologías (la existencia de copatología EA-enfermedad cuerpos de Lewy empeora el pronóstico funcional de los pacientes). A diferencia de los biomarcadores directos de tau en LCR, tau-total y tau-fosforilada, que se correlacionan mejor con la progresión de la EA pero que se encuentran también alterados en otras enfermedades neurodegenerativas como las enfermedades priónicas (los niveles de tau-t suelen ser mucho más elevados que en casos de EA) y/o en el caso de un TCE, entre otros (19).

En la siguiente tabla (Tabla 2) se recogen los biomarcadores de amiloide y tau en LCR con aplicabilidad en la práctica clínica empleados en la actualidad en centros de referencia $(33,88)$ :

\begin{tabular}{|l|l|}
\hline $\mathbf{A} \boldsymbol{\beta} 4 \mathbf{2}$ & Disminuido en LCR. \\
\hline $\mathbf{A} \boldsymbol{\beta} 40$ & $\begin{array}{l}\text { Ratio } \mathbf{A} \boldsymbol{\beta} \mathbf{4 2 / A} \boldsymbol{\beta} 40 \text { descendido en LCR (el ratio } \\
\text { es menos vulnerable a ser modificado por } \\
\text { problemas técnicos que la determinación aislada } \\
\text { de Aß42). }\end{array}$ \\
\hline t-tau & Aumentado en LCR. \\
\hline -tau & Aumentado en LCR. \\
\hline
\end{tabular}

Existen también otros biomarcadores con potencial aplicabilidad clínica como la determinación de YKL-40 (Chitinase-3-like protein 1) en LCR, siendo considerado como un biomarcador indirecto de EA, al igual que el caso de la RMc estructural y/o del PET- 
FDG. YKL-40 se considera un biomarcador de neuroinflamación y se ha demostrado como un buen indicador de la progresión del estadio de deterioro cognitivo leve a EA establecida. El PET-FDG sería sugestivo de EA si mostrase hipometabolismo parietotemporal bilateral y la RMc si mostrase atrofia desproporcionada con afectación mayoritaria de la región medial, basal y lateral de los lóbulos temporales y del córtex parietal medial (19).

El principal problema de los biomarcadores core aprobados para uso en la práctica clínica para el diagnóstico de EA (en LCR: $A \beta$, tau-total y tau-fosforilada, y PET de metabolismo de glucosa y de depósito de amiloide) es su carácter invasivo y/o coste excesivo, lo que dificulta su aplicación en un gran número de pacientes (89-93).

Otro de los problemas de nueva aparición y pendiente de resolver en la actualidad es el hecho de que el empleo de biomarcadores puede permitir el diagnóstico de casos de EA en la fase preclínica. Sin embargo, se desconoce cuántos de estos sujetos desarrollarán o no la enfermedad y no está claro cómo transmitir la información de que el hallazgo de un perfil compatible de biomarcadores con EA supone un incremento de riesgo para EA pero no una certeza para su desarrollo.

No se debe de olvidar que los biomarcadores core reflejan los cambios fisiopatológicos de la EA. Se conoce que dichos cambios acontecen de forma lentamente progresiva en un período superior a 20 años. A su vez, y tal como se ha señalado con anterioridad, dichos cambios ocurren de forma secuencial, y también así se refleja en la detección progresiva de la positividad para distintos biomarcadores. 


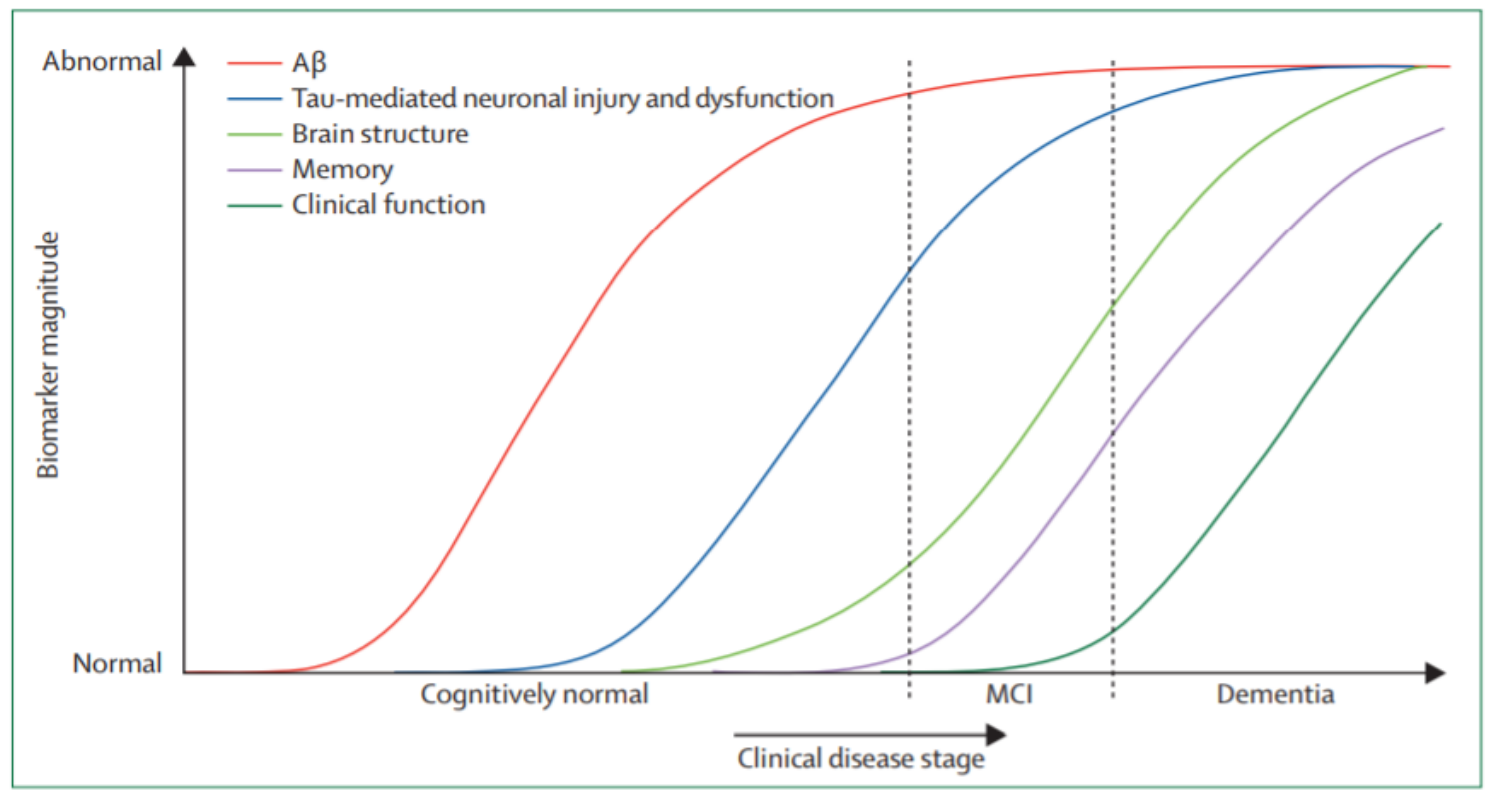

Figura 11 obtenida de Clifford et al. publicada en Lancet Neurology en el año 2013 (94).

\subsubsection{Proceso de identificación de nuevos biomarcadores:}

No obstante, se debe señalar que la investigación de nuevos biomarcadores diagnósticos es un proceso lento, puesto que requiere la consecución de estudios seriados y progresivamente más complejos antes de establecer un biomarcador como utilizable en la práctica clínica. Por ejemplo, actualmente se usan los niveles de procalcitonina como un biomarcador sensible y específico de infección bacteriana y sirven para predecir el riesgo de sepsis y guiar el tratamiento antibiótico. Desde la primera descripción de la asociación de la procalcitonina con la infección bacteriana en 1993 (95), hasta su introducción en las guías internacionales de práctica clínica en 2016 (96) tuvo que pasar casi un cuarto de siglo. La primera fase en el estudio de biomarcadores se realiza mediante estudios de descubrimiento no sesgado (discovery), en los que se analizan miles de moléculas en un grupo muy reducido de individuos y, preferiblemente, en muestras de tejido afecto por la enfermedad a estudio. A 
continuación, se realizan estudios de validación técnica y clínica utilizando cada vez menos moléculas y tamaños muestrales progresivamente mayores.

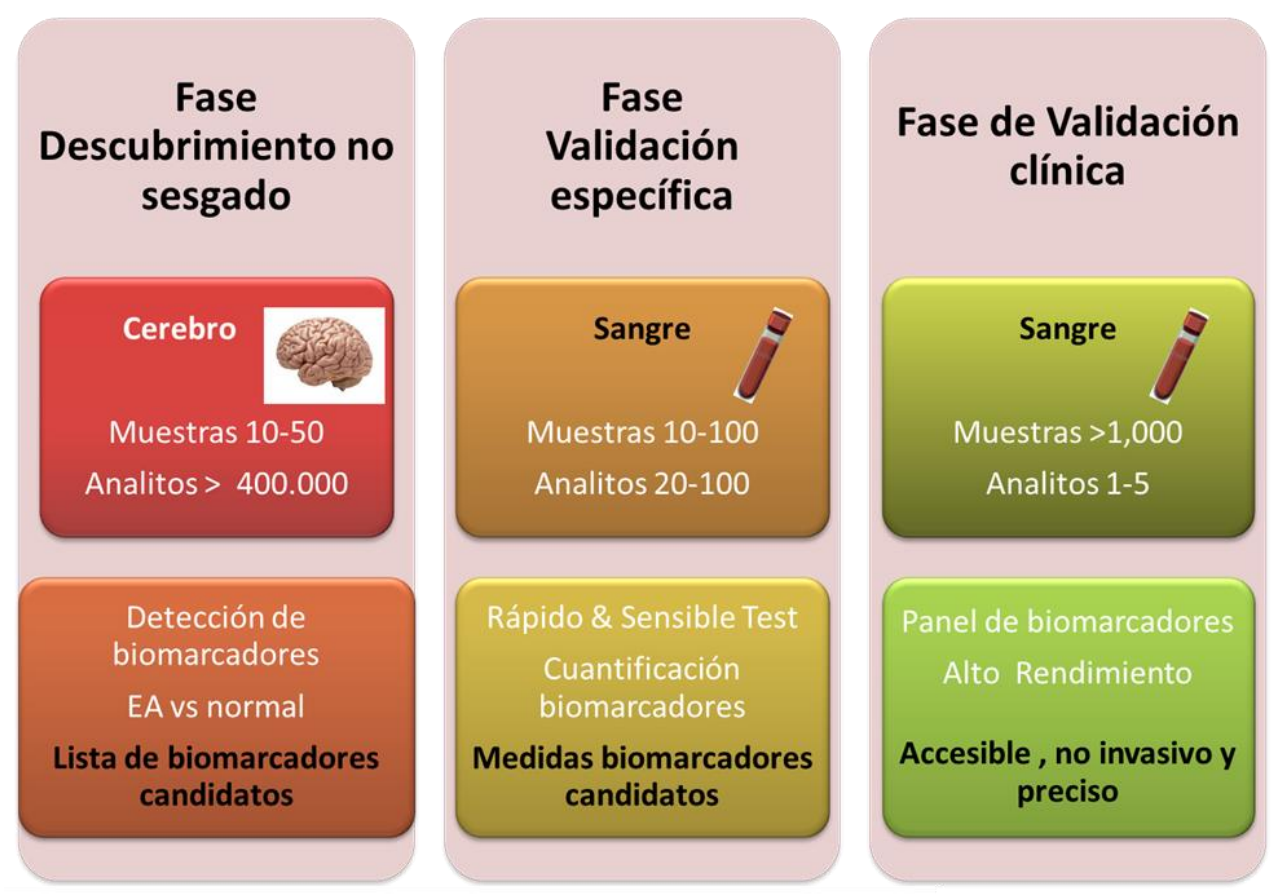

Figura 12 cedida por Maite Mendioroz. 
INTRODUCCIÓN:

PROBLEMA A INVESTIGARSE: HIPÓTESIS Y OBJETIVOS DE LA INVESTIGACIÓN 


\section{PROBLEMA A INVESTIGARSE: HIPÓTESIS Y OBJETIVOS DE LA INVESTIGACIÓN:}

En el año 2013 los países integrantes de la cumbre del G8 llegaron a reconocer a la EA como uno de los grandes retos del siglo XXI que requerían un abordaje global y prioritario. En este sentido es indiscutible el gran esfuerzo realizado en los últimos años para mejorar las herramientas diagnósticas $y$, aunque sin éxito hasta la fecha, también para obtener terapias modificadoras de la enfermedad.

Se ha producido una gran revolución diagnóstica debida al empleo de los biomarcadores core para el diagnóstico de la EA en los últimos años. Aunque la instauración en la práctica clínica del uso de biomarcadores es una realidad innegable en unidades específicas de memoria y hospitales de referencia, no lo es así en la mayoría de los medios, estando lejos todavía de universalizarse su empleo (no en todos los lugares se dispone de acceso a equipos de PET y/o a las herramientas requeridas para proceder al correcto procesamiento de las muestras de LCR). Ahora el reto diagnóstico consiste en la identificación de biomarcadores más accesibles y menos costosos, para su potencial uso universal, siendo los biomarcadores sanguíneos los mejores candidatos hasta la fecha.

Dada la cantidad de información publicada en los últimos años sobre biomarcadores sanguíneos con potencial utilidad tanto diagnóstica como pronóstica se ha creído adecuada y necesaria la realización de una revisión sistemática sobre los biomarcadores más prometedores. Se han revisado biomarcadores identificados mediante estrategia de molécula candidata y también mediante el empleo de técnicas ómicas.

Con la creencia de que las alteraciones en la regulación epigenética descritas hasta la fecha pueden tener un rol patogénico en la EA y que también en un futuro puedan servir como biomarcadores diagnósticos se han utilizado dos aproximaciones diferentes aunque complementarias para intentar su identificación: una estrategia no apriorística de aproximación del genoma completo (genes) y una estrategia de gen candidato. 
Se ha desarrollado un estudio en fase de descubrimiento del patrón de metilación diferencial del ADN (genoma completo), también llamado metiloma, en el hipocampo de pacientes afectos de EA comparado con respecto a controles. Estudios similares sobre el metiloma se han realizado con anterioridad en otras regiones cerebrales pero, que nos conste a nosotros, es el primer estudio realizado en el hipocampo en el caso de EA, siendo dicha región de gran relevancia al ser el origen de la patología tau. Además, es relevante identificar si los cambios en el metiloma descritos son reproducibles entre distintos estudios y distintas regiones cerebrales, para luego valorar su posible futura consistencia al ser estudiados en otros tejidos más accesibles como en el caso de la sangre periférica.

Además del estudio previo también se ha analizado el patrón de metilación de un gen candidato, en concreto del gen PLD3 en las mismas muestras de hipocampo de pacientes y controles, gen cuya identificación como factor de riesgo genético para el desarrollo de EA ha sido considerado controvertido con resultados contradictorios desde la primera descripción por Cruchaga et al en el año 2014 (47).

Las muestras de hipocampo humano empleadas para este proyecto de identificación del metiloma y para el estudio de patrón específico de metilación de genes candidatos corresponden en su inmensa mayoría a cerebros en fases avanzadas de la enfermedad (diagnosticados por anatomía patológica siguiendo los criterios de Braak \& Braak y estadiaje $A B C$ score). En cambio, se debe señalar que todas las muestras incluidas en el presente estudio corresponden a casos puros de EA, sin existir en ninguno de los casos coexpresión de otras proteínas como bien podrían ser alfa-sinucleína o TDP43, entre otros, y no existe tampoco daño vascular significativo. El carácter estricto de la selección de casos puros de EA sin copatología significativa (descartada por anatomía patológica gold standard-) se considera una fortaleza, ya que los cambios objetivados entre muestras de casos y controles no van a poder estar influenciadas por la presencia de otras proteinopatías y/o daño significativo de la vasculatura cerebral. 


\subsection{HIPÓTESIS}

Nuestra hipótesis es que existen cambios en el patrón de metilación del ADN en una región cerebral clave para el desarrollo de la enfermedad de Alzheimer (EA), el hipocampo, que pueden ser identificados mediante aproximación de gen candidato y/o genoma completo, que podrían mejorar el conocimiento sobre la fisiopatogenia de la enfermedad y que constituyen una fuente potencial de biomarcadores epigenéticos candidatos para la EA.

\subsection{OBJETIVOS:}

1. Realizar una revisión sistemática de los biomarcadores sanguíneos tanto diagnósticos como pronósticos previamente publicados para su futura aplicabilidad en la EA.

2. Identificar variantes epigenéticas en el patrón de metilación del ADN mediante la caracterización del metiloma en el hipocampo de pacientes con EA con respecto a controles.

3. Analizar la posible relación entre el patrón de metilación diferencial del ADN en el hipocampo de pacientes con EA con respecto a controles y la patogenia de la EA.

4. Identificar variantes epigenéticas en el patrón de metilación del ADN de un gen candidato, PLD3, factor de riesgo genético de la EA, en el hipocampo de pacientes con EA con respecto a controles.

5. Determinar el nivel de correlación entre los niveles de metilación del ADN del gen PLD3 y los cambios neuropatológicos característicos de la EA en el hipocampo. 


\section{METODOLOGÍA Y EXPOSICIÓN DE RESULTADOS}




\section{METODOLOGÍA Y EXPOSICIÓN DE RESULTADOS:}

El trabajo aquí expuesto se ha realizado mediante la fórmula de compendio de artículos. De esta forma los apartados de metodología y resultados se han podido agrupar y detallar individualmente en cada una de las publicaciones.

A continuación, se facilitan los tres artículos publicados en revistas indexadas entre los años 2018 y 2019 que pretenden responder a los objetivos planteados en el apartado anterior.

Los títulos de los trabajos que se presentan a continuación son los siguientes (siguiendo el orden de presentación):

1. Biomarcadores sanguíneos en la enfermedad de Alzheimer.

2. DNA methylation signature of human hippocampus in Alzheimer's disease is linked to neurogenesis.

3. PLD3 epigenetic changes in the hippocampus of Alzheimer's disease.

Se han incluido artículos originales y una revisión sistemática publicados entre los años 2018 y 2019. En cada uno de los dos artículos originales se detalla la metodología empleada para su realización junto con los resultados pormenorizados. Por otro lado, cada uno de los artículos dispone de un apartado de discusión aunque tras finalizar la sección de resultados se procederá a una discusión conjunta de todos ellos.

Al final del presente trabajo, en el apartado titulado anexos, se presentan los artículos en el formato de cada revista. Sin embargo, en este apartado se ha decidido adaptarlos todos a un mismo formato para facilitar la continuidad y la interpretación del mensaje conjunto a transmitir. 
Artículo

número 1

Biomarcadores sanguíneos en la enfermedad de Alzheimer. $M$. Altuna-Azkargorta, M. Mendioroz-Iriarte. Neurologia. 2018 May 8. Pii: S0213-4853(18)30091-4. Doi: 10.1016/j.nrl.2018.03.006. 


\subsection{BIOMACARDORES SANGUÍNEOS EN LA ENFERMEDAD DE ALZHEIMER}

M. Altuna-Azkargorta ${ }^{a,}{ }^{*}$ y M. Mendioroz-Iriarte ${ }^{a, b}$

\footnotetext{
a Laboratorio de Neuroepigenética, Navarrabiomed, Complejo Hospitalario de Navarra, Universidad Pública de Navarra (UPNA), IdisNA, Pamplona, España.

b Servicio de Neurología, Complejo Hospitalario de Navarra.
}

* Autor para correspondencia.

\section{Resumen:}

Introducción: El diagnóstico precoz de la enfermedad de Alzheimer mediante la utilización de biomarcadores podría facilitar la instauración y monitorización de intervenciones terapéuticas tempranas con potencial capacidad para modificar significativamente el curso de la enfermedad.

Desarrollo: Los biomarcadores clásicos de líquido cefalorraquídeo y de neuroimagen estructural y funcional aprobados tienen una aplicación clínica limitada, dado su carácter invasivo o su elevado coste. La identificación de biomarcadores más accesibles y menos costosos, como los sanguíneos, facilitaría su aplicación en la práctica clínica. Se presenta una revisión bibliográfica de los principales biomarcadores bioquímicos sanguíneos con potencial utilidad para el diagnóstico de enfermedad de Alzheimer.

Conclusiones: Los biomarcadores sanguíneos son coste y tiempo efectivos con respecto a los marcadores de líquido cefalorraquídeo. Sin embargo, la aplicabilidad inmediata de los biomarcadores sanguíneos en la práctica clínica es poco esperable. Las principales limitaciones estriban en la dificultad para la medición y estandarización de los umbrales entre los diferentes laboratorios y en los fallos de replicación de resultados. Entre todas 
las moléculas estudiadas, los biomarcadores de apoptosis y neurodegeneración, al igual que los paneles de biomarcadores obtenidos mediante aproximaciones ómicas -como la metabolómica de forma aislada o combinada- ofrecen los resultados más prometedores.

\section{Palabras Clave:}

- Demencia; Enfermedad de Alzheimer; Diagnóstico precoz; Biomarcadores sanguíneos.

\section{Abstract:}

Introduction: The early diagnosis of Alzheimer's disease (AD) via the use of biomarkers could facilitate the implementation and monitoring of early therapeutic interventions with the potential capacity to significantly modify the course of the disease.

Development: Classic cerebrospinal fluid biomarkers and approved structural and functional neuroimaging have a limited clinical application given their invasive nature and/or high cost. The identification of more accessible and less costly biomarkers, such as blood biomarkers, would facilitate application in clinical practice. We present a literature review of the main blood biochemical biomarkers with potential use for diagnosing Alzheimer's disease.

Conclusions: Blood biomarkers are cost and time effective with regard to cerebrospinal fluid biomarkers. However, the immediate applicability of blood biochemical biomarkers in clinical practice is not very likely. The main limitations come from the difficulties in measuring and standardising thresholds between different laboratories and in failures to replicate results. Among all the molecules studied, apoptosis and neurodegeneration biomarkers and the biomarker panels obtained through omics approaches, such as isolated or combined metabolomics, offer the most promising results. 


\section{Keywords:}

- Dementia; Alzheimer's disease; Early diagnosis; Blood biomarkers.

\section{Introducción:}

La enfermedad de Alzheimer (EA) es la enfermedad neurodegenerativa más frecuente, responsable del $50-70 \%$ de los casos de demencia $(1-6,97)$, con una previsión de hasta 115 millones de personas afectadas para el año 2050 (23,98,99). En la actualidad, la demencia es la tercera causa de muerte tras las enfermedades cardiovasculares y el cáncer (3).

A pesar de su gran impacto, la patogénesis de la EA permanece en gran medida desconocida. La hipótesis más aceptada es la de la cascada amiloide (99-102), aunque también se han descritos trastornos de la homeostasis de calcio, colesterol y glucosa como factores contribuyentes a la patogenia de la EA (4). Además, se ha postulado que la enfermedad micro- y macrovascular podría contribuir a la generación de enfermedad amiloide y neurodegeneración, procediendo al desarrollo de la demencia asociada a la EA (100).

Por otro lado, se estima que los procesos neurodegenerativos pueden comenzar hasta 20-30 años antes del inicio de los síntomas (3)(21). La detección precoz de la EA en etapas presintomáticas ofrecería una gran oportunidad para establecer intervenciones terapéuticas tempranas y con mayor probabilidad de éxito, puesto que se realizarían antes de que el daño sináptico y la pérdida neuronal estuvieran extendidos. En este escenario, resultaría muy útil la incorporación a la práctica clínica de nuevos biomarcadores, más accesibles y menos costosos que los biomarcadores clásicos (103).

En este trabajo, se presenta una revisión bibliográfica de los principales biomarcadores bioquímicos sanguíneos con potencial utilidad en la práctica clínica para el diagnóstico de la EA. 


\section{Utilidad y limitaciones de los biomarcadores sanguíneos en la enfermedad}

\section{de Alzheimer}

La principal limitación de los biomarcadores clásicos de la EA -biomarcadores <<core»> en líquido cefalorraquídeo (LCR), $A \beta$, tau-total (tau-t) y tau fosforilada (tau-p) y PET metabolismo de glucosa y depósito de amiloide $(4,86,89,91-93,104-106)$ - es su carácter invasivo y coste excesivo, lo que dificulta su aplicación en la práctica clínica (107).

La sangre es un fluido accesible que puede utilizarse como origen de potenciales biomarcadores de cribado o diagnóstico para EA. Además, los biomarcadores sanguíneos son coste y tiempo efectivos con respecto a los biomarcadores de LCR $(2,90,105,108)$. Los biomarcadores deben de estar relacionados con características específicas de la enfermedad, tener gran sensibilidad y especificidad para EA y ser reproducibles, no invasivos, fáciles de realizar y de bajo coste (98). Cumpliendo los anteriores postulados, los biomarcadores sanguíneos podrían identificar a pacientes en riesgo de presentar $E A$, de progresión de deterioro cognitivo leve (DCL) a $E A$ y de progresión rápida dentro de la EA clínicamente establecida (23).

Una de las dificultades para la identificación de biomarcadores sanguíneos en la EA estriba en que es una enfermedad lentamente progresiva y que se desconoce el grado de pérdida de integridad de barrera hematoencefálica. Sin embargo, se ha descrito la existencia de disfunción de la barrera hematoencefálica en los pacientes con EA, lo que implicaría la existencia de intercambio de proteínas y otras moléculas entre el LCR y la sangre (89).

Otra limitación es que la sangre es un fluido complejo con múltiples factores de confusión: son necesarios protocolos estandarizados para la preparación de la muestra y su análisis $(90,104)$. Las diferencias descritas en concentraciones de analitos específicos podrían deberse a la falta de estandarización de los métodos de calibración, a diferentes diluciones de muestras biológicas, a variabilidad en los anticuerpos utilizados y a diferencias de sensibilidad y fiabilidad instrumental $(2,90)$. 
Las aproximaciones para identificar biomarcadores sanguíneos de EA se pueden dividir en dirigidas a identificar moléculas concretas (candidatas) relacionadas con mecanismos patogénicos conocidos y a explorar de forma no sesgada un perfil sérico o plasmático de moléculas mediante tecnologías ómicas (90).

\section{Identificación de biomarcadores sanguíneos en la enfermedad de}

\section{Alzheimer con aproximación de <<molécula candidata >}

\section{Péptidos $A \beta$}

Se han intentado identificar marcadores de enfermedad amiloidea en sangre periférica, dada la creencia que la amiloidogénesis es el centro de la patogenia de la EA (98) (Tabla 1).

Tabla 1 Listado de biomarcadores identificados con aproximación molécula candidata con posible finalidad diagnóstica en EA

\begin{tabular}{lll}
\hline Molécula & Vía patogénica & Tendencia en la enfermedad \\
\hline A $\beta 1-42$ & Amiloidogénica & Incremento en EA y DCL frente a controles \\
Tau-t y Tau-p & Taupatía & Incremento en EA y DCL frente a controles \\
GSK-3 $\beta$ & Taupatía & Incremento en EA y DCL frente a controles \\
DYRK1A & Taupatía & Disminución en EA y DCL frente a controles \\
& Amiloidogénica & \\
NF-L & Neurodegeneración & Incremento en EA y DCL frente a controles \\
BDNF & Neurodegeneración & Disminución en EA frente a controles, pero no en DCL \\
TNF $\alpha$ & Inflamatoria & Incremento en EA y DCL frente a controles \\
CCL-1 & Inflamatoria & Incremento en EA y DCL frente a controles \\
Monoamino oxidasa B & Daño vascular & Incremento en EA y DCL frente a controles \\
Actividad fosfolipasa 2 & Daño vascular & Incremento en EA frente a controles \\
BACE-1 & Daño vascular & Incremento en EA y DCL frente a controles \\
Homocisteína & Daño vascular & Incremento en EA frente a controles. \\
Ácido fólico & Daño vascular & Disminución en EA frente a controles \\
Cistatina C & Daño vascular & Disminuido en EA y DCL frente a controles \\
& Amiloidogénica & \\
Clusterina & Amiloidogénica & Incremento en EA y DCL frente a controles \\
\hline
\end{tabular}

BDNF: factor neurotrófico derivado de cerebro 
La isoforma de $A \beta-42$ es el principal componente de placas seniles (1). Es un producto de degradación de la proteína precursora de amiloide y puede producir daño en el ácido desoxirribonucleico (ADN) mediante mecanismos de estrés oxidativo. El A $\beta$ circulante tiene origen tanto periférico como central. Se ha observado que diferentes factores bioquímicos, técnicos, clínicos, demográficos y genéticos afectan a los niveles de péptidos $A \beta$. Por ejemplo, el $A \beta$ circulante se une a proteínas plasmáticas y a las paredes de los tubos de ensayo, dado su carácter hidrofóbico, e induce enmascaramiento de epítopos e interferencia analítica (89).

Existe una pobre correlación entre los niveles de $A \beta$ en sangre y en LCR (1). Aún así, se ha detectado un incremento de $A \beta 1-42$ sérico en pacientes con respecto a controles, que es más Ilamativo en pacientes con EA familiar o asociada $(3,104)$ a trisomía 21 . Los niveles plasmáticos elevados de $A \beta-42$, bajos de $A \beta-40$ y un ratio $A \beta-42 / A \beta-40$ reducido en pacientes con edad avanzada podrían indicar conversión de normalidad cognitiva a DCL o EA (3).

Sin embargo, debido a la influencia de múltiples factores, la imposibilidad para reproducir muchos de los resultados y su controversia, actualmente no se puede establecer un claro papel de $A \beta$ como biomarcador plasmático $(3,90)$.

\section{Proteína tau y enzimas relacionadas con la fosforilación}

La fosforilación de la proteína tau en diferentes residuos regula su capacidad para formar oligómeros y agregados $(3,98)$ que contribuirán a la formación de ovillos neurofibrilares.

Los métodos basados en las técnicas de inmunoanálisis ELISA no tienen suficiente sensibilidad para detectar concentraciones bajas de tau plasmática $(1,2)$, pero sí una nueva técnica ultrasensible de inmunoanálisis. Mediante esta técnica se han detectado concentraciones plasmáticas de tau más elevadas en pacientes con EA con respecto a DCL y controles. La correlación entre tau plasmática y tau en LCR es muy débil, prácticamente inexistente (109). 
La detección de proteína tau en plasma se ha asociado con una mayor pérdida longitudinal de volumen hipocámpico y de grosor cortical en regiones específicamente afectas en EA, como la corteza entorrinal, la región inferomedial del lóbulo temporal, el giro fusiforme y el precuneus $(108,110,111)$.

Se ha postulado que los niveles de tau-t y tau-p se correlacionarían con las puntuaciones de los test neuropsicológicos y podrían discriminar a pacientes con EA de los de DCL, y estos de los controles $(1,4,23,90,109)$. Sin embargo, la existencia de un gran solapamiento entre los valores de controles y pacientes dificulta su empleo como biomarcador $(90,108)$.

La proteína tau plasmática podría ser un marcador inespecífico de neurodegeneración, al objetivarse incrementado en pacientes con ictus isquémico, traumatismo craneoencefálico y prionopatías (89). Pero la asociación descrita entre niveles de tau plasmático y atrofia en regiones específicamente afectas en la EA permite plantearla como un potencial marcador de cribado de EA precoz (104).

Algunas proteínas-cinasas, entre ellas la cinasa-glicógenosintetasa- $3 \beta$ (GSK-3ß), se han relacionado con la hiperfosforalización de proteína tau (3). Los niveles plasmáticos de GSK-3 $\beta$ estarían significativamente incrementados en pacientes con EA y DCL frente a controles de la misma edad, lo que lo convierte en un potencial biomarcador (104).

Por otra parte, DYRK1A (dual specificity tyrosine-phosphorylation regulated kinase A) está implicada en la hiperfosforilación de tau. Esta enzima vincula la enfermedad amiloidea y tau, al regularse los niveles de DYRK1A por los niveles de $A \beta$. Los niveles sanguíneos de DYRK1A son significativamente menores en pacientes con EA respecto a controles, incluso en estadios precoces de la enfermedad (98), lo que lo habilita como potencial biomarcador de diagnóstico precoz. También se ha relacionado DYRK1A con la disregulación de vías neurotróficas, sobre todo, del factor neurotrófico derivado de cerebro, molécula con múltiples funciones en la plasticidad sináptica y la supervivencia neuronal, y cuyos niveles sanguíneos están disminuidos en fases moderadas-avanzadas de la EA $(98,112)$. 


\section{Neurofilamento ligero}

Los pacientes con EA presentan concentraciones elevadas de neurofilamento ligero (NFL), marcador de daño neuronal, en el LCR (108). Además existe una excelente correlación entre los niveles plasmáticos y en LCR $(1,104)$. Los niveles plasmáticos de NF-L están elevados en pacientes con EA y DCL $A \beta$ positivos y están asociados con el grado de deterioro cognitivo (puntuación en MiniMental Test y Trail Making Test parte B) y con alteraciones descritas en neuroimagen al diagnóstico y evolución de la enfermedad. Sin embargo, la elevación plasmática de NF-L no es específica de la EA: se detecta en otras enfermedades neurodegenerativas y se considera, por tanto, como un marcador de neurodegeneración (108).

\section{Biomarcadores basados en la hipótesis inflamatoria de la enfermedad de Alzheimer}

En la hipótesis inflamatoria, la neuroinflamación no es consecuencia de la neurodegeneración, sino un factor patogénico en fases iniciales y en la progresión de la enfermedad que perpetuaría el daño neuronal, con activación de microglía y linfocitos T periféricos e implicación del sistema inmune innato (99). El depósito de tau activaría la microglía y los astrocitos. Además, las formas insolubles de $A \beta$ actuarían sobre los receptores toll-like, mientras que las $A \beta$ solubles serían fagocitadas por la microglía, activando las proteína-cinasas-mitógeno-activadas y estimulando la producción de genes inflamatorias y citocinas, lo que perpetuaría la inflamación. Las citocinas, a su vez, atraerían a células del sistema inmune periférico y producirían alteraciones en la permeabilidad de la barrera hematoencefálica.

Los mediadores inflamatorios presentes en LCR y sangre, y particularmente citocinas y quimocinas, podrían ser utilizados como biomarcadores para el diagnóstico precoz de la EA. En el cerebro de pacientes con EA, como citocinas mediadoras de la respuesta inmune (IL-1, IL-4, IL-6, IL-10), el interferón-y y el factor de necrosis tumoral $\alpha$ (TNF $\alpha$ ) $(4,106,112)$.

La citocina I-309 es una glicoproteína secretada por linfocitos T activados. Su función principal es atraer a linfocitos $\mathrm{B}$ inmaduros, monocitos, células natural killers y 
dendríticas con receptores CCR8. Se ha postulado como posible predictor de progresión de DCL a EA (90).

\section{Autoanticuerpos}

La presencia de autoanticuerpos en la EA está bien establecida, pero no así su papel patogénico. Su aplicación como posibles biomarcadores es de gran interés, dada su presencia en sangre y LCR.

Se han estudiado anticuerpos anti-A $\beta$ sin concluir su utilidad clínica y se ha planteado el uso de perfiles de autoanticuerpos sanguíneos con prometedores resultados $(85,89,113)$.

Existe evidencia de que determinados anticuerpos antifosfolípido obtenidos mediante oxidorreducción están disminuidos en LCR de pacientes con EA, pero no claramente en sangre. Los niveles de anticuerpos antifosfolípido obtenidos mediante oxidorreducción tienen un incremento inicial en fases de $\mathrm{DCL}$ y posterior disminución con la evolución de la enfermedad. Por tanto, se postulan como marcadores de estadio y no como diagnósticos (102).

\section{Biomarcadores de apoptosis}

La clusterina está relacionada con procesos de neurodegeneración y sus niveles sanguíneos están incrementados en pacientes con EA. Los niveles de clusterina se correlacionan con el depósito de amiloide objetivado mediante PET y con el grado de atrofia hipocámpica. Se ha postulado que la clusterina podría actuar como transportadora de proteínas extracelulares entre ellas la $A \beta$, y que dicha unión disminuiría su toxicidad $(90,114)$.

\section{Biomarcadores de plaquetas}

Se ha detectado un incremento de la actividad $\beta$-secretasa-1, expresión elevada de monoamino oxidasa $B$ y actividad fosfolipasa $A 2$ en plaquetas sanguíneas y en el cerebro de pacientes con EA $(3,104)$. 


\section{Biomarcadores de daño microvascular}

Los factores de riesgo vascular clásicamente se han implicado en el incremento de riesgo de la EA. Se ha detectado una elevación sanguínea del péptido natriurético auricular y la adrenomedulina desde las fases prodrómicas. Además, la adrenomodulina se ha encontrado elevada en el cerebro de pacientes con EA (115), confirmándose como potencial biomarcador relacionado con la patogenia de la enfermedad. Por el contrario, no se han detectado diferencias en la expresión de las moléculas de adhesión (VCAM-1 e ICAM-1), ni en selectinas (116).

Los niveles plasmáticos de homocisteína estarían relacionados con los niveles de A $\beta-42$. La hiperhomocisteinemia reduce la neurogénesis mediante un mecanismo que implica el factor del crecimiento de fibroblastos. La homocisteína moderadamente elevada es un factor de riesgo para demencia vascular y EA: se ha objetivado un incremento significativo en los niveles plasmáticos de homocisteína en pacientes con EA (98).

Por otra parte, se ha descrito asociación entre EA y niveles plasmáticos bajos de ácido fólico. El ácido fólico es esencial para el metabolismo de la homocisteína. En la EA, la reparación del $A D N$ se encuentra inhibida por el daño oxidativo inducido por $A \beta$ acompañado de deficiencia de ácido fólico. El ácido fólico regula la actividad ADN-metiltransferasa atenuando la producción de $A \beta$. La actividad ADN-metil-transferasa se correlaciona con la formación de la memoria reciente y el mantenimiento de la memoria remota. Se ha postulado que la combinación de niveles de folato, hemoglobina y APOE incrementaría la sensibilidad predictiva respecto al nivel de folato usado de forma aislada como biomarcador diagnóstico de EA. También se ha documentado que la hemoglobina se uniría a $A \beta$ y favorecería su agregación; por tanto, cifras elevadas de hemoglobina podrían considerarse un factor de riesgo de la EA (101).

La cistatina $C$ es un inhibidor endógeno de cisteína, producida por casi todas las células humanas y disponible prácticamente en todos los fluidos corporales y es considerada como uno de los potenciales marcadores del daño vascular. La cistatina C impide la agregación de $A \beta$ y su depósito de forma concentración-dependiente por su unión a la 
proteína precursora de amiloide y a los péptidos $A \beta 1-40$ y $A \beta 1-42$. Los niveles séricos y en LCR de cistatina C estarían disminuidos en pacientes con EA desde fases iniciales (117).

\section{Identificación de biomarcadores sanguíneos en la enfermedad de}

\section{Alzheimer mediante tecnologías ómicas}

\section{Proteómica plasmática}

Con el objetivo de discriminar pacientes con EA de sujetos sanos, varios estudios han aportado paneles de biomarcadores compuestos por gran cantidad de proteínas con diferentes combinaciones de alta sensibilidad y especificad. Sin embargo, los resultados muestran un alcance limitado, dada la dificultad para replicarlos $(90,105,118)$ (Tabla 2$)$.

Tabla 2 Listado de biomarcadores identificados con aproximación proteómica con posible finalidad diagnóstica en EA

\begin{tabular}{lll}
\hline Molécula & Vía patogénica & Tendencia en la enfermedad \\
\hline Apolipoproteína A1 & Amiloidogénica & Disminuido en EA y DCL frente a controles \\
Alfa-2-HS-glicoproteína & Inflamatoria & Disminuido en EA y DCL frente a controles \\
Afamina & Amiloidogénica & Disminuido en EA frente a controles \\
Plasminógeno & Daño vascular & Disminuido en EA frente a controles \\
Apolipoproteína A4 & Daño vascular & Aumentado en EA y DCL frente a controles \\
Cadenas gamma fibrinógeno & Daño vascular & Aumentado en EA y DCL frente a controles \\
$\alpha$-1-antitripsina & Amiloidogénica & Incremento en EA frente a controles \\
$\alpha$-2-macroglobulina & Amiloidogénica & Incremento en EA frente a controles \\
Complemento C3 & Inflamatoria & Incremento en EA frente a controles \\
\hline
\end{tabular}

Comparando los perfiles proteómicos en sangre periférica, se ha objetivado desde fases precoces de la EA que los niveles de apolipoproteína A-1 (que inhibe la agregación de oligómeros $A \beta$ disminuyendo su acúmulo extracelular), $\alpha$-2-HS-glicoproteína (con funciones antiinflamatorias y efecto neuroprotector), afamina (proteína de unión específica a vitamina $\mathrm{E}$ que permite su transporte por la barrera hematoencefálica con potencial efecto beneficioso sobre el daño ocasionado por $A \beta$ o estrés oxidativo) y 
plasminógeno están significativamente más bajos en pacientes respecto a controles. Los niveles de apolipoproteína A-4 y cadenas gamma de fibrinógeno, propuestos como responsables de anomalías vasculares en la EA, están significativamente más elevados con respecto a controles $(3,89,105)$. Por ello, se podrían convertir en biomarcadores para el diagnóstico precoz de EA. Al igual que $\alpha$-1-antitripsina, $\alpha$-2-macroglobulina, apolipoproteína E y complemento C3, propuestos como biomarcadores diagnósticos de EA tras una revisión sistemática con replicación posterior (119).

\section{Metabolómica plasmática}

La metabolómica permite identificar alteraciones metabólicas monitorizando simultáneamente una gran variedad de metabolitos, lo que contribuye a comprender mejor la patogenia de la enfermedad. Así, los estudios de perfiles de lipodómica en pacientes con EA esporádica han mostrado la existencia de déficits significativos en 2 categorías importantes de lípidos estructurales: glicerofosfolípidos y esfingolípidos, junto con modificaciones en su metabolismo $(89,104,120-122)$.

\section{Conclusiones}

En la actualidad, existe un amplio consenso sobre la necesidad de aplicación de terapias anti-A $\beta$ en fases tempranas, posiblemente preclínicas, de la EA. El lento depósito de $A \beta$ enfatiza la existencia de una amplia ventana temporal en la que modificar la acumulación de $A \beta$, pero su identificación clínica requiere el uso de biomarcadores. De elección serían los no invasivos y no excesivamente costosos, como los biomarcadores sanguíneos.

Históricamente, la sensibilidad y la especificidad de los biomarcadores sanguíneos ha sido menor que la de los de LCR. La gran dificultad para reproducir y validar con adecuada sensibilidad y especificidad los resultados de biomarcadores sanguíneos ha limitado su aplicación en la práctica clínica hasta la fecha. No obstante, es obvio que existe evidencia creciente sobre la existencia de una especie de firma biológica 
sanguínea de la EA (103). Los biomarcadores sanguíneos de neurodegeneración, entre ellos tau y NF-L más que $A \beta$; de apoptosis como la clusterina; paneles de proteómica y metabolómica probablemente sean los más prometedores. En cambio, es más discutible en la actualidad la utilización de biomarcadores inflamatorios, de plaquetas o daño microvascular.

La identificación de biomarcadores sanguíneos fiables para el diagnóstico de la EA sigue limitada en la actualidad por problemas técnicos: es muy difícil estandarizar un biomarcador sanguíneo para su uso mundial, dadas las diferencias de muestra, de población estudiada, etc. Pero, gracias a que existen iniciativas globales para superar dichas limitaciones, es posible que, en un futuro próximo, se podrán aplicar en la práctica clínica. Además, dadas las limitaciones encontradas en los biomarcadores sanguíneos individuales en cuanto su sensibilidad, especificidad y valores predictivos, su combinación en paneles de biomarcadores surge como la opción más realista para su aplicación en la práctica clínica.

Por otra parte, nuevos campos del conocimiento están emergiendo como fuentes de potenciales herramientas diagnósticas, como es el caso de biomarcadores epigenéticos, entre ellos las marcas de metilación del ADN y ciertos ARN no codificantes, como los microARN.

En el futuro, los estudios de aproximación ómica permitirán nuevos niveles de conocimiento y análisis. Por ejemplo, mediante la aplicación simultánea de diferentes tecnologías ómicas al mismo conjunto de muestras o por medio de nuevos métodos de análisis de datos, combinando técnicas bioinformáticas, estadísticas y de inteligencia artificial, se podrán identificar nuevas vías biológicas alteradas en la EA. La identificación de nuevos patrones de biomarcadores junto con las cascadas moleculares afectadas podría ser utilizada para el descubrimiento de futuras dianas terapéuticas para tratamiento de la EA. 


\section{Artículo}

número 2

DNA methylation signature of human hippocampus in Alzheimer's disease is linked to neurogenesis. Altuna, $M$ et al. Clinical Epigenetics 11, 91 (2019) doi:10.1186/s1318-019-0672-7. 


\subsection{DNA METHYLATION SIGNATURE OF HUMAN HIPPOCAMPUS IN ALZHEIMER'S DISEASE IS LINKED TO NEUROGENESIS}

Miren Altuna ${ }^{1,2}$, Amaya Urdánoz-Casado ${ }^{1}$, Javier Sánchez-Ruiz de Gordoa ${ }^{1,2}$, María V. Zelaya $^{3}$, Alberto Labarga ${ }^{4}$, Julie M. J. Lepesant ${ }^{5}$, Miren Roldán ${ }^{1}$, Idoia Blanco-Luquin ${ }^{1}$, Álvaro Perdones ${ }^{4}$, Rosa Larumbe ${ }^{1,2}$, Ivonne Jericó ${ }^{2}$, Carmen Echavarri ${ }^{1,2}$, Iván MéndezLópez $^{1,6}$, Luisa Di Stéfano ${ }^{5}$ and Maite Mendioroz ${ }^{1,2^{*}}$.

*Correspondence: maitemendilab@gmail.com; tmendioi@navarra.es

${ }^{1}$ Neuroepigenetics Laboratory, Navarrabiomed, Public University of Navarra (UPNA), IdiSNA (Navarra Institute for Health Research), c/Irunlarrea 3, 31008 Pamplona, Spain,

2 Department of Neurology, Complejo Hospitalario de Navarra, IdisNA (Navarra Institute for Health Research), Pamplona, Spain.

\section{Abstract:}

Background: Drawing the epigenome landscape of Alzheimer's diseases (AD) still remains a challenge. To characterize the epigenetic molecular basis of the human hippocampus in $A D$, we profiled genome-wide DNA methylation levels in hippocampal samples from a cohort of pure AD patients and controls by using Illumina $450 \mathrm{~K}$ methylation arrays.

Results: Up to 118 AD-related differentially methylated positions (DMPs) were identified in the $A D$ hippocampus, and extended mapping of specific regions was obtained by bisulfite cloning-sequencing. AD-related DMPs were enriched in poised promoters that were not generally maintained in committed neural progenitor cells, as shown by ChiPqPCR experiments. Interestingly, AD-related DMPs preferentially involved neurodevelopmental and neurogenesis-related genes. Finally, InterPro ontology 
analysis revealed enrichment in homeobox-containing transcription factors in the set of AD-related DMPs.

Conclusions: These results suggest that altered DNA methylation in the AD hippocampus occurs at specific regulatory regions crucial for neural differentiation supporting the notion that adult hippocampal neurogenesis may play a role in AD through epigenetic mechanisms.

Keywords: DNA methylation, Alzheimer's, Hippocampus, Adult neurogenesis, Poised promoters, Homeobox, Neurodevelopment, Epigenetics. 


\section{Graphical abstract:}

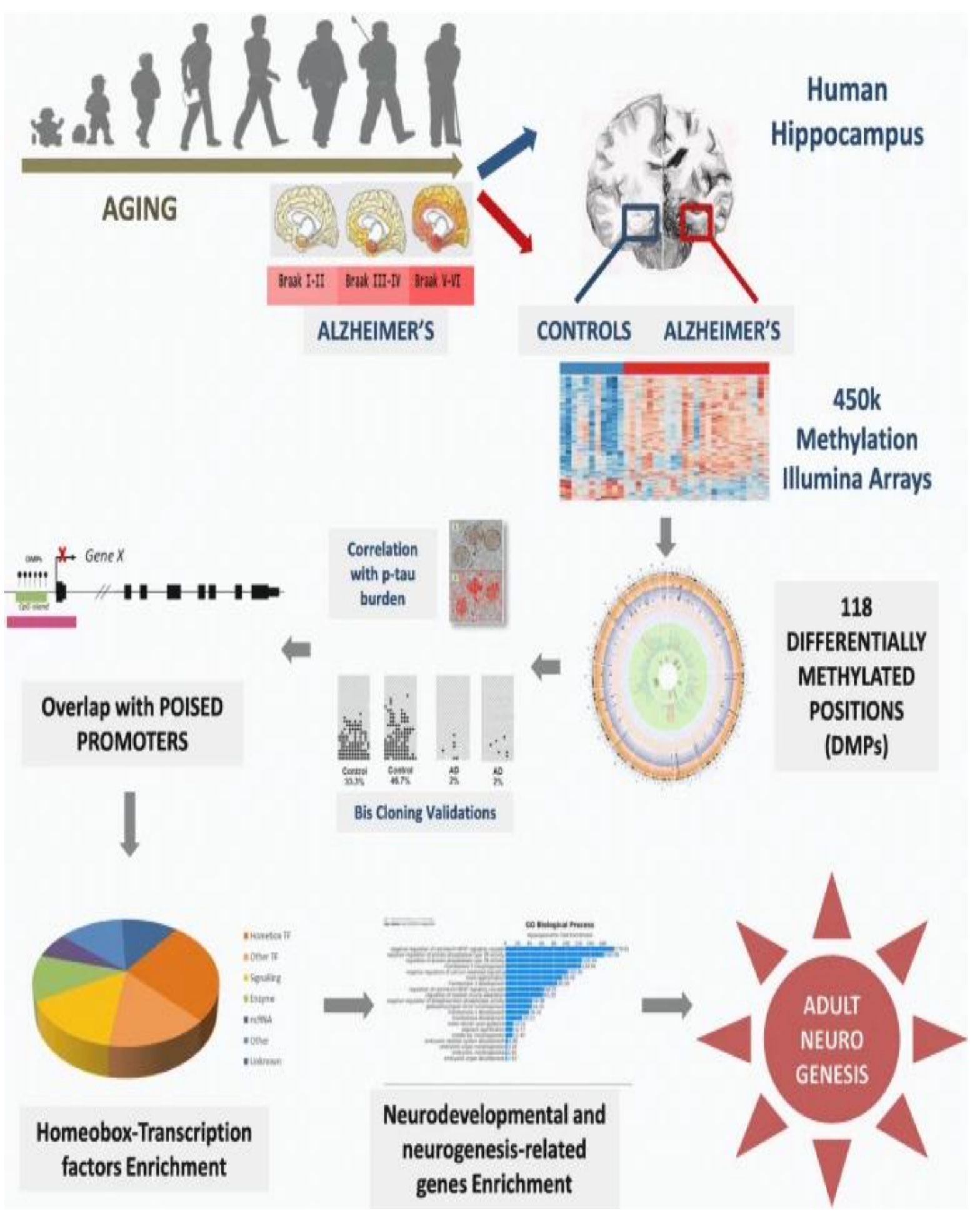




\section{Background:}

Alzheimer's disease (AD) is the leading cause of age-related dementia and one of the major global challenges of our time (123). As knowledge about AD increases, so does the appreciation of the pathogenic complexity of the disorder (124). Currently, AD is considered a complex disease that arises from the interaction between environmental and genetic factors (125), modulated through epigenetic mechanisms. Since epigenetics acts as an interface between the environment and the genome, a major focus has been upon studying epigenetic alterations in $A D$ to shed some light on the pathogenesis of the disease. DNA methylation is a major epigenetic modification that involves the attachment of a methyl group to 5-carbon position of a cytosine residue and usually occurs at cytosine-guanine dinucleotides (CpG). These $\mathrm{CpG}$ dinucleotides are clustered in the genome constituting CpG islands, which are enriched in the promoter of more than half of human genes and other important regulatory regions.

DNA methylation is known to be altered in complex disease including AD. Indeed, a number of gene-specific differences in DNA methylation have been reported so far (82,126-129). More recently, genome-wide approaches have uncovered additional gene-specific methylation differences across different brain regions in $A D(77,78)$. By using Illumina Infinium HumanMethylation450K arrays, several genes have been found to be differentially methylated in AD brain autopsy samples, including some genes previously identified as harboring genetic variants for AD, such as ANK1 (ankyrin-1) or BIN1 (amphihysin II) (79-81,130). Importantly, a number of these DNA methylation marks are present in early stages of $A D$, suggesting that such changes might play a role in the onset of the disorder (80). On the whole, these reports are providing significant data to enrich understanding of AD pathogenesis $(83,84)$.

So far, genome-wide DNA methylation studies on AD have been performed across different brain regions including prefrontal, frontal, and superior temporal neocortex, along with entorhinal cortex. In this study, we have taken a complementary strategy to 
profile genome-wide DNA methylation in the human hippocampus, a brain region particularly vulnerable to $A D(131-133)$ and the core of pathological protein tau deposits (134). We have applied Infinium HumanMethylation450 BeadChip array to hippocampal samples obtained from a homogeneous cohort of pure $A D$ brains and controls. As a result, we report on novel gene-specific DNA methylation changes, recurrent across multiple affected subjects, which occur in the AD hippocampus. This DNA methylation signature of the AD hippocampus correlates with tau burden and also with specific changes in histone marks. Finally, in silico functional analysis of these changes points to molecular and biological alterations that may be especially relevant to the pathogenesis of $A D$, including adult brain neurogenesis.

\section{Results}

\section{Hippocampal samples from AD patients and controls}

DNA methylation changes were evaluated in 36 post-mortem hippocampal samples obtained from 26 patients with AD and 12 control subjects. To avoid spurious molecular findings related to multiprotein deposits, only $A D$ cases with pure deposits of $p$-tau and $\beta$-amyloid were eligible for the study and controls were free of any protein aggregates. This approach maximizes the chances of finding true molecular associations with $A D$, even though reducing the number of older controls.

Neuropathological and demographic features of subjects, including age, gender; $A B C$ score, and postmortem interval (PMI), are listed in Additional file 1: Table S1. AD subjects were older than controls $(81.2+/-12.1$ versus $50.7+/-21.5 ; p$ value $<0.01)$, and no differences were found regarding gender $(p$ value $=0.16)$. The PMI ranged from 1.4 to $33 \mathrm{~h}$ and were not significantly different between groups $(8.2+/-4.2 \mathrm{~h}$ in controls versus $7.9+/-7.1 \mathrm{~h}$ in $\mathrm{AD}$ samples; $p$ value $=0.91$ ).

Since DNA methylation may be affected by cellular composition of the brain samples, cell proportions were estimated by using the CETS R package as previously described 
$(130,135)$. No statistically significant differences were found in cell proportions between the $A D$ group and the control group (control mean neuronal cell proportion $=0.18$ versus $A D$ mean neuronal cell proportion $=0.20, p$ value $=0.64)$.

\section{Characterization of differentially methylated positions in the AD hippocampus}

Differential methylation analysis between the $A D$ and control hippocampus was performed by using the limma package (R/Bioconductor). After adjusting for age and false discovery rate (FDR) correction, the analysis revealed 118 AD-related differentially methylated positions (DMPs) (about $\beta$-difference $\geq 0.1$ and adjusted $p$ value $\leq 0.05$ ) located next to 159 genes (Fig.1, Table 1). Most of DMPs, 102 (86.4\%), were hypermethylated in $A D$ cases compared to controls (Fig. 2a-2c). Inspection of methylation patterns revealed that AD-related DMPs showed a mild-to-moderate effect size, as the average absolute $\beta$-difference was $0.12(S D=0.02$ ) (Fig. $2 b$ ). These results are in line with previous $A D$ methylome studies, which showed recurrent gains in DNA methylation of a mild-to-moderate effect size in other brain regions (77-81,130). Indeed, up to 17 (10.7\%) differentially methylated genes in our study are found among the top-ranked genes in previous AD methylome studies performed on frontal, temporal, or entorhinal cortex $(79,80,130)$ (Additional file 1: Table S2).

Genomic distribution of AD-related DMPs was next analyzed. We observed that DMPs were more likely to locate in CPG islands, showing a 1-5-fold enrichment ( $p$ value $<$ 0.001 ) compared with random expectation based on all probes included in the analysis. In addition, significant enrichment was found at first exon $(2.4$-fold, $p$ value $<0.001)$ and body $(1.2$-fold, $p$ value $<0.05)$ regions (Fig. 2 d). Moreover, up to $13(8.1 \%)$ genes were associated with 2 or more AD-related DMPs which world suggest the presence of hotspots of aberrant methylation gain in the human hippocampus affected by AD.

Fig.1. CIRCOS plot of differentially methylated positions (DMPS) in AD hippocampus. The CIRCOS plot show a summary of DNA methylation screening results in the $A D$ 
hippocampus and its validation by bisulfite cloning sequencing. The perimeter of the circular figure represents the human chromosomes, showing the cytogenetic bands and centromeres (in red). Only those chromosomes harboring DMPs are represented in the painted circles. $X$ and $Y$ chromosomes were excluded from the analysis. The orange circle represents $p$ value for each DMPs. The inner red and blue dots represent the results of the differential analysis (beta difference) for each DMPs, including gains in methylation (red dots) and losses in methylation (blue dots). The next green circle reports the names of the genes associated to each DMPs. Those genes associated with neurogenesis are highlighted in red front. In black font, those genes that were validated by bisulfite cloning sequencing are shown.

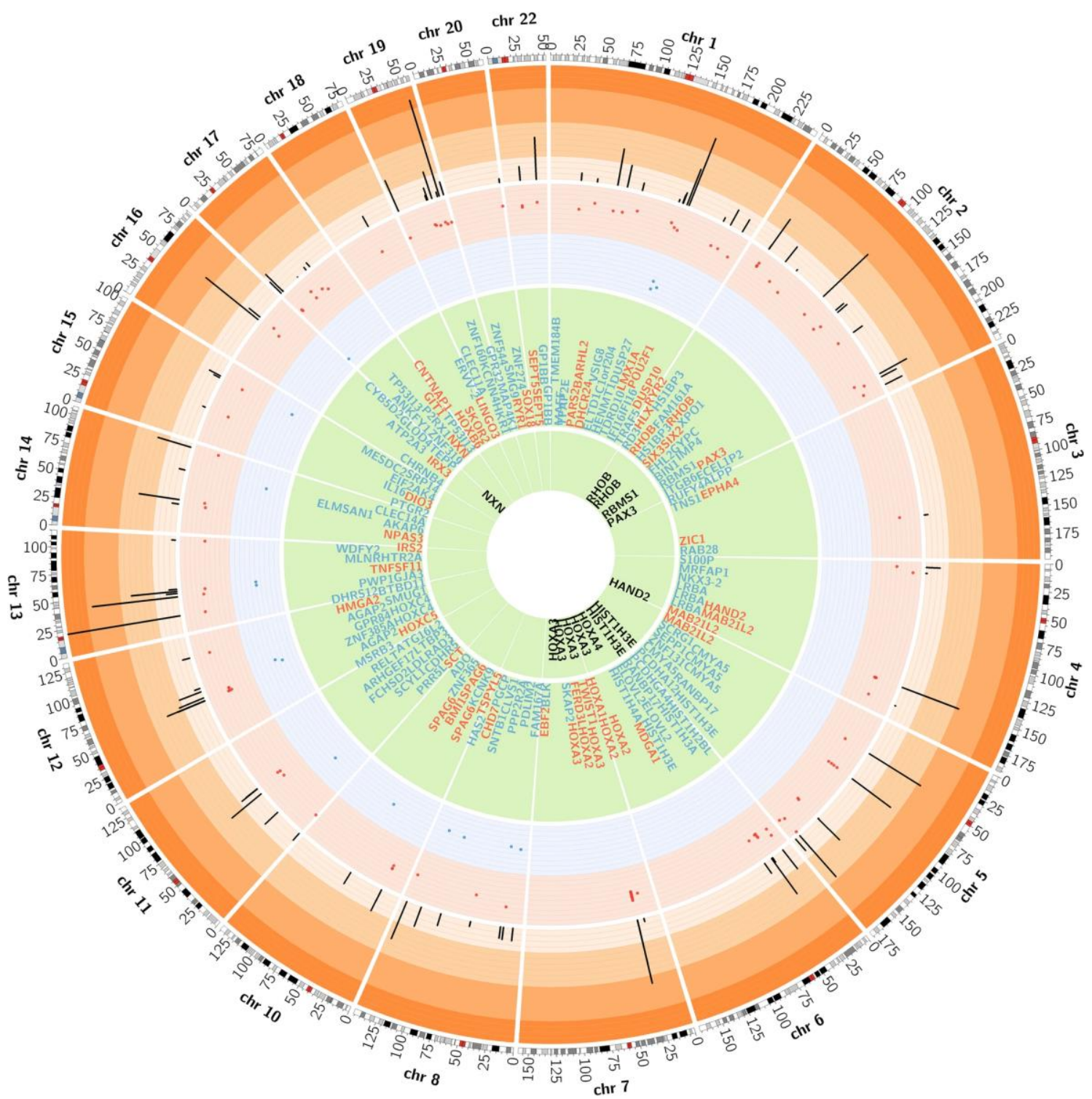


Table 1. Differentially methylated positions (DMPs) in AD hippocampus measured by 450K Illumina BeadChip array. The table shows 118 DMPs with 6-difference $>0.100$, prioritized by beta difference (delta) criteria. FDR false discovery rate, Adj. adjusted, ID identification, PMID PubMed Identification. Each probe (CPG site) was annotated by UCSC hg19 build. The last two columns show the PMID of papers supporting the involvement of the genes into neurogenesis or neural development.

\begin{tabular}{|c|c|c|c|c|c|c|c|c|c|}
\hline DMPs & \multicolumn{2}{|c|}{$\begin{array}{c}\text { Genomic } \\
\text { coordinates }\end{array}$} & $\begin{array}{c}\text { Beta. } \\
\text { Difference }\end{array}$ & FDR $p$ value & GenelD1 & GenelD2 & $\begin{array}{l}\text { Neurogenesis- } \\
\text { related }\end{array}$ & \multicolumn{2}{|c|}{$\begin{array}{l}\text { Neurogenesis- } \\
\text { related PMID }\end{array}$} \\
\hline cg02091185 & 5 & 170288766 & 0.198 & 0.003 & RANBP17 & & No & & \\
\hline cg07333191 & 4 & 13526769 & 0.168 & 0.002 & RAB28 & NKX3-2 & No & & \\
\hline cg14780466 & 2 & 20870812 & 0.150 & 0.011 & GDF7 & АРОВ & Yes & 17293457 & 22897442 \\
\hline cg04370442 & 16 & 58019866 & 0.147 & 0.013 & TEPP & ZNF319 & No & & \\
\hline $\operatorname{cg} 16867657$ & 6 & 11044877 & 0.145 & 0.002 & ELOVL2 & & No & & \\
\hline cg04154027 & 5 & 78985588 & 0.144 & 0.002 & CMYA5 & & No & & \\
\hline cg19506623 & 2 & 161265259 & 0.143 & 0.036 & RBMS1 & ITGB6 & No & & \\
\hline cg04498198 & 17 & 27899966 & 0.140 & 0.002 & TP53113 & GIT1 & Yes & & 25792865 \\
\hline cg23077820 & 2 & 223154176 & 0.140 & 0.002 & PAX3 & EPHA4 & Yes & 26287727 & 25978062 \\
\hline cg11015251 & 7 & 27170554 & 0.138 & 0.005 & HOXA4 & & No & & \\
\hline cg16258854 & 2 & 20648194 & 0.138 & 0.005 & RHOB & HS1BP3 & Yes & 15306568 & \\
\hline cg01463828 & 8 & 22446721 & 0.137 & 0.007 & PDLIM2 & & No & & \\
\hline cg13935577 & 12 & 107974897 & 0.136 & 0.008 & BTBD11 & PWP1 & No & & \\
\hline cg12100751 & 1 & 109203672 & 0.134 & 0.002 & HENMT1 & & No & & \\
\hline cg19022697 & 1 & 55247140 & 0.133 & 0.004 & PARS2 & DHCR24 & Yes & 29410512 & 24842139 \\
\hline cg25840926 & 2 & 20647987 & 0.133 & 0.002 & RHOB & HS1BP3 & Yes & 15306568 & \\
\hline cg22962123 & 7 & 27153605 & 0.131 & 0.008 & HOXAЗ & HOXA2 & Yes & 12954718 & 10230789 \\
\hline cg05637536 & 1 & 154475068 & 0.130 & 0.002 & TDRD10 & & No & & \\
\hline cg01331772 & 2 & 131094827 & 0.129 & 0.002 & IMP4 & & No & & \\
\hline cg23279355 & 5 & 78985592 & 0.128 & 0.002 & CMYA5 & & No & & \\
\hline cg01579024 & 5 & 170288757 & 0.127 & 0.013 & RANBP17 & & No & & \\
\hline cg15548613 & 22 & 38610795 & 0.127 & 0.002 & MAFF & TMEM184B & No & & \\
\hline cg13172549 & 7 & 27153636 & 0.125 & 0.019 & HOXA3 & HOXA2 & Yes & 12954718 & 10230789 \\
\hline cg02231404 & 20 & 62679635 & 0.124 & 0.008 & SOX18 & & Yes & 29666335 & \\
\hline cg13327545 & 10 & 22623548 & 0.124 & 0.002 & SPAG6 & BMI1 & Yes & 29666335 & 19212323 \\
\hline cg18247055 & 10 & 22634226 & 0.122 & 0.003 & SPAG6 & & Yes & 26130477 & \\
\hline cg00921266 & 7 & 27153663 & 0.122 & 0.039 & HOXАЗ & HOXA2 & Yes & 12954718 & 10230789 \\
\hline
\end{tabular}


IDENTIFICACIÓN DE BIOMARCADORES EPIGENÉTICOS EN LA ENFERMEDAD DE ALZHEIMER

\begin{tabular}{|c|c|c|c|c|c|c|c|c|c|}
\hline DMPs & \multicolumn{2}{|c|}{$\begin{array}{c}\text { Genomic } \\
\text { coordinates }\end{array}$} & \multirow{2}{*}{$\begin{array}{c}\begin{array}{c}\text { Beta. } \\
\text { Difference }\end{array} \\
0.120\end{array}$} & \multirow{2}{*}{$\begin{array}{c}\text { FDR } \boldsymbol{p} \text { value } \\
0.011\end{array}$} & \multirow{2}{*}{$\begin{array}{l}\text { GeneID1 } \\
\text { ECEL1P2 }\end{array}$} & \multirow{2}{*}{$\begin{array}{l}\text { GenelD2 } \\
\text { ALPP }\end{array}$} & \multirow{2}{*}{$\begin{array}{c}\text { Neurogenesis- } \\
\text { related } \\
\text { No }\end{array}$} & \multicolumn{2}{|c|}{$\begin{array}{l}\text { Neurogenesis- } \\
\text { related PMID }\end{array}$} \\
\hline cg09490371 & 2 & 233253024 & & & & & & & \\
\hline cg17448336 & 3 & 147141588 & 0.119 & 0.047 & ZIC1 & & Yes & 17507568 & \\
\hline cg16127683 & 15 & 40268777 & 0.119 & 0.021 & EIF2AK4 & SRP14 & No & & \\
\hline cg25774643 & 11 & 627175 & 0.119 & 0.028 & SCT & CDHR5 & Yes & 21159798 & \\
\hline cg18121224 & 5 & 176559563 & 0.119 & 0.010 & NSD1 & & No & & \\
\hline cg07816556 & 6 & 26017280 & 0.119 & 0.004 & HIST1H4A & HIST1H3A & No & & \\
\hline cg16308533 & 17 & 40838983 & 0.118 & 0.004 & CNTNAP1 & EZH1 & Yes & 26740489 & 23932971 \\
\hline cg04533276 & 22 & 19709548 & 0.117 & 0.007 & SEPT5 & GP1BB & Yes & 17935997 & \\
\hline cg22900415 & 13 & 20736075 & 0.117 & 0.010 & GJA3 & & No & & \\
\hline cg22385702 & 2 & 45175881 & 0.116 & 0.025 & SIX3 & SIX2 & Yes & 17576749 & 11401394 \\
\hline cg09655403 & 5 & 78985495 & 0.116 & 0.004 & CMYA5 & & No & & \\
\hline cg22507154 & 1 & 91185233 & 0.116 & 0.016 & BARHL2 & & Yes & 22307612 & \\
\hline $\operatorname{cg} 24369989$ & 15 & 78933807 & 0.115 & 0.002 & CHRNB4 & & No & & \\
\hline $\operatorname{cg} 16404157$ & 14 & 38724648 & 0.115 & 0.010 & CLEC14A & & No & & \\
\hline cg03146625 & 12 & 54448729 & 0.115 & 0.018 & HOXC4 & SMUG1 & No & & \\
\hline cg04027736 & 7 & 27143403 & 0.115 & 0.011 & HOXA2 & & Yes & 10230789 & \\
\hline cg12024906 & 19 & 37825679 & 0.115 & 0.005 & HKR1 & & No & & \\
\hline cg00303378 & 1 & 159825552 & 0.115 & 0.002 & VSIG8 & C1orf204 & No & & \\
\hline cg17508941 & 7 & 19183280 & 0.114 & 0.002 & TWIST1 & FERD3L & Yes & 23555309 & 23254923 \\
\hline cg24079702 & 2 & 106015771 & 0.114 & 0.005 & FHL2 & & No & & \\
\hline cg15084543 & 1 & 79472408 & 0.113 & 0.006 & ELTD1 & & No & & \\
\hline cg25738176 & 17 & 3848506 & 0.113 & 0.033 & АTP2A3 & P2RX1 & No & & \\
\hline cg20864214 & 11 & 73054121 & 0.113 & 0.018 & RELT & ARHGEF17 & No & & \\
\hline cg06452665 & 13 & 43148436 & 0.113 & 0.010 & TNFSF11 & & Yes & 24087792 & \\
\hline cg21572722 & 6 & 11044894 & 0.113 & 0.003 & ELOVL2 & & No & & \\
\hline cg26092675 & 6 & 26225258 & 0.112 & 0.002 & HIST1H3E & & No & & \\
\hline cg07336350 & 16 & 54322127 & 0.111 & 0.013 & IRX3 & & Yes & 10704856 & \\
\hline cg07809484 & 19 & 51231968 & 0.111 & 0.002 & GPR32 & CLEC11A & No & & \\
\hline cg16651126 & 7 & 27170552 & 0.111 & 0.007 & HOXA4 & & No & & \\
\hline cg05726109 & 22 & 19709755 & 0.111 & 0.007 & SEPT5 & GP1BB & Yes & 17935997 & \\
\hline cg07584855 & 1 & 221055545 & 0.110 & 0.007 & HLX & DUSP10 & Yes & 7907015 & 19139271 \\
\hline cg14566959 & 5 & 140772681 & 0.110 & 0.006 & PCDHGA4 & & No & & \\
\hline cg02798280 & 19 & 39087135 & 0.110 & 0.007 & MAP4K1 & RYR1 & No & & 17767953 \\
\hline cg24756378 & 14 & 33401638 & 0.110 & 0.027 & NPAS3 & AKAP6 & Yes & 21709683 & \\
\hline cg11864574 & 10 & 22635028 & 0.110 & 0.015 & SPAG6 & & Yes & 29666335 & \\
\hline cg06555959 & 8 & 61835620 & 0.110 & 0.050 & CLVS1 & CHD7 & Yes & & 23827709 \\
\hline cg12253175 & 12 & 58132093 & 0.110 & 0.029 & AGAP2 & & No & & \\
\hline $\operatorname{cg} 15834355$ & 12 & 54442075 & 0.110 & 0.014 & HOXC4 & HOXC5 & Yes & & 23103965 \\
\hline
\end{tabular}


IDENTIFICACIÓN DE BIOMARCADORES EPIGENÉTICOS EN LA ENFERMEDAD DE ALZHEIMER

\begin{tabular}{|c|c|c|c|c|c|c|c|c|c|}
\hline DMPs & \multicolumn{2}{|c|}{$\begin{array}{c}\text { Genomic } \\
\text { coordinates }\end{array}$} & \multirow{2}{*}{$\begin{array}{c}\text { Beta. } \\
\text { Difference } \\
0.109\end{array}$} & \multirow{2}{*}{$\begin{array}{c}\text { FDR } \boldsymbol{p} \text { value } \\
0.031\end{array}$} & \multirow{2}{*}{$\begin{array}{l}\text { GenelD1 } \\
\text { AGAP2 }\end{array}$} & \multirow[t]{2}{*}{ GeneID2 } & \multirow{2}{*}{$\begin{array}{c}\text { Neurogenesis- } \\
\text { related } \\
\text { No }\end{array}$} & \multicolumn{2}{|c|}{$\begin{array}{l}\text { Neurogenesis- } \\
\text { related PMID }\end{array}$} \\
\hline cg09596958 & 12 & 58132105 & & & & & & & \\
\hline cg02267270 & 6 & 37616410 & 0.109 & 0.047 & MDGA1 & CCDC167 & Yes & 21104742 & \\
\hline cg18181229 & 1 & 164545699 & 0.109 & 0.016 & PBX1 & LMX1A & Yes & 27226325 & 24172139 \\
\hline cg01421119 & 1 & 211555733 & 0.109 & 0.019 & TRAF5 & RD3 & No & & \\
\hline cg03729251 & 4 & 151501035 & 0.108 & 0.012 & LRBA & MAB21L2 & Yes & & 11960703 \\
\hline cg22090150 & 17 & 4098227 & 0.107 & 0.002 & ANKFY1 & CYB5D2 & No & & \\
\hline cg05877788 & 17 & 27899874 & 0.107 & 0.003 & TP53I13 & GIT1 & Yes & & 25792865 \\
\hline cg06396119 & 13 & 49792767 & 0.106 & 0.025 & MLNR & & No & & \\
\hline cg22154659 & 7 & 27134369 & 0.106 & 0.015 & HOXA1 & SKAP2 & Yes & 14522873 & \\
\hline cg14266527 & 4 & 151501298 & 0.106 & 0.004 & LRBA & MAB21L2 & Yes & & 11960703 \\
\hline cg24177393 & 5 & 43037517 & 0.105 & 0.033 & SEPP1 & ZNF131 & No & & \\
\hline cg07942135 & 7 & 27154262 & 0.105 & 0.022 & HOXАЗ & HOXA2 & Yes & 12954718 & 10230789 \\
\hline cg22904711 & 19 & 44278628 & 0.105 & 0.041 & KCNN4 & SMG9 & No & & \\
\hline cg01566965 & 4 & 174447847 & 0.104 & 0.028 & HAND2 & SCRG1 & Yes & 22323723 & \\
\hline cg14557699 & 5 & 140254909 & 0.104 & 0.002 & PCDHA12 & & No & & \\
\hline cg26698460 & 19 & 58716004 & 0.104 & 0.010 & ZNF274 & ZNF544 & No & & \\
\hline cg02287710 & 14 & 102027660 & 0.103 & 0.004 & $\mathrm{DIO} 3$ & & Yes & 27707971 & \\
\hline cg21415530 & 8 & 140715802 & 0.103 & 0.010 & KCNK9 & & No & & \\
\hline cg07589899 & 2 & 62020677 & 0.103 & 0.002 & XPO1 & FAM161A & No & & \\
\hline cg20192747 & 18 & 44774846 & 0.103 & 0.003 & SKOR2 & & Yes & 24491816 & \\
\hline cg17179862 & 17 & 46681362 & 0.103 & 0.003 & HOXB6 & LOC404266 & Yes & 10686603 & \\
\hline $\operatorname{cg} 26587870$ & 6 & 27730563 & 0.103 & 0.010 & ZNF184 & HIST1H2BL & No & & \\
\hline cg01089914 & 2 & 218843229 & 0.102 & 0.017 & RUFY4 & TNS1 & No & & \\
\hline cg14962509 & 1 & 36039655 & 0.102 & 0.004 & TFAP2E & & No & & \\
\hline cg21869609 & 19 & 2291613 & 0.102 & 0.018 & LINGO3 & & Yes & 18297755 & \\
\hline cg08865099 & 7 & 27281581 & 0.102 & 0.043 & EVX1 & & Yes & 10399918 & \\
\hline cg13836098 & 6 & 26225268 & 0.102 & 0.002 & HIST1H3E & & No & & \\
\hline cg00611789 & 5 & 78985432 & 0.102 & 0.011 & CMYA5 & & No & & \\
\hline cg13771313 & 11 & 72533295 & 0.102 & 0.017 & ATG16L2 & FCHSD2 & No & & \\
\hline cg21811021 & 4 & 6659346 & 0.101 & 0.015 & S100P & MRFAP1 & No & & \\
\hline cg11254700 & 19 & 53561386 & 0.101 & 0.020 & ERVV-2 & ZNF160 & No & & \\
\hline cg14557202 & 12 & 54764371 & 0.101 & 0.028 & ZNF385A & GPR84 & No & & \\
\hline cg03422911 & 1 & 237205295 & 0.101 & 0.004 & RYR2 & & Yes & 17767953 & \\
\hline cg19153828 & 2 & 127782651 & 0.101 & 0.009 & BIN1 & GYPC & No & & \\
\hline cg06867571 & 11 & 65306934 & 0.101 & 0.019 & LTBP3 & SCYL1 & No & & \\
\hline cg09317554 & 4 & 151505084 & 0.101 & 0.014 & LRBA & MAB21L2 & Yes & & 11960703 \\
\hline cg05404236 & 13 & 110437093 & 0.100 & 0.017 & IRS2 & & Yes & 28833887 & \\
\hline cg027711117 & 8 & 11279352 & -0.100 & 0.022 & FAM167A & BLK & No & & \\
\hline
\end{tabular}




\begin{tabular}{|c|c|c|c|c|c|c|c|c|c|}
\hline DMPs & \multicolumn{2}{|c|}{$\begin{array}{c}\text { Genomic } \\
\text { coordinates }\end{array}$} & \multirow{2}{*}{$\begin{array}{c}\text { Beta. } \\
\text { Difference } \\
-0.101\end{array}$} & \multirow{2}{*}{$\begin{array}{c}\text { FDR } p \text { value } \\
0.017\end{array}$} & \multirow{2}{*}{$\begin{array}{l}\text { GenelD1 } \\
\text { DHRS12 }\end{array}$} & \multirow{2}{*}{$\begin{array}{l}\text { GenelD2 } \\
\text { WDFY2 }\end{array}$} & \multirow{2}{*}{$\begin{array}{c}\text { Neurogenesis- } \\
\text { related } \\
\text { No }\end{array}$} & \multicolumn{2}{|c|}{$\begin{array}{l}\text { Neurogenesis- } \\
\text { related PMID }\end{array}$} \\
\hline cg10373891 & 13 & 52338758 & & & & & & & \\
\hline cg24607755 & 11 & 36171375 & -0.102 & 0.010 & LDLRAD3 & PRR5L & No & & \\
\hline cg20102280 & 13 & 47470793 & -0.102 & 0.004 & HTR2A & & No & & \\
\hline cg21735068 & 8 & 97975467 & -0.104 & 0.015 & PGCP & TSPYL5 & Yes & & 26911678 \\
\hline cg23907053 & 12 & 70215816 & -0.107 & 0.015 & RAB3IP & MYRFL & No & & \\
\hline cg14701867 & 10 & 64193068 & -0.107 & 0.023 & ZNF365 & ADO & No & & \\
\hline cg14830371 & 8 & 25991602 & -0.108 & 0.027 & PPP2R2A & EBF2 & Yes & & 25762221 \\
\hline cg16668651 & 15 & 81316319 & -0.110 & 0.035 & IL16 & MESDC2 & No & & \\
\hline cg06688910 & 8 & 122466955 & -0.110 & 0.027 & SNTB1 & HAS2 & No & & \\
\hline cg07463059 & 1 & 158979810 & -0.119 & 0.010 & IFI16 & & No & & \\
\hline cg05165025 & 14 & 74253312 & -0.119 & 0.046 & PTGR2 & ELMSAN1 & No & & \\
\hline cg07677157 & 12 & 66050928 & -0.133 & 0.026 & HMGA2 & MSRB3 & Yes & 18640244 & \\
\hline $\operatorname{cg} 11236550$ & 1 & 167090757 & -0.138 & 0.012 & DUSP27 & POU2F1 & No & & 18241856 \\
\hline cg20597486 & 1 & 158979841 & -0.151 & 0.002 & IFI16 & & No & & \\
\hline cg19987768 & 17 & 750306 & -0.162 & 0.043 & NXN & GLOD4 & Yes & 29037191 & \\
\hline
\end{tabular}

Fig 2 (next page): Characterization of AD-related DMPs. $\underline{A}$. The histogram of betta difference value distribution per CpGs shows a clear bias toward the hypermethylated changes (> 0.0) in AD hippocampal samples compared to controls. $\underline{B}$. The volcano plot shows a greater number of hypermethylated marks (red dots) compared to hypomethylated marks (blue dots) that crossed the statistical threshold (dotted lines) in this study. The graph also shows that DNA methylation changes in AD hippocampus are mild to moderate in effect size. $\underline{C}$. The heat map graph reveals that most of DNA methylation changes represent gain (red squares) in methylation. $\underline{D}$. Distribution of DMPs regarding gene structure. The bar graph shows the log2 ratios of observed (fraction differentially methylated probes the overlap a particular region) to expected (fraction of probes selected for analysis to overlap a particular region). $S=$ south, $N=$ north, TSS = transcription start site. E. Differential analysis revealed up to $8 A D$-related DMPs located within the HOXA genes cluster in the short arm of chromosome 7. The upper tracks show 450k microarray values and results of differential analysis. Blue dots represent per CpG median B-values for patients and controls. Vertical red bars represent B difference values for CpGs included in the DMPs that crossed statistical threshold 
( $B$ difference $>0.1$ and $p$-value $<0.05$ ). Grey bars represent $B$ difference values for the CPGs included in the DMPs. Methylation values are aligned to ENCODE/Broad data for H3K27me3 histone marks in H1 human Embryonic Stem Cells (H1-hESC) at the bottom. F. Dot-plot graphs show $450 \mathrm{~K}$ microarray 8 values for the CpGs with most significant $p$ value for each 4 genes within DMPs in the HOXA cluster. The selected CpGs are as follow, HOXA2: cg04027736, HOXA3: cg22962123, HOXA4:cg16651126, EVX1:cg08865099. G. Extended mapping of hypermethylated DMPs within HOXA3 gene in 2 AD cases (below) compared to 2 controls (above) obtained by bisulfite cloning sequencing that shows how differential methylation affects multiple contiguous CpGs. The amplicon overlaps cg00921266 (blue arrow) and cg22962123 (red arrow). Black circles represent methylated cytosines while white circles denote unmethylated cytosines. Each column symbolizes a unique CPG site in the examined amplicon and each line represents an individual DNA clone. Average percentage of methylation for each analyzed sample (control or patient) at this particular amplicon is indicated at the bottom of each sample. 
A

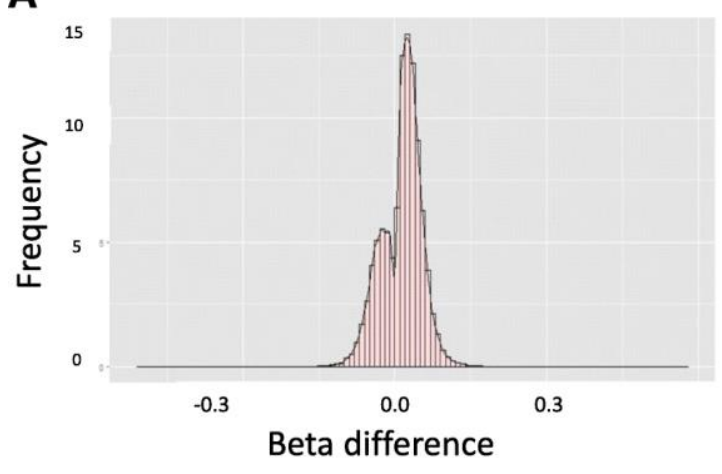

C

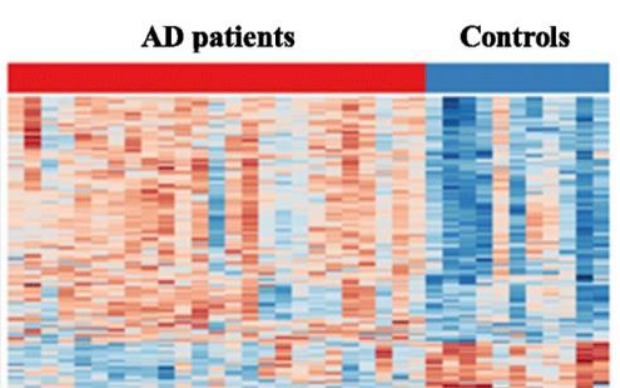

Methylation level
B

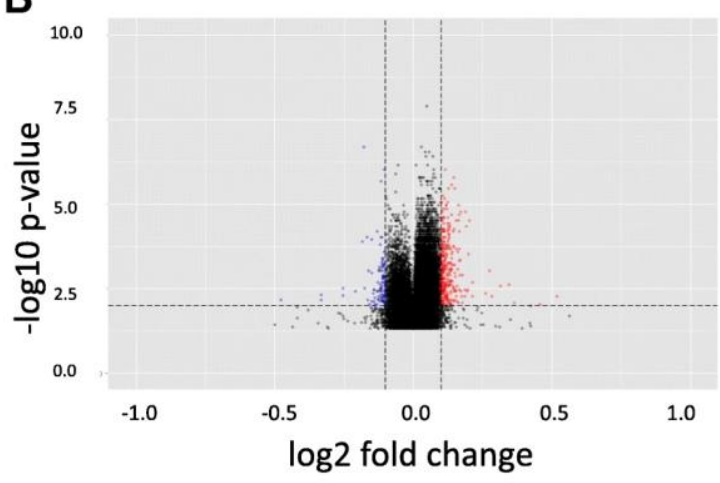

D

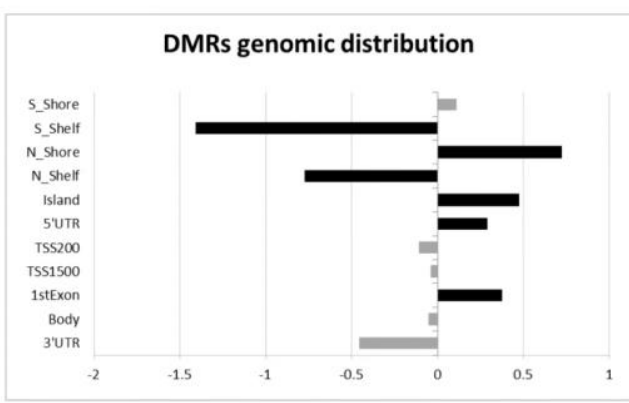

E

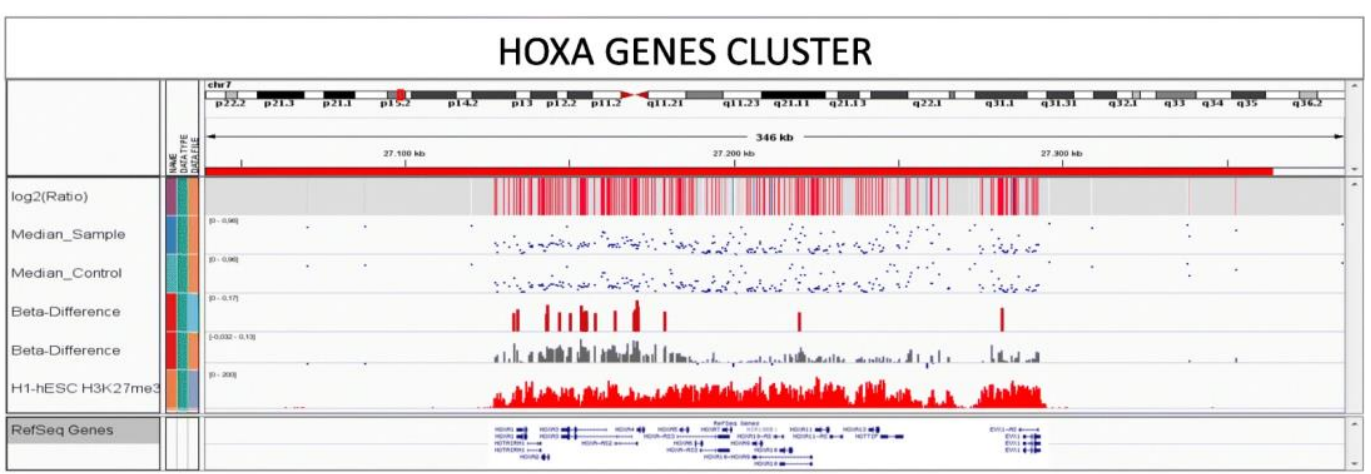

$\mathbf{F}$
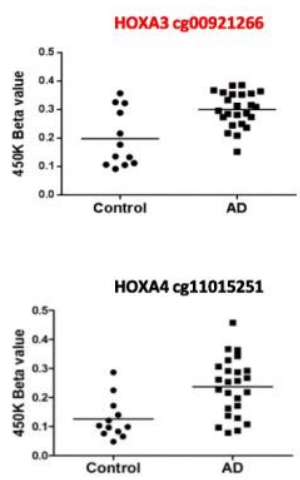

HOXA3 cg22962123
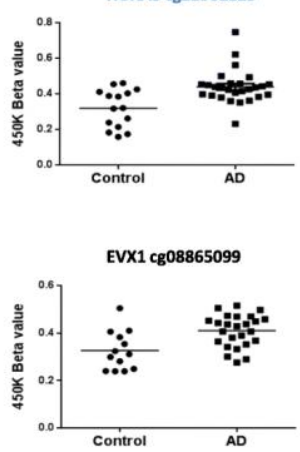

G
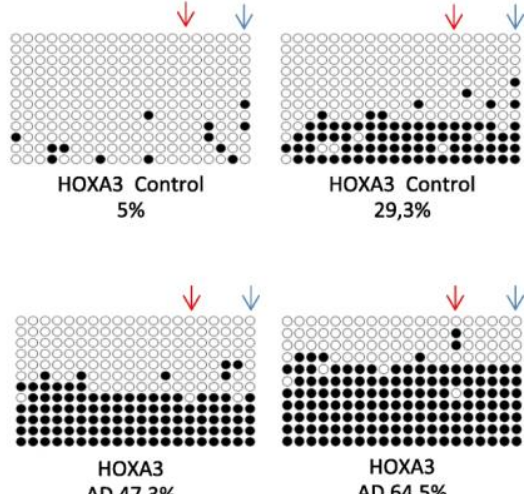


\section{Validation and additional mapping of DMPs}

Among the 118 AD-related DMPs, we selected 7 DMPs to be validated based on their genomic location in or near genes relevant to brain function or AD pathology, including some of the candidate hotspots, i.e., HAND2, HOXA3, HIST1H3E, NXN, PAX3, RBMS1, and $R H O B$. All the selected genes were successfully validated by bisulfite cloning sequencing (Additional file 1: Table S3). Additional mapping of the altered methylation pattern across multiple contiguous CpGs was generated (Fig. $2 \mathrm{~g}$ and Fig. 3, Additional file 1: Figure S1). The results of this mapping support the idea that changes in DNA methylation are not confined to the CpGs queried by the array. On the contrary, alterations of DNA methylation in AD seem to be consistently distributed across discrete regions of the genome and to involve multiple contiguous CpGs.

\section{DNA methylation levels correlate with phosphorylated tau protein burden}

The human hippocampus is particularly vulnerable to specific anatomopathological changes in $A D$ and is considered the region where tau pathology initiates, together with entorhinal cortex (131-133). To explore whether the altered DNA methylation patter reflects $A D$ pathological changes in the hippocampus, we used a semi-automated quantitative method described in detail elsewhere (128) to measure the extension of phosphorylated tau (p-tau) deposits in our set of hippocampal samples. Next, Pearson's coefficient was calculated to evaluate the correlation between DNA methylation levels at each of the identified 118 AD-related DMPs and the extension of $p$-tau deposits in the hippocampus. We found that DNA methylation levels in 43 (36.4\%) DMPs were significantly correlated with the burden of p-tau deposits (Additional file 1: Table S4).

The strongest correlation was observed for differentially methylated CpGs located close to the SOX18, HKR1, PCDHA12, and ATG16L2 genes. 
A
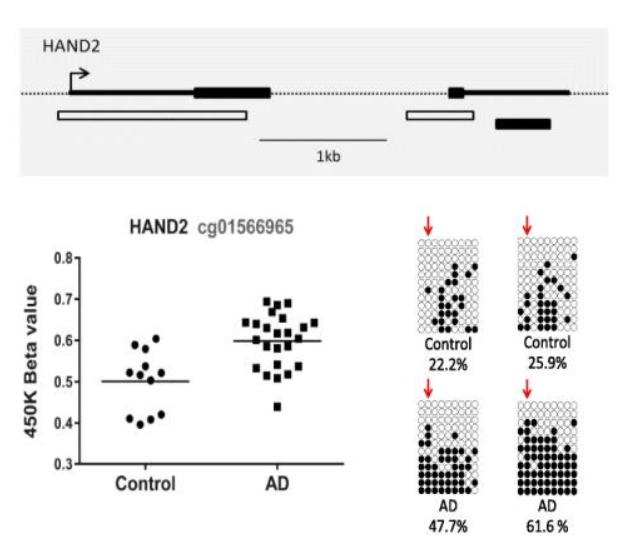

C

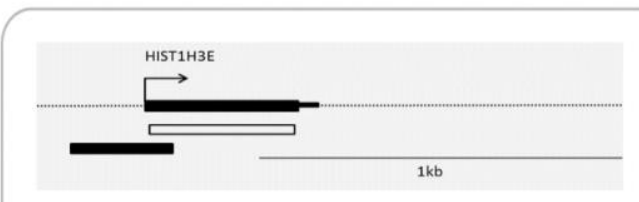

HIST1H3E cg26092675
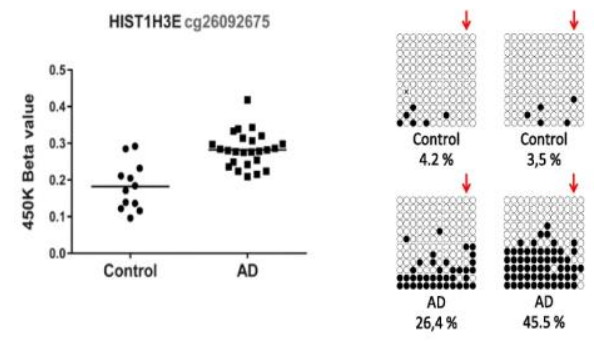

B
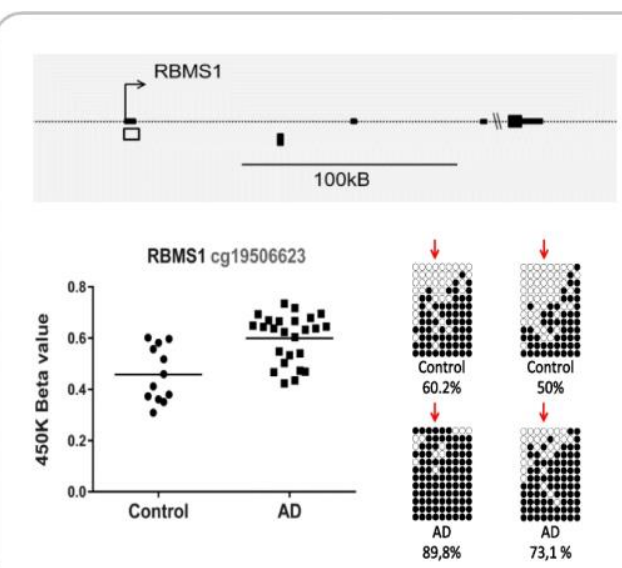

D
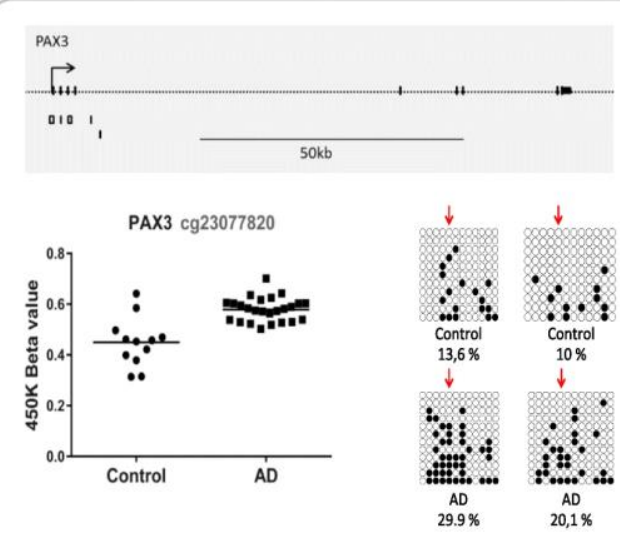

Fig.3. Validation and extended for the differentially methylated genes HAND2, RBMS1, HIST1H3E, and PAX3. Bisulfite cloning sequencing experiments show that hypermethylation affects multiple contiguous CpGs located in the 3'UTR of HAND2 (A), first exon of RBMS1 (B), the promoter region of HIST1H3E (C), and the body of PAX3 (D). The upper track of each panel shows a genomic map of each gene. White boxes below each gene denote CPG islands and black boxes represent bisulfite cloning sequencing amplicons. Dot-plot graphs show the results of the 450K array (beta values) for each CpG. Validation results are represented by black/white circle-style figures. Each rectangle corresponds to one sample and shows the methylation pattern at a discrete genomic region surrounding the significant $C p G$ probed by the $450 \mathrm{~K}$ array which is marked by a red arrow. Black circles represent methylated cytosines while white circles denote unmethylated cytosines. Each column symbolizes a unique CpG site in the examined amplicon and each line represents an individual DNA clone. Average percentage of 
methylation for each analyzed sample (control or patient) at this particular amplicon is indicated at the bottom of each sample.

\section{AD-related DMPs overlap bivalent histone marks and poised promoters}

Independent epigenetic mechanisms may play together to coordinately fine-tune gene expression. Therefore, we next asked whether the set of 118 AD-related DMPs was predicted to associate with other epigenetic features such as histone modifications. To this end, we first performed a functional in silico analysis for enrichment in histone marks using ENCODE/Broad data for human brain hippocampus, normal human astrocytes (NH-A), and H1 human Embryonic Stem Cells (H1hESC) identified through the WashU Epigenome Browser (136) and the UCSC Genome Browser (137).

We found that AD-related DMPs were overrepresented in regions of repressive histone marks, particularly in $\mathrm{H} 3 \mathrm{~K} 27$ me3 mark in $\mathrm{H} 1 \mathrm{hESC}$ and $\mathrm{H} 3 \mathrm{~K} 9$ me3 in the human hippocampus (Fig. 4a). We also realized that may of the AD-related DMPs shared both repressive (H3K27me3) and activating (H3K4me2 and H3K4me3) marks in the same locus. In other words, these DMPs overlapped regions of bivalent chromatin that usually characterizes poised promoters. Genes with poised promoters are generally repressed but ready for immediate activation in response to certain signals (138), and are thought to be key developmentally regulated genes not only in stem cells (138-140) but also in differentiated cells (140-142). In our study, 70 (59.3\%) AD-related DMPs overlapped poised promoters. When taking into account the direction of the methylation change, we observed that up to 68 (66.6\%) of the hypermethylated DMPs overlapped bivalent promoters, whereas only $2(12.5 \%)$ of the hypomethylated DMPs overlapped bivalent promoters (Fig. 4b). 
A.

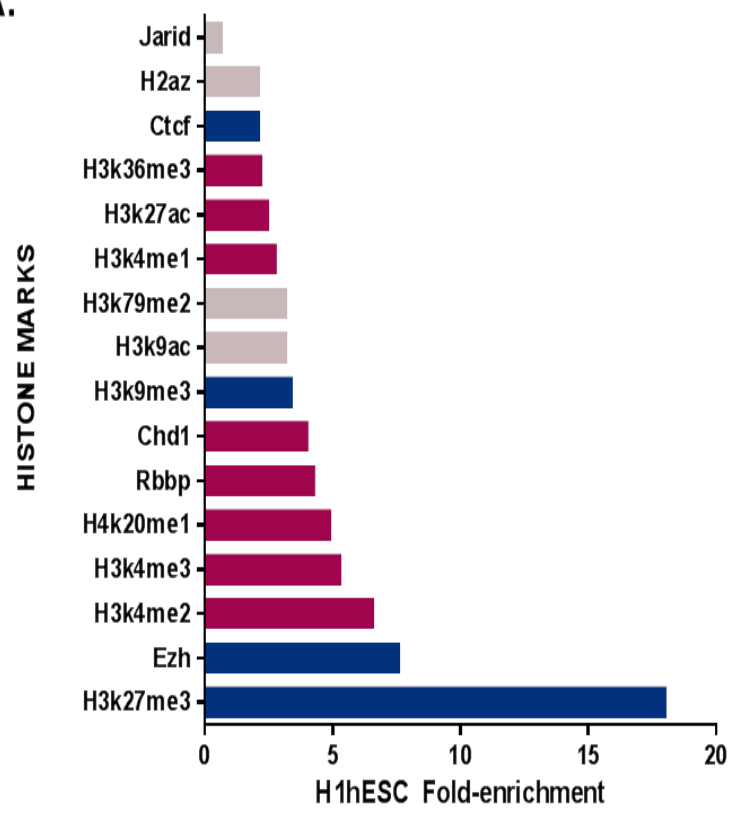

B.

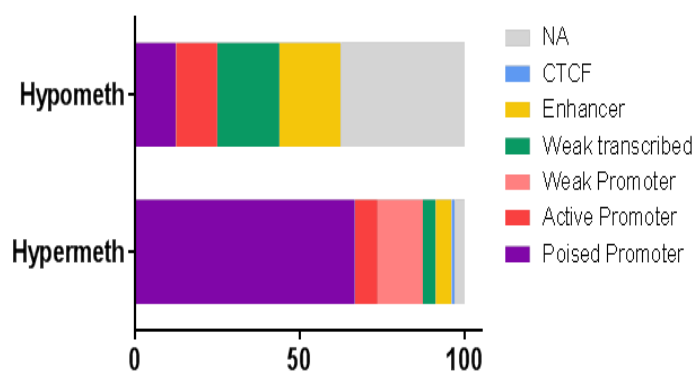

$\%$ of AD-related DMPs
C.
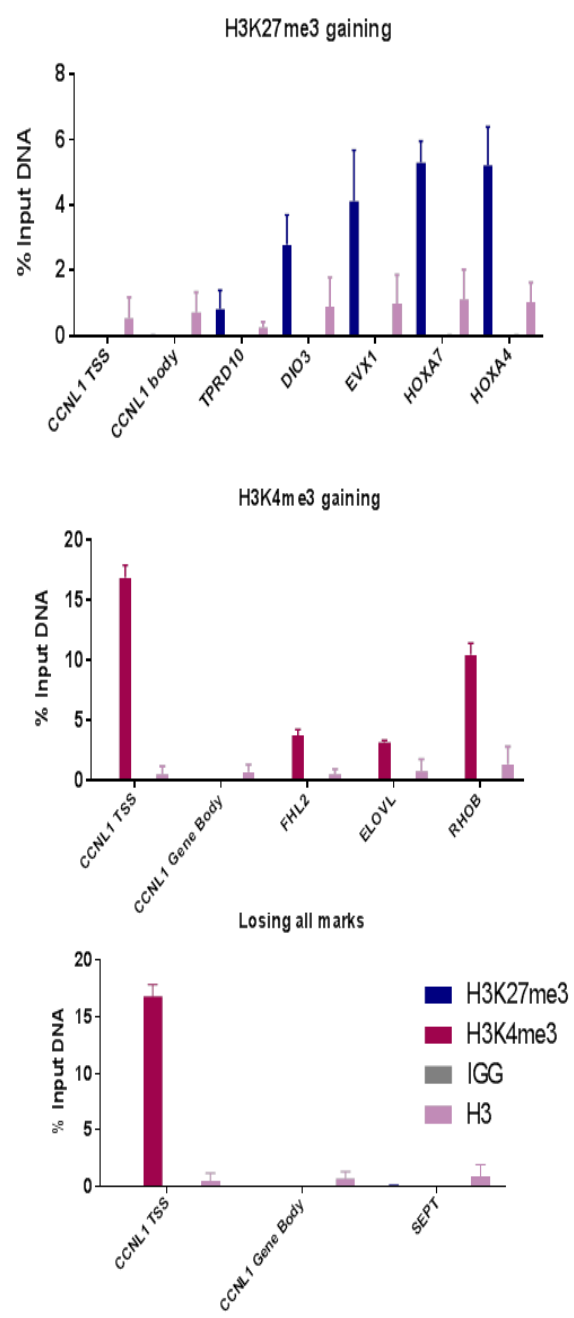

ChIP analysis in NHPCs

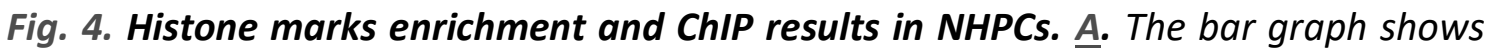
the strong enrichment in repressive histone marks (blue bars), particularly H3K27me3 and H3K9me3, in our set of AD-related DMPs. Milder enrichment of active chromatin marks (red bars) is also shown. Only statistically significant results of the hypergeometric test for the available histone marks are shown. $\underline{B}$. DMPs that were hypermethylated occur preferentially in promoters in a poised or bivalent chromatin state. $\underline{\text { C. }}$ A variety of fates for "poised" genes in committed NHPCs is represented by the results of ChIP experiments. Some of the promoters resolved to repressive (H3K27me3) or active (H3K4me3) promoters while others lost all histone marks. ChIP of the CCNL1 promoter 
and gene body regions were used as positive control for active promoter histone marks (H3K4me3) and negative control for repressive histone marks (H3K27me3).

\section{ChIP analysis of bivalent promoters in neural human progenitor cells}

Although most of the bivalent modifications in hESC are usually resolved during lineage commitment, a small subset of poised promoters in $\mathrm{hESC}$ may remain bivalent during differentiation $(138,140)$. Indeed, bivalent promoters may play complex roles in differentiated cells, keeping some genes poised for activation $(138,142,143)$. To explore the fate of bivalent chromatin modifications in our set of AD-related DMPs, we performed a number of chromatin immunoprecipitation-quantitative PCR (ChIP-qPCR) experiments in neural human progenitor cells (NHPCs) which represent a more differentiated state than hESC in the brain tissue. We ran ChIP-qPCR assays on NHPCs using anti-H3K27me3 and anti-H3K4me3 antibodies for selected differentially methylated genes, including the HOXA gene cluster. ChIP-qPCR analysis revealed that genes within the HOXA locus resolved to the repressive H3K27me3 status in NHPCs, as was also the case of the DIO3 and TDRD10 genes. On the contrary, ROHB, ELOVL2, and FHL2 resolved to H3K4me3 active status in the committed NHPCs. Only SEPT5 lost both H3K4me3 and H3K27me3 chromatin marks (Fig. 4c). These results illustrate a wide variety of histone marks fates for these differentially methylated genes which are poised in H1hESCs. Although additional research on this issue would be needed, these results suggest that AD-related DMPs are not enriched in genes that retain bivalent marks in lineage-committed cells.

\section{AD-related differentially methylated genes are linked to neural development and neurogenesis}

Next, we wanted to know whether the set of AD-related DMPs was enriched for genes involved in specific diseases, functions, and pathways. To this end, we performed 
different levels of analysis. First, manually curated search using PubMed revealed that 50 (42.4\%) AD-related DMPs were associated with genes related with neural development and neurogenesis (Table 1, Fig. 1). Consistently, most of these genes overlapped poised promoters (90.9\%), since they are key developmentally regulated genes.

Next, we used the Genomic Regions Enrichment of Annotations Tool (GREAT) (144) to identify enriched ontological terms in our set of AD-related DMPs. The enriched gene ontology (GO) terms in the biological process category revealed a set of different processes consistently associated with embryonic and brain morphogenesis among others (Additional file 1: Figure S2). In addition, our set of AD-related DMPs was enriched in the "high mobility group (HMG) box domain binding" term in the GO molecular category (fold enrichment $=12.3$; FDR $Q$-value $<0.01$ ). HMG is a protein domain which confers proteins the ability to bind DNA and is related to a number of DNA processes, including transcription and DNA repair (145).

Next, an InterPro ontology analysis was performed to test for protein domains, families, and functional sites. The analysis showed enrichment for homeobox domain-related terms in the set of AD-related DMPs (Additional file 1: Table S5). Homeobox transcription factors are crucial in regulating pluripotency and cellular differentiation (146).

\section{Discussion}

In this study, we profiled genome-wide DNA methylation levels to identify novel ADrelated methylation changes in the human hippocampus. These results revealed genomic loci hypermethylated in $A D$ cases compared to controls that largely overlap regulatory regions, mainly bivalent promoters. In addition, the DNA methylation signature was consistently related to genes crucial for neural development or neurogenesis and homeobox-containing transcription factors. 
Neuropathological hallmarks of AD tend to occur in particularly vulnerable regions in the human brain (131)(134) and are associated to neuronal death and synapse loss from the very early stages of the disease (147). However, molecular mechanisms underlying the specific brain region pattern of neuropathological changes in $A D$ are not entirely clear. That was the rationale for selecting the human hippocampus to perform this epigenetic screening since it is a highly vulnerable region to $A D$ neuropathological changes. In this regard, our analysis showed a statistically significant positive correlation between DNA methylation levels at $36.4 \%$ of the AD-related DMPs and the hippocampal burden of $p$-tau. On the other hand, and supporting the robustness of the present study, our results partially overlap those previously reported from methylome studies performed on other $A D$ brain regions, such as prefrontal, frontal, and superior temporal neocortex or entorhinal cortex $(77-81,130)$. The overlap of DMPs among different AD brain regions suggests that a limited number of DMPs may be related to characteristic molecular processes of $A D$, regardless of the affected brain area. In any case, our complete set of AD-related DMPs extends and complements the current epigenomic landscape of the AD brain.

Interestingly, the functional analysis showed that a significant percentage of the differentially methylated genes were related to neural development and neurogenesis. It was astounding that other biological, cellular, and molecular processes generally associated with neurodegeneration such as apoptosis, autophagy, inflammation, oxidative stress, and mitochondrial or lysosomal dysfunction were not overrepresented in the set of AD-related DMPs. Though strongly related to brain development, neurogenesis is also maintained in the adult human brain, mainly in two distinct areas, i.e., the subventricular zone and the subgranular zone of the dentate gyrus in the hippocampus. There is substantial neurogenesis throughout life in the human hippocampus as it is estimated that up to one third of human hippocampal neurons are subject to constant turnover (148). Adult neurogenesis is linked to hippocampaldependent learning and memory tasks (149-151) and is reduced during aging $(148,151)$. Recent evidence suggests that adult neurogenesis is altered in the neurodegenerative 
process of AD (152-154), but it is still controversial with some authors reporting increased neurogenesis $(155,156)$, whereas others show reduced neurogenesis $(151,154,157,158)$. In the human hippocampus, a sharp drop in adult neurogenesis has been observed in subjects with AD (154). Remarkably, protein tau has been also involved in the modulation of adult hippocampal neurogenesis exerted by external stimuli (159) and impairs proliferation of neuronal precursors in the hippocampal dentate gyrus in a tauopathy mouse model (160). Definitely, the molecular mechanisms involved in defective neurogenesis in AD remain to be elucidated (153).

In this scenario, the results of the present study point to neurogenesis-related genes as targets of epigenetic changes in the hippocampus affected by AD. Enrichment of ADrelated DNA methylation marks in neurodevelopmental and neurogenesis-related genes may reflect changes in epigenetic regulation of the neuronal population subjected to exchange in the hippocampus, whose function and balance could be relevant to $A D$ pathogenesis. These methylation changes might be built throughout life due to external and internal cues and would represent an example of epigenetic interaction between environmental and genetic factors in developing AD. As an alternative explanation, these epigenetic marks might also represent the trace of DNA methylation alterations induced during early developmental stages of the hippocampus, which would remain as a fingerprint in the larger proportion of hippocampal neurons that are not exchanged. This second hypothesis would link AD to early life stages, in concordance with recent studies that revealed abnormal p-tau deposits (pre-tangles) in brains of young individuals under $30(161,162)$ suggesting AD pathology would start earlier in life than it was previously thought. The influence of the genetic risk for AD has also been postulated to begin in early life (163), and other AD risk factors may be influenced by in utero environment (164).

We also observed that $A D$-related DMPs overlap relevant regulatory regions in the genome, such as CpG islands and bivalent histone marks corresponding to poised promoters. This result is in line with previous studies that found hypermethylated DMPs in the AD superior temporal gyrus to be enriched in poised promoters (130). Promoters 
may be found in three distinct states: active, repressed, and poised. In the poised state, promoters are repressed but may be rapidly activated in response to certain cues (138). Interestingly, poised promoters are very often associated with genes critical to the development and, as such, are characteristic of stem cells $(138-140,165)$. A number of poised promoters can also be maintained in lineage-committed and differentiated cells (142-144). In our study, ChIP-qPCR analysis suggests that the bivalent promoters enriched in the set of AD-related DMPs resolve to a variety of states in committed NPCs and therefore are not enriched in genes retaining bivalent marks in lineage-committed cells.

The functional in silico analysis showed enrichment for the homeobox domaincontaining family of genes in the set of AD-related DMPs. Homeobox domain-containing genes encode transcription factors (TFs) that result crucial during early embryonic development and morphogenesis (146). Some homeobox TFs act by inducing cellular differentiation while other homeobox TFs are involved in maintaining pluripotency. Homeobox genes are known to be tightly regulated by DNA methylation and modifications of the chromatin state. Notably, homeobox domain-containing TFs are being closely connected to neurogenesis (166-168) and specific homeobox TFs, such as Dbx2, are involved in age-related neurogenic decline (169). Most interestingly, Dbx2 is involved in the molecular changes that characterize the aged phenotype of neural stem/progenitor cells from the subventricular zone in mice, and it has been proposed as a player in promoting age-related neurogenic decline (169).

Deregulation of homeobox genes is related to certain diseases, such as cancer. However, the relationship with $A D$ and neurodegenerative disorders has been barely assessed. Only a few reports are found in the literature regarding $A D$ and homeobox domaincontaining genes, e.g., low expression of GAX gene, a regulator of vascular differentiation, in brain endothelial cells in AD (170), or GTX gene, a homeobox gene with neuroprotective properties (171). Therefore, these findings open a new avenue for research to better understand the role of homeobox TFs in the AD pathogenesis. 
At any rate, we want to be cautious with our conclusions. There was a significant difference in age between controls and $A D$ patients, being the latter group older than the former group. Although we adjusted for age in the statistical differential methylation analysis, the accuracy of this correction may be limited as there is little overlap in the age ranges of both groups. For the sake of external validity, these findings should be replicated in an independent cohort of human hippocampal samples.

\section{Conclusions}

On the whole, our results suggest that altered DNA methylation in the AD hippocampus occurs at specific regulatory regions that are crucial for neural differentiation and support the notion that adult hippocampal neurogenesis may play a role in the development of AD. However, we are far from understanding how DNA methylation changes, interacting with other epigenetic mechanisms, modulate relevant molecular pathways in developing the disease. In addition, other topics such as the role of nonCpG methylation or hydroxymethylation would be interesting to address in the AD hippocampus. Therefore, further research on the alterations of epigenetic mechanisms in $A D$ is guaranteed.

\section{Methods}

\section{Aim, design, and setting of the study}

The aim of this study was to profile genome-wide DNA methylation in the human hippocampus, a brain region particularly vulnerable to $A D$ and the core of pathological protein tau deposits. This is an observational, transversal, case-control study to identify differentially methylated positions among AD cases and controls. 


\section{Human brain samples and neuropathological examination}

We evaluated postmortem hippocampal samples from 38 subjects (26 AD patients and 12 controls), provided by the Navarrabiomed Brain Bank. After death, half brain specimens from donors were cryopreserved at $-80^{\circ} \mathrm{C}$. Neuropathological examination was performed following the usual recommendations (171). Assessment of $\beta$-amyloid deposit was carried out by immunohistochemical staining of paraffin-embedded sections (3-5 $\mu \mathrm{m}$ thick) with a mouse monoclonal (S6F/3D) anti- $\beta$-amyloid antibody (dilution 1/50) (Leica Biosystems Newcastle Ltd, Newcastle upon Tyne, UK). Evaluation of neurofibrillary pathology was performed with a mouse monoclonal antibody antihuman PHF-TAU, clone AT-8 (Tau AT8) (dilution 1/1000) (Innogenetics, Gent, Belgium), which identifies $p$-tau (133). The reaction product was visualized using an automated slide immunostainer (Leica Bond Max) with Bond Polymer Refine Detection (Leica Biosystems Newcastle Ltd). AD staging was performed by using the ABC score according to the updated National Institute on Aging-Alzheimer's Association guidelines (172). Agreement for any diagnosis was reached by members of a panel composed of two neuropathologists (VZ, CE) and two neurologists (JS, MM).

\section{Genome-wide DNA methylation profiling and differential methylation analysis}

CPG methylation levels were profiled genome-wide by using Infinium HumanMethylation450 BeadChip array (Illumina, Inc., San Diego, CA, USA) (173) at the Roswell Park Cancer Institute Genomics Shared Resource (Buffalo, NY, USA). Briefly, $500 \mathrm{ng}$ of genomic DNA from each brain sample was bisulfite treated and hybridized to the BeadChip according to the manufacturer's protocol. A total of 485,577 cytosine positions were interrogated throughout the human genome, covering the $99 \%$ of RefSeq genes and $96 \%$ of $\mathrm{CpG}$ islands. 


\section{Quality control and data processing}

In order to minimize the potential bias introduced by batch effects, we performed samples-to-batch allocation using the OSAT tool (174). Microarray image processing was carried out using Genome Studio Methylation Module (v1.8.5). Background was corrected, and adjustment was performed to avoid type I/II assay chemistry bias. So as to minimize technical variation and improve data quality, the Dasen method (175) was used as a normalization tool.

Before performing differential methylation analysis, we removed probes that overlapped common single nucleotide polymorphisms (SNPs) and also those probes classified as internal controls of the Illumina microarray. Additionally, probes located on the $\mathrm{X}$ and $\mathrm{Y}$ chromosomes were discarded along with those probes previously described to hybridize to multiple locations in the genome (176)(177). Probes that technically did not pass the Illumina quality threshold (1188 probes with bead count $<3$ in $>5 \%$ of samples and 378 probes having $1 \%$ of samples with a detection $p$ value $>0.05$ ) were also removed. In the end, a total of 264,031 probes (representing individual CpG sites) were further analyzed for differential methylation (Additional file 1: Figure S3).

\section{Differential methylation analysis}

Our aim was to identify differentially methylated positions (DMPs), that is to say, differentially methylated CpGs related with $A D$ status. Linear model of microarray analysis (LIMMA) adjusted for age was performed to fit a linear regression model for each CpG site (R/Bioconductor package) (178). Percentage of methylation (B-value) at each surveyed $\mathrm{CpG}$ site was calculated and ranged from 0 to 1. Benjamini and Hochberg false discovery rate (FDR) correction was used ( $p$ value $<0.05$ ). Methylation differences were prioritized by lowest adjusted $p$ values to ensure the most consistent DMPs between AD patients and controls. This analysis identified sets of candidate loci with consistent differences in methylation in $A D$ versus control hippocampus. Gene 
annotation was obtained using the Genomic Regions Enrichment of Annotations Tool (GREAT) (144).

\section{Bisulfite sequencing validation of DMPs}

Next, 500 ng of genomic DNA was bisulfite converted using the EpiTect Bisulfite Kit (QIAGEN, Redwood City, CA, USA) according to the manufacturer's instructions. Primer pair sequences were designed by MethPrimer (179) and are listed in Additional file 1: Table S6. PCR products were cloned using the TopoTA Cloning System (Invitrogen, Carlsbad, CA, USA), and between 12 and 24 independent clones were sequenced for each examined subject and region by Sanger sequencing (180). Methylation graphs were obtained by using QUMA software (181), and maps of genes were drawn by using IGV software.

\section{Quantitative assessment of $p$-tau deposits in the hippocampus}

In order to quantitatively assess $p$-tau burden in the hippocampal samples of AD subjects, we applied a method described in detail elsewhere (128). Briefly, sections of the hippocampus were examined after performing immunostaining with anti-p-tau antibody (clone AT-8) (dilution 1/1000), and representative images were analyzed with ImageJ software to obtain an average quantitative measure of the global $p$-tau deposit for each section and patient. Examples of AT-8 staining for control and different AD stages are shown in Additional file 1: Figure S4.

\section{Chromatin immunoprecipitation in Normal Human Neural Progenitor Cells}

Normal Human Neural Progenitor (NHNP) cells (Lonza) were grown in $75 \mathrm{~cm}^{2}$ culture flasks in NPBM medium (Neural Progenitor Basal Medium, Lonza) with the addition of 
hFGF, hEGF, NSF-1, and GA. NHNP cells were fixed in $1 \%$ formaldehyde for $10 \mathrm{~min}$ at room temperature; the reaction was stopped by addition of $1.25 \mathrm{M}$ glycine solution, and cells were washed in PBS and harvested in IP buffer (1 volume of SDS buffer to 0.5 volume of Triton dilution buffer and protease inhibitors).

For each ChIP, $100 \mu \mathrm{g}$ of DNA was used. Chromatin was sonicated to an average size of $750 \mathrm{bp}$. Sonicated sample was then blocked by incubating with Protein $G$ and $A$ sepharose beads at $4{ }^{\circ} \mathrm{C}$ for $1 \mathrm{~h}$. Ten percent of the sample was kept aside as INPUT, and $1 \mu \mathrm{g}$ of antibody or IgG was added to the remaining sample and incubated overnight at $4{ }^{\circ} \mathrm{C}$. The next day Protein $\mathrm{G}$ and $\mathrm{A}$ sepharose beads were added and incubated for $2 \mathrm{~h}$ at $4{ }^{\circ} \mathrm{C}$. After extensive washes, immunocomplexes were eluted from the beads and cross-links were reversed. The DNA was recovered by phenol-chloroform extraction and ethanol precipitation. DNA was resuspended in $150 \mu \mathrm{l}$ of water, and $3.75 \mu$ l were used for real-time qPCRs in a final volume of $10 \mu \mathrm{l}$. The antibodies used in this study were anti-H3 (ab1791, Abcam), anti-H3K27me3 (ab6002, Abcam), and anti-H3K4me3 (ab8580, Abcam). ChIP of the CCNL1 promoter and gene body regions were used as a positive control for active promoter histone marks (H3K4me3) and negative control for repressive histone marks (H3K27me3).

\section{Functional in silico analysis of DMPs}

We performed a systematic manual curation of the literature using PubMed to identify whether AD-related differentially methylated genes were enriched in nervous system functions, including neurogenesis and neural development.

In order to determine the biological significance of AD-related DMPs, gene ontology analysis and pathway analysis were performed using the Genomic Regions Enrichment of Annotations Tool (GREAT) (144). To define gene regulatory domains, each gene was assigned a basal regulatory domain of a minimum distance upstream $(5.0 \mathrm{~kb})$ and downstream of the transcription start site (TSS) (1 Kb plus distal up to $1000 \mathrm{~Kb}$ ). The gene regulatory domain was extended in both directions to the nearest gene's basal domain but no more than the maximum extension in one direction. By using GREAT, we 
got InterPro ontology which contains data on protein domains, families, and functional sites. InterPro annotations give information about the function, structure, and evolution of the domains by combining several other databases (PROSITE, PRINTS, Pfam, ProDom, SMART, TIGRFAMs, PIRSF, SUPERFAMILY, PANTHER, and Gene3D). Only those terms with a FDR-corrected $p$ value less than 0.05 were reported.

\section{Acknowledgements}

We want to kindly thank Isabel Gil M.D., Ph.D., Ana Purroy, Valle Coca, and Ana Aramendía from the Navarrabiomed BrainBank for their technical support and help and Genomics Shared Resource of the Roswell Park Cancer Institute (Buffalo, NY, USA). We are very thankful to Teresa Tuñón M.D., Ph.D. and Federico García Bragado M.D., Ph.D., for their encouragement and anatomopathological support. We also want to thank Pitu Manubens + M.D., Ph.D., for invaluable mentoring and inspiration. Finally,we are very grateful to the patients and relatives that generously donor the brain tissue to the Navarrabiomed Brain Bank. 
Supplemental Table S1. Brain sample set analyzed by 450K Illumina BeadChip array.

\begin{tabular}{|c|c|c|c|c|c|c|c|c|}
\hline No. & Status & ABC score & $\begin{array}{c}\text { Braak \& } \\
\text { Braak stage }\end{array}$ & APS & $\begin{array}{l}\text { Age at death } \\
\text { (years) }\end{array}$ & Gender & PMI (h) & $\begin{array}{c}\text { Region } \\
\text { hippocampus }\end{array}$ \\
\hline 1 & Control & control & NA & NPD & 61 & male & 8 & Yes \\
\hline 2 & Control & control & NA & NPD & 81 & male & 10.5 & Yes \\
\hline 3 & Control & control & NA & NPD & 43 & female & 3 & Yes \\
\hline 4 & Control & control & NA & NPD & 88 & male & 9 & Yes \\
\hline 5 & Control & control & NA & NPD & 53 & male & 7 & Yes \\
\hline 6 & Control & control & NA & NPD & 41 & male & 3.5 & Yes \\
\hline 7 & Control & control & NA & NPD & 28 & male & 6 & Yes \\
\hline 8 & Control & control & NA & NPD & 46 & female & 7 & Yes \\
\hline 9 & Control & control & NA & NPD & 69 & male & 12 & Yes \\
\hline 10 & Control & control & NA & NPD & 19 & female & NA & Yes \\
\hline 11 & Control & control & NA & NPD & 26 & male & 6.2 & Yes \\
\hline 12 & Control & control & NA & NPD & 54 & male & 18 & Yes \\
\hline 13 & $A D$ & A1B1C1 & 1 & 0.00 & 60 & male & 15.3 & Yes \\
\hline 14 & $A D$ & A1B1C1 & 1 & 2.00 & 85 & male & 3.2 & Yes \\
\hline 15 & $A D$ & A1B1C1 & II & 0.00 & 66 & female & 1.4 & Yes \\
\hline 16 & $A D$ & A1B2C1 & III & 0.00 & 88 & female & 33 & Yes \\
\hline 17 & $A D$ & $\mathrm{~A} 1 \mathrm{~B} 2 \mathrm{C} 1$ & III & 3.00 & 96 & female & 1.5 & Yes \\
\hline 18 & $A D$ & A1B2C2 & III & 0.33 & 79 & female & 13 & Yes \\
\hline 19 & $A D$ & A1B2C2 & III & 1.00 & 81 & female & 9 & Yes \\
\hline 20 & $A D$ & A1B2C3 & IV & 2.33 & 84 & female & 13 & Yes \\
\hline 21 & $A D$ & $\mathrm{~A} 2 \mathrm{~B} 2 \mathrm{C} 2$ & III & 5.00 & 88 & male & 3.5 & yes \\
\hline 22 & $A D$ & $\mathrm{~A} 2 \mathrm{~B} 2 \mathrm{C} 2$ & IV & 2.33 & 91 & female & 10 & yes \\
\hline 23 & $A D$ & $\mathrm{~A} 2 \mathrm{~B} 2 \mathrm{C} 2$ & IV & 1.33 & 84 & male & 3.3 & yes \\
\hline 24 & $A D$ & $\mathrm{~A} 2 \mathrm{~B} 2 \mathrm{C} 2$ & IV & 3.00 & 97 & female & NA & yes \\
\hline 25 & $A D$ & A2B2C3 & IV & 1.33 & 78 & male & 5 & yes \\
\hline 26 & $A D$ & A2B3C3 & $\mathrm{V}$ & 5.67 & 77 & female & 4 & yes \\
\hline 27 & $A D$ & A3B2C1 & IV & 1.33 & 90 & female & 3 & yes \\
\hline 28 & $A D$ & A3B2C3 & III & 6.67 & 98 & female & 3 & yes \\
\hline 29 & $A D$ & A3B2C3 & III & 2.67 & 85 & female & NA & yes \\
\hline 30 & $A D$ & A3B3C2 & $\mathrm{V}$ & 3.00 & 92 & female & 14 & yes \\
\hline 31 & $A D$ & A3B3C2 & V & 7.00 & 82 & female & 9 & yes \\
\hline 32 & $A D$ & A3B3C2 & V & 8.00 & 91 & male & 5 & yes \\
\hline 33 & $A D$ & A3B3C 3 & $\mathrm{~V}$ & 4.00 & 77 & female & 11 & yes \\
\hline 34 & $A D$ & A3B3C3 & $\mathrm{VI}$ & 3.33 & 93 & female & 3 & yes \\
\hline 35 & $A D$ & АЗВ3С 3 & $\mathrm{VI}$ & 4.33 & 61 & male & 10 & yes \\
\hline 36 & $A D$ & АЗВ3С 3 & $\mathrm{VI}$ & 9.67 & 70 & male & 2.35 & yes \\
\hline
\end{tabular}




\section{Braak \&}

Age at death

Region

No. Status ABC score Braak stage APS (years) Gender PMI (h) hippocampus

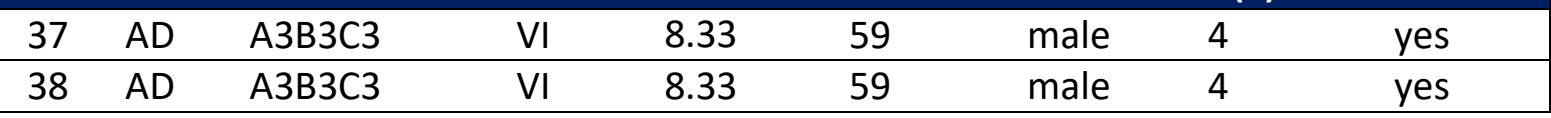

The table shows the characteristic of the samples included in the study. No.:

Number; AD: Alzheimer's disease; APS: amyloid plaque score; NPD: no protein deposit; PMI: post mortem interval; h: hours; NA: not applicable. 
Supplemental Table S2. Differentially methylated genes in previous AD methylome studies.

\begin{tabular}{|l|l|}
\hline Genes & AD methylome study \\
\hline ATG16L2 & De Jager et al. \\
\hline BIN1 & De Jager et al.; Yu et al. \\
\hline CMYA5 & Watson et al.; Bakulski et al. \\
\hline DUSP27 & Lunnon el al. \\
\hline GP1BB & Lunnon el al. \\
\hline HOTAIRM1 & De Jager et al. \\
\hline HOXA1 & De Jager et al. \\
\hline HOXA2 & Lunnon el al.; De Jager et al. \\
\hline HOXA3 & Lunnon el al. \\
\hline HOXA4 & De Jager et al. \\
\hline KCNN4 & De Jager et al. \\
\hline MAP4K1 & Lunnon el al. \\
\hline NXN & De Jager et al. \\
\hline PARS2 & De Jager et al. \\
\hline SEPT5 & Lunnon el al. \\
\hline SIX3 & De Jager et al. \\
\hline SMG9 & De Jager et al. \\
\hline
\end{tabular}

The table shows the genes that have been previously found associated with $A D$ in methylome studies performed on human brain samples. 
Supplemental Table S3. Correlation between DNA methylation levels at each DMPs and tau burden. ${ }^{*} p$-value $<0.05 ;{ }^{* *} p$-value $<0.01$.

\begin{tabular}{|l|c|c|}
\hline Probe ID & $\begin{array}{c}\text { Pearson's } \\
\text { correlation } \\
\text { coefficient }\end{array}$ & $\begin{array}{c}\text { p- } \\
\text { value }\end{array}$ \\
\hline $\operatorname{cg} 04154027$ & $.406^{*}$ &, 014 \\
\hline $\operatorname{cg} 04498198$ & $.357^{*}$ &, 032 \\
\hline $\operatorname{cg} 01463828$ & $.360^{*}$ &, 031 \\
\hline $\operatorname{cg} 13935577$ & $.389^{*}$ &, 019 \\
\hline $\operatorname{cg} 19022697$ & $.40)^{*}$ &, 013 \\
\hline $\operatorname{cg} 25840926$ & $.404^{*}$ &, 015 \\
\hline $\operatorname{cg} 22962123$ & $.349^{*}$ &, 037 \\
\hline $\operatorname{cg} 05637536$ & $.362^{*}$ &, 030 \\
\hline $\operatorname{cg} 01331772$ & $.335^{*}$ &, 046 \\
\hline $\operatorname{cg} 23279355$ & $.348^{*}$ &, 038 \\
\hline $\operatorname{cg} 13172549$ & $.40)^{*}$ &, 016 \\
\hline $\operatorname{cg} 02231404$ & $.550^{*}$ &, 001 \\
\hline $\operatorname{cg} 00921266$ & $.355^{*}$ &, 034 \\
\hline $\operatorname{cg} 09490371$ & $.349^{*}$ &, 037 \\
\hline $\operatorname{cg} 16127683$ & $.414^{*}$ &, 012 \\
\hline $\operatorname{cg} 22385702$ & $.330^{*}$ &, 049 \\
\hline $\operatorname{cg} 24369989$ & $.407^{*}$ &, 014 \\
\hline $\operatorname{cg} 12024906$ & $.517^{*}$ &, 001 \\
\hline $\operatorname{cg} 00303378$ & $.359^{*}$ &, 031 \\
\hline $\operatorname{cg} 20864214$ & $.418^{*}$ &, 011 \\
\hline $\operatorname{cg} 05726109$ & $.335^{*}$ &, 046 \\
\hline $\operatorname{cg} 07584855$ & $.379^{*}$ &, 023 \\
\hline $\operatorname{cg} 02798280$ & $.394^{*}$ &, 018 \\
\hline $\operatorname{cg} 24756378$ & $.378^{*}$ &, 023 \\
\hline $\operatorname{cg} 12253175$ & $.350^{*}$ &, 037 \\
\hline $\operatorname{cg} 09596958$ & $.370^{*}$ &, 026 \\
\hline $\operatorname{cg} 02267270$ & $.373^{*}$ &, 025 \\
\hline $\operatorname{cg} 01421119$ & $.403^{*}$ &, 015 \\
\hline $\operatorname{cg} 22090150$ & $.404^{*}$ &, 015 \\
\hline $\operatorname{cg} 05877788$ & $.399^{*}$ &, 016 \\
\hline $\operatorname{cg} 06396119$ & $.422^{*}$ &, 010 \\
\hline $\operatorname{cg} 14557699$ & $.444^{*}$ &, 007 \\
\hline $\operatorname{cg} 07589899$ & $.345^{*}$ &, 039 \\
\hline $\operatorname{cg} 17179862$ & $.344^{*}$ &, 040 \\
\hline $\operatorname{cg} 14962509$ & $.354^{*}$ &, 034 \\
\hline
\end{tabular}




\begin{tabular}{|c|c|c|}
\hline Probe ID & $\begin{array}{l}\text { Pearson's } \\
\text { correlation } \\
\text { coefficient }\end{array}$ & $\begin{array}{c}p- \\
\text { value }\end{array}$ \\
\hline cg13836098 & $.392 *$ & ,018 \\
\hline $\operatorname{cg} 00611789$ & $.350 *$ & ,037 \\
\hline cg13771313 & $.436 * *$ & ,008 \\
\hline cg21811021 & $.330 *$ & ,049 \\
\hline cg03422911 & $.340 *$ & ,043 \\
\hline cg19153828 & $.353^{*}$ & ,035 \\
\hline cg09317554 & $.346^{*}$ & ,039 \\
\hline cg20597486 & $-.397^{*}$ & ,017 \\
\hline $\operatorname{cg} 04154027$ & $.406 *$ & , 014 \\
\hline cg04498198 & $.357^{*}$ & ,032 \\
\hline cg01463828 & $.360 *$ & ,031 \\
\hline cg13935577 & $.389 *$ & ,019 \\
\hline cg19022697 & $.409 *$ & ,013 \\
\hline cg25840926 & $.404^{*}$ & ,015 \\
\hline cg22962123 & $.349 *$ & ,037 \\
\hline $\operatorname{cg} 05637536$ & $.362 *$ & ,030 \\
\hline $\operatorname{cg} 01331772$ & $.335^{*}$ & ,046 \\
\hline cg23279355 & $.348 *$ & ,038 \\
\hline $\operatorname{cg} 13172549$ & $.400 *$ & ,016 \\
\hline cg02231404 & $.550 * *$ & ,001 \\
\hline cg00921266 & $.355^{*}$ & ,034 \\
\hline cg09490371 & $.349 *$ & ,037 \\
\hline cg16127683 & $.414^{*}$ & ,012 \\
\hline cg22385702 & $.330 *$ & ,049 \\
\hline cg24369989 & $.407^{*}$ & ,014 \\
\hline cg12024906 & $.517 * *$ & ,001 \\
\hline cg00303378 & $.359 *$ & ,031 \\
\hline cg20864214 & $.418^{*}$ & ,011 \\
\hline $\operatorname{cg} 05726109$ & $.335^{*}$ & ,046 \\
\hline $\operatorname{cg} 07584855$ & $.379 *$ & ,023 \\
\hline cg02798280 & $.394^{*}$ & ,018 \\
\hline cg24756378 & $.378 *$ & ,023 \\
\hline $\operatorname{cg} 12253175$ & $.350 *$ & ,037 \\
\hline cg09596958 & $.370 *$ & ,026 \\
\hline cg02267270 & $.373^{*}$ & ,025 \\
\hline $\operatorname{cg} 01421119$ & $.403^{*}$ & ,015 \\
\hline cg22090150 & $.404^{*}$ & ,015 \\
\hline cg05877788 & $.399 *$ & ,016 \\
\hline cg06396119 & $.422 *$ & ,010 \\
\hline cg14557699 & $.444^{* *}$ & ,007 \\
\hline cg07589899 & $.345^{*}$ & ,039 \\
\hline $\operatorname{cg} 17179862$ & $.344^{*}$ & ,040 \\
\hline
\end{tabular}




\begin{tabular}{|c|c|c|}
\hline Probe ID & $\begin{array}{l}\text { Pearson's } \\
\text { correlation } \\
\text { coefficient }\end{array}$ & $\begin{array}{c}\text { p- } \\
\text { value }\end{array}$ \\
\hline $\operatorname{cg} 14962509$ & $.354^{*}$ & ,034 \\
\hline $\operatorname{cg} 13836098$ & $.392 *$ & ,018 \\
\hline cg00611789 & $.350^{*}$ & ,037 \\
\hline $\operatorname{cg} 13771313$ & $.436^{* *}$ & ,008 \\
\hline cg21811021 & $.330 *$ & ,049 \\
\hline cg03422911 & $.340^{*}$ & ,043 \\
\hline cg19153828 & $.353^{*}$ & ,035 \\
\hline cg09317554 & $.346 *$ & ,039 \\
\hline cg20597486 & $-.397^{*}$ & ,017 \\
\hline cg04154027 & $.406 *$ & ,014 \\
\hline cg04498198 & $.357^{*}$ & ,032 \\
\hline cg01463828 & $.360 *$ & ,031 \\
\hline cg13935577 & $.389 *$ & ,019 \\
\hline cg19022697 & $.409 *$ & ,013 \\
\hline cg25840926 & $.404^{*}$ & ,015 \\
\hline cg22962123 & $.349 *$ & ,037 \\
\hline cg05637536 & $.362 *$ & ,030 \\
\hline cg01331772 & $.335 *$ & ,046 \\
\hline cg23279355 & $.348^{*}$ & ,038 \\
\hline $\operatorname{cg} 13172549$ & $.400^{*}$ & ,016 \\
\hline cg02231404 & $.550 * *$ & ,001 \\
\hline cg00921266 & $.355^{*}$ & ,034 \\
\hline cg09490371 & $.349 *$ & ,037 \\
\hline $\operatorname{cg} 16127683$ & $.414^{*}$ & ,012 \\
\hline cg22385702 & $.330 *$ & ,049 \\
\hline cg24369989 & $.407 *$ & ,014 \\
\hline cg12024906 & $.517^{* *}$ & ,001 \\
\hline cg00303378 & $.359 *$ & ,031 \\
\hline cg20864214 & $.418^{*}$ & ,011 \\
\hline $\operatorname{cg} 05726109$ & $.335^{*}$ & ,046 \\
\hline cg07584855 & $.379 *$ & ,023 \\
\hline cg02798280 & $.394 *$ & ,018 \\
\hline cg24756378 & $.378^{*}$ & ,023 \\
\hline $\operatorname{cg} 12253175$ & $.350 *$ & ,037 \\
\hline cg09596958 & $.370 *$ & ,026 \\
\hline $\operatorname{cg} 02267270$ & $.373^{*}$ & ,025 \\
\hline cg01421119 & $.403 *$ & ,015 \\
\hline cg22090150 & $.404^{*}$ & ,015 \\
\hline cg05877788 & $.399 *$ & ,016 \\
\hline cg06396119 & $.422 *$ & ,010 \\
\hline cg14557699 & $.444^{* *}$ & ,007 \\
\hline cg07589899 & $.345 *$ & ,039 \\
\hline
\end{tabular}




\begin{tabular}{|l|c|c|}
\hline \multicolumn{1}{|c|}{ Probe ID } & $\begin{array}{c}\text { Pearson's } \\
\text { correlation } \\
\text { coefficient }\end{array}$ & $\begin{array}{c}\mathbf{p}- \\
\text { value }\end{array}$ \\
\hline $\operatorname{cg} 17179862$ & $.344^{*}$ &, 040 \\
\hline $\operatorname{cg} 14962509$ & $.354^{*}$ &, 034 \\
\hline $\operatorname{cg} 13836098$ & $.392^{*}$ &, 018 \\
\hline $\operatorname{cg} 00611789$ & $.350^{*}$ &, 037 \\
\hline $\operatorname{cg} 13771313$ & $.436^{* *}$ &, 008 \\
\hline $\operatorname{cg} 21811021$ & $.330^{*}$ &, 049 \\
\hline $\operatorname{cg} 03422911$ & $.340^{*}$ &, 043 \\
\hline $\operatorname{cg} 19153828$ & $.353^{*}$ &, 035 \\
\hline $\operatorname{cg} 09317554$ & $.346^{*}$ &, 039 \\
\hline $\operatorname{cg} 20597486$ & $-.397^{*}$ &, 017 \\
\hline
\end{tabular}


Supplemental Table S4. Gene Ontology enrichment analysis. Top-ranked categories obtained by using the InterPro Ontology set.

\begin{tabular}{|c|c|c|c|c|c|c|c|c|c|}
\hline Ontology & \# Term Name & $\begin{array}{l}\text { Hyper } \\
\text { Rank }\end{array}$ & $\begin{array}{c}\text { Hyper FDR } \\
\text { Q-Val }\end{array}$ & $\begin{array}{l}\text { Hyper Fold } \\
\text { Enrichment }\end{array}$ & $\begin{array}{l}\text { Hyper } \\
\text { Foreground } \\
\text { Region Hits }\end{array}$ & $\begin{array}{l}\text { Hyper } \\
\text { Total } \\
\text { Regions }\end{array}$ & $\begin{array}{c}\text { Hyper } \\
\text { Region Set } \\
\text { Coverage }\end{array}$ & \begin{tabular}{c|} 
Hyper \\
Foreground \\
Gene Hits
\end{tabular} & $\begin{array}{c}\text { Total } \\
\text { Genes } \\
\text { Annotated }\end{array}$ \\
\hline \multirow{11}{*}{ InterPro } & Homeodomain-like & 4 & $1.34044 \mathrm{e}-4$ & 3.6792 & 23 & 14059 & $19.49 \%$ & 21 & 327 \\
\hline & Homeobox domain & 5 & $2.95230 \mathrm{e}-4$ & 3.9476 & 20 & 11394 & $16.95 \%$ & 18 & 243 \\
\hline & $\begin{array}{l}\text { Homeobox, } \\
\text { conserved site }\end{array}$ & 3 & $3.24527 \mathrm{e}-5$ & 4.6678 & 20 & 9636 & $16.95 \%$ & 17 & 188 \\
\hline & $\begin{array}{l}\text { Homeodomain, } \\
\text { metazoa }\end{array}$ & 2 & $2.74152 e-5$ & 6.8887 & 15 & 4897 & $12.71 \%$ & 11 & 92 \\
\hline & B30.2/SPRY domain & 10 & $2.48293 \mathrm{e}-2$ & 10.5090 & 6 & 1284 & $5.08 \%$ & 3 & 91 \\
\hline & $\begin{array}{l}\text { SPla/RYanodine } \\
\text { receptor SPRY }\end{array}$ & 9 & $2.52847 \mathrm{e}-2$ & 10.6753 & 6 & 1264 & $5.08 \%$ & 3 & 89 \\
\hline & $\begin{array}{l}\text { Homeobox protein, } \\
\text { antennapedia type }\end{array}$ & 7 & $6.26551 \mathrm{e}-3$ & 21.0968 & 5 & 533 & $4.24 \%$ & 4 & 12 \\
\hline & $\begin{array}{l}\text { Homeobox protein, } \\
\text { antennapedia type, } \\
\text { conserved site }\end{array}$ & 1 & $1.01380 \mathrm{e}-8$ & 32.3586 & 10 & 695 & $8.47 \%$ & 6 & 20 \\
\hline & $\begin{array}{l}\text { Domain of unknown } \\
\text { function DUF4074 }\end{array}$ & 6 & $7.82430 \mathrm{e}-4$ & 65.6620 & 4 & 137 & $3.39 \%$ & 1 & 3 \\
\hline & Mab-21-like & 8 & $1.31348 \mathrm{e}-2$ & 71.7742 & 3 & 94 & $2.54 \%$ & 1 & 2 \\
\hline & HIN-200/IF120x & 11 & $2.55725 \mathrm{e}-2$ & 249.8804 & 2 & 18 & $1.69 \%$ & 1 & 4 \\
\hline
\end{tabular}

The table shows the top-ranked categories obtained by using the InterPro Ontology set. 
Supplemental Table S5. Bisulfite PCR primers.

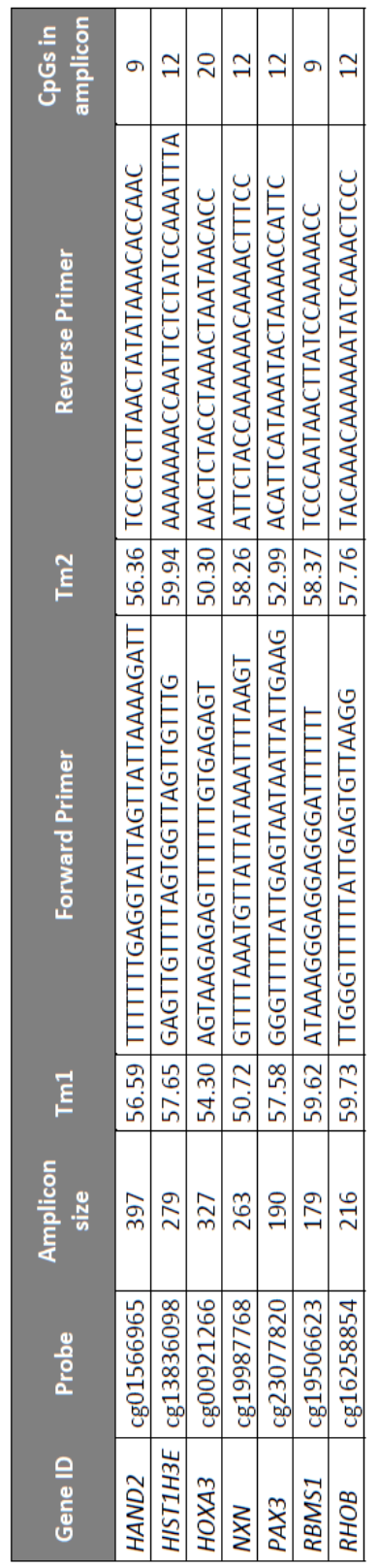

ID: identification; Tm1: Melting Temperature Forward Primer; Tm2: Melting Temperature Reverse Primer 


\section{Supplemental Figure S1}

A.
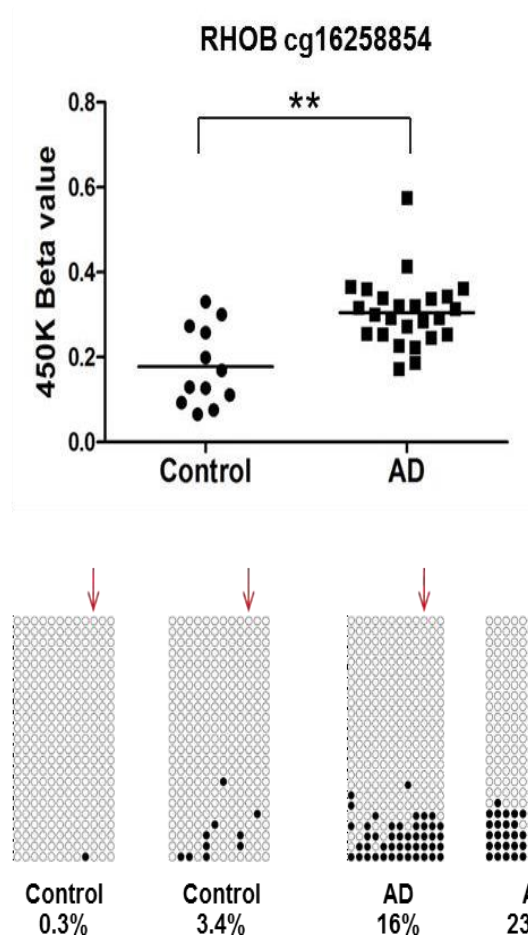

B.
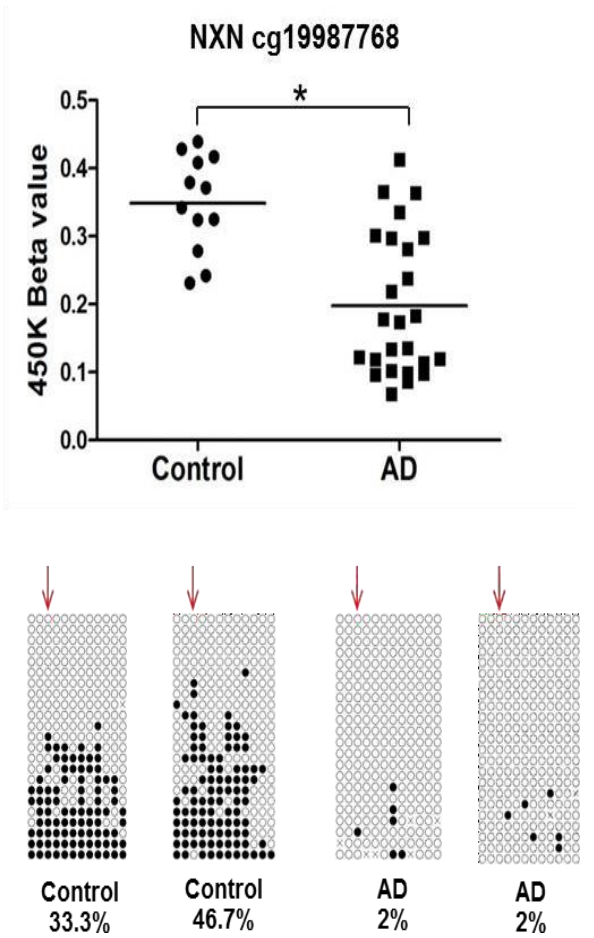

\section{Validation and extended mapping for the differentially methylated genes RHOB and}

$\boldsymbol{N X N}$. Bisulfite cloning sequencing shows that hypermethylation affects multiple contiguous CpGs within $R H O B$ gene $(\mathrm{A})$ and hypomethylation affects multiple contiguous CpGs within NXN gene (B). White boxes below each gene denote CpG islands and black boxes represent bisulfite cloning sequencing amplicons. Dot-plot graphs show the results of the $450 \mathrm{~K}$ array (beta values) for $\mathrm{CpG}$ probes. Validation results are represented by black/white circle-style figures. Each rectangle corresponds to one sample and shows the methylation pattern at a discrete genomic region surrounding the significant $\mathrm{CpG}$ probed by the $450 \mathrm{~K}$ array which is denoted by a red arrow. Black circles represent methylated cytosines while white circles denote unmethylated cytosines. Each column symbolizes a unique CpG site in the examined amplicon and each line represents an individual DNA clone. Average percentage of 
methylation for each analyzed sample (control or patient) at this particular amplicon is indicated at the bottom of each sample.

\section{Supplemental Figure S2}

\section{GO Biological Process}

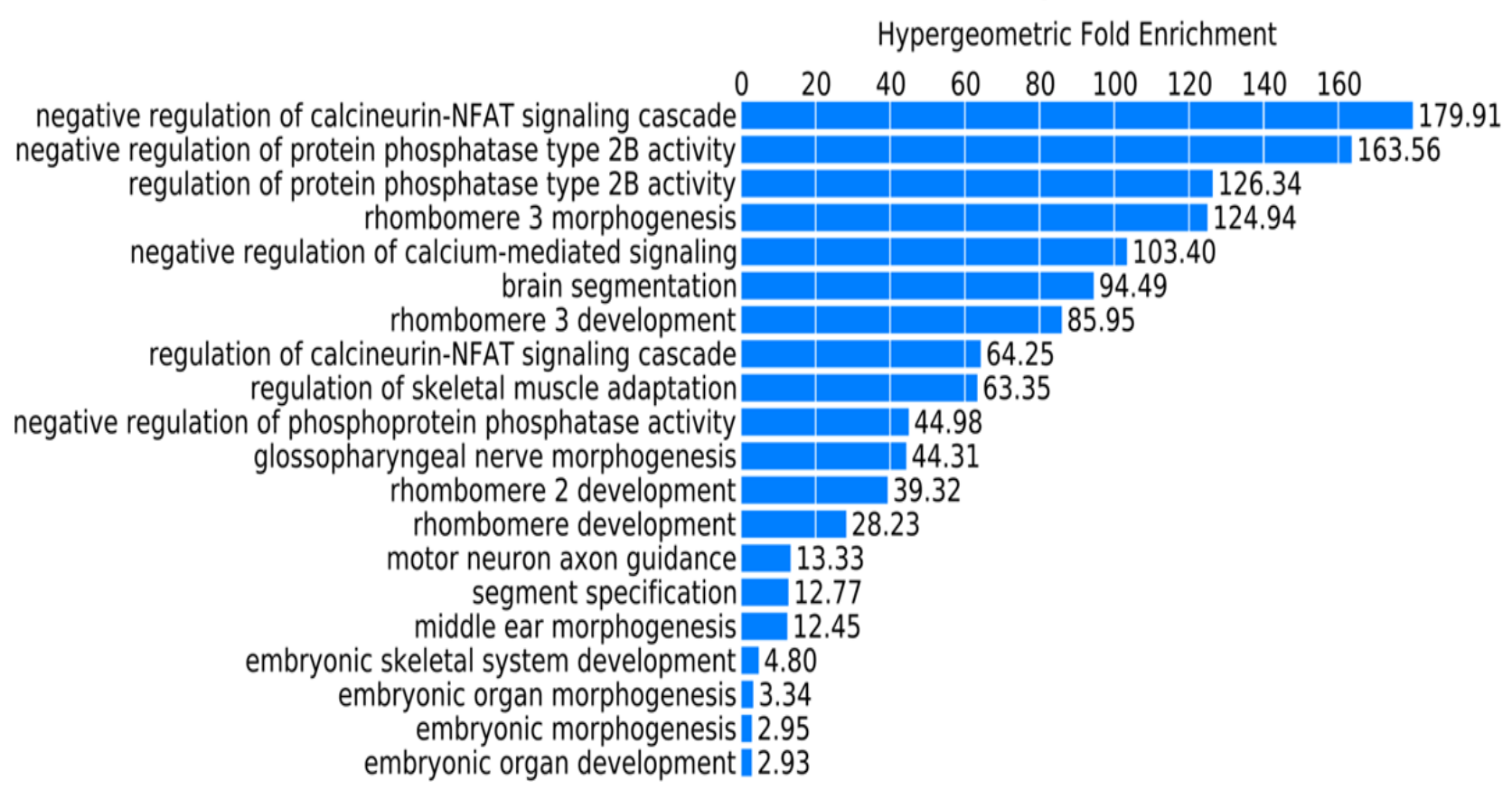

Functional in silico study of DMPs. The bar graph shows the results of the InterPro ontology analysis that revealed strong enrichment in processes consistently associated with embryonic and brain morphogenesis among others in our set of DMPs in the hippocampus of AD patients. 


\section{Supplemental Figure S3}

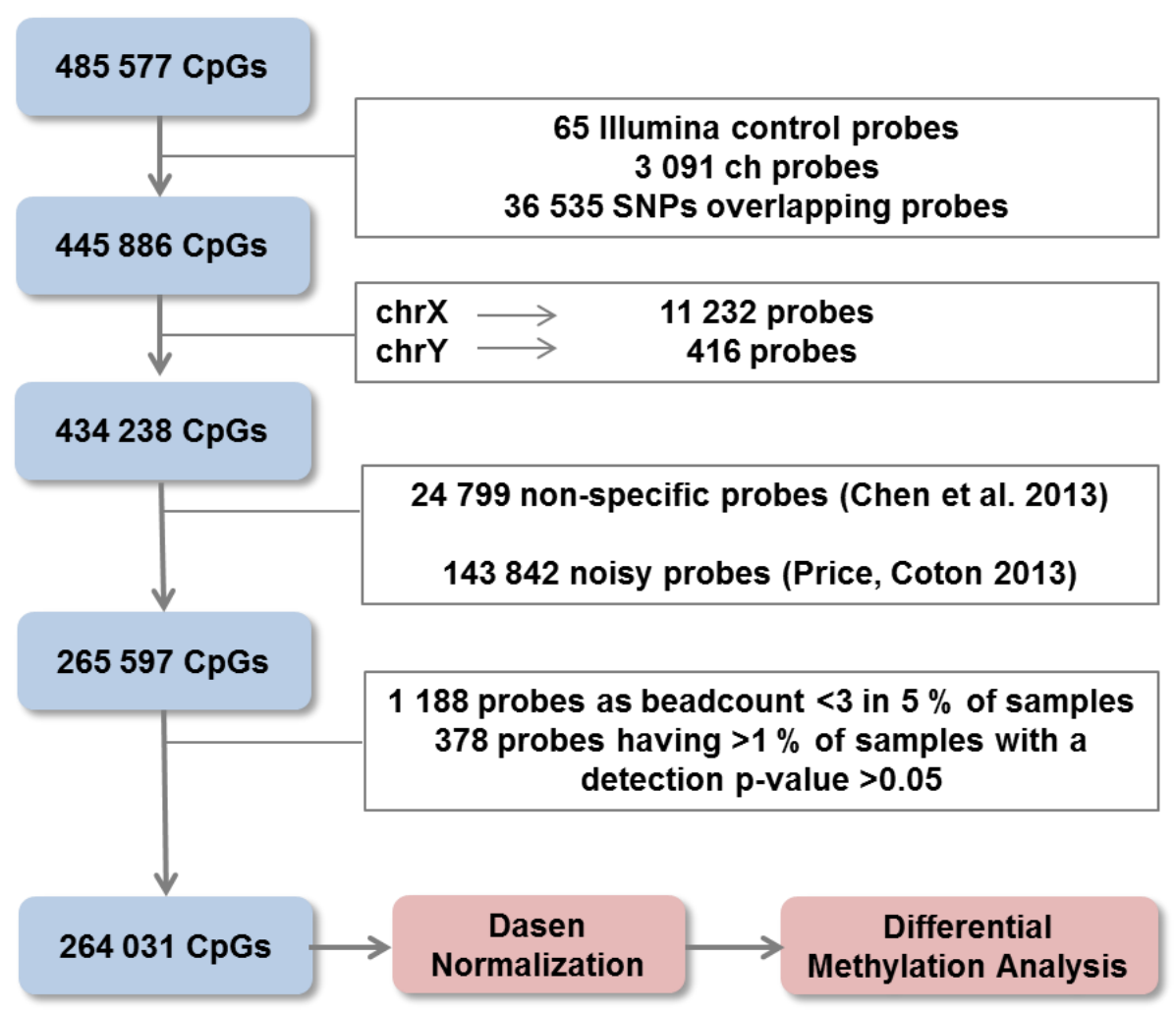

The diagram shows the bioinformatics pipeline used in this study: procedures for $450 \mathrm{~K}$ methylation data quality control and normalization analysis. 


\section{Supplemental Figure S4}
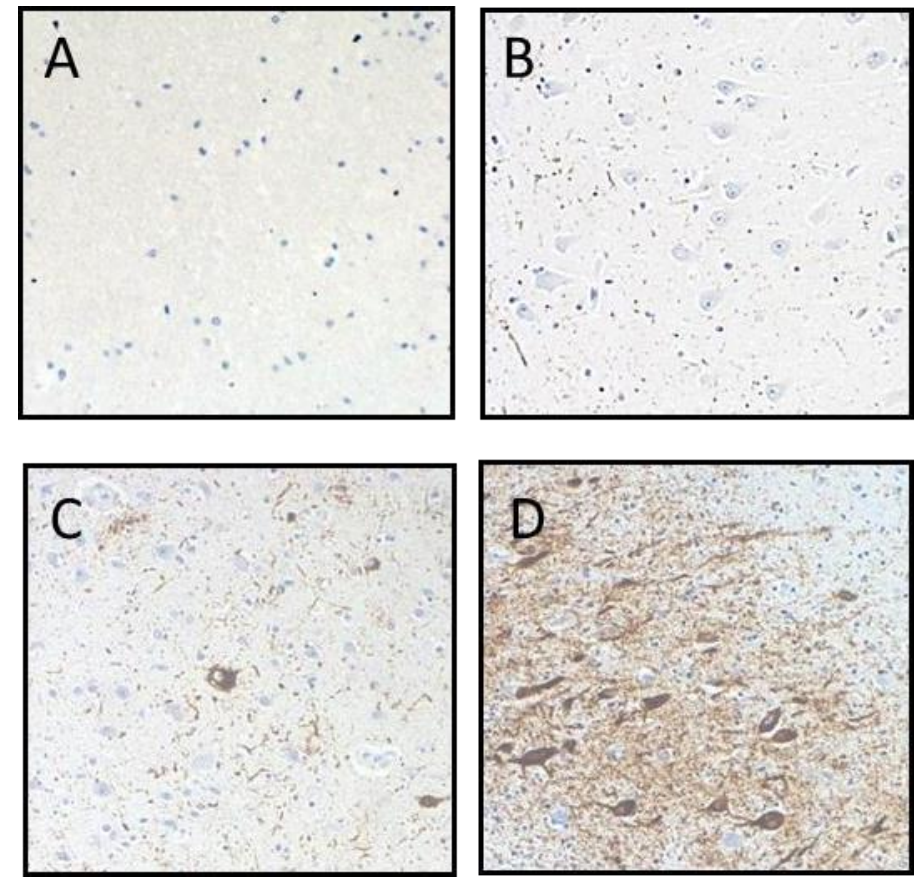

Representative examples of tau staining (AT8) for control and AD stages.

Pictures were obtained at $10 \mathrm{x}$ from cases showing different degree of protein tau deposit. A-D: AT-8 staining. Density degree of neurophil threads and tangles ( $A$, control; $B$, low; $C$, intermediate; $D$, high). 
Artículo

número 3

PLD3 epigenetic changes in the hippocampus of Alzheimer's disease. Blanco-Luquin I, Altuna M. et al. Clinical Epigenetics 11, 2018; 10: 116. Doi: 10.1186/s13148-018-0547-3. 


\subsection{PLD3 EPIGENETIC CHANGES IN THE HIPPOCAMPUS OF ALZHEIMER'S}

\section{DISEASE}

Idoia Blanco-Luquin, ${ }^{1}$ Miren Altuna, ${ }^{1,2}$ Javier Sánchez-Ruiz de Gordoa, ${ }^{1,2}$ Amaya UrdánozCasado, ${ }^{1}$ Miren Roldán, ${ }^{1}$ María Cámara, ${ }^{2}$ Victoria Zelaya, ${ }^{3}$ María Elena Erro, ${ }^{1,2}$ Carmen Echavarri, $^{1,4}$ and Maite Mendioroz ${ }^{1,2, *}$.

* Correspondence: maitemendilab@gmail.com; tmendioi@navarra.es

1 Neuroepigenetics Laboratory, Navarrabiomed, Public University of Navarra (UPNA), IdiSNA (Navarra Institute for Health Research), c/Irunlarrea 3, 31008 Pamplona, Spain,

${ }^{2}$ Department of Neurology, Complejo Hospitalario de Navarra, IdisNA (Navarra Institute for Health Research), Pamplona, Spain.

\section{Abstract}

Background: Whole-exome sequencing has revealed a rare missense variant in PLD3 gene (rs145999145) to be associated with late onset Alzheimer's disease (AD). Nevertheless, the association remains controversial and little is known about the role of PLD3 in AD. Interestingly, PLD3 encodes a phospholipase that may be involved in amyloid precursor protein (APP) processing. Our aim was to gain insight into the epigenetic mechanisms regulating PLD3 gene expression in the human hippocampus affected by $A D$.

Results: We assessed PLD3 mRNA expression by qPCR and protein levels by Western blot in frozen hippocampal samples from a cohort of neuropathologically confirmed pure $A D$ cases and controls. Next, we profiled DNA methylation at cytosine-phosphate-guanine dinucleotide $(\mathrm{CpG})$ site resolution by pyrosequencing and further validated results by bisulfite cloning sequencing in two promoter regions of the PLD3 gene. A 1.67-fold decrease in PLD3 mRNA levels ( $p$ value $<0.001$ ) was observed in the hippocampus of AD 
cases compared to controls, and a slight decrease was also found by Western blot at protein level. Moreover, PLD3 mRNA levels inversely correlated with the average area of $\beta$-amyloid burden (tau-b $=-0,331 ; p$ value $<0.01$ ) in the hippocampus. A differentially methylated region was identified within the alternative promoter of PLD3 gene showing higher DNA methylation levels in the AD hippocampus compared to controls $(21.7 \pm 4.7 \%$ vs. $18.3 \pm 4.8 \%$; $p$ value $<0.05)$.

Conclusions: PLD3 gene is downregulated in the human hippocampus in AD cases compared to controls. Altered epigenetic mechanisms, such as differential DNA methylation within an alternative promoter of PLD3 gene, may be involved in the pathological processes of AD. Moreover, PLD3 mRNA expression inversely correlates with hippocampal $\beta$-amyloid burden, which adds evidence to the hypothesis that PLD3 protein may contribute to AD development by modifying APP processing.

Keywords: PLD3, Alzheimer's disease, Epigenetics, DNA methylation, Gene and protein expression, Hippocampus, APP, Lysosome.

\section{Background}

Alzheimer's disease (AD) is a genetically complex process where $\varepsilon 4$ allele of the $A P O E$ gene (APOE4) is by far the best-established genetic susceptibility risk factor. In addition, genome-wide association studies have revealed a considerable number of small-effect common variants in genes related to AD (182-184).

However, those variants do not explain the full heritability of this disease. More recently, novel sequencing technologies are enabling the identification of other rare genetic variants that could potentially contribute to the development of sporadic AD. Notable recent discoveries in this area include rare disease variants in TREM2, UNC5C, AKAP9, TM2D3, ADAM10, and PLD3 genes $(183,185,186)$.

PLD3 (phospholipase D family, member 3) (OMIM * 615698) gene is located at chromosome 19q13.2 and encodes a lysosomal protein that belongs to the phospholipase 
D (PLD) superfamily, which catalyzes the hydrolysis of membrane phospholipids. However, PLD3 catalytic function has not yet been demonstrated $(187,188)$. PLD3 gene is highly expressed in the brain of healthy controls, particularly in several brain regions vulnerable to $A D$ pathology, such as frontal, temporal, and occipital cortices and hippocampus, but reduced in neurons from $A D$ brains $(47,184)$. Nevertheless, little is known on the regulation, the function, and the involvement of PLD3 in AD pathogenesis.

Interestingly, controversial association exists about this gene conferring increased risk for the development of AD. Cruchaga et al. performed whole-exome sequencing on $A D$ patients and identified a rare missense variant (rs145999145) in exon 7 of the PLD3 gene which resulted in a val232-to-met (V232M) substitution (47). Their results revealed that carriers of the PLD3 coding variant had a twofold increased risk for late onset AD. Moreover, they showed that PLD3 influences amyloid precursor protein (APP) processing, acting as a negative regulator, since PLD3 overexpression in cultured neuroblastoma cells correlated with lower intracellular APP, extracellular A 342 , and A 340 levels and that PLD3 protein could be co-immunoprecipitated with APP. In that regard, Satoh et al. showed an accumulation of PLD3 on neuritic plaques in AD brains and suggested a key role for PLD3 in the pathological processes of AD (189).

Other authors confirmed that PLD3 gene variant $\mathrm{V} 232 \mathrm{M}$ was associated with AD risk and significantly lower cognitive function (190) providing a systematic view of the involvement of PLD3 in AD at genetic, mRNA, and protein level expression. However, additional studies were not able to define an essential role of PLD3 rare variants in AD (191), neither to support an important contribution of PLD3 rare variants in the etiology of $A D$, given the high variability of the frequency of PLD3 Val232Met variant across populations (192). Indeed, follow-up studies have questioned the role of PLD3 rare variants in AD, obtaining negative replication data (193-195) and suggesting a more complex role of PLD3 in the etiology of the disease.

Keeping in mind the results mentioned above, we wanted to gain insight into the epigenetic mechanisms regulating PLD3 expression in order to add evidence to the potential contribution of PLD3 to AD. Further knowledge on these mechanisms may 
provide opportunities for new AD therapeutic strategies. Here, we profiled PLD3 gene expression and methylation in the human hippocampus, one of the most vulnerable brain regions to AD. To that end, we selected a cohort of neuropathologically defined "pure" AD cases and controls to measure hippocampal PLD3 expression by quantitative PCR and Western blot. Next, we explored the correlation of PLD3 expression with AD neuropathological changes. Finally, DNA methylation levels at two distinct promoter regions of the PLD3 gene were assessed by pyrosequencing and bisulfite cloning sequencing.

\section{Methods}

\section{Human hippocampal samples and neuropathological examination}

Brain hippocampal samples from $30 \mathrm{AD}$ patients and 12 controls were provided by Navarrabiomed Brain Bank. After death, half brain specimens from donors were cryopreserved at $-80^{\circ} \mathrm{C}$. Neuropathological examination was completed following the usual recommendations (171) and according to the updated National Institute on AgingAlzheimer's Association guidelines (172). Assessment of $\beta$-amyloid deposition was carried out by immunohistochemical staining of paraffin-embedded sections ( $3-5 \mu \mathrm{m}$ thick) with a mouse monoclonal (S6F/3D) anti $\beta$-amyloid antibody (Leica Biosystems Newcastle Ltd., Newcastle upon Tyne, UK). Evaluation of neurofibrillary pathology was performed with a mouse monoclonal antibody anti-human PHF-TAU, clone AT-8, (Tau AT8) (Innogenetics, Gent, Belgium), which identifies hyperphosphorylated tau (p-tau) (133). The reaction product was visualized using an automated slide immunostainer (Leica Bond Max) with Bond Polymer Refine Detection (Leica Biosystems, Newcastle Ltd.).

To avoid spurious findings related to multiprotein deposits, "pure" AD cases with deposits of only $p$-tau and $\beta$-amyloid were eligible for the study and controls were free of any pathological protein aggregate. This approach maximizes chances of finding true associations with $A D$, even though reducing the final sample size. A summary of characteristics of subjects included in this study is shown in Additional file 1: Table S1. 
AD subjects were older than controls ( $82.3 \pm 11.3$ versus $50.7 \pm 21.5 ; p$ value $<0.01)$, and no differences were found regarding gender ( $p$ value $=0.087$ ). The postmortem interval (PMI) were not significantly different between groups $(8.2 \pm 4.4 \mathrm{~h}$ in the control group versus $7.9 \pm 7.1 \mathrm{~h}$ in the $\mathrm{AD}$ group; $p$ value $=0.91$ )

\section{PLD3 mRNA expression analysis by RT-qPCR}

Total RNA was isolated from hippocampal homogenates using Rneasy Lipid Tissue Mini kit (QIAGEN, Redwood City, CA, USA), following the manufacturer's instructions. Genomic DNA was removed with recombinant Dnase (TURBO DNA-free ${ }^{\mathrm{TM}}$ Kit, Ambion, Inc., Austin, TX, USA). RNA integrity was checked by $1.25 \%$ agarose gel electrophoresis under denaturing conditions. Concentration and purity of RNA were both evaluated with NanoDrop spectrophotometer. Only RNA samples showing a minimum quality index $(260 \mathrm{~nm} / 280 \mathrm{~nm}$ absorbance ratios between 1.8 and 2.2 and $260 \mathrm{~nm} / 230 \mathrm{~nm}$ absorbance ratios higher than 1.8) were included in the study. Complementary DNA (cDNA) was reverse transcribed from 1500 ng total RNA with SuperScript ${ }^{\circledR}$ III First-Strand Synthesis Reverse Transcriptase (Invitrogen, Carlsbad, CA, USA) after priming with oligo-d (T) and random primers. RT-qPCR reactions were performed in triplicate with Power SYBR Green PCR Master Mix (Invitrogen, Carlsbad, CA, USA) in a QuantStudio 12K Flex Real-Time PCR System (Applied Biosystems, Foster City, CA, USA) and repeated twice within independent CDNA sets. Sequences of primer pair were designed using Real Time PCR tool (IDT, Coralville, IA, USA) and are listed in Additional file 1: Table S2. Relative expression level of PLD3 mRNA in a particular sample was calculated as previously described (196) and ACTB gene was used as the reference gene to normalize expression values.

\section{PLD3 protein expression analysis by Western blot}

Human hippocampus tissue from patients and control samples was lysed with $100 \mu \mathrm{L}$ lysis buffer containing urea, thiourea, and DTT. After centrifugation at $35.000 \mathrm{rpm}$ for $1 \mathrm{~h}$ at 
$15^{\circ} \mathrm{C}$, extracted proteins were quantified following the Bradford-Protein Assay (Bio-Rad, Hercules, CA, USA) by using a spectrophotometer.

Next, $5 \mu \mathrm{g}$ of protein per sample were resolved in $4-20 \%$ Criterion TGX stain-free gels (Bio-Rad) and electrophoretically transferred onto nitrocellulose membranes using a Trans-blot Turbo transfer system ( $25 \mathrm{~V}, 7 \mathrm{~min}$ ) (Bio-Rad). Equal loading of the gel was assessed by stain-free digitalization and by Ponceau staining. Membranes were probed with rabbit anti-human PLD3 primary antibody (Sigma-Aldrich; 1:250) in 5\% nonfat milk and incubated with peroxidase-conjugated anti-rabbit secondary antibody (Cell Signaling; 1:2000). Immunoblots were then visualized by exposure to an enhanced chemiluminescence Clarity Western ECL Substrate (Bio-Rad) using a ChemidocMP Imaging System (Bio-Rad). Expression levels of PLD3 were standardized by the corresponding band intensity of GAPDH (Calbiochem; 1:10000).

\section{Quantitative assessment of $\beta$-amyloid and $p$-tau deposits in hippocampal samples}

In order to quantitatively assess the $\beta$-amyloid and $p$-tau burden for further statistical analysis, we applied a method to quantify protein deposits, as described in detail elsewhere (128). In brief, hippocampal sections were examined after performing immunostaining with anti $\beta$-amyloid and anti $p$-tau antibodies. Focal deposit of $\beta$-amyloid, including neuritic, immature, and compact plaques (132), was analyzed with the ImageJ software. Moreover, $\beta$-amyloid plaque count, referred to as amyloid plaque score (APS), was measured. Finally, p-tau deposit was also analyzed with ImageJ software in order to obtain an average quantitative measure of the global p-tau deposit for each section.

\section{PLD3 methylation measurement by pyrosequencing}

Genomic DNA was isolated from frozen hippocampal tissue by phenol-chloroform method (197). Next, 500 ng of genomic DNA was bisulfite converted using the EpiTect Bisulfite Kit (Qiagen, Redwood City, CA, USA) according to the manufacturer's protocol. Primers to amplify and sequence two promoter regions of PLD3 were designed with PyroMark Assay Design version 2.0.1.15 (Qiagen) (Additional file 1: Table S2), and PCR 
reactions were carried out on a VeritiTM Thermal Cycler (Applied Biosystems, Foster City, CA, USA). Next, $20 \mu \mathrm{l}$ of biotinylated PCR product was immobilized using streptavidincoated sepharose beads (GE Healthcare Life Sciences, Piscataway, NJ, USA) and $0.3 \mu \mathrm{M}$ sequencing primer was annealed to purified DNA strands. Pyrosequencing was performed using the PyroMark Gold Q96 reagents (Qiagen) on a PyroMark ${ }^{\text {TM }}$ Q96 ID System (Qiagen). For each particular cytosine-phosphate-guanine dinucleotide ( $C p G)$, methylation levels were expressed as percentage of methylated cytosines over the sum of total cytosines. Unmethylated and methylated DNA samples (EpiTect PCR Control DNA Set, Qiagen) were used as controls for the pyrosequencing reaction.

\section{PLD3 methylation validations by bisulfite cloning sequencing}

Bisulfite-converted genomic DNA was used to validate pyrosequencing results. Primer pair sequences were designed by MethPrimer (179) and are listed in Additional file 1: Table S2. PCR products were cloned using the TopoTA Cloning System (Invitrogen, Carlsbad, CA, USA), and a minimum of 10-12 independent clones were sequenced for each examined subject and region. Methylation graphs were obtained with QUMA software (181).

\section{Statistical data analysis}

Statistical analysis was performed with SPSS 21.0 (IBM, Inc., USA). Before performing differential analysis, we checked that all continuous variables showed a normal distribution, as per one-sample Kolgomorov-Smirnov test and the normal quantil-quantil (QQ) plots. Data represents the mean \pm standard deviation (SD). Significance level was set at $p$ value $<0.05$. Statistical significance for PLD3 mRNA levels and pyrosequecing intergroup differences was assessed by $T$ test. One-way analysis of variance (ANOVA) followed by Games-Howell post hoc analysis was used to analyze differences in the expression levels of PLD3 mRNA between Braak and Braak stage groups. A logistic regression model (ENTER method) was fit to assess the independent association of PLD3 
mRNA levels with $A D$ status, using gender and age as covariates. Kendall's tau-b correlation coefficient was used to determine correlation between AD-related pathology and PLD3 mRNA expression levels. Difference between two bisulfite cloning sequencing groups was evaluated with Mann-Whitney $U$ test. GraphPad Prism version 6.00 for Windows (GraphPad Software, La Jolla, CA, USA) was used to draw graphs except for methylation figures that were obtained by QUMA software.

\section{$\underline{\text { Results }}$}

\section{PLD3 expression is downregulated in Alzheimer's disease hippocampus}

As the first step in this study, we measured PLD3 mRNA expression levels by real-time quantitative PCR (RT-qPCR) in the hippocampus of AD patients compared to controls. Five samples did not pass the RNA quality threshold (see the "Methods" section) and so were not included in the experiments. Eventually, 26 AD cases were compared to 11 controls. As shown in Fig. 1a, PLD3 mRNA levels were significantly decreased by 1.67-fold in the hippocampus of AD cases compared to controls [ $p$ value $<0.001$ ]. Next, a disease-staging analysis was performed to investigate changes of PLD3 mRNA levels depending on the AD severity measured by Braak \& Braak staging (132). We found that PLD3 mRNA levels were significantly reduced across Braak \& Braak stages [ $p$ value < 0.005; Fig. 1b]. Games-Howell post hoc analysis revealed that PLD3 mRNA expression was significantly different between control and Braak stages III-IV [ $p$ value $<0.05$ ] and between control and Braak stages V-VI [ $p$ value $<0.05]$ (Fig. 1). 
A

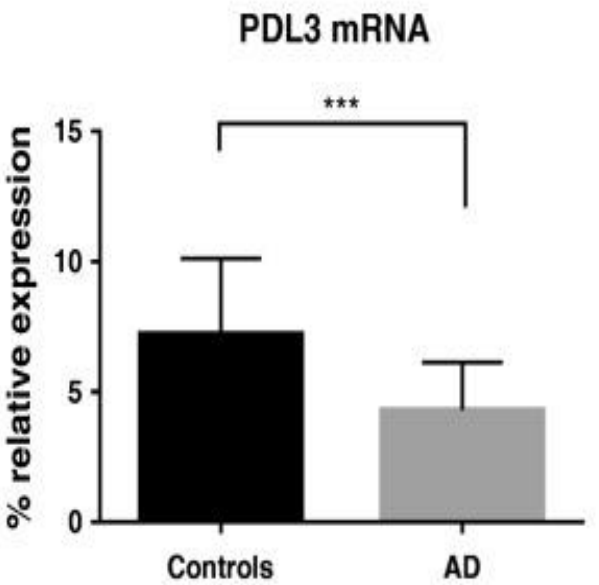

C

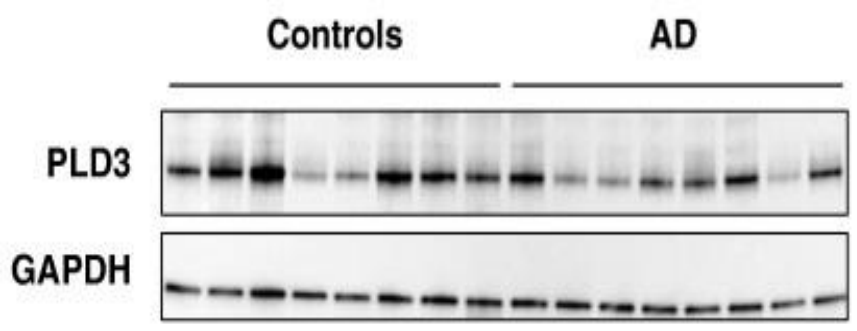

B

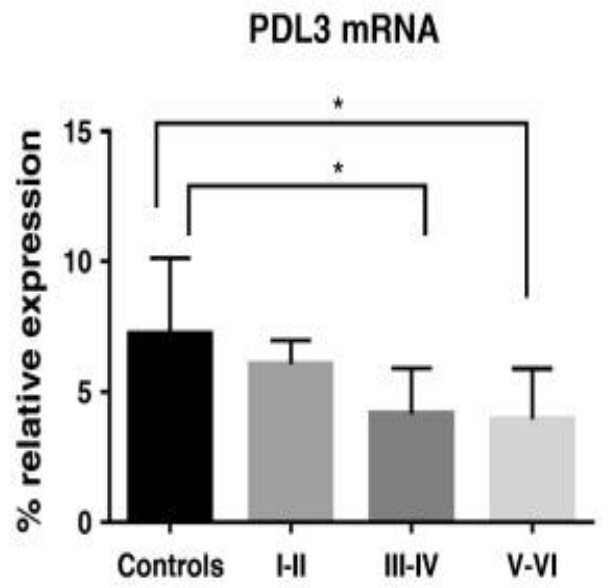

PLD3 protein (WB)

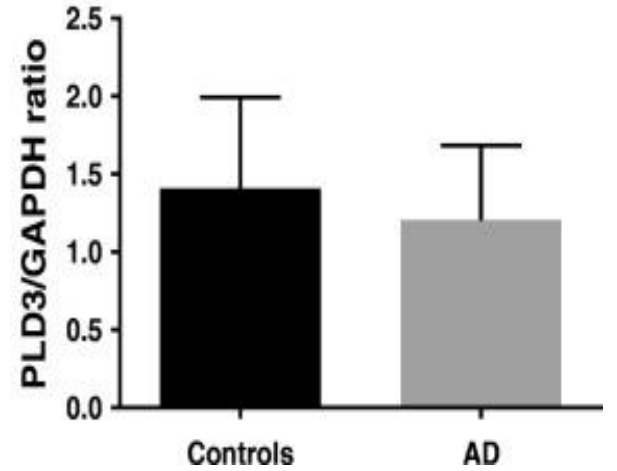

Fig 1. PLD3 expression is decreased in human hippocampus in Alzheimer's disease (AD). A. The graph shows a significant 1.67-fold decrease in PLD3 mRNA levels in AD hippocampal samples compared to control hippocampal samples. $\underline{B}$. PLD3 mRNA expression decreased across AD stages, as shown when PLD3 mRNA expression levels are sorted by Braak and Braak stages. Bars represent percentage of PLD3 mRNA expression relative to ACTB housekeeping gene expression. Vertical lines represent the standard error of the mean. ${ }^{*} p$ value $<0.05 ;{ }^{* * *} p$ value $<0.001$. $c$. Western blot analysis of PLD3 shows a mild protein expression decrease in AD. Human hippocampus samples from controls or $A D$ patients were loaded as labeled on top of lanes. GADPH expression is shown as reference control. The bar chart represents the quantitative measurement of the PLD3 protein relative to GADPH expression. 
Then, to identify adjusted estimates of the association of PLD3 mRNA levels with AD status (control = $0 ; A D=1$ ), a logistic regression model was designed. Age and gender were included into the model to adjust for potentially confounding variables. As shown in Table 1, PLD3 mRNA expression levels remained as an independent predictor of AD status after adjusting for age and gender [ $p$ value $<0.05]$ (Table 1 ).

\begin{tabular}{|l|l|l|l|l|}
\hline Variable & B & Wald & $\boldsymbol{p}$ value & OR \\
\hline PLD3 mRNA levels & -0.544 & 4.212 & $0.040^{*}$ & 0.581 \\
\hline Gender (female) & 0.613 & 0.286 & 0.593 & 1.847 \\
\hline Age $<65$ years old & 2.774 & 5.981 & $0.014^{*}$ & 16.02 \\
\hline Constant & -1.494 & 0.254 & 0.614 & 0.224 \\
\hline
\end{tabular}

Table 1. Adjusted logistic regression model to predict AD status.

Alzheimer status (control $=0, A D=1$ ) was considered as the dependent variable and PLD3 mRNA expression levels, gender, and age were included as covariants.

$B$ regression coefficient, $O R$ odds ratio.

${ }^{*} p$ value $<0.05$

In order to examine whether the decrease in PLD3 mRNA levels in the AD hippocampus extended to the protein level, a Western blot analysis was performed. Protein extracts from frozen hippocampal samples that were included in the qPCR experiment were obtained, and a polyclonal antibody against a recombinant protein epitope signature tag (PrEST) of PLD3 was used. GAPDH protein detection was used as housekeeping. In line with the PLD3 mRNA expression results, we observed that PLD3 protein expression tends to be decreased in samples from hippocampus of $A D$ patients as compared to controls (Fig. 1c). 


\section{Correlation of PLD3 mRNA expression levels with p-tau and amyloid deposits}

Next, we aimed to correlate PLD3 mRNA levels with AD-related neuropathological changes in hippocampal sections. In brief, $\beta$-amyloid and hyperphosphorylated tau ( $p$ tau) burden were measured and averaged for each subject by a semi-automated quantitative method by using the ImageJ software (see the "Methods" section). The amyloid plaque score (APS) was also recorded. As $\beta$-amyloid and $p$-tau data were not normally distributed, the non-parametric Kendall's tau-b correlation coefficient was used. We found that the average area of $\beta$-amyloid burden in the hippocampus was inversely correlated with PLD3 mRNA levels [tau- $b=-0,331 ; p$ value $<0.01$ ], and accordingly, an inverse association was found between APS and PLD3 mRNA levels [tau-b $=-0,319 ; p$ value $<0.01]$. Regarding $p$-tau deposits, a statistically significant correlation was found for an inverse correlation [tau- $\mathrm{b}=-0,306 ; p$ value $<0.01$.

\section{DNA methylation in PLD3 is increased in hippocampus of AD cases compared to controls}

DNA methylation levels of regulatory regions in the genome modulate the expression of related or nearby genes. Thus, we tested whether DNA methylation levels in PLD3 gene were also altered in the AD hippocampus. PLD3 gene is located in the long arm of chromosome 19 (19q13.2) and has two distinct CpG island-containing promoter regions as shown by the UCSC Genome Browser website (137) (Fig. 2a). The principal promoter, which is placed at the $5^{\prime}$ end of the gene, contains a 553 bp CpG island (chr19:4085418140854733; GRCh37/hg19) while an alternative promoter overlapping exon 2 contains a smaller 207 bp CpG island (chr19:40871618-40871824; GRCh37/hg19). Pyrosequencing primers were designed to amplify and sequence specific CpGs within both promoters regions (P_prom CpG1 and CpG2 for the principal promoter and A_prom CpG1 and CpG2 for the alternative promoter) (Fig. 2a).

We observed that the principal promoter of PLD3 was mostly demethylated [mean \pm SD, $1.8 \pm 2.9 \%]$, as it corresponds to the constitutive promoter of an actively expressed gene. 
Average DNA methylation levels were slightly higher in AD cases compared to controls only for P_prom CpG2 [2.6 $\pm 3.13 \%$ vs. $0 \pm 0 \% ; p$ value $<0.001]$. The alternative promoter showed intermediate levels of DNA methylation [20.5 $\pm 4.91 \%]$. A_prom CpG1 showed a statistical trend to be highly methylated in $A D$ cases compared to controls [ $23 \pm 7.8 \%$ vs. $18.4 \pm 6.2 \% ; p$ value $=0.09$ ] and a statistically significant difference in DNA methylation levels was observed for A_prom CpG2 in AD cases compared to controls [ $21.5 \pm 5.8 \%$ vs. $15.3 \pm 3.8 \% ; p$ value $<0.01]$

Next, we sought to replicate pyrosequencing results by extending the initial cohort with additional $A D$ and control hippocampal samples for which DNA was available. These samples came from Navarrabiomed Brain Bank and were used to increase the sample size for the methylation experiments. Eventually, $36 \mathrm{AD}$ patients and 18 controls were analyzed by pyrosequencing. In the principal promoter, average DNA methylation levels showed a trend to be higher in $A D$ cases compared to controls at $P \_p r o m ~ C p G 2[2.3 \pm 2 \%$ vs. $1 \pm 2.4 \% p$ value $=0.094]$. In the alternative promoter, no differences were found for A_prom CpG1 between AD cases and controls [ $p$ value $>0.05]$. However, we observed a statistically significant difference in DNA methylation levels for A_prom CpG2 between $A D$ cases and controls $[21.7 \pm 4.7 \%$ vs. $18.3 \pm 4.8 \%$; $p$ value $<0.05]$, pointing to a differentially methylated region located within the alternative promoter of PLD3 in the AD hippocampus (Fig. 2b). In order to test whether A_prom CpG2 methylation was an independent predictor of $A D$ status (control $=0 ; A D=1$ ), a binary logistic regression model was performed. After adjusting for age and gender, A_prom CpG2 methylation levels remain as an independent predictor of $A D$ (Additional file 1: Table S3).

We validated the pyrosequencing results and extended the methylation local mapping by using bisulfite cloning sequencing in two independent amplicons overlapping both PLD3 promoter regions. DNA methylation percentage was measured at $\mathrm{CpG}$ site resolution and further averaged across all the CPG sites for each amplicon. In line with the previous pyrosequencing results, we found that average DNA methylation levels of the amplicon at PLD3 principal promoter were very low and showed no differences between AD patients and controls (Fig. 2c). On the contrary, average DNA methylation levels of the 
amplicon at PLD3 alternative promoter were increased in AD patients compared to controls [19.1 $\pm 7.8 \%$ vs. $6 \pm 4 \% ; p$ value $<0.05]$ (Fig. 2 c)

Since DNA methylation is one of the major mechanisms to regulate gene expression, we analyzed the correlation between PLD3 mRNA expression and PLD3 DNA methylation in our sample set. No significant correlation was found between expression and DNA methylation measured by pyrosequencing [A_prom CpG1 $r=-0.264, p$ value $=0.114$; A_prom CpG2 $r=-0.275, p$ value $=0.110]$. However, a significant inverse correlation was observed between expression and DNA methylation in the PLD3 alternative promoter measured by bisulfite cloning sequencing $[r=-0.683 ; p$ value $<0.05]$.

Fig.2. (Next Page) PLD3 DNA methylation levels in human hippocampal samples. A. $^{\text {The }}$ graph shows genomic position of the amplicons (black boxes) validated by bisulfite cloning sequencing which contain the cytosines assayed by pyrosequencing (CpG1 and CpG2) within the promoter regions (principal and alternative) of the PLD3 gene. PLD3 is located on the long arm of chromosome 19 (chr19:40,854,332-40,884,390 -GRchr19/hg19 coordinates). CpG islands are represented by isolated green boxes. At the bottom of the graph, predicted functional elements are shown for each of nine human cell lines explored by chromatine immunoprecipitation (ChIP) combined with massively parallel DNA sequencing. Boxes represent promoter regions (red), enhancers (yellow), transcriptional transition and elongation (dark green), and weak transcribed regions (light green). The track was obtained from the Chromatin State Segmentation by HMM from ENCODE/Broad track shown at the UCSC Genome Browser. B. Dot-plot charts representing methylation levels for principal and alternative promoter of PLD3 by pyrosequencing. Horizontal lines represent median methylation values for each group. ${ }^{*} p$ value $<0.05$. $\underline{C_{.}}$Representative examples of bisulfite cloning sequencing validation for the two independent amplicons (principal and alternative promoter regions). Black and white circles denote methylated and unmethylated cytosines respectively. Each column symbolizes a unique $\mathrm{CpG}$ site in the examined amplicon, and each line represents an individual DNA clone. 
A

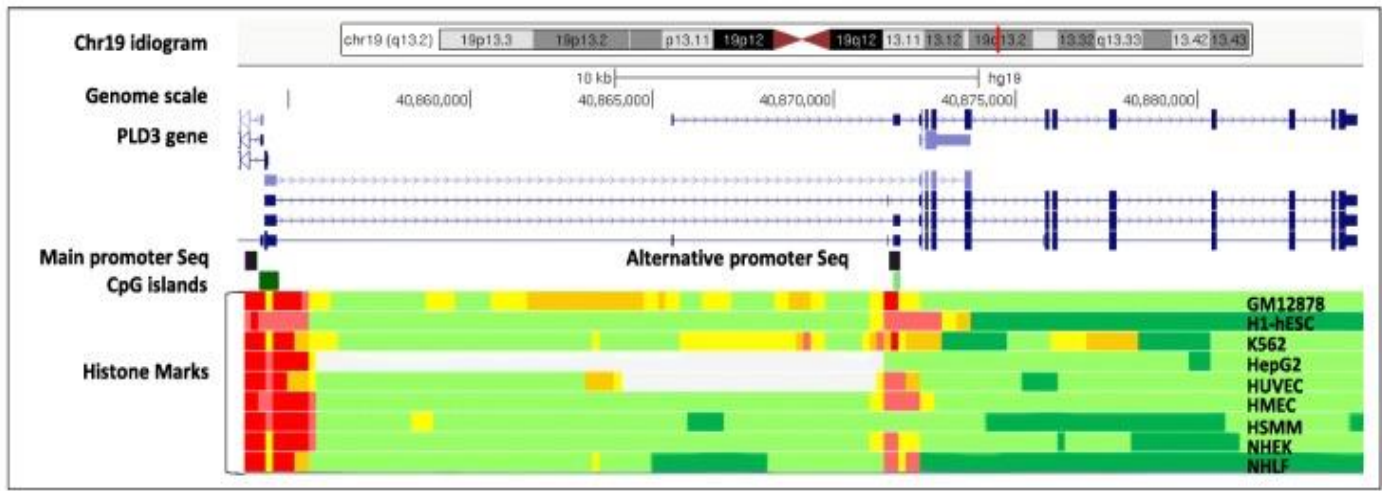

B

Principal Promoter CpG2

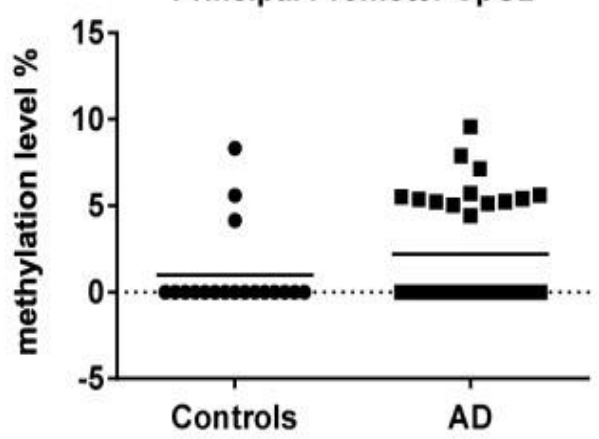

Alternative Promoter $\mathrm{CpG} 2$

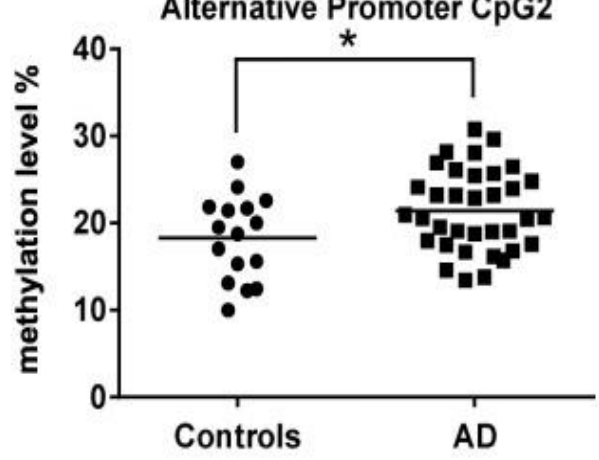

C

PLD3 Principal Promoter

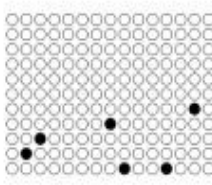

Control

$3.6 \%$

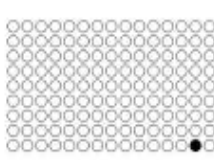

AD

$0.7 \%$

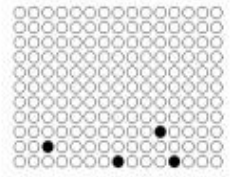

Control

$2.4 \%$

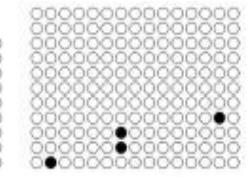

$A D$

$2.4 \%$

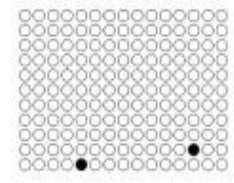

Control

$1.2 \%$

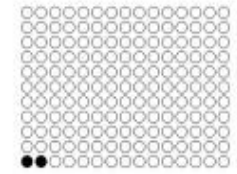

AD

$1.2 \%$
PLD3 Alternative Promoter

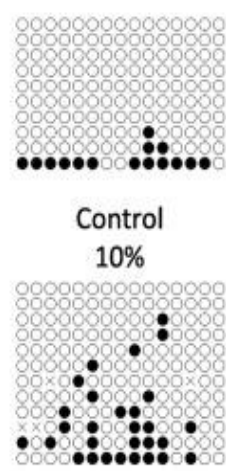

AD

$16.5 \%$

AD

$21.4 \%$

$\mathrm{AD}$

$27.8 \%$ 


\section{Discussion}

We report PLD3 gene to be downregulated at both transcript and protein level in the human hippocampus affected by AD. In addition, we show that the decrease in PLD3 mRNA expression inversely correlates with $\beta$-amyloid burden in the hippocampus. An important finding of this study is that an alternative promoter of PLD3 gene is differentially methylated in the hippocampus of $A D$ patients compared to controls suggesting that epigenetic disturbances in PLD3 may occur in the pathological process of AD.

Our results showing a reduction in PLD3 expression in the AD hippocampus add to previous evidence supporting the idea that PLD3 gene is downregulated in brain areas affected by $A D$ processes $(47,189)$. Cruchaga et al. $(47)$ used data from genome-wide transcriptomics in laser-captured neurons from 33 AD cases and 16 controls (GEO dataset GSE5281) (198) to reveal that PLD3 gene expression was significantly lower in AD cases compared to controls. In addition, Satoh et al. found a marginal reduction in PLD3 mRNA levels in the frontal cortex of $7 \mathrm{AD}$ cases compared to 14 non-AD subjects, including other neurodegenerative disorders such as amyotrophic lateral sclerosis and Parkinson disease (189). In agreement with the previous results, we observed a statistically significant decrease in PLD3 mRNA expression in the hippocampus, a vulnerable region to AD pathology, and also show that PLD3 is reduced across Braak \& Braak stages indicating that $P L D 3$ is somehow related to the progressive neurodegenerative processes of AD.

A number of different mechanisms could explain the decrease in PLD3 gene expression in the AD hippocampus, including the progressive loss of neuronal populations, changes in cellular composition with increasing astrogliosis in late stages of $A D$, or cell-type-specific decrease in PLD3 gene expression. A limitation of the present study is that it has been designed on a tissue-specific basis, and therefore, changes in gene expression at cellspecific level, including neuron-specific level, cannot be assessed. In fact, the ratio of cellular components in the human hippocampus may change across different stages of 
AD. In this case, and if the expression of PLD3 were cell type specific, the gene expression changes observed globally in the hippocampus could be attributed to the loss of a given cell population and not reflect actual PLD3 expression changes. However, the fact of having found epigenetic modifications in the same sample set would support the existence of a true alteration in the regulation of PLD3 gene expression. To know whether the difference in PLD3 gene expression is driven by a decreased expression in neurons or by changes in the ratio of cell populations in the brain of AD patients, other technologies, such as the emerging single-cell techniques, should be used.

The reduction in PLD3 expression is in line with the classical $\beta$-amyloid cascade hypothesis of AD, since PLD3 protein seems to act as a negative regulator of APP processing (47). It has been shown that knockdown of PLD3 expression in cells results in higher levels of extracellular $A \beta 42$ and $A \beta 40$ levels, and conversely, overexpression of PLD3 is associated with reduced extracellular $A \beta 42$ and $A \beta 40$ levels (47). Furthermore, PLD3 protein is accumulated in neuritic plaques in human AD brains (189). Indeed, it has been demonstrated that PLD3 protein can be co-immunoprecipitated with APP in cultured cells (47). Even more, PLD3 protein has been recently characterized as a novel endosome-toGolgi retrieval gene that regulates the endosomal protein sorting, whose loss of function results in increased processing of APP (199). Accordingly, we have found an inverse correlation between PLD3 mRNA expression levels and the burden of hippocampal $\beta$ amyloid assessed by two measurements, averaged deposit of $\beta$-amyloid and amyloid plaque score (APS). All these data supports the notion that PLD3 protein could display a protective effect against AD pathology through its role in APP trafficking, as other authors have previously suggested (199).

Interestingly, PLD3 protein is co-expressed with other lysosomal proteins (189), including progranulin, which regulates lysosomal functioning and is also accumulated in neuritic plaques $(189,200)$. Moreover, PLD3 protein is required to preserve the structure of lysosomes in vivo and, therefore, impairment of the endosomal-lysosomal systems has been proposed as an alternative mechanism by which PLD3 could contribute to the development of AD (201). Most Interestingly, another genetic variant in PLD3, 
p.Leu308Pro, was recently found to cause autosomal dominant spinocerebellar ataxia (202), a neurodegenerative condition where lysosomal disturbances are thought to be crucial $(203,204)$. As an additional alternative explanation, PLD3 might also influence AD pathological processes by altering adult neurogenesis since PLD3 gene expression seems to be turned on at late stages of neurogenesis (205).

Finally, we describe an altered pattern of DNA methylation within an alternative promoter of the PLD3 gene in the human hippocampus affected by AD. To our knowledge, no previous reports on altered DNA methylation in PLD3 gene have been published and very little is known about regulation of PLD3 gene expression. The alternative promoter of PLD3 is placed $\sim 17,500$ bp downstream the principal promoter overlapping exon 2 . It contains a small CpG island and is conserved across several cell types (Fig. 2a). In our study, it was found to be differentially methylated showing higher DNA methylation levels in $A D$ patients than in controls. Since DNA methylation of $C p G$ islands is one of the major epigenetic mechanisms that influence gene expression, our results indicate that altered DNA methylation at this particular regulatory region might contribute to downregulate PLD3 expression in AD.

In this regard, we also show a significant correlation between PLD3 mRNA expression and DNA methylation in our dataset when measured by bisulfite cloning sequencing, while the pyrosequencing results did not show correlation with expression. It is intriguing why the significant correlation is found only for the bisulfite cloning sequencing results. First of all, although not significant, an inverse correlation appears in the statistical analysis for the pyrosequencing results. However, it is only a statistical trend. One possible explanation would be that DNA methylation levels measured by bisulfite cloning sequencing average the methylation levels of an extended genomic region (15 CpGs), and therefore, this result may be more close to the real functional effect of methylation on gene expression than the result of individual CpGs.

Epigenetic disturbances are increasingly being described for a number of genes related to $A D$, including genes harboring rare variants that contribute to developing $A D$ (77$81,128,130)$. In this sense, our work provides new knowledge about the epigenetic 
alterations involved in gene transcription regulation in key brain regions for the development of AD. Additionally, our results support the involvement of PLD3 in the pathology of AD.

\section{Conclusions}

To sum up, this study confirms that PLD3 gene is downregulated in the hippocampus of AD patients. Moreover, PLD3 expression inversely correlates with $\beta$-amyloid burden, which adds evidence to the hypothesis that PLD3 protein may contribute to AD development through modifying APP processing. Having identified a differentially methylated region in an alternative promoter of $P L D 3$, our study suggests that epigenetic disturbances in PLD3 gene may be involved in the pathological processes of AD. 


\section{Additional File 1}

Supplemental Table S1. Brain sample set analyzed in our study.

\begin{tabular}{|c|c|c|c|c|c|c|c|}
\hline No. & Diagnosis & $\begin{array}{l}\text { Braak } \\
\text { stage }\end{array}$ & APS & $\begin{array}{l}\text { Age at } \\
\text { death } \\
\text { (years) }\end{array}$ & Gender & PMI (h) & Cohort type \\
\hline 1 & Control & 0 & NA & 61 & male & 8 & original \\
\hline 2 & Control & 0 & NA & 81 & male & 10,5 & original \\
\hline 3 & Control & 0 & NA & 43 & female & 3 & original \\
\hline 4 & Control & 0 & NA & 88 & male & 9 & original \\
\hline 5 & Control & 0 & NA & 53 & male & 7 & original \\
\hline 6 & Control & 0 & NA & 41 & male & 3,5 & original \\
\hline 7 & Control & 0 & NA & 28 & male & 6 & original \\
\hline 8 & Control & 0 & NA & 46 & female & 7 & original \\
\hline 9 & Control & 0 & NA & 69 & male & 12 & original \\
\hline 10 & Control & 0 & NA & 19 & female & NA & original \\
\hline 11 & Control & 0 & NA & 26 & male & 6,2 & original \\
\hline 12 & Control & 0 & NA & 54 & male & 18 & original \\
\hline 13 & Control & 0 & NA & 54 & male & 2,7 & additional \\
\hline 14 & Control & 0 & NA & 66 & male & 6,5 & additional \\
\hline 15 & Control & 0 & NA & 88 & female & 3,5 & additional \\
\hline 16 & Control & 0 & NA & 76 & female & 11,5 & additional \\
\hline 17 & Control & 0 & NA & 65 & male & 3 & additional \\
\hline 18 & Control & 0 & NA & 69 & female & 15 & additional \\
\hline 19 & $A D$ & 1 & 0,00 & 60 & male & 15,3 & original \\
\hline 20 & $A D$ & 1 & 2,00 & 85 & male & 3,2 & original \\
\hline 21 & $A D$ & 1 & NA & 85 & female & 2 & additional \\
\hline 22 & $A D$ & 1 & NA & 80 & male & 3 & additional \\
\hline 23 & $A D$ & II & 0,00 & 66 & female & 1,4 & original \\
\hline 24 & $A D$ & II & NA & 80 & female & 3,7 & additional \\
\hline 25 & $A D$ & II & NA & 71 & female & 4 & additional \\
\hline 26 & $A D$ & II & NA & 71 & male & 11,5 & additional \\
\hline 27 & $A D$ & II & NA & 74 & male & 2,5 & additional \\
\hline 28 & $A D$ & III & 0 & 85 & female & 4,3 & original \\
\hline 29 & $A D$ & III & 0,00 & 88 & female & 33 & original \\
\hline 30 & $A D$ & III & 3,00 & 96 & female & 1,5 & original \\
\hline 31 & $A D$ & III & 0,33 & 79 & female & 13 & original \\
\hline 32 & $A D$ & III & 2,33 & 84 & female & 13 & original \\
\hline 33 & $A D$ & III & 2,00 & 98 & female & 23 & original \\
\hline 34 & $A D$ & III & 2,67 & 85 & female & NA & original \\
\hline
\end{tabular}




\begin{tabular}{|c|c|c|c|c|c|c|c|}
\hline No. & Diagnosis & $\begin{array}{l}\text { Braak } \\
\text { stage }\end{array}$ & APS & $\begin{array}{c}\text { Age at } \\
\text { death } \\
\text { (years) }\end{array}$ & Gender & PMI (h) & Cohort type \\
\hline 35 & $A D$ & III & 3,67 & 83 & male & 9 & original \\
\hline 36 & $A D$ & III & 6,67 & 69 & female & 4,3 & original \\
\hline 37 & $A D$ & III-IV & 1,00 & 81 & female & 9 & original \\
\hline 38 & $A D$ & III-IV & 6,67 & 98 & female & 3 & original \\
\hline 39 & $A D$ & IV & 5,00 & 88 & male & 3,5 & original \\
\hline 40 & $A D$ & IV & 2,33 & 91 & female & 10 & original \\
\hline 41 & $A D$ & IV & 1,33 & 84 & male & 3,3 & original \\
\hline 42 & $A D$ & IV & 3,00 & 97 & female & NA & original \\
\hline 43 & $A D$ & IV & 1,33 & 78 & male & 5 & original \\
\hline 44 & $A D$ & IV & 1,33 & 90 & female & 3 & original \\
\hline 45 & $A D$ & $\mathrm{~V}$ & 3,00 & 92 & female & 14 & original \\
\hline 46 & $A D$ & $\mathrm{~V}$ & 4,00 & 77 & female & 11 & original \\
\hline 47 & $A D$ & $\mathrm{~V}$ & 7,00 & 82 & female & 9 & original \\
\hline 48 & $A D$ & V & 8,00 & 91 & male & 5 & original \\
\hline 49 & $A D$ & $\mathrm{~V}$ & 5,67 & 77 & female & 4 & original \\
\hline 50 & $A D$ & $\mathrm{VI}$ & 3,33 & 93 & female & 3 & original \\
\hline 51 & $A D$ & $\mathrm{VI}$ & 8,00 & 86 & female & 2,3 & original \\
\hline 52 & $A D$ & $\mathrm{VI}$ & 4,33 & 61 & male & 10 & original \\
\hline 53 & $A D$ & $\mathrm{VI}$ & 9,67 & 70 & male & 2,35 & original \\
\hline 54 & $A D$ & $\mathrm{VI}$ & 8,33 & 59 & male & 4 & original \\
\hline
\end{tabular}

The table shows the characteristic of the samples included in the study $(n=54)$.

No.: Number; APC: amyloid plaque score; h: hours; AD: Alzheimer's disease; PMI: post mortem interval;

$\mathrm{NA}=$ not applicable. 
Supplemental Table S2. RT-qPCR and Bisulfite PCR primers.

\begin{tabular}{|c|c|c|c|c|c|c|c|}
\hline ID & $\begin{array}{l}\text { Accesio } \\
\text { n } \\
\text { number }\end{array}$ & Purpose & $\begin{array}{c}\text { Ampli } \\
\text { con } \\
\text { size }\end{array}$ & $\mathrm{Tm}$ & Primer F & $\begin{array}{c}\mathrm{Tm} \\
2\end{array}$ & PrimerR \\
\hline $\begin{array}{l}\text { PLD3 } \\
\text { bis }\end{array}$ & \multirow{2}{*}{ NA } & \multirow{2}{*}{$\begin{array}{l}\text { Bisulfite } \\
\text { PCR }\end{array}$} & 269 & 59. & $\begin{array}{l}\text { TTTTTTTTGTTTTTTATTTGT } \\
\text { GGTTTT }\end{array}$ & $\begin{array}{l}59 . \\
09\end{array}$ & $\begin{array}{l}\text { AACCCCAACTTCTATCTAA } \\
\text { ACAAACTA }\end{array}$ \\
\hline $\begin{array}{l}\text { PLD3_p } \\
\text { rom bis }\end{array}$ & & & 318 & $\begin{array}{c}59 . \\
1\end{array}$ & $\begin{array}{l}\text { TGGGATTATTTGTTTTTATT } \\
\text { GTATAGATG }\end{array}$ & $\begin{array}{l}59 . \\
37\end{array}$ & $\begin{array}{l}\text { ATTTCTTTAAACCTCAATTT } \\
\text { ССТCC }\end{array}$ \\
\hline $\begin{array}{l}\text { PLD3 } \\
\text { pyro }\end{array}$ & \multirow{2}{*}{ NA } & \multirow{2}{*}{$\begin{array}{c}\text { Pyroseque } \\
\text { ncing }\end{array}$} & 240 & $\begin{array}{c}60 . \\
1\end{array}$ & $\begin{array}{l}\text { ATTTTAGGGTGGAATGTAG } \\
\text { TAAAGT }\end{array}$ & 61 & $\begin{array}{l}\text { AАCTACCTCCCATAAACCC } \\
\text { СААСТTСТА }\end{array}$ \\
\hline $\begin{array}{l}\text { PLD3 } \\
\text { seq }\end{array}$ & & & & 40. & GTGAGTTAGGATTGGG & & \\
\hline $\begin{array}{l}\text { PLD3_p } \\
\text { rin pyro }\end{array}$ & \multirow{2}{*}{ NA } & \multirow{2}{*}{$\begin{array}{l}\text { Pyroseque } \\
\text { ncing }\end{array}$} & 112 & 55. & $\begin{array}{l}\text { ATGAGAAAGGAGTATGTTT } \\
\text { GGT }\end{array}$ & $\begin{array}{c}58 . \\
3\end{array}$ & $\begin{array}{l}\text { CCCACACCCACCTTCCAAA } \\
\text { CTATA }\end{array}$ \\
\hline $\begin{array}{l}\text { PLD3_p } \\
\text { rin seq }\end{array}$ & & & & $\begin{array}{c}42 . \\
1\end{array}$ & $\begin{array}{l}\text { TTGGTTTTAGTAGGTTTGTA } \\
\text { GTTTA }\end{array}$ & & \\
\hline PLD3_q & $\begin{array}{c}\text { NM_012 } \\
268\end{array}$ & $q P C R$ & 141 & $\begin{array}{c}61 . \\
8\end{array}$ & $\begin{array}{l}\text { TTCTATGACACCCGCTACAA } \\
\text { C }\end{array}$ & $\begin{array}{c}62 \\
1\end{array}$ & $\begin{array}{l}\text { CACGTTGAGTAGAGCCTTC } \\
\text { AG }\end{array}$ \\
\hline
\end{tabular}

The table shows the primer pairs used in the study. Amplified transcripts are identified by RefSeq Accession or GeneBank accesion number.

qPCR: quantitative PCR; bp: base pair; Tm: Melting Temperature; NA: not applicable. 
Supplemental Table S3. Adjusted Logistic Regression Model to predict AD status.

\begin{tabular}{|cccccc|}
\hline Variable & B & Wald & p-value & OD & CI 95\% for OD \\
\hline A_prom CpG2 methylation levels & 0.085 & 6.104 & $0.013^{*}$ & 0.92 & $0.86-0.98$ \\
\hline Gender (Female) & -0.271 & 0.113 & 0.737 & 1.31 & $0.27-6.37$ \\
\hline Age $<65$ yo & -2.671 & 10.027 & $0.002 * *$ & 14.45 & $2.77-75.50$ \\
\hline
\end{tabular}

Alzheimer status (Control=0; $A D=1$ ) was considered as the dependent variable and PLD3 A_prom CpG2 methylation levels, gender and age were included as covariates. B: regression coefficient; OD: odds ratio; IC: confidence interval; yo: year-old; *: $p$-value $<0.05 ;{ }^{* *}$ : $p$-value $<0.01$ 


\section{DISCUSIÓN}




\section{DISCUSIÓN}

En los últimos años ha existido un gran interés para la identificación de biomarcadores sanguíneos (sobre todo plasmáticos) tanto diagnósticos como pronósticos en la $E A$, tal y como queda reflejado en la revisión sistemática que constituye el primer estudio de este trabajo. Es evidente que la identificación de los mismos podría tener un gran impacto en la práctica clínica, ya que su instauración universal sería a priori más fácil que en el caso de los biomarcadores diagnósticos de LCR y PET (invasivos y/o excesivamente costosos).

Aunque la instauración de biomarcadores plasmáticos para establecer el diagnóstico de la EA no es todavía una realidad, parece estar cada vez más cerca. Como se ha comentado el biomarcador que tiene una mayor probabilidad de traslación a la práctica clínica en un período de tiempo relativamente corto es el neurofilamento-ligero (NF-L). Los neurofilamentos son esenciales para el crecimiento radial de los axones durante el desarrollo, para dar soporte estructural, para la transmisión de impulsos eléctricos y son a su vez necesarios para una adecuada función sináptica. Por todo ello es esperable que el daño axonal que acontece en la EA, al igual que en el caso de otras enfermedades neurodegenerativas, se pueda reflejar por la alteración de los niveles de NF-L (33).

Se ha descrito que existe una buena correlación entre niveles de NF-L entre el LCR y el plasma, al igual que la capacidad para discriminar sujetos sin deterioro y sujetos con EA establecida mediante la determinación plasmática de NF-L en personas adultas con síndrome de Down (SD) -modelo de enfermedad de Alzheimer genéticamente determinada- $(206,207)$. Resultados similares también se han obtenido en sujetos de la población general, sin trisomía 21 ni EA genéticamente determinada (108).

La elevación plasmática de NF-L se ha descrito incluso en el estadio presintomático en formas de EA autosómica dominante. También se ha referido que a mayores niveles de NFL plasmático se detecta un mayor grado de atrofia cerebral tanto en formas de EA familiar como de EA esporádica. A su vez se ha descrito asociación en estadios sintomáticos de las distintas formas de EA con la severidad del deterioro cognitivo $(33,208,209)$; y los niveles de NF-L más bajos (pero significativamente incrementados con respecto a controles) en 
caso de DCL con respecto a demencia por EA (210). Tampoco sorprende por todo lo señalado que exista asociación entre los niveles de NF-L y el grado de hipometabolismo medido por PET-FDG cerebral $(108,211)$.

Estudios realizados en sujetos asintomáticos con seguimiento longitudinal han mostrado que aquellos individuos con niveles basales más altos de NF-L tienen mayor riesgo para conversión a DCL y mayor rapidez en la evolución de los cambios de neuroimagen estructural asociados a EA, como es el adelgazamiento cortical (212). Se ha notificado también la existencia de una buena correlación en LCR de los niveles de NF-L y p-tau y ttau, lo que apoya la idea de que los niveles de NF-L reflejarían la neurodegeneración asociada a la proteína tau (213). Dada la buena correlación de los niveles plasmáticos y de LCR de NF-L, que podría estar reflejando la neurodegeneración que acontece en tejido cerebral, sería esperable encontrar resultados similares en el caso de t-tau y p-tau con la mejoría de las técnicas para su detección plasmática.

Pero tampoco se debe de olvidar que el incremento de NF-L refleja daño axonal y que, por tanto, no es específico de la patología EA. Además de en otras demencias neurodegenerativas, como la demencia frontotemporal $(214,215)$ o la enfermedad de Creutzfeldt-Jacob $(216,217)$, también se ha detectado incremento de los niveles plasmáticos de NF-L en otras enfermedades como la asociada a la existencia de daño vascular cerebral (tanto patología de pequeño como de gran vaso) (218) e incluso se ha postulado que los niveles plasmáticos de NF-L tras un ictus isquémico pueden ayudar a predecir el grado de recuperación funcional de los pacientes (219). Así mismo, se ha descrito que dichos niveles pueden ayudar a monitorizar el seguimiento de pacientes con esclerosis múltiple (220) y/o determinar el pronóstico de sujetos que han experimentado traumatismo craneoencefálico (221). En el área de neuro-infecciosas, en casos de afectación del SNC por el virus de la inmunodeficiencia humana, como es el caso del complejo demencia-SIDA, se ha detectado incremento de los niveles plasmáticos de NF-L (222) y también se ha objetivado dicho aumento en distintas enfermedades de la esfera psiquiátrica como es el caso de la anorexia nerviosa (223). 
En definitiva, existen numerosas publicaciones que apoyan la existencia de un incremento de los niveles plasmáticos de NF-L en distintas enfermedades con afectación del SNC sea cual sea la causa. Por tanto, aunque es una molécula prometedora como potencial biomarcador en la EA, probamente su rol sea más como una herramienta para realizar un screening preliminar y/o, en el caso de poder establecer unos niveles determinados de referencia, para conocer el pronóstico de progresión de DCL a demencia. Pero no se debe de olvidar su carácter inespecífico en ningún momento.

Aunque en la revisión sistemática realizada se ha mostrado cierto escepticismo para el uso de tau-t y tau-p es cierto que tras su publicación (artículo publicado en mayo del año 2018), se ha producido un incremento de trabajos con resultados congruentes sobre la existencia de un incremento de los niveles plasmáticos de ambos en la EA (224-227). Se ha señalado que, en los casos de DCL amnésico, los niveles plasmáticos de tau-t elevados, sobre todo si están asociados a niveles de $A \beta 42$ elevados, pueden predecir el riesgo de conversión a demencia (228). Esto en parte se ha debido a la mejora de las técnicas de detección empleadas como es el caso de la incorporación de técnicas ultrasensibles de inmunoanálisis como es el SIMOA (229), una versión digital del convencional inmunoensayo ELISA. Aunque se debe señalar que, a diferencia del NF-L, la asociación entre niveles plasmáticos y de LCR es débil en el caso tanto de tau-t como de tau-p (225). En cambio según lo publicado durante este último año 2020, posiblemente debido a la mejoría en las técnicas de detección plasmática, la correlación entre los niveles de tau-p plasmáticos y de LCR sería mejor de lo anteriormente señalado (230)(231).

El principal problema de tau-t plasmático es que sigue siendo un marcador inespecífico de neurodegeneración y además presenta una mala correlación entre los niveles plasmáticos y los de LCR. Existen menos publicaciones en la actualidad que estudian la utilidad de la determinación de los niveles de tau-p plasmático, que en teoría reflejaría mejor la presencia de ovillos neurofibrilares y sería más específico de la EA. Si bien es cierto que recientemente se ha postulado la potencial utilidad para el diagnóstico diferencial entre EA y Degeneración Lobar Frontotemporal (DFT) -y otras demencias neurodegenerativas- de los niveles plasmáticos de tau-p (incrementados en casos confirmados con EA no sólo con 
respecto a controles sino que también frente a otras causas de demencias neurodegenerativas) (230-232).

Por todo ello, y al igual que en el caso de NF-L, se ha constatado un incremento de sus niveles plasmáticos en múltiples enfermedades neurodegenerativas como es el caso de la enfermedad de Creutzfeldt-Jakob -enfermedad donde los niveles de LCR son mucho más elevados que en la EA- $(233,234)$, en demencia frontotemporal $(235) ;$ y/o en caso de daño cerebral traumático crónico (236), en este caso los niveles de tau-p tendrían mayor rendimiento que los de tau-t, entre otros. Se ha observado que los niveles basales de tau-t plasmático elevado conllevan mayor riesgo de desarrollar deterioro cognitivo tras ictus isquémico (237) y/o incluso mayor probabilidad de presentar ictus isquémico (238). Además, y de igual forma que el NF-L, el incremento de tau-t se ha asociado a otras múltiples patologías, habiéndose descrito por ejemplo un mayor riesgo de presentar encefalopatía en contexto de sepsis si hay niveles plasmáticos elevados de tau-t (239).

Por otro lado, las mejoras en las técnicas de detección (como la aplicación de la técnica de reducción inmunomagnética además del uso de técnicas de inmunoanálisis ultrasensibles) también han permitido obtener resultados más robustos en lo referente a los biomarcadores de amiloidosis en plasma en comparación a lo descrito en la revisión sistemática aquí presentada, fiel reflejo de la constante innovación en el campo y también de la gran cantidad de producción científica a lo largo de los últimos años. Se ha constatado un descenso de niveles plasmáticos de $\mathbf{A} \beta 1-42$ no sólo en fase de EA prodrómica o establecida (240) sino que incluso en fases de la EA asintomática (241). En este sentido se ha descrito que el cociente de niveles plasmáticos de $\mathbf{A} \beta 1-42 / A \beta 1-40$ descendido tendría buena correlación con el PET-amiloide positivo (33,242-244). Obviamente, de confirmarse estos datos, su uso en la práctica clínica sería menos costoso y más fácilmente aplicable que el empleo de PET-amiloide y/o de la determinación en LCR de la ratio $A \beta 1-42 / A \beta 1-40$ que cuando está descendido tiene mejor correlato con la amiloidosis cerebral que el decremento aislado en LCR de los niveles de Aß1-42 (245).

Resulta muy interesante el trabajo de Palmquist et al publicado en el año 2019 que estudia la trayectoria de los biomarcadores diagnósticos de la EA no sólo en LCR sino que también 
en plasma. Detectan que la mayoría de los cambios acontecen de forma simultánea en LCR y plasma, pero que en general la magnitud de los cambios es menor en plasma con respecto a LCR, lo que dificulta su detección (246).

Dado el rendimiento subóptimo de los biomarcadores plasmáticos de patología tau y amiloide empleados de forma independiente se han realizados estudios para conocer si, al igual que acontece en el LCR, la combinación de ambos tipos de biomarcadores podría tener mayor utilidad para la práctica clínica. Se ha postulado que el uso conjunto de biomarcadores plasmáticos t-tau y Aß1-42 aumenta el rendimiento diagnóstico al tener una buena correlación los niveles obtenidos del cociente tau-t/amiloide- $\beta 1-42$ con el volumen hipocámpico, y con los hallazgos en PET-amiloide y PET-FDG cerebral en casos de EA (227)

Como ya se ha señalado en la revisión sistemática presentada un biomarcador diagnóstico ideal debe reflejar las características específicas de la enfermedad y tener gran sensibilidad y especificidad diagnóstica, a la vez que ser preferiblemente obtenido mediante una técnica no invasiva y no excesivamente costosa (1). En este sentido, y aplicado a la EA, los biomarcadores plasmáticos cumplirían a priori los requisitos de ser accesibles (es menos cruento y mejor aceptado por la población la realización de una analítica sanguínea que una punción lumbar) y menos costosos. Incluso se podría asegurar que la determinación plasmática de NF-L y de tau-t (y probablemente de p-tau, aunque más discutido en el caso de este último) cumplirían también el criterio de gran sensibilidad diagnóstica para EA, aunque no de especificidad; en cambio, en el caso de la determinación plasmática de Aß142 o del ratio $A \beta 1-42 / A \beta 1-40$, tendría mayor especificidad pero menor sensibilidad diagnóstica. Por tanto, se cree que en un futuro cercano el empleo de biomarcadores directamente relacionados con la patología amiloidea y con la patología de tau, al igual que y sobre todo la determinación de NF-L se emplearán como una herramienta de cribado inicial ya que, una vez estandarizados sus valores, tendrán un elevado valor predictivo negativo. La interpretación de los biomarcadores plasmáticos, de la misma forma que pasa con el resto de los biomarcadores diagnósticos de EA disponibles en la actualidad, no 
sustituirá la realización de una historia clínica detallada al paciente y/o familiares ni tampoco la realización de una valoración neuropsicológica bien orientada. A su vez se debe señalar que se ha sugerido que la determinación plasmática de tau-t pueda tener un papel pronóstico e incluso podría ser una medida de respuesta a emplear en futuros ensayos clínicos.

Además de los biomarcadores plasmáticos vinculados a la patología tau y amiloide, y el neurofilamento como representante de biomarcador de neurodegeneración, se ha postulado el empleo de otros biomarcadores relacionados con las teorías patogénicas vascular e inflamatoria entre otras. En este sentido, parece improbable que la aplicación de alguna de estas moléculas de forma aislada pueda ser empleada como biomarcador plasmático en el screening de EA. Sin embargo, la asociación de varias de estas moléculas y/o de paneles de las mismas sí podría tener una mayor utilidad, aunque probablemente combinada con la determinación plasmática de NF-L, tau-t, $p$-tau y/o ratio A $\beta 1-42 / A \beta 1-40$. En resumen, la identificación de un panel de biomarcadores plasmáticos sería de gran interés clínico si se consiguiera un alto valor predictivo negativo, ya que podría sustituir a los actuales biomarcadores, con la consiguiente reducción de los costes y efectos asociados a las punciones lumbares y/o PET, y sobre todo (y eso sería en entorno ideal) si se pudiese aplicar a nivel de atención primaria.

A pesar de los avances significativos en la identificación de biomarcadores diagnósticos de la EA, que incluye los instaurados recientemente en la práctica clínica, pero no de forma universal (los biomarcadores core de EA), y los que presumiblemente están ya en fase avanzada para su próxima aplicación como son los biomarcadores plasmáticos arriba señalados, es necesario tratar de emplear otras estrategias para mejorar la capacidad diagnóstica de la EA de forma precoz. Además, no se debe olvidar que los trabajos realizados para la identificación de biomarcadores tanto diagnósticos como pronósticos de la EA han permitido obtener un mayor conocimiento sobre su patogenia y también han contribuido al reconocimiento de potenciales dianas terapéuticas diferentes a las empleadas hasta la actualidad y que hasta la fecha no han obtenido los resultados esperados. Un abordaje relativamente novedoso y con interés creciente en los últimos años 
es la búsqueda de biomarcadores en el área de la epigenética. Parte del interés radica en el hecho de que la epigenética puede explicar cómo factores de riesgo ambientales pueden influir en la expresión génica, algo de crucial relevancia en una enfermedad con una patogenia tan compleja donde múltiples factores de riesgo tanto ambientales como genéticos han sido señalados hasta la fecha. En la revisión sistemática aportada sólo se menciona que se han postulado distintas marcas epigenéticas, como por ejemplo cambios en la metilación del ADN o en los microARN circulantes, como posibles biomarcadores diagnósticos de EA, pero la verdad es que la investigación en esta área está menos avanzada. Siguiendo la estrategia global de descubrimiento de biomarcadores, es necesario primero identificar los cambios detectables en tejido cerebral (algunas regiones cerebrales especialmente vulnerables a la patología de EA no han sido ampliamente estudiadas desde el punto de vista epigenético hasta la fecha) previo a validar dichos resultados en fluidos accesibles tales como la sangre periférica. En definitiva, se trata de aplicar la misma secuencia de identificación de cambios que en el resto de las estrategias científicas: primero constatar los cambios en el tejido afecto (cerebro) y a posteriori intentar corroborar su correlato en otros tejidos y/o fluidos con los que el cerebro pueda tener contacto (LCR o sangre periférica entre otros).

Una de las regiones cerebrales particularmente vulnerable a la patología Alzheimer es el hipocampo, especialmente a la patología tau que es a su vez la que se correlaciona mejor con el deterioro cognitivo que acontece en el contexto de la EA $(49,134)$. Por ello, se ha procedido a estudiar en el trabajo aquí presentado el perfil de la metilación del ADN (el principal mecanismo epigenético regulatorio de la expresión génica) en muestras de hipocampo procedentes de pacientes afectos de EA con diagnóstico gold standard anatomopatológico (132). Se han empleado para ello dos abordajes diferentes: el primero de ellos el referido al estudio del metiloma, esto es, la determinación de la metilación del ADN en todos los genes (según la base RefSeq) conocidos, y el otro, en cambio, el aplicado al estudio de las diferencias en la metilación del ADN de un gen candidato (PLD3), elegido por haberse descrito que un polimorfismo de dicho gen aumentaría el riesgo de presentar EA de inicio tardío (47). 
En ambos artículos, publicados entre los años 2018 y 2019 en la revista Clinical Epigenetics, se han empleado muestras de hipocampo de pacientes con EA "puros". Se refiere que las muestras son "puras" porque los únicos agregados proteicos presentes en las muestras de hipocampo procedentes de paciente fueron: depósitos de $p$-tau y $\beta$-amiloide. Esta selección facilita la identificación de mecanismos moleculares relacionados de forma más específica con la EA. Al mismo tiempo la rigidez de los criterios de inclusión conlleva la reducción del número de muestras procedentes de pacientes con $E A$, sobre todo de las muestras procedentes de personas de edad más avanzada, al ser muy frecuente la coexpresión de otras proteínas y más aún a medida que aumenta la edad. De hecho, se ha descrito que hasta en el $50-70 \%$ de los casos de EA confirmados anatomopatológicamente en regiones tales como hipocampo y/o amígdala se detecta la presencia de inclusiones de $\alpha$-sinucleína $(147,247)$ y en más del $50 \%$ de los casos la presencia de inclusiones de la TAR DNA binding protein-43 (TDP-43) (248). Los controles también son controles "puros" que no muestran inclusiones de otras proteínas no definitorias de EA (y obviamente no cumplen criterios anatomopatológicos según Braak \& Braak para el diagnóstico de EA), lo cual también conlleva la dificultad de encontrar controles de mayor edad, ya que no es infrecuente que personas de edad avanzada pueda cumplir criterios anatomopatológicos de EA en ausencia de deterioro cognitivo (249). Por ello, es esperable tal cual acontece en los trabajos aquí presentados, que exista una diferencia de edad significativa entre pacientes y controles, que en parte puede ser subsanado gracias a los ajustes en los análisis estadísticos. Dicho ajuste, para reducir el posible efecto debido a la diferencia de edad entre grupos, adquiere gran relevancia ya que es ampliamente conocido que la edad aumenta la inestabilidad genómica y provoca acortamiento de telómeros, disfunción mitocondrial, reducción del número de células progenitoras y también existen alteraciones epigenéticas vinculadas con la propia edad, independientemente de si existe o no un proceso patológico subyacente (250-252). En cambio, y tal y como se señala en ambos artículos, nuestra estrategia reduce la posibilidad de objetivar alteraciones que no se deban a la patología definitoria de EA diagnosticada por estudio anatomopatológico riguroso. 
Otra de las limitaciones de ambos trabajos es que el estudio del metiloma y del perfil de metilación de ADN en las regiones promotoras del gen PLD3 en el hipocampo se ha realizado a nivel tisular, y no a nivel celular, en concreto a nivel de población neuronal. Por tanto, no se puede establecer mediante ninguno de los trabajos que la alteración de la metilación del ADN descrita sea exclusiva de las neuronas. En cambio, mediante procedimientos bioinformáticos de inferencia, se ha asegurado que el porcentaje celular (de todas las células) no era significativamente diferente entre el grupo de pacientes y controles.

El trabajo realizado apoya la existencia de unos cambios en el metiloma del hipocampo de sujetos afectos de EA con respecto a controles. Estos cambios son de bajo o medio tamaño del efecto, al igual que lo observado en estudios previos de metilación del ADN en otras regiones cerebrales de la EA, y mayoritariamente representan ganancias de metilación, también de forma similar a lo referido en los trabajos publicados con anterioridad. El hecho de que un porcentaje sustancial $(10,7 \%)$ de los genes con mayor diferencia en la metilación se hayan identificado previamente por otros autores en tejido cerebral afecto por la EA contribuye a reforzar la robustez técnica y analítica de nuestro estudio. Por otro lado, la gran mayoría de genes identificados como diferencialmente metilados en nuestro estudio no se habían descrito previamente y representan un interesante grupo en el que merece la pena profundizar y que refleja una de las características de la metilación del ADN, como es la especificidad celular, regional y tisular.

Otro aspecto a destacar es que la validación realizada mediante secuenciación por bisulfito muestra que los cambios en la metilación diferencial no afectan a $\mathrm{CpGs}$ aisladas sino que los valores de metilación se extienden por regiones discretas del genoma que comprenden a varias $\mathrm{CpGs}$, sean o no regiones correspondientes a islas $\mathrm{CpGs}$. Este hecho induce a pensar que los cambios de metilación observados podrían tener un correlato en la función biológica de la metilación en dichas regiones y no ser cambios puntuales estocásticos sin significado biológico. De hecho, otro dato que apoyaría su efecto biológico es el hallazgo de que los cambios de la metilación diferencial coinciden con regiones del genoma que 
presentan simultáneamente marcas activadoras y represoras de las histonas (otro mecanismo epigenético). Este tipo de marca epigenética bivalente es característico de los llamados promotores "poised", que a su vez son propios de factores de transcripción esenciales en el desarrollo embrionario.

En la misma línea, resulta interesante que la firma del patrón diferencial de metilación del ADN detectado implica, entre otros, a factores de transcripción de la familia homeobox. No se debe de olvidar que los genes $H O X$, parte de la familia de los genes homeobox, codifican para factores de transcripción esenciales en el desarrollo embrionario y la morfogénesis (146), necesarios también para la pluripotencialidad y para la diferenciación celular, y recientemente se ha descrito que podrían ejercer un papel neuroprotector según estudios realizados en Drosophila (253). Es bien conocido que los genes de la familia homeobox, por la relevancia de las funciones celulares que desempeñan, presentan una regulación de su expresión muy estricta, siendo especialmente relevante el rol de los mecanismos epigenéticos combinados (tanto la metilación del ADN como de la regulación de las histonas) (254). Los seres humanos tenemos 39 genes HOX agrupados en 4 complejos de genes (HOXA en el cromosoma 7, HOXB en el cromosoma 17, HOXC en el cromosoma 12 y HOXD en el cromosoma 2). En este sentido, y en la misma línea de lo señalado en este trabajo, recientemente se ha publicado un estudio que constata la existencia de ganancia de metilación en 208 CpGs localizados en los genes del complejo HOXA al estudiar el metiloma de muestras de córtex prefrontal y giro temporal superior de pacientes con EA (255). Se ha constatado a su vez que los genes HOX son esenciales para mantener la expresión del gen ANK1 (253), que ya se había mostrada alterado en casos de EA con respecto a controles (79). También resulta interesante el hecho de que se ha registrado ganancia de metilación en los genes del complejo HOXA en muestras de sangre periférica de sujetos adultos con SD, sujetos con alto riesgo de desarrollar la EA (256).

En la actualidad no está claro el motivo del patrón de distribución espacial anatomopatológico característico de la EA y por ello, intentar correlacionar los resultados obtenidos en los cambios en mecanismos regulatorios con los hallazgos anatomopatológicos de la EA se considera recomendado. Otro aspecto interesante del 
trabajo es el haber sido capaces de encontrar una correlación entre los niveles del depósito histológico de p-tau medidos de forma cuantitativa y más de un tercio de las DMPs identificadas en el hipocampo de los pacientes, sobre todo teniendo en cuenta que el hipocampo es la región donde se inicia la patología tau y más aún conociendo que ésta es la que más se correlaciona con la sintomatología presente en la EA (49).

A su vez, y tal y como se ha señalado en el artículo, fue sorprendente el hecho de no encontrar relación entre la localización de DMPs y procesos celulares, ya ampliamente explicados en la introducción, vinculados a la neurodegeneración como serían los mecanismos asociados a la apoptosis, autofagia, inflamación, estrés oxidativo y/o a la función mitocondrial. En cambio, sí se constató una robusta asociación entre DMPs en el hipocampo y genes asociados a la neurogénesis. En los últimos años el estudio de la neurogénesis en el hipocampo adulto ha recibido cada vez mayor atención. El hipocampo es una región crítica para determinadas funciones superiores como el aprendizaje y la memoria, y es una región especialmente vulnerable a la patología de la EA. Se ha publicado que la neurogénesis en el giro dentado del hipocampo y en la zona subventricular es un fenómeno que persiste hasta la 9a década en sujetos sanos, mientras que se ha constatado una progresiva disminución (a medida que se avanza en los estadios anatomopatológicos de la enfermedad) de la misma en relación a la EA, aunque parecen ya existir alteraciones significativas desde estadios precoces de la EA, previo al depósito abundante de placas seniles y de ovillos neurofibrilares $(154,257,258)$. Los resultados aquí expuestos sugieren la existencia de una asociación entre la neurogénesis y cambios epigenéticos en la metilación del ADN en el contexto de la EA. Sin embargo, resulta imposible mediante un estudio observacional señalar si los DMPs localizados en los genes implicados en la neurogénesis son un fenómeno precoz o tardío dentro de la patogenia de la EA y también es imposible establecer su posible rol en la causalidad de la patología. A pesar de esta limitación, en la literatura se encuentran ejemplos que apoyarían un posible papel causal. Por ejemplo, se ha referido que la disminución de dicho fenómeno es un evento precoz en la EA en estudios realizados en modelos animales (259). La alteración en la neurogénesis encontrada en otros trabajos podría tratarse de un fenómeno relativamente inicial y por tanto, podría 
corresponder a una posible diana terapéutica con potencial efecto modificador en el curso de la enfermedad: bien impidiendo su progresión a fases clínicas o al menos demorándolo (260). En cualquier caso, resulta especialmente interesante la implicación de la regulación epigenética en este fenómeno, ya que puede también dar lugar a la identificación de más factores de riesgo ambientales externos de la EA que puedan ser modificables (ya se ha descrito el efecto entre otros del ejercicio físico y/o de la dieta en la neurogénesis).

La motivación para estudiar el patrón de metilación del gen PLD3 vino dada por la controversia previamente existente de si efectivamente la variante rs145999145 localizada en el exón 7 conduce o no a un incremento de riesgo para desarrollo de la EA de inicio tardío, tal y como fue descrito por Cruchaga et al (47). Se decidió estudiar si este gen presenta alteraciones epigenéticas en el contexto de la EA, mediante la determinación del nivel de mRNA y del patrón de metilación diferencial tanto del promotor principal como del alternativo del gen PLD3. Siguiendo esta estrategia se pretendía conocer si realmente podría existir asociación entre PLD3 y la patogenia de la EA, ya que los datos sobre su implicación en el procesamiento de APP y como consecuencia en la formación de placas seniles extracelulares no estaban completamente claros $(189,193-195)$; a la vez que evaluar si una desregulación epigenética y las diferencias en la expresión de su producto (mRNA y proteína) podrían asociarse (sin poder establecer si sería causa o consecuencia) al estatus de enfermedad (EA vs control). En nuestro estudio no se analizó la presencia de la variante rs145999145 en nuestra muestra; ya que dada su baja frecuencia a nivel poblacional (frecuencia del alelo menor $A$ en la población=0,297\%; dbSNP151) no se consideró necesario. Por tanto, el estudio se enfocó al papel que el gen PLD3 podría tener en la EA esporádica.

En el trabajo aquí presentado se objetivó una menor expresión del mRNA de PLD3 entre el grupo de muestras de hipocampo de pacientes (en estadios Braak \& Braak igual o superior a 3) comparado con controles tal y como se había descrito en otras regiones cerebrales como en el córtex frontal procedentes de pacientes con EA (189). En cambio, y a diferencia de otros estudios anteriores (190), no fuimos capaces de encontrar diferencias estadísticamente significativas en la expresión proteica de $P L D 3$ aunque sí constatamos una 
tendencia a la reducción de la expresión de la misma en pacientes con respecto a controles. Quizás este último punto hubiese mostrado un resultad de diferencia significativa con un mayor tamaño muestral, sobre todo del grupo de pacientes en estadios Braak \& Braak igual o superior a 3. También se debe señalar que se ha detectado en nuestra muestra una mayor reducción en los niveles de mRNA de PLD3 a medida que progresa la enfermedad medida por criterios anatomopatológicos, lo que sugiere que la alteración en la expresión del gen PLD3 podría no ser un fenómeno precoz y por tanto ser más indicador de progresión de la enfermedad que de su inicio. Pero esta última afirmación no es más que una hipótesis dadas las características intrínsecas de los estudios observacionales. Además porque el hecho de haber realizado el estudio a nivel tisular (y no celular neuronal) como ya se ha explicado con anterioridad puede al menos en parte inducir diferencias en la expresión de PLD3 debidos a cambio de composición celular que acontece de forma progresiva (mayor pérdida neuronal) a medida que progresa el deterioro y se producen los cambios anatomopatológicos medidos por los estadios Braak \& Braak.

A su vez se pudo constatar que existía una ganancia de metilación significativa en la región promotora alternativa del gen $P L D 3$, región promotora regulada por una isla CpG de menor tamaño que la localizada en la región promotora principal, donde no detectamos diferencias significativas. Es bien conocido que la ganancia de metilación de una región promotora se asocia al silenciamiento en la expresión de dicho gen. Por ello era esperable el hallazgo objetivado de la existencia de una relación inversa entre los niveles de metilación de las CpGs localizadas en la región promotora alternativa y los niveles de mRNA de PLD3 medidos en el hipocampo.

Ha sido relevante constatar que existe una correlación inversa entre los niveles de mRNA de PLD3 y los niveles de $A \beta$ a nivel del hipocampo; ello va en la misma línea de lo anteriormente publicado que vincula la función de PLD3 con el procesamiento de la APP y con la formación de placas seniles (47)(189). De hecho apoyaría el rol protector de PLD3 ya descrito con anterioridad (199). Pero también resulta interesante constatar que existe una correlación inversa con los niveles de depósito de tau medidos de forma cuantitativa en el hipocampo, lo cual es relevante porque apoya si cabe aún más el papel patogénico de PLD3, 
teniendo sobre todo presente que el hipocampo es la región donde se inicia la patología tau, y ésta es a su vez la que mejor correlato tiene con los síntomas derivados de la EA.

La vinculación del gen PLD3 con el fenómeno de la neurogénesis también ha sido descrito (205). La constatación de una alteración en la regulación epigenética, en concreto en la metilación de la región promotora alternativa del gen (con ganancia de metilación), a nivel del hipocampo en un gen con un rol posible en la neurogénesis también iría en la misma línea de los resultados publicados en el otro trabajo.

\section{Resumen:}

Para concluir el apartado de discusión, señalar que el trabajo aquí presentado ha pretendido exponer el conocimiento actual sobre los biomarcadores diagnósticos de la EA y a su vez ha intentado identificar la huella específica de la metilación del ADN en el hipocampo de pacientes con EA utilizando distintas estrategias para ello. La descripción de un metiloma específico para EA en el hipocampo es un paso crucial para intentar identificar en un futuro las alteraciones epigenéticas detectables en fluidos tan accesible como la sangre periférica. Comentar también que en el apartado discusión de cada uno de los artículos incorporados a este trabajo se han especificado las limitaciones de los mismos pero sin olvidar la fortaleza del trabajo en su conjunto. Es un trabajo exploratorio para poder avanzar en una futura identificación de biomarcadores epigenéticos en tejidos/fluidos accesibles que pueda potencialmente contribuir a establecer un diagnóstico, pronóstico o como futura diana terapéutica para la EA. 


\section{LIMITACIONES}




\section{LIMITACIONES}

Los resultados más interesantes del trabajo aquí expuesto se han señalado en cada uno de los artículos y también en el apartado de discusión conjunta, donde también se han citado las fortalezas del trabajo en cuestión. Pero también se cree necesario reflejar aspectos a mejorar o debilidades del presente trabajo como son:

1- La revisión sistemática publicada en el año 2018 pero redactada a finales del año 2017 puede haber perdido cierta actualidad. Si bien es cierto que han transcurrido menos de 2 años desde su publicación, la expansión de técnicas ultrasensibles que han cambiado la perspectiva de la futura aplicabilidad de biomarcadores sanguíneos en el diagnóstico de la EA es, a día de hoy, una realidad. Pero por otro lado se debe señalar que, a pesar de los avances muy destacados en este ámbito, desde la publicación de la revisión sistemática todavía no hay ningún biomarcador sanguíneo que de forma estandarizada se utilice en la práctica clínica como herramienta diagnóstica.

Otra limitación de este artículo de revisión es que se centra en biomarcadores no epigenéticos de la EA. Si bien es cierto que hubiese sido interesante indagar en las publicaciones que estudiaban la huella epigenética en sangre periférica de la EA, se decidió centrar el artículo en otros aspectos dado que en ese momento: 1- había pocos estudios epigenéticos publicados al respecto; 2 - se consideró necesario hacer una revisión detallada de otras disciplinas empleadas para la identificación de posibles biomarcadores diagnósticos y pronósticos de EA y así disponer de un amplio background antes de llevar a cabo un estudio en fase de discovery de la huella específica de metilación diferencial de la EA. 
2- Una limitación adicional es, sin lugar a dudas, el relativo reducido tamaño muestral de los artículos número 2 y 3 incluidos en este trabajo. El motivo de dicho tamaño muestral son los criterios estrictos de selección, ya señalados en varias ocasiones, consistentes principalmente en la ausencia de copatología. Es complicada la obtención de muestras de tejido cerebral a partir de cierta edad que no tengan copatología asociada a la EA y también es difícil encontrar controles que a partir de cierta edad no cumplan criterios anatomopatológicos de EA ni de otras proteinopatías. Esto es uno de los principales motivos de la diferencia de edad significativa existente entre el grupo de pacientes y controles, que evidentemente se ha tenido en cuenta en los rigurosos análisis estadísticos realizados. A pesar de lo señalado, se debe destacar que la naturaleza "pura" de los casos y controles hace más probable que los hallazgos objetivados se puedan deber a la condición de EA. También se debe señalar que la clasificación en el grupo de casos y controles se ha basado exclusivamente en criterios anatomopatológicos y no se ha realizado un análisis pormenorizado en función de si existía correlato con síntomas clínicos.

Por último, aunque el tamaño muestral pueda parecer limitado, conviene resaltar que la potencia del estudio para detectar como estadísticamente significativa una metilación diferencial entre pacientes $(n=26)$ y controles $(n=12)$ de 0,1 en un contraste bilateral y aceptando un riesgo alfa de 0,05 es del 82\% (cálculo realizado a posteriori) y, por tanto, aceptable para confiar en las conclusiones del estudio.

3- El estudio del patrón de metilación tanto por gen candidato como del metiloma del hipocampo se ha realizado a nivel tisular y no a nivel celular, si bien es cierto que se ha constatado que no existen diferencias significativas en la celularidad entre el grupo de hipocampos de pacientes con respecto a controles. De esta manera, no se pueden atribuir los cambios observados en la metilación a las neuronas y deben interpretarse como un promedio del conjunto de células que componen el hipocampo humano. 
En cambio, el hecho de haber realizado el estudio en el hipocampo, región cerebral donde se inicia la patología tau, que tiene mejor correlato con la evolución clínica que la patología amiloide, se considera una fortaleza muy relevante. 


\section{FUTUROS PROYECTOS DE INVESTIGACIÓN:}

El trabajo aquí expuesto se considera que puede tener una continuidad en el futuro, existiendo varias vías para ello que se exponen a continuación:

1. Estudiar la relación entre cambios epigenéticos detectados a nivel de tejido cerebral y variables clínicas en la evolución de enfermedad de Alzheimer:

Es indudable que el estudio de la regulación epigenética ha adquirido especial relevancia en los últimos años en el estudio de enfermedades neurodegenerativas, entre ellas en la EA. Como ya se ha señalado, se han estudiado distintos mecanismos epigenéticos por separado, siendo la metilación del ADN el mecanismo más conocido, pero también se ha indagado en la relación existente entre dichos mecanismos. Para el estudio de los cambios de metilación del ADN también se han utilizado distintas estrategias: estudios de metiloma y estudios gen-específicos. A pesar de ello, a día de hoy, hay todavía muchas incógnitas por desvelar como es el conocer si existen huellas epigenéticas diferentes no sólo en función de la condición o no de la enfermedad de EA, sino en función de la exposición a factores de riesgos no genéticos conocidos, al curso clínico de la enfermedad, y/o si los fármacos empleados en su evolución podrían influir en el patrón de metilación, etc.

Con la finalidad de intentar analizar si existen diferencias o no que relacionan cambios en la metilación con aspectos clínicos, incluyendo síntomas, signos y tratamientos empleados en el curso clínico de la EA, se plantea proceder a una revisión detallada de los casos y controles incluidos en el artículo del estudio del metiloma del hipocampo de EA previamente comentado. De forma retrospectiva, revisar las historias clínicas de los controles y pacientes para obtener la información sobre variables clínicas. Se es consciente de que la recogida de datos de forma retrospectiva conlleva mayores dificultades para su adquisición y reduce su robustez. Pero es un problema que existe en otros muchos estudios que implican comparar resultados del tejido cerebral postmortem con enfermedades 
crónicas de larga evolución, como sería el caso de la EA y es el motivo fundamental por los que este tipo de estudios escasean en la producción científica. Aunque también se es consciente de otra posible limitación de analizar los datos en el conjunto de la muestra y no sólo en el grupo de casos de EA, como es la gran disparidad existente en la edad de pacientes y controles. El análisis de las diferencias de metilación detectados en el hipocampo de sujetos con EA fue corregido por edad en el estudio del metiloma, pero no se debe obviar que existen enfermedades y alteraciones analíticas cuya prevalencia también se incrementa con la edad.

En cambio, la ausencia de copatología vascular cerebral significativa y de coexpresión de otros agregados proteicos permite postular que las diferencias que potencialmente se obtengan sí que podrían estar vinculadas con la fisiopatología de la EA. Otro aspecto a destacar es que los niveles de metilación se han medido de forma transversal y ello imposibilita establecer una relación de causalidad con las variables clínicas a recoger.

Tras comentar las debilidades potenciales de este nuevo estudio se debe señalar que dentro del grupo de EA se incluirían, a pesar de disponer de una muestra pequeña, 24 hipocampos de sujetos que incluyen una gran variabilidad tanto de estadios anatomopatológicos como estadios clínicos.

Disponer de muestras de hipocampo, región cerebral donde se inicia la patología tau, la que se relaciona de forma más directa con los síntomas de EA y región implicada en funciones mnésicas, resulta especialmente interesante para poder estudiar la asociación entre variables clínicas y los cambios en el patrón de metilación. A la vez que resulta interesante valorar si existen cambios o no en los hallazgos en el patrón de metilación en función de la toma de psicofármacos, si bien es cierto que por el diseño del estudio no se podría postular relación de causalidad de los mismos. 
2. Intentar identificar huellas de metilación diferencial de la EA en líquido cefalorraquídeo y sangre periférica:

Otra línea de trabajo que deriva de lo aquí expuesto es intentar conocer si los cambios en el metiloma del hipocampo descritos podrían ser detectables en fluidos accesibles para el estudio en vida de los sujetos, ya sea líquido cefaloraquídeo o sangre periférica. Un aspecto indiscutiblemente esencial para avanzar en la identificación de biomarcadores epigenéticos para su potencial uso ya sea diagnóstico, pronóstico o en la monitorización de respuesta al tratamiento.

A día de hoy existen múltiples trabajos que estudian el metiloma de la EA en distintas regiones cerebrales, existiendo resultados variables en función del tejido estudiado, pero poco se conoce sobre si dichos resultados pueden replicarse o no en fluidos accesibles como sangre periférica, si bien es cierto que es un tema que despierta un interés creciente. Sería el estudio lógico para avanzar en la aplicabilidad práctica de los resultados aquí expuestos y además podría permitir realizar estudios longitudinales. De esta forma, potencialmente se podría estudiar la relación causa-efecto de la aparición/control de factores de riesgo modificables para desarrollo de la EA, el efecto de factores protectores y también el impacto de los fármacos empleados en la EA. 


\section{CONCLUSIONES}




\section{CONCLUSIONES}

\section{Biomarcadores sanguíneos en la enfermedad de Alzheimer:}

- El diagnóstico precoz de la EA es probablemente la mejor vía para conseguir la identificación de tratamientos modificadores de la enfermedad. Para lograrlo la mejor herramienta disponible, además de la anamnesis, exploración física y la valoración neuropsicológica, es el estudio de biomarcadores ligados a la patogenia de la enfermedad. Sin embargo, los biomarcadores «<core $>>$ de la EA, , probablemente no se puedan instaurar para su uso universal por su excesivo coste y/o su carácter invasivo.

- La identificación de biomarcadores plasmáticos que reflejen la patogenia de la EA dará lugar a los potenciales biomarcadores diagnósticos ideales. En el momento actual la determinación de neurofilamento ligero en plasma parece ser el analito más prometedor para realizar un primer cribado ante sospecha clínica de DCL, aunque no se debe olvidar su carácter inespecífico.

- La mejoría en las técnicas de laboratorio probablemente puede permitir aumentar el rendimiento del primer cribado a realizar mediante la analítica sanguínea, permitiendo la determinación de biomarcadores que además de reflejar inespecíficamente la neurodegeneración, reflejen también la existencia de patología amiloidea y la patología tau.

\section{Caracterización del metiloma del hipocampo de pacientes con EA con respecto a} controles.

- Se han identificado 118 variantes epigenéticas en el patrón de metilación del ADN mediante la caracterización del metiloma en el hipocampo de pacientes con EA con respecto a controles. 
- Este patrón de metilación del ADN en el hipocampo de la EA ocurre mayoritariamente en regiones reguladoras específicas, preferentemente en promotores bivalentes o "poised", que marcan genes cruciales para la diferenciación neuronal, como los factores de transcripción del grupo HOX.

- Estos hallazgos afianzan la hipótesis de que la alteración de la neurogénesis puede ser un evento crucial en la patogenia de la EA.

3. Estudio de patrón de metilación de PLD3, factor de riesgo genético de la EA, en el hipocampo de pacientes con EA con respecto a controles.

- Se han identificado variantes epigenéticas en el patrón de metilación del ADN en el promotor alternativo de un gen candidato, PLD3, factor de riesgo genético de la EA, en el hipocampo de pacientes con EA con respecto a controles.

- La identificación de un patrón de metilación diferencial en el promotor alternativo de dicho gen se asocia a una menor expresión del mRNA de PLD3, en el hipocampo de pacientes con EA con respecto a controles.

- La correlación de dichos hallazgos con los niveles de proteína tau y $\beta$-amiloide apoyan la posible relación de $P L D 3$ con la patogenia de la EA. 


\section{ÍNDICE DE ABREVIATURAS}




\section{8. ÍNDICE DE ABREVIATURAS}

$>\underline{A \beta}$ : beta-amiloide.

ABCA7: ATP Binding Cassette Subfamily A Member 7.

$>$ ACTB: Actin Beta.

ADAM10: ADAM Metallopeptidase Domain 10.

$>$ AD: Alzheimer's Disease.

$>$ ADN: ácido desoxirribonucleico.

$>$ AKAP9: A-Kinase Anchoring Protein 9.

$>$ ANK1: ankyrin 1.

$>$ APOE: apolipoproteína E.

$>$ APP: proteína precursora de amiloide.

$>$ APS: amyloid plaque score.

$>$ ARN: ácido ribonucleico.

BACE-1: $\beta$-site amyloid precursor protein-cleaving enzyme 1.

BDNF: Brain-derived neurotrophic factor.

$>$ BHE: barrera hemato-encefálica.

$>$ BIN1: Bridging Integrator 1.

$>$ Ca: Calcio.

> CALHM1: Calcium homeostasis modulator 1.

> CASS4: Cas Scaffold Protein Family Member 4.

$>$ CCL-1: C-C Motif Chemokine Ligand 1.

$>$ CCNL1: Cyclin L1.

D CCR8: C-C Motif Chemokine Receptor 8.

$>$ cDNA: complementary DNA.

$>$ CD2AP: CD2 Associated Protein.

> CDK5: Cyclin Dependent Kinase 5.

$>$ CELF1: CUGBP Elav-Like Family Member 1.

$>$ ChIP: chromatin immunoprecipitation.

Chip-qPCR: chromatin immunoprecipitation quantitative PCR. 
CLU: clusterina.

C CpG: dinucleótido citosina-guanina enlazada por fosfato.

> CR1: Complement receptor type 1.

Dbx2: Developing Brain Homeobox 2.

$>$ DCL: deterioro cognitivo leve.

D DIO3: lodothyronine Deiodinase 3.

$>$ DNA: deoxyribonucleic acid.

$>$ DNMT: DNA methyltransferase.

DMP: differentially methylated positions.

DSG2: desmoglein 2.

D DUSP22: Dual Specificity Phosphatase 22.

$>$ DYRK1A: Dual specificity tyrosine phosphorylation regulated kinase 1.

$>$ EA: enfermedad de Alzheimer.

ELOVL2: ELOVL Fatty Acid Elongase 2.

$>$ EPHA1: EPH Receptor A1.

D EVX1: Even-Skipped Homeobox 1.

> FERMT2: Fermitin Family Member 2.

FDG: fluorodesoxiglucosa.

PDR: false discovery rate.

FHL2: Four and A Half LIM Domains 2.

FR: factores de riesgo.

$>$ GADPH: Glyceraldehyde-3-Phosphate Dehydrogenase.

$>$ GAX: Growth arrest homeobox transcription factor.

$>$ GO: gene ontology.

$>$ GREAT: genomic regions enrichment of annotations tool.

> GSK3ß: Glycogen Synthase Kinase 3 Beta.

$>$ GWAS: Genome-wide association study.

$>$ h: horas.

> HAND2: Heart And Neural Crest Derivatives Expressed 2.

HLA-DRB1: major histocompatibility complex, class II, DR beta 1. 
HMG: high mobility group.

HTA: hipertensión arterial.

H1-hESC: histone marks in H1 human embryonic stem cells.

ICAM-1: Intercellular Adhesion Molecule 1.

$>$ ID: identificación.

$>$ IL: interleuquina.

> IMG: International Working Group.

$>$ LIMMA: Linear model of microarray analysis.

$>$ LCR: líquido cefalorraquídeo.

D MEF2C: Myocyte-specific enhancer factor 2C.

$>$ mRNA: ARN mensajero.

MAPT: microtubule-associated protein tau.

$>$ MBD: Methyl-CpG-binding domain.

MS4A: membrane-spanning 4-domains subfamily A.

DA: no applicable.

$>$ NFKB: Nuclear factor kappa B.

$>$ NF-L: neurofilamento ligero.

NGS: next generation sequencing.

$>$ NH-A: normal human astrocytes.

$>$ NHPCs: neural human progenitor cells.

$>$ NIA/AA: National Institute on Aging and the Alzheimer's Association.

DME8: NME/NM23 Family Member 8.

No: número.

NPBM: neural progenitor basal medium.

$>$ NXN: Nucleoredoxin.

PAX3: paired box gene 3.

$>$ PCDHA12: Protocadherin alpha-12.

$>$ PET: tomografía por emisión de positrones.

> PICALM: Phosphatidylinositol Binding Clathrin Assembly Protein.

> PLD3: phospholipase D3. 
PMI: postmortem Interval.

$>$ PSEN1: presenilina 1.

$>$ PSEN2: presenilina 2.

$>$ PrEST: protein epitope signature tag.

$>$ PTK2B: Protein Tyrosine Kinase 2 Beta.

D QPCR: quantitative polymerase chain reaction.

$>$ QQ: quantil-quantil plots.

DBMS1: RNA Binding Motif Single Stranded Interacting Protein 1.

RHOB: Ras Homolog Family Member B.

$>$ RMc: resonancia magnética craneal.

D RT-qPCR: Reverse transcription polymerase chain reaction.

SAHS: síndrome apnea-hipopnea del sueño.

$>$ SD: standard deviation.

DEPT5: septin-5.

SLC24A4: Solute Carrier Family 24 Member 4.

SNC: sistema nervioso central.

SNP: polimorfismo de un único nucleótido.

> SORL1: Sortilin Related Receptor 1.

SPINT1: Serine Peptidase Inhibitor, Kunitz Type 1.

Tau-p: tau fosforilada.

$>$ Tau-t: tau total.

$>$ TCE: traumatismo craneoncefálico.

$>$ TDP43: Transactive response DNA binding protein of $43 \mathrm{kDa}$.

$>$ IF: transcription factor.

> TMEM59: Transmembrane Protein 59.

$>$ Im1: melting temperature forward primer.

$>$ Im2: melting temperature forward primer.

TM2D3: TM2 Domain Containing 3.

TNFa: factor de necrosis tumoral alfa.

TREM2: Triggering receptor expressed on myeloid cells 2. 
TSS: transcriptional start site.

UNC5C: Unc-5 Netrin Receptor C.

VCAM-1: Vascular cell adhesion protein 1.

$>$ YKL-40: Chitinase 3-like 1.

5mC: 5-metilcitosina. 


\section{BIBLIOGRAFÍA}




\section{BIBLIOGRAFÍA:}

1. Zetterberg H. Applying fluid biomarkers to Alzheimer's disease. Am J Physiol Cell Physiol. 2017 Jul;313(1):C3-10.

2. Jammeh E, Zhao P, Carroll C, Pearson S, Ifeachor E. Identification of blood biomarkers for use in point of care diagnosis tool for Alzheimer's disease. Conf Proc . Annu Int Conf IEEE Eng Med Biol Soc IEEE Eng Med Biol Soc Annu Conf. 2016 Aug;2016:24158.

3. Jellinger KA, Janetzky B, Attems J, Kienzl E. Biomarkers for early diagnosis of Alzheimer disease: 'ALZheimer ASsociated gene'--a new blood biomarker? J Cell Mol Med. 2008 Aug;12(4):1094-117.

4. Tatebe $H$, Kasai $T$, Ohmichi $T$, Kishi $Y$, Kakeya $T$, Waragai $M$, et al. Quantification of plasma phosphorylated tau to use as a biomarker for brain Alzheimer pathology: pilot case-control studies including patients with Alzheimer's disease and down syndrome. Mol Neurodegener. 2017 Sep;12(1):63.

5. Doecke JD, Laws SM, Faux NG, Wilson W, Burnham SC, Lam C-P, et al. Blood-based protein biomarkers for diagnosis of Alzheimer disease. Arch Neurol. 2012 Oct;69(10):1318-25.

6. Huynh RA, Mohan C. Alzheimer's Disease: Biomarkers in the Genome, Blood, and Cerebrospinal Fluid. Front Neurol. 2017;8:102.

7. Walker LC. Prion-like mechanisms in Alzheimer disease. Handb Clin Neurol. 2018;153:303-19.

8. Kocahan S, Dogan Z. Mechanisms of Alzheimer's Disease Pathogenesis and Prevention: The Brain, Neural Pathology, N-methyl-D-aspartate Receptors, Tau Protein and Other Risk Factors. Clin Psychopharmacol Neurosci. 2017 Feb;15(1):18.

9. Sanabria-Castro A, Alvarado-Echeverria I, Monge-Bonilla C. Molecular Pathogenesis 
of Alzheimer's Disease: An Update. Ann Neurosci. 2017 May;24(1):46-54.

10. McKhann GM, Knopman DS, Chertkow H, Hyman BT, Jack CRJ, Kawas CH, et al. The diagnosis of dementia due to Alzheimer's disease: recommendations from the National Institute on Aging-Alzheimer's Association workgroups on diagnostic guidelines for Alzheimer's disease. Alzheimers Dement. 2011 May;7(3):263-9.

11. Holtzman DM, Morris JC, Goate AM. Alzheimer's disease: the challenge of the second century. Sci Transl Med. 2011 Apr;3(77):77sr1.

12. Dubois $B$, Hampel $H$, Feldman $H H$, Scheltens $P$, Aisen $P$, Andrieu $S$, et al. Preclinical Alzheimer's disease: Definition, natural history, and diagnostic criteria. Alzheimers Dement. 2016 Mar;12(3):292-323.

13. Vos SJB, Visser PJ. Preclinical Alzheimer's Disease: Implications for Refinement of the Concept. J Alzheimers Dis. 2018;64(s1):S213-27.

14. Niemantsverdriet E, Valckx S, Bjerke M, Engelborghs S. Alzheimer's disease CSF biomarkers: clinical indications and rational use. Acta Neurol Belg. 2017 Sep;117(3):591-602.

15. Hebert LE, Weuve J, Scherr PA, Evans DA. Alzheimer disease in the United States (2010-2050) estimated using the 2010 census. Neurology. 2013 May;80(19):177883.

16. 2016 Alzheimer's disease facts and figures. Alzheimers Dement. 2016 Apr;12(4):459-509.

17. Rabinovici GD. Late-onset Alzheimer Disease. Continuum (Minneap Minn). 2019 Feb;25(1):14-33.

18. Lane CA, Hardy J, Schott JM. Alzheimer's disease. Eur J Neurol. 2018 Jan;25(1):5970.

19. Hane FT, Robinson M, Lee BY, Bai O, Leonenko Z, Albert MS. Recent Progress in Alzheimer's Disease Research, Part 3: Diagnosis and Treatment. J Alzheimers Dis. 2017;57(3):645-65. 
20. Tan C-C, Yu J-T, Tan L. Biomarkers for preclinical Alzheimer's disease. J Alzheimers Dis. 2014;42(4):1051-69.

21. Knopman DS. Alzheimer disease biomarkers and insights into mild cognitive impairment. Vol. 80, Neurology. United States; 2013. p. 978-80.

22. Blennow K, Zetterberg H. Biomarkers for Alzheimer's disease: current status and prospects for the future. J Intern Med. 2018 Dec;284(6):643-63.

23. Shekhar S, Kumar R, Rai N, Kumar V, Singh K, Upadhyay AD, et al. Estimation of Tau and Phosphorylated Tau181 in Serum of Alzheimer's Disease and Mild Cognitive Impairment Patients. PLoS One. 2016;11(7):e0159099.

24. Castro DM, Dillon C, Machnicki G, Allegri RF. The economic cost of Alzheimer's disease: Family or public health burden? Dement Neuropsychol. 2010;4(4):262-7.

25. Niu H, Alvarez-Alvarez I, Guillen-Grima F, Aguinaga-Ontoso I. Prevalence and incidence of Alzheimer's disease in Europe: A meta-analysis. Neurologia. 2017 Oct;32(8):523-32.

26. Garre-Olmo J. [Epidemiology of Alzheimer's disease and other dementias]. Rev Neurol. 2018 Jun;66(11):377-86.

27. Rius-Perez S, Tormos AM, Perez S, Talens-Visconti R. Vascular pathology: Cause or effect in Alzheimer disease? Neurologia. 2018 Mar;33(2):112-20.

28. Apostolova LG. Alzheimer Disease. Continuum (Minneap Minn). 2016 Apr;22(2 Dementia):419-34.

29. Podcasy JL, Epperson CN. Considering sex and gender in Alzheimer disease and other dementias. Dialogues Clin Neurosci. 2016 Dec;18(4):437-46.

30. Deb A, Thornton JD, Sambamoorthi U, Innes K. Direct and indirect cost of managing alzheimer's disease and related dementias in the United States. Expert Rev Pharmacoecon Outcomes Res. 2017 Apr;17(2):189-202.

31. Kumar A, Singh A, Ekavali. A review on Alzheimer's disease pathophysiology and its management: an update. Pharmacol Rep. 2015 Apr;67(2):195-203. 
32. Liao D, Miller EC, Teravskis PJ. Tau acts as a mediator for Alzheimer's disease-related synaptic deficits. Eur J Neurosci. 2014 Apr;39(7):1202-13.

33. Molinuevo JL, Ayton S, Batrla R, Bednar MM, Bittner T, Cummings J, et al. Current state of Alzheimer's fluid biomarkers. Acta Neuropathol. 2018 Dec;136(6):821-53.

34. Bergem AL, Engedal K, Kringlen E. The role of heredity in late-onset Alzheimer disease and vascular dementia. A twin study. Arch Gen Psychiatry. 1997 Mar;54(3):264-70.

35. Gatz M, Reynolds CA, Fratiglioni L, Johansson B, Mortimer JA, Berg S, et al. Role of genes and environments for explaining Alzheimer disease. Arch Gen Psychiatry. 2006 Feb;63(2):168-74.

36. Fernandez-Viadero C, Rodriguez Rodriguez E, Combarros Pascual O, Crespo Santiago D. [Genetics and Alzheimer's disease: a population at risk]. Rev Esp Geriatr Gerontol. 2013;48(1):39-44.

37. Chaudhury S, Brookes KJ, Patel T, Fallows A, Guetta-Baranes T, Turton JC, et al. Alzheimer's disease polygenic risk score as a predictor of conversion from mildcognitive impairment. Transl Psychiatry [Internet]. 2019;9(1):154. Available from: https://doi.org/10.1038/s41398-019-0485-7

38. Escott-Price V, Myers AJ, Huentelman M, Hardy J. Polygenic risk score analysis of pathologically confirmed Alzheimer disease. Ann Neurol. 2017 Aug;82(2):311-4.

39. Nelson AR, Sweeney MD, Sagare AP, Zlokovic B V. Neurovascular dysfunction and neurodegeneration in dementia and Alzheimer's disease. Biochim Biophys Acta. 2016 May;1862(5):887-900.

40. Van Acker ZP, Bretou M, Annaert W. Endo-lysosomal dysregulations and late-onset Alzheimer's disease: impact of genetic risk factors. Mol Neurodegener. 2019 Jun;14(1):20.

41. Qing-Qing Tao Zhi-Ying $\mathrm{Wu}$ Y-CC. The role of CD2AP in the Pathogenesis of Alzheimer\&\#x00027;s Disease [Internet]. Vol. 10, Aging and disease. p. 901-7. Available from: http://www.aginganddisease.org 
42. Cochran JN, Rush T, Buckingham SC, Roberson ED. The Alzheimer's disease risk factor CD2AP maintains blood-brain barrier integrity. Hum Mol Genet. 2015 Dec;24(23):6667-74.

43. Green KN. Calcium in the initiation, progression and as an effector of Alzheimer's disease pathology. J Cell Mol Med. 2009 Sep;13(9A):2787-99.

44. Chapuis J, Hansmannel F, Gistelinck M, Mounier A, Van Cauwenberghe C, Kolen K V, et al. Increased expression of BIN1 mediates Alzheimer genetic risk by modulating tau pathology. Mol Psychiatry. 2013 Nov;18(11):1225-34.

45. Moreno-Grau S, de Rojas I, Hernandez I, Quintela I, Montrreal L, Alegret M, et al. Genome-wide association analysis of dementia and its clinical endophenotypes reveal novel loci associated with Alzheimer's disease and three causality networks: The GR@ACE project. Alzheimers Dement. 2019 Aug;

46. Van Cauwenberghe C, Van Broeckhoven C, Sleegers K. The genetic landscape of Alzheimer disease: clinical implications and perspectives. Genet Med. 2016 May;18(5):421-30.

47. Cruchaga C, Karch CM, Jin SC, Benitez BA, Cai Y, Guerreiro R, et al. Rare coding variants in the phospholipase D3 gene confer risk for Alzheimer's disease. Nature. 2014 Jan;505(7484):550-4.

48. Scheltens P, Blennow K, Breteler MMB, de Strooper B, Frisoni GB, Salloway S, et al. Alzheimer's disease. Lancet (London, England). 2016 Jul;388(10043):505-17.

49. Kametani F, Hasegawa M. Reconsideration of Amyloid Hypothesis and Tau Hypothesis in Alzheimer's Disease. Front Neurosci. 2018;12:25.

50. Jonsson T, Atwal JK, Steinberg S, Snaedal J, Jonsson PV, Bjornsson S, et al. A mutation in APP protects against Alzheimer's disease and age-related cognitive decline. Nature. 2012 Aug;488(7409):96-9.

51. Wu L, Zhao L. ApoE2 and Alzheimer's disease: time to take a closer look. Neural Regen Res. 2016 Mar;11(3):412-3.

52. van der Lee SJ, Conway OJ, Jansen I, Carrasquillo MM, Kleineidam L, van den Akker 
$\mathrm{E}$, et al. A nonsynonymous mutation in PLCG2 reduces the risk of Alzheimer's disease, dementia with Lewy bodies and frontotemporal dementia, and increases the likelihood of longevity. Acta Neuropathol. 2019 Aug;138(2):237-50.

53. Hampel H, O'Bryant SE, Durrleman S, Younesi E, Rojkova K, Escott-Price V, et al. A Precision Medicine Initiative for Alzheimer's disease: the road ahead to biomarkerguided integrative disease modeling. Climacteric. 2017 Apr;20(2):107-18.

54. Ohara T, Ninomiya T, Hata J, Ozawa M, Yoshida D, Mukai N, et al. Midlife and LateLife Smoking and Risk of Dementia in the Community: The Hisayama Study. J Am Geriatr Soc. 2015 Nov;63(11):2332-9.

55. Hersi M, Irvine B, Gupta P, Gomes J, Birkett N, Krewski D. Risk factors associated with the onset and progression of Alzheimer's disease: A systematic review of the evidence. Neurotoxicology. 2017 Jul;61:143-87.

56. de Bruijn RFAG, Ikram MA. Cardiovascular risk factors and future risk of Alzheimer's disease. BMC Med. 2014 Nov;12:130.

57. Perini GF, Campregher PV, Santos FP de S, Hamerschlak N. Primary central nervous system lymphoma: what a neurologist/neurosurgeon should know? Arq Neuropsiquiatr. 2013 Apr;71(4):254-7.

58. Pan W, Kastin AJ. Can sleep apnea cause Alzheimer's disease? Neurosci Biobehav Rev. 2014 Nov;47:656-69.

59. Silva MVF, Loures C de MG, Alves LCV, de Souza LC, Borges KBG, Carvalho M das G. Alzheimer's disease: risk factors and potentially protective measures. J Biomed Sci. 2019 May;26(1):33.

60. Penke B, Bogar F, Fulop L. beta-Amyloid and the Pathomechanisms of Alzheimer's Disease: A Comprehensive View. Molecules. 2017 Oct;22(10).

61. Barage SH, Sonawane KD. Amyloid cascade hypothesis: Pathogenesis and therapeutic strategies in Alzheimer's disease. Neuropeptides. 2015 Aug;52:1-18.

62. de la Torre JC. Is Alzheimer's disease a neurodegenerative or a vascular disorder? Data, dogma, and dialectics. Lancet Neurol. 2004 Mar;3(3):184-90. 
63. Hansen D V, Hanson JE, Sheng M. Microglia in Alzheimer's disease. J Cell Biol. 2018 Feb;217(2):459-72.

64. Rodriguez-Arellano JJ, Parpura V, Zorec R, Verkhratsky A. Astrocytes in physiological aging and Alzheimer's disease. Neuroscience. 2016 May;323:170-82.

65. Newcombe EA, Camats-Perna J, Silva ML, Valmas N, Huat TJ, Medeiros R. Inflammation: the link between comorbidities, genetics, and Alzheimer's disease. J Neuroinflammation. 2018 Sep;15(1):276.

66. Maccioni RB, Gonzalez A, Andrade V, Cortes N, Tapia JP, Guzman-Martinez L. Alzheimer $s$ Disease in the Perspective of Neuroimmunology. Open Neurol J. 2018;12:50-6.

67. Hampel H, Mesulam MM, Cuello AC, Khachaturian AS, Farlow MR, Snyder PJ, et al. WITHDRAWN: Revisiting the cholinergic hypothesis in Alzheimer's disease: Emerging evidence from translational and clinical research. Alzheimer's \& dementia : the journal of the Alzheimer's Association. United States; 2017.

68. Magi S, Castaldo P, Macri ML, Maiolino M, Matteucci A, Bastioli G, et al. Intracellular Calcium Dysregulation: Implications for Alzheimer's Disease. Biomed Res Int. 2016;2016:6701324.

69. Aoyagi A, Condello C, Stohr J, Yue W, Rivera BM, Lee JC, et al. Abeta and tau prionlike activities decline with longevity in the Alzheimer's disease human brain. Sci Transl Med. 2019 May;11(490).

70. Bekris LM, Yu C-E, Bird TD, Tsuang DW. Genetics of Alzheimer disease. J Geriatr Psychiatry Neurol. 2010 Dec;23(4):213-27.

71. Loy CT, Schofield PR, Turner AM, Kwok JBJ. Genetics of dementia. Lancet (London, England). 2014 Mar;383(9919):828-40.

72. Lye TC, Shores EA. Traumatic brain injury as a risk factor for Alzheimer's disease: a review. Neuropsychol Rev. 2000 Jun;10(2):115-29.

73. Oh G, Ebrahimi S, Wang S-C, Cortese R, Kaminsky ZA, Gottesman II, et al. Epigenetic assimilation in the aging human brain. Genome Biol. 2016 Apr;17:76. 
74. Suzuki MM, Bird A. DNA methylation landscapes: provocative insights from epigenomics. Nat Rev Genet. 2008 Jun;9(6):465-76.

75. Mendioroz Iriarte M, Pulido Fontes L, Mendez-Lopez I. [Neuroepigenetics: Desoxyribonucleic acid methylation in Alzheimer's disease and other dementias]. Med Clin (Barc). 2015 May;144(10):457-64.

76. Cui D, Xu X. DNA Methyltransferases, DNA Methylation, and Age-Associated Cognitive Function. Int J Mol Sci. 2018 Apr;19(5).

77. Bakulski KM, Dolinoy DC, Sartor MA, Paulson HL, Konen JR, Lieberman AP, et al. Genome-wide DNA methylation differences between late-onset Alzheimer's disease and cognitively normal controls in human frontal cortex. J Alzheimers Dis. 2012;29(3):571-88.

78. Sanchez-Mut JV, Aso E, Heyn H, Matsuda T, Bock C, Ferrer I, et al. Promoter hypermethylation of the phosphatase DUSP22 mediates PKA-dependent TAU phosphorylation and CREB activation in Alzheimer's disease. Hippocampus. 2014 Apr;24(4):363-8.

79. Lunnon K, Smith R, Hannon E, De Jager PL, Srivastava G, Volta M, et al. Methylomic profiling implicates cortical deregulation of ANK1 in Alzheimer's disease. Nat Neurosci. 2014 Sep;17(9):1164-70.

80. De Jager PL, Srivastava G, Lunnon K, Burgess J, Schalkwyk LC, Yu L, et al. Alzheimer's disease: early alterations in brain DNA methylation at ANK1, BIN1, RHBDF2 and other loci. Nat Neurosci. 2014 Sep;17(9):1156-63.

81. Yu L, Chibnik LB, Srivastava GP, Pochet N, Yang J, Xu J, et al. Association of Brain DNA methylation in SORL1, ABCA7, HLA-DRB5, SLC24A4, and BIN1 with pathological diagnosis of Alzheimer disease. JAMA Neurol. 2015 Jan;72(1):15-24.

82. Sanchez-Mut J V, Graff J. Epigenetic Alterations in Alzheimer's Disease. Front Behav Neurosci. 2015;9:347.

83. Klein H-U, Bennett DA, De Jager PL. The epigenome in Alzheimer's disease: current state and approaches for a new path to gene discovery and understanding disease 
mechanism. Acta Neuropathol. 2016 Oct;132(4):503-14.

84. Delgado-Morales R, Esteller M. Opening up the DNA methylome of dementia. Mol Psychiatry. 2017 Apr;22(4):485-96.

85. Gustaw-Rothenberg KA, Siedlak SL, Bonda DJ, Lerner A, Tabaton M, Perry G, et al. Dissociated amyloid-beta antibody levels as a serum biomarker for the progression of Alzheimer's disease: a population-based study. Exp Gerontol. 2010 Jan;45(1):4752.

86. Jack CRJ, Knopman DS, Jagust WJ, Petersen RC, Weiner MW, Aisen PS, et al. Tracking pathophysiological processes in Alzheimer's disease: an updated hypothetical model of dynamic biomarkers. Lancet Neurol. 2013 Feb;12(2):207-16.

87. Illan-Gala I, Pegueroles J, Montal V, Vilaplana E, Carmona-Iragui M, Alcolea D, et al. Challenges associated with biomarker-based classification systems for Alzheimer's disease. Alzheimer's Dement (Amsterdam, Netherlands). 2018;10:346-57.

88. Alcolea D, Clarimon J, Carmona-Iragui M, Illan-Gala I, Morenas-Rodriguez E, Barroeta I, et al. The Sant Pau Initiative on Neurodegeneration (SPIN) cohort: A data set for biomarker discovery and validation in neurodegenerative disorders. Alzheimer's Dement (New York, N Y). 2019;5:597-609.

89. Henriksen K, O’Bryant SE, Hampel H, Trojanowski JQ, Montine TJ, Jeromin A, et al. The future of blood-based biomarkers for Alzheimer's disease. Alzheimers Dement. 2014 Jan;10(1):115-31.

90. O'Bryant SE, Mielke MM, Rissman RA, Lista S, Vanderstichele $H$, Zetterberg $H$, et al. Blood-based biomarkers in Alzheimer disease: Current state of the science and a novel collaborative paradigm for advancing from discovery to clinic. Alzheimers Dement. 2017 Jan;13(1):45-58.

91. Molinuevo JL, Blennow K, Dubois B, Engelborghs S, Lewczuk P, Perret-Liaudet A, et al. The clinical use of cerebrospinal fluid biomarker testing for Alzheimer's disease diagnosis: a consensus paper from the Alzheimer's Biomarkers Standardization Initiative. Alzheimers Dement. 2014 Nov;10(6):808-17. 
92. Lleo A, Cavedo E, Parnetti L, Vanderstichele H, Herukka SK, Andreasen N, et al. Cerebrospinal fluid biomarkers in trials for Alzheimer and Parkinson diseases. Nat Rev Neurol. 2015 Jan;11(1):41-55.

93. Gordon BA, Friedrichsen K, Brier M, Blazey T, Su Y, Christensen J, et al. The relationship between cerebrospinal fluid markers of Alzheimer pathology and positron emission tomography tau imaging. Brain. 2016 Aug;139(Pt 8):2249-60.

94. Jack CRJ, Bennett DA, Blennow K, Carrillo MC, Dunn B, Haeberlein SB, et al. NIA-AA Research Framework: Toward a biological definition of Alzheimer's disease. Alzheimers Dement. 2018 Apr;14(4):535-62.

95. Assicot M, Gendrel D, Carsin H, Raymond J, Guilbaud J, Bohuon C. High serum procalcitonin concentrations in patients with sepsis and infection. Lancet (London, England). 1993 Feb;341(8844):515-8.

96. Rhodes A, Evans LE, Alhazzani W, Levy MM, Antonelli M, Ferrer R, et al. Surviving Sepsis Campaign: International Guidelines for Management of Sepsis and Septic Shock: 2016. Intensive Care Med. 2017 Mar;43(3):304-77.

97. Lehmann S, Teunissen CE. Editorial: Biomarkers of Alzheimer's Disease: The Present and the Future. Vol. 7, Frontiers in neurology. Switzerland; 2016. p. 158.

98. Janel N, Sarazin M, Corlier F, Corne H, de Souza LC, Hamelin L, et al. Plasma DYRK1A as a novel risk factor for Alzheimer's disease. Transl Psychiatry. 2014 Aug;4:e425.

99. Mietelska-Porowska A, Wojda U. T Lymphocytes and Inflammatory Mediators in the Interplay between Brain and Blood in Alzheimer's Disease: Potential Pools of New Biomarkers. J Immunol Res. 2017;2017:4626540.

100. Ewers M, Mielke MM, Hampel H. Blood-based biomarkers of microvascular pathology in Alzheimer's disease. Exp Gerontol. 2010 Jan;45(1):75-9.

101. Yoshinaga T, Nishimata H, Kajiya Y, Yokoyama S. Combined assessment of serum folate and hemoglobin as biomarkers of brain amyloid beta accumulation. PLoS One. 2017;12(4):e0175854.

102. Mclntyre JA, Ramsey CJ, Gitter BD, Saykin AJ, Wagenknecht DR, Hyslop PA. 
Antiphospholipid autoantibodies as blood biomarkers for detection of early stage Alzheimer's disease. Autoimmunity. 2015;48(5):344-51.

103. Fiandaca MS, Mapstone ME, Cheema AK, Federoff HJ. The critical need for defining preclinical biomarkers in Alzheimer's disease. Alzheimers Dement. 2014 Jun;10(3 Suppl):S196-212.

104. Lista S, O'Bryant SE, Blennow K, Dubois B, Hugon J, Zetterberg H, et al. Biomarkers in Sporadic and Familial Alzheimer's Disease. J Alzheimers Dis. 2015;47(2):291-317.

105. Kitamura $Y$, Usami R, Ichihara S, Kida H, Satoh $M$, Tomimoto $H$, et al. Plasma protein profiling for potential biomarkers in the early diagnosis of Alzheimer's disease. Neurol Res. 2017 Mar;39(3):231-8.

106. Sharma N, Singh AN. Exploring Biomarkers for Alzheimer's Disease. J Clin Diagn Res. $2016 \mathrm{Jul} ; 10(7):$ KE01-6.

107. de Wilde A, van Maurik IS, Kunneman M, Bouwman F, Zwan M, Willemse EAJ, et al. Alzheimer's biomarkers in daily practice (ABIDE) project: Rationale and design. Alzheimer's Dement (Amsterdam, Netherlands). 2017;6:143-51.

108. Mattsson N, Andreasson U, Zetterberg H, Blennow K. Association of Plasma Neurofilament Light With Neurodegeneration in Patients With Alzheimer Disease. JAMA Neurol. 2017 May;74(5):557-66.

109. Deters KD, Risacher SL, Kim S, Nho K, West JD, Blennow K, et al. Plasma Tau Association with Brain Atrophy in Mild Cognitive Impairment and Alzheimer's Disease. J Alzheimers Dis. 2017;58(4):1245-54.

110. Dage JL, Wennberg AM V, Airey DC, Hagen CE, Knopman DS, Machulda MM, et al. Levels of tau protein in plasma are associated with neurodegeneration and cognitive function in a population-based elderly cohort. Alzheimers Dement. 2016 Dec;12(12):1226-34.

111. Mielke MM, Hagen CE, Wennberg AM V, Airey DC, Savica R, Knopman DS, et al. Association of Plasma Total Tau Level With Cognitive Decline and Risk of Mild Cognitive Impairment or Dementia in the Mayo Clinic Study on Aging. JAMA Neurol. 
2017 Sep;74(9):1073-80.

112. Gezen-Ak D, Dursun E, Hanagasi H, Bilgic B, Lohman E, Araz OS, et al. BDNF, TNFalpha, HSP90, CFH, and IL-10 serum levels in patients with early or late onset Alzheimer's disease or mild cognitive impairment. J Alzheimers Dis. 2013;37(1):18595.

113. DeMarshall CA, Nagele EP, Sarkar A, Acharya NK, Godsey G, Goldwaser EL, et al. Detection of Alzheimer's disease at mild cognitive impairment and disease progression using autoantibodies as blood-based biomarkers. Alzheimer's Dement (Amsterdam, Netherlands). 2016;3:51-62.

114. Gupta VB, Hone E, Pedrini S, Doecke J, O'Bryant S, James I, et al. Altered levels of blood proteins in Alzheimer's disease longitudinal study: Results from Australian Imaging Biomarkers Lifestyle Study of Ageing cohort. Alzheimer's Dement (Amsterdam, Netherlands). 2017;8:60-72.

115. Ferrero H, Larrayoz IM, Martisova E, Solas M, Howlett DR, Francis PT, et al. Increased Levels of Brain Adrenomedullin in the Neuropathology of Alzheimer's Disease. Mol Neurobiol. 2017 Sep;

116. Bandaru VVR, Troncoso J, Wheeler D, Pletnikova O, Wang J, Conant K, et al. ApoE4 disrupts sterol and sphingolipid metabolism in Alzheimer's but not normal brain. Neurobiol Aging. 2009 Apr;30(4):591-9.

117. Sundelof J, Arnlov J, Ingelsson E, Sundstrom J, Basu S, Zethelius B, et al. Serum cystatin C and the risk of Alzheimer disease in elderly men. Neurology. 2008 Sep;71(14):1072-9.

118. Bjorkqvist $M$, Ohlsson $M$, Minthon L, Hansson O. Evaluation of a previously suggested plasma biomarker panel to identify Alzheimer's disease. PLoS One. 2012;7(1):e29868.

119. Kiddle SJ, Sattlecker M, Proitsi P, Simmons A, Westman E, Bazenet C, et al. Candidate blood proteome markers of Alzheimer's disease onset and progression: a systematic review and replication study. J Alzheimers Dis. 2014;38(3):515-31. 
120. Nagaraj S, Laskowska-Kaszub K, Debski KJ, Wojsiat J, Dabrowski M, Gabryelewicz T, et al. Profile of 6 microRNA in blood plasma distinguish early stage Alzheimer's disease patients from non-demented subjects. Oncotarget. 2017 Mar;8(10):1612243.

121. de Leeuw FA, Peeters CFW, Kester MI, Harms AC, Struys EA, Hankemeier T, et al. Blood-based metabolic signatures in Alzheimer's disease. Alzheimer's Dement (Amsterdam, Netherlands). 2017;8:196-207.

122. Han X, Rozen S, Boyle SH, Hellegers C, Cheng H, Burke JR, et al. Metabolomics in early Alzheimer's disease: identification of altered plasma sphingolipidome using shotgun lipidomics. PLoS One. 2011;6(7):e21643.

123. Winblad B, Amouyel P, Andrieu S, Ballard C, Brayne C, Brodaty H, et al. Defeating Alzheimer's disease and other dementias: a priority for European science and society. Lancet Neurol. 2016 Apr;15(5):455-532.

124. Blennow K, de Leon MJ, Zetterberg H. Alzheimer's disease. Lancet (London, England). 2006 Jul;368(9533):387-403.

125. Reitz C, Brayne C, Mayeux R. Epidemiology of Alzheimer disease. Nat Rev Neurol. 2011 Mar;7(3):137-52.

126. Rao JS, Keleshian VL, Klein S, Rapoport SI. Epigenetic modifications in frontal cortex from Alzheimer's disease and bipolar disorder patients. Transl Psychiatry. 2012 Jul;2:e132.

127. Mendioroz M, Celarain N, Altuna M, Sánchez-Ruiz De Gordoa J, Zelaya MV, Roldán $M$, et al. CRTC1 gene is differentially methylated in the human hippocampus in Alzheimer's disease. Alzheimer's Res Ther. 2016;8(1).

128. Celarain N, Sanchez-Ruiz de Gordoa J, Zelaya MV, Roldan M, Larumbe R, Pulido L, et al. TREM2 upregulation correlates with 5-hydroxymethycytosine enrichment in Alzheimer's disease hippocampus. Clin Epigenetics. 2016;8:37.

129. Siegmund KD, Connor CM, Campan M, Long TI, Weisenberger DJ, Biniszkiewicz D, et al. DNA methylation in the human cerebral cortex is dynamically regulated 
throughout the life span and involves differentiated neurons. PLoS One. 2007 Sep;2(9):e895.

130. Watson CT, Roussos P, Garg P, Ho DJ, Azam N, Katsel PL, et al. Genome-wide DNA methylation profiling in the superior temporal gyrus reveals epigenetic signatures associated with Alzheimer's disease. Genome Med. 2016 Jan;8(1):5.

131. Wenk GL. Neuropathologic changes in Alzheimer's disease. J Clin Psychiatry. 2003;64 Suppl 9:7-10.

132. Braak H, Braak E. Neuropathological stageing of Alzheimer-related changes. Acta Neuropathol. 1991;82(4):239-59.

133. Braak H, Alafuzoff I, Arzberger T, Kretzschmar H, Del Tredici K. Staging of Alzheimer disease-associated neurofibrillary pathology using paraffin sections and immunocytochemistry. Acta Neuropathol. 2006 Oct;112(4):389-404.

134. Lace G, Savva GM, Forster G, de Silva R, Brayne C, Matthews FE, et al. Hippocampal tau pathology is related to neuroanatomical connections: an ageing populationbased study. Brain. 2009 May;132(Pt 5):1324-34.

135. Guintivano J, Aryee MJ, Kaminsky ZA. A cell epigenotype specific model for the correction of brain cellular heterogeneity bias and its application to age, brain region and major depression. Epigenetics. 2013 Mar;8(3):290-302.

136. Zhou X, Maricque B, Xie M, Li D, Sundaram V, Martin EA, et al. The Human Epigenome Browser at Washington University. Vol. 8, Nature methods. 2011. p. 989-90.

137. Kent WJ, Sugnet CW, Furey TS, Roskin KM, Pringle TH, Zahler AM, et al. The human genome browser at UCSC. Genome Res. 2002 Jun;12(6):996-1006.

138. Harikumar A, Meshorer E. Chromatin remodeling and bivalent histone modifications in embryonic stem cells. EMBO Rep. 2015 Dec;16(12):1609-19.

139. Bernstein BE, Mikkelsen TS, Xie X, Kamal M, Huebert DJ, Cuff J, et al. A bivalent chromatin structure marks key developmental genes in embryonic stem cells. Cell. 2006 Apr;125(2):315-26. 
140. Abraham BJ, Cui K, Tang Q, Zhao K. Dynamic regulation of epigenomic landscapes during hematopoiesis. BMC Genomics. 2013 Mar;14:193.

141. Mikkelsen TS, Ku M, Jaffe DB, Issac B, Lieberman E, Giannoukos G, et al. Genomewide maps of chromatin state in pluripotent and lineage-committed cells. Nature. 2007 Aug;448(7153):553-60.

142. Maupetit-Mehouas S, Montibus B, Nury D, Tayama C, Wassef M, Kota SK, et al. Imprinting control regions (ICRs) are marked by mono-allelic bivalent chromatin when transcriptionally inactive. Nucleic Acids Res. 2016 Jan;44(2):621-35.

143. Yoo S, Bieda MC. Differences among brain tumor stem cell types and fetal neural stem cells in focal regions of histone modifications and DNA methylation, broad regions of modifications, and bivalent promoters. BMC Genomics. 2014 Aug;15:724.

144. McLean CY, Bristor D, Hiller M, Clarke SL, Schaar BT, Lowe CB, et al. GREAT improves functional interpretation of cis-regulatory regions. Nat Biotechnol. 2010 May;28(5):495-501.

145. Thomas JO. HMG1 and 2: architectural DNA-binding proteins. Biochem Soc Trans. 2001 Aug;29(Pt 4):395-401.

146. Corsetti MT, Briata P, Sanseverino L, Daga A, Airoldi I, Simeone A, et al. Differential DNA binding properties of three human homeodomain proteins. Nucleic Acids Res. 1992 Sep;20(17):4465-72.

147. Serrano-Pozo A, Frosch MP, Masliah E, Hyman BT. Neuropathological alterations in Alzheimer disease. Cold Spring Harb Perspect Med. 2011 Sep;1(1):a006189.

148. Spalding KL, Bergmann O, Alkass K, Bernard S, Salehpour M, Huttner HB, et al. Dynamics of hippocampal neurogenesis in adult humans. Cell. 2013 Jun;153(6):1219-27.

149. Dokter M, von Bohlen und Halbach O. Neurogenesis within the adult hippocampus under physiological conditions and in depression. Neural Regen Res. 2012 Mar;7(7):552-9.

150. Ming G-L, Song H. Adult neurogenesis in the mammalian brain: significant answers 
and significant questions. Neuron. 2011 May;70(4):687-702.

151. Mathews KJ, Allen KM, Boerrigter D, Ball H, Shannon Weickert C, Double KL. Evidence for reduced neurogenesis in the aging human hippocampus despite stable stem cell markers. Aging Cell. 2017 Oct;16(5):1195-9.

152. Mu Y, Gage FH. Adult hippocampal neurogenesis and its role in Alzheimer's disease. Mol Neurodegener. 2011 Dec;6:85.

153. Crews L, Masliah E. Molecular mechanisms of neurodegeneration in Alzheimer's disease. Hum Mol Genet. 2010 Apr;19(R1):R12-20.

154. Moreno-Jimenez EP, Flor-Garcia M, Terreros-Roncal J, Rabano A, Cafini F, PallasBazarra $\mathrm{N}$, et al. Adult hippocampal neurogenesis is abundant in neurologically healthy subjects and drops sharply in patients with Alzheimer's disease. Nat Med. 2019 Apr;25(4):554-60.

155. Jin K, Peel AL, Mao XO, Xie L, Cottrell BA, Henshall DC, et al. Increased hippocampal neurogenesis in Alzheimer's disease. Proc Natl Acad Sci U S A. 2004 Jan;101(1):3437.

156. Gomez-Nicola D, Suzzi S, Vargas-Caballero M, Fransen NL, Al-Malki H, Cebrian-Silla $A$, et al. Temporal dynamics of hippocampal neurogenesis in chronic neurodegeneration. Brain. 2014 Aug;137(Pt 8):2312-28.

157. Boekhoorn K, Joels M, Lucassen PJ. Increased proliferation reflects glial and vascularassociated changes, but not neurogenesis in the presenile Alzheimer hippocampus. Neurobiol Dis. 2006 Oct;24(1):1-14.

158. Li B, Yamamori H, Tatebayashi Y, Shafit-Zagardo B, Tanimukai H, Chen S, et al. Failure of neuronal maturation in Alzheimer disease dentate gyrus. J Neuropathol Exp Neurol. 2008 Jan;67(1):78-84.

159. Pallas-Bazarra N, Jurado-Arjona J, Navarrete M, Esteban JA, Hernandez F, Avila J, et al. Novel function of Tau in regulating the effects of external stimuli on adult hippocampal neurogenesis. EMBO J. 2016 Jul;35(13):1417-36.

160. Houben S, Leroy K, Ando K, Yilmaz Z, Widomski C, Buee L, et al. Genetic ablation of 
tau in postnatal neurons rescues decreased adult hippocampal neurogenesis in a tauopathy model. Neurobiol Dis. 2019 Jul;127:131-41.

161. Braak H, Del Tredici K. The pathological process underlying Alzheimer's disease in individuals under thirty. Acta Neuropathol. 2011 Feb;121(2):171-81.

162. Braak H, Thal DR, Ghebremedhin E, Del Tredici K. Stages of the pathologic process in Alzheimer disease: age categories from 1 to 100 years. J Neuropathol Exp Neurol. 2011 Nov;70(11):960-9.

163. Mormino EC, Sperling RA, Holmes AJ, Buckner RL, De Jager PL, Smoller JW, et al. Polygenic risk of Alzheimer disease is associated with early- and late-life processes. Neurology. 2016 Aug;87(5):481-8.

164. Ross MG, Desai M, Khorram O, McKnight RA, Lane RH, Torday J. Gestational programming of offspring obesity: a potential contributor to Alzheimer's disease. Curr Alzheimer Res. 2007 Apr;4(2):213-7.

165. Zhao XD, Han X, Chew JL, Liu J, Chiu KP, Choo A, et al. Whole-genome mapping of histone H3 Lys4 and 27 trimethylations reveals distinct genomic compartments in human embryonic stem cells. Cell Stem Cell. 2007 Sep;1(3):286-98.

166. Estacio-Gomez A, Diaz-Benjumea FJ. Roles of Hox genes in the patterning of the central nervous system of Drosophila. Fly (Austin). 2014;8(1):26-32.

167. Karalay O, Doberauer K, Vadodaria KC, Knobloch M, Berti L, Miquelajauregui A, et al. Prospero-related homeobox 1 gene (Prox1) is regulated by canonical Wnt signaling and has a stage-specific role in adult hippocampal neurogenesis. Proc Natl Acad Sci U S A. 2011 Apr;108(14):5807-12.

168. Technau GM, Rogulja-Ortmann A, Berger C, Birkholz O, Rickert C. Composition of a neuromere and its segmental diversification under the control of Hox genes in the embryonic CNS of Drosophila. J Neurogenet. 2014;28(3-4):171-80.

169. Lupo G, Nisi PS, Esteve P, Paul Y-L, Novo CL, Sidders B, et al. Molecular profiling of aged neural progenitors identifies $\mathrm{Dbx} 2$ as a candidate regulator of age-associated neurogenic decline. Aging Cell. 2018 Jun;17(3):e12745. 
170. Wu Z, Guo H, Chow N, Sallstrom J, Bell RD, Deane R, et al. Role of the MEOX2 homeobox gene in neurovascular dysfunction in Alzheimer disease. Nat Med. 2005 Sep;11(9):959-65.

171. Bell JE, Alafuzoff I, Al-Sarraj S, Arzberger T, Bogdanovic N, Budka H, et al. Management of a twenty-first century brain bank: experience in the BrainNet Europe consortium. Acta Neuropathol. 2008 May;115(5):497-507.

172. Montine TJ, Phelps CH, Beach TG, Bigio EH, Cairns NJ, Dickson DW, et al. National Institute on Aging-Alzheimer's Association guidelines for the neuropathologic assessment of Alzheimer's disease: a practical approach. Acta Neuropathol. 2012 Jan;123(1):1-11.

173. Sandoval J, Heyn H, Moran S, Serra-Musach J, Pujana MA, Bibikova M, et al. Validation of a DNA methylation microarray for 450,000 CpG sites in the human genome. Epigenetics. 2011 Jun;6(6):692-702.

174. Yan L, Ma C, Wang D, Hu Q, Qin M, Conroy JM, et al. OSAT: a tool for sample-tobatch allocations in genomics experiments. BMC Genomics. 2012 Dec;13:689.

175. Pidsley R, Y Wong CC, Volta M, Lunnon K, Mill J, Schalkwyk LC. A data-driven approach to preprocessing Illumina 450K methylation array data. BMC Genomics. 2013 May;14:293.

176. Chen Y, Lemire M, Choufani S, Butcher DT, Grafodatskaya D, Zanke BW, et al. Discovery of cross-reactive probes and polymorphic CpGs in the Illumina Infinium HumanMethylation450 microarray. Epigenetics. 2013 Feb;8(2):203-9.

177. Price ME, Cotton AM, Lam LL, Farre P, Emberly E, Brown CJ, et al. Additional annotation enhances potential for biologically-relevant analysis of the Illumina Infinium HumanMethylation450 BeadChip array. Epigenetics Chromatin. 2013 Mar;6(1):4.

178. Ritchie ME, Phipson B, Wu D, Hu Y, Law CW, Shi W, et al. limma powers differential expression analyses for RNA-sequencing and microarray studies. Nucleic Acids Res. 2015 Apr;43(7):e47. 
179. Li L-C, Dahiya R. MethPrimer: designing primers for methylation PCRs. Bioinformatics. 2002 Nov;18(11):1427-31.

180. Sanger F, Nicklen S, Coulson AR. DNA sequencing with chain-terminating inhibitors. Proc Natl Acad Sci U S A. 1977 Dec;74(12):5463-7.

181. Kumaki Y, Oda M, Okano M. QUMA: quantification tool for methylation analysis. Nucleic Acids Res. 2008 Jul;36(Web Server issue):W170-5.

182. Bettens K, Sleegers K, Van Broeckhoven C. Genetic insights in Alzheimer's disease. Lancet Neurol. 2013 Jan;12(1):92-104.

183. Zhu J-B, Tan C-C, Tan L, Yu J-T. State of Play in Alzheimer's Disease Genetics. J Alzheimers Dis. 2017;58(3):631-59.

184. Humphries C, Kohli MA. Rare Variants and Transcriptomics in Alzheimer disease. Curr Genet Med Rep. 2014 Jun;2(2):75-84.

185. Giri M, Zhang M, Lu Y. Genes associated with Alzheimer's disease: an overview and current status. Clin Interv Aging. 2016;11:665-81.

186. Guimas Almeida C, Sadat Mirfakhar F, Perdigao C, Burrinha T. Impact of late-onset Alzheimer's genetic risk factors on beta-amyloid endocytic production. Cell Mol Life Sci. 2018 Jul;75(14):2577-89.

187. Munck A, Bohm C, Seibel NM, Hashemol Hosseini Z, Hampe W. Hu-K4 is a ubiquitously expressed type 2 transmembrane protein associated with the endoplasmic reticulum. FEBS J. 2005 Apr;272(7):1718-26.

188. Gonzalez AC, Schweizer M, Jagdmann S, Bernreuther C, Reinheckel T, Saftig P, et al. Unconventional Trafficking of Mammalian Phospholipase D3 to Lysosomes. Cell Rep. 2018 Jan;22(4):1040-53.

189. Satoh J-I, Kino Y, Yamamoto Y, Kawana N, Ishida T, Saito Y, et al. PLD3 is accumulated on neuritic plaques in Alzheimer's disease brains. Alzheimers Res Ther. 2014;6(9):70.

190. Engelman CD, Darst BF, Bilgel M, Vasiljevic E, Koscik RL, Jedynak BM, et al. The effect of rare variants in TREM2 and PLD3 on longitudinal cognitive function in the 
Wisconsin Registry for Alzheimer's Prevention. Neurobiol Aging. 2018 Jun;66:177.e1-177.e5.

191. Zhang D-F, Fan Y, Wang D, Bi R, Zhang C, Fang Y, et al. PLD3 in Alzheimer's Disease: a Modest Effect as Revealed by Updated Association and Expression Analyses. Mol Neurobiol. 2016 Aug;53(6):4034-45.

192. van der Lee SJ, Holstege H, Wong TH, Jakobsdottir J, Bis JC, Chouraki V, et al. PLD3 variants in population studies. Vol. 520, Nature. England; 2015. p. E2-3.

193. Cacace R, Van den Bossche T, Engelborghs S, Geerts N, Laureys A, Dillen L, et al. Rare Variants in PLD3 Do Not Affect Risk for Early-Onset Alzheimer Disease in a European Consortium Cohort. Hum Mutat. 2015 Dec;36(12):1226-35.

194. Lambert J-C, Grenier-Boley B, Bellenguez C, Pasquier F, Campion D, Dartigues J-F, et al. PLD3 and sporadic Alzheimer's disease risk. Vol. 520, Nature. England; 2015. p. E1.

195. Heilmann S, Drichel D, Clarimon J, Fernandez V, Lacour A, Wagner H, et al. PLD3 in non-familial Alzheimer's disease. Vol. 520, Nature. England; 2015. p. E3-5.

196. Livak KJ, Schmittgen TD. Analysis of relative gene expression data using real-time quantitative PCR and the 2(-Delta Delta C(T)) Method. Methods. 2001 Dec;25(4):402-8.

197. Miller SA, Dykes DD, Polesky HF. A simple salting out procedure for extracting DNA from human nucleated cells. Nucleic Acids Res. 1988 Feb;16(3):1215.

198. Liang WS, Reiman EM, Valla J, Dunckley T, Beach TG, Grover A, et al. Alzheimer's disease is associated with reduced expression of energy metabolism genes in posterior cingulate neurons. Proc Natl Acad Sci U S A. 2008 Mar;105(11):4441-6.

199. Mukadam AS, Breusegem SY, Seaman MNJ. Analysis of novel endosome-to-Golgi retrieval genes reveals a role for PLD3 in regulating endosomal protein sorting and amyloid precursor protein processing. Cell Mol Life Sci. 2018 Jul;75(14):2613-25.

200. Tanaka Y, Suzuki G, Matsuwaki T, Hosokawa M, Serrano G, Beach TG, et al. Progranulin regulates lysosomal function and biogenesis through acidification of 
lysosomes. Hum Mol Genet. 2017 Mar;26(5):969-88.

201. Fazzari P, Horre K, Arranz AM, Frigerio CS, Saito T, Saido TC, et al. PLD3 gene and processing of APP. Nature. 2017 Jan;541(7638):E1-2.

202. Nibbeling EAR, Duarri A, Verschuuren-Bemelmans CC, Fokkens MR, Karjalainen JM, Smeets CJLM, et al. Exome sequencing and network analysis identifies shared mechanisms underlying spinocerebellar ataxia. Brain. 2017 Nov;140(11):2860-78.

203. Unno T, Wakamori M, Koike M, Uchiyama $Y$, Ishikawa K, Kubota $H$, et al. Development of Purkinje cell degeneration in a knockin mouse model reveals lysosomal involvement in the pathogenesis of SCA6. Proc Natl Acad Sci U S A. 2012 Oct;109(43):17693-8.

204. Alves S, Cormier-Dequaire F, Marinello M, Marais T, Muriel M-P, Beaumatin F, et al. The autophagy/lysosome pathway is impaired in SCA7 patients and SCA7 knock-in mice. Acta Neuropathol. 2014 Nov;128(5):705-22.

205. Pedersen KM, Finsen B, Celis JE, Jensen NA. Expression of a novel murine phospholipase $D$ homolog coincides with late neuronal development in the forebrain. J Biol Chem. 1998 Nov;273(47):31494-504.

206. Fortea J, Carmona-Iragui M, Benejam B, Fernandez S, Videla L, Barroeta I, et al. Plasma and CSF biomarkers for the diagnosis of Alzheimer's disease in adults with Down syndrome: a cross-sectional study. Lancet Neurol. 2018 Oct;17(10):860-9.

207. Strydom A, Heslegrave A, Startin CM, Mok KY, Hardy J, Groet J, et al. Neurofilament light as a blood biomarker for neurodegeneration in Down syndrome. Alzheimers Res Ther. 2018 Apr;10(1):39.

208. Weston PSJ, Poole T, Ryan NS, Nair A, Liang Y, Macpherson K, et al. Serum neurofilament light in familial Alzheimer disease: A marker of early neurodegeneration. Neurology. 2017 Nov;89(21):2167-75.

209. Preische O, Schultz SA, Apel A, Kuhle J, Kaeser SA, Barro C, et al. Serum neurofilament dynamics predicts neurodegeneration and clinical progression in presymptomatic Alzheimer's disease. Nat Med [Internet]. 2019;25(2):277-83. Available from: 
https://doi.org/10.1038/s41591-018-0304-3

210. Lewczuk P, Ermann N, Andreasson U, Schultheis C, Podhorna J, Spitzer P, et al. Plasma neurofilament light as a potential biomarker of neurodegeneration in Alzheimer's disease. Alzheimers Res Ther [Internet]. 2018;10(1):71. Available from: https://doi.org/10.1186/s13195-018-0404-9

211. Benedet AL, Ashton NJ, Pascoal TA, Leuzy A, Mathotaarachchi S, Kang MS, et al. Plasma neurofilament light associates with Alzheimer's disease metabolic decline in amyloid-positive individuals. Alzheimer's Dement Diagnosis, Assess Dis Monit [Internet]. 2019;11:679-89. Available from: http://www.sciencedirect.com/science/article/pii/S2352872919300600

212. Mielke MM, Syrjanen JA, Blennow K, Zetterberg H, Vemuri P, Skoog I, et al. Plasma and CSF neurofilament light. Neurology [Internet]. 2019 Jul 16;93(3):e252 LP-e260. Available from: http://n.neurology.org/content/93/3/e252.abstract

213. Jin M, Cao L, Dai Y-P. Role of Neurofilament Light Chain as a Potential Biomarker for Alzheimer's Disease: A Correlative Meta-Analysis. Vol. 11, Frontiers in aging neuroscience. Switzerland; 2019. p. 254.

214. Steinacker P, Anderl-Straub S, Diehl-Schmid J, Semler E, Uttner I, von Arnim CAF, et al. Serum neurofilament light chain in behavioral variant frontotemporal dementia. Neurology. 2018 Oct;91(15):e1390-401.

215. Steinacker P, Semler E, Anderl-Straub S, DiehI-Schmid J, Schroeter ML, Uttner I, et al. Neurofilament as a blood marker for diagnosis and monitoring of primary progressive aphasias. Neurology. 2017 Mar;88(10):961-9.

216. Steinacker P, Blennow K, Halbgebauer S, Shi S, Ruf V, Oeckl P, et al. Neurofilaments in blood and CSF for diagnosis and prediction of onset in Creutzfeldt-Jakob disease. Sci Rep. 2016 Dec;6:38737.

217. Thompson AGB, Luk C, Heslegrave AJ, Zetterberg H, Mead SH, Collinge J, et al. Neurofilament light chain and tau concentrations are markedly increased in the serum of patients with sporadic Creutzfeldt-Jakob disease, and tau correlates with 
rate of disease progression. J Neurol Neurosurg \&amp;amp; Psychiatry [Internet]. 2018 Sep 1;89(9):955 LP-961. Available from: http://jnnp.bmj.com/content/89/9/955.abstract

218. Duering M, Konieczny MJ, Tiedt S, Baykara E, Tuladhar AM, Leijsen E van, et al. Serum Neurofilament Light Chain Levels Are Related to Small Vessel Disease Burden. J stroke. 2018 May;20(2):228-38.

219. Uphaus T, Bittner S, Groschel S, Steffen F, Muthuraman M, Wasser K, et al. NfL (Neurofilament Light Chain) Levels as a Predictive Marker for Long-Term Outcome After Ischemic Stroke. Stroke. 2019 Nov;50(11):3077-84.

220. Varhaug KN, Torkildsen O, Myhr K-M, Vedeler CA. Neurofilament Light Chain as a Biomarker in Multiple Sclerosis. Front Neurol. 2019;10:338.

221. Shahim $P$, Gren $M$, Liman $V$, Andreasson $U$, Norgren N, Tegner $Y$, et al. Serum neurofilament light protein predicts clinical outcome in traumatic brain injury. Sci Rep. 2016 Nov;6:36791.

222. Gisslen M, Price RW, Andreasson U, Norgren N, Nilsson S, Hagberg L, et al. Plasma Concentration of the Neurofilament Light Protein (NFL) is a Biomarker of CNS Injury in HIV Infection: A Cross-Sectional Study. EBioMedicine. 2016 Jan;3:135-40.

223. Nilsson IAK, Millischer V, Karrenbauer VD, Juréus A, Salehi AM, Norring C, et al. Plasma neurofilament light chain concentration is increased in anorexia nervosa. Transl Psychiatry [Internet]. 2019;9(1):180. Available from: https://doi.org/10.1038/s41398-019-0518-2

224. Schöll $M$, Maass A, Mattsson N, Ashton NJ, Blennow $K$, Zetterberg $H$, et al. Biomarkers for tau pathology. Mol Cell Neurosci. 2019 Jun;97:18-33.

225. Fossati S, Ramos Cejudo J, Debure L, Pirraglia E, Sone JY, Li Y, et al. Plasma tau complements CSF tau and P-tau in the diagnosis of Alzheimer's disease. Alzheimer's Dement (Amsterdam, Netherlands). 2019 Dec;11:483-92.

226. Pase MP, Beiser AS, Himali JJ, Satizabal CL, Aparicio HJ, DeCarli C, et al. Assessment of Plasma Total Tau Level as a Predictive Biomarker for Dementia and Related 
Endophenotypes. JAMA Neurol [Internet]. 2019 May 1;76(5):598-606. Available from: https://doi.org/10.1001/jamaneurol.2018.4666

227. Plasma tau/amyloid- $\beta 1-42$ ratio predicts brain tau deposition and neurodegeneration in Alzheimer's disease. Brain [Internet]. 2019 Feb 11;142(5):e19-e19. Available from: https://doi.org/10.1093/brain/awz033

228. Chen T-B, Lee Y-J, Lin S-Y, Chen J-P, Hu C-J, Wang P-N, et al. Plasma A $\beta 42$ and Total Tau Predict Cognitive Decline in Amnestic Mild Cognitive Impairment. Sci Rep. 2019 Sep;9(1):13984.

229. Chunyk AG, Joyce A, Fischer SK, Dysinger M, Mikulskis A, Jeromin A, et al. A Multisite In-depth Evaluation of the Quanterix Simoa from a User's Perspective. AAPS J. 2017 Dec;20(1):10.

230. Karikari TK, Pascoal TA, Ashton NJ, Janelidze S, Benedet AL, Rodriguez JL, et al. Blood phosphorylated tau 181 as a biomarker for Alzheimer's disease: a diagnostic performance and prediction modelling study using data from four prospective cohorts. Lancet Neurol. 2020 May;19(5):422-33.

231. Janelidze S, Mattsson N, Palmqvist S, Smith R, Beach TG, Serrano GE, et al. Plasma Ptau181 in Alzheimer's disease: relationship to other biomarkers, differential diagnosis, neuropathology and longitudinal progression to Alzheimer's dementia. Nat Med. 2020 Mar;26(3):379-86.

232. Thijssen EH, La Joie $R$, Wolf $A$, Strom A, Wang $P$, laccarino $L$, et al. Diagnostic value of plasma phosphorylated tau181 in Alzheimer's disease and frontotemporal lobar degeneration. Nat Med. 2020 Mar;26(3):387-97.

233. Staffaroni AM, Kramer AO, Casey M, Kang H, Rojas JC, Orru CD, et al. Association of Blood and Cerebrospinal Fluid Tau Level and Other Biomarkers With Survival Time in Sporadic Creutzfeldt-Jakob Disease. JAMA Neurol. 2019 May;

234. Kovacs GG, Andreasson U, Liman V, Regelsberger G, Lutz MI, Danics K, et al. Plasma and cerebrospinal fluid tau and neurofilament concentrations in rapidly progressive neurological syndromes: a neuropathology-based cohort. Eur J Neurol. 2017 
Nov;24(11):1326-e77.

235. Foiani MS, Woollacott IO, Heller C, Bocchetta M, Heslegrave A, Dick KM, et al. Plasma tau is increased in frontotemporal dementia. J Neurol Neurosurg Psychiatry. 2018 Aug;89(8):804-7.

236. Rubenstein R, Chang B, Yue JK, Chiu A, Winkler EA, Puccio AM, et al. Comparing Plasma Phospho Tau, Total Tau, and Phospho Tau-Total Tau Ratio as Acute and Chronic Traumatic Brain Injury Biomarkers. JAMA Neurol. 2017 Sep;74(9):1063-72.

237. Chi N-F, Chao S-P, Huang L-K, Chan L, Chen Y-R, Chiou H-Y, et al. Plasma Amyloid Beta and Tau Levels Are Predictors of Post-stroke Cognitive Impairment: A Longitudinal Study [Internet]. Vol. 10, Frontiers in Neurology . 2019. p. 715. Available from: https://www.frontiersin.org/article/10.3389/fneur.2019.00715

238. Pase MP, Himali JJ, Aparicio HJ, Romero JR, Satizabal CL, Maillard P, et al. Plasma total-tau as a biomarker of stroke risk in the community. Ann Neurol [Internet]. 2019 Sep 1;86(3):463-7. Available from: https://doi.org/10.1002/ana.25542

239. Zhao T, Xia Y, Wang D, Pang L. Association between Elevated Serum Tau Protein Level and Sepsis-Associated Encephalopathy in Patients with Severe Sepsis. Can J Infect Dis Med Microbiol = J Can des Mal Infect la Microbiol medicale. 2019;2019:1876174

240. Janelidze S, Stomrud E, Palmqvist S, Zetterberg H, van Westen D, Jeromin A, et al. Plasma $\beta$-amyloid in Alzheimer's disease and vascular disease. Sci Rep. 2016 May;6:26801.

241. de Wolf F, Ghanbari M, Licher S, McRae-McKee K, Gras L, Weverling GJ, et al. Plasma tau, neurofilament light chain and amyloid- $\beta$ levels and risk of dementia; a population-based cohort study. Brain. 2020 Apr;143(4):1220-32.

242. Risacher SL, Fandos N, Romero J, Sherriff I, Pesini P, Saykin AJ, et al. Plasma amyloid beta levels are associated with cerebral amyloid and tau deposition. Alzheimer's Dement (Amsterdam, Netherlands). 2019 Dec;11:510-9.

243. Nakamura A, Kaneko N, Villemagne VL, Kato T, Doecke J, Dore V, et al. High performance plasma amyloid-beta biomarkers for Alzheimer's disease. Nature. 2018 
Feb;554(7691):249-54.

244. Doecke JD, Pérez-Grijalba V, Fandos N, Fowler C, Villemagne VL, Masters CL, et al.

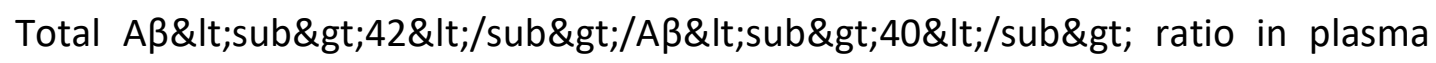
predicts amyloid-PET status, independent of clinical AD diagnosis. Neurology [Internet]. 2020 Apr 14;94(15):e1580 LP-e1591. Available from: http://n.neurology.org/content/94/15/e1580.abstract

245. Alcolea D, Pegueroles J, Muñoz L, Camacho V, López-Mora D, Fernández-León A, et al. Agreement of amyloid PET and CSF biomarkers for Alzheimer's disease on Lumipulse. Ann Clin Transl Neurol. 2019 Sep;6(9):1815-24.

246. Palmqvist S, Insel PS, Stomrud E, Janelidze S, Zetterberg H, Brix B, et al. Cerebrospinal fluid and plasma biomarker trajectories with increasing amyloid deposition in Alzheimer's disease. EMBO Mol Med. 2019 Dec;11(12):e11170.

247. Twohig D, Nielsen HM. $\alpha$-synuclein in the pathophysiology of Alzheimer's disease. Mol Neurodegener [Internet]. 2019;14(1):23. Available from: https://doi.org/10.1186/s13024-019-0320-x

248. McAleese KE, Walker L, Erskine D, Thomas AJ, McKeith IG, Attems J. TDP-43 pathology in Alzheimer's disease, dementia with Lewy bodies and ageing. Brain Pathol. 2017 Jul;27(4):472-9.

249. Mufson EJ, Malek-Ahmadi M, Perez SE, Chen K. Braak staging, plaque pathology, and APOE status in elderly persons without cognitive impairment. Neurobiol Aging. 2016 Jan;37:147-53.

250. Mattson MP, Arumugam T V. Hallmarks of Brain Aging: Adaptive and Pathological Modification by Metabolic States. Cell Metab. 2018 Jun;27(6):1176-99.

251. López-Otín C, Blasco MA, Partridge L, Serrano M, Kroemer G. The hallmarks of aging. Cell. 2013 Jun;153(6):1194-217.

252. Frenk S, Houseley J. Gene expression hallmarks of cellular ageing. Biogerontology [Internet]. 2018;19(6):547-66. Available from: https://doi.org/10.1007/s10522-0189750-z 
253. Friedrich J, Sorge S, Bujupi F, Eichenlaub MP, Schulz NG, Wittbrodt J, et al. Hox Function Is Required for the Development and Maintenance of the Drosophila Feeding Motor Unit. Cell Rep. 2016 Feb;14(4):850-60.

254. Srivastava S, Dhawan J, Mishra RK. Epigenetic mechanisms and boundaries in the regulation of mammalian Hox clusters. Mech Dev [Internet]. 2015;138:160-9. Available from: http://www.sciencedirect.com/science/article/pii/S0925477315300162

255. Smith RG, Hannon E, De Jager PL, Chibnik L, Lott SJ, Condliffe D, et al. Elevated DNA methylation across a 48-kb region spanning the HOXA gene cluster is associated with Alzheimer's disease neuropathology. Alzheimers Dement. 2018 Dec;14(12):1580-8.

256. Bacalini MG, Gentilini D, Boattini A, Giampieri E, Pirazzini C, Giuliani C, et al. Identification of a DNA methylation signature in blood cells from persons with Down Syndrome. Aging (Albany NY). 2015 Feb;7(2):82-96.

257. Gallardo G. Neurogenesis takes a hit in Alzheimer's disease. Sci Transl Med [Internet]. 2019 May 1;11(490):eaax1726. Available from: http://stm.sciencemag.org/content/11/490/eaax1726.abstract

258. Tobin MK, Musaraca K, Disouky A, Shetti A, Bheri A, Honer WG, et al. Human Hippocampal Neurogenesis Persists in Aged Adults and Alzheimer's Disease Patients. Cell Stem Cell. 2019 Jun;24(6):974-982.e3.

259. Scopa C, Marrocco F, Latina V, Ruggeri F, Corvaglia V, La Regina F, et al. Impaired adult neurogenesis is an early event in Alzheimer's disease neurodegeneration, mediated by intracellular A $\beta$ oligomers. Cell Death Differ [Internet]. 2019; Available from: https://doi.org/10.1038/s41418-019-0409-3

260. Choi SH, Tanzi RE. Is Alzheimer's Disease a Neurogenesis Disorder? Cell Stem Cell. 2019 Jul;25(1):7-8. 


\section{ANEXOS}


Biomarcadores sanguíneos en la enfermedad de Alzheimer. $M$. Altuna-Azkargorta, M. Mendioroz-Iriarte. Neurologia. 2018 May 8. pii: S0213-4853(18)30091-4. doi: 10.1016/j.nrl.2018.03.006. 


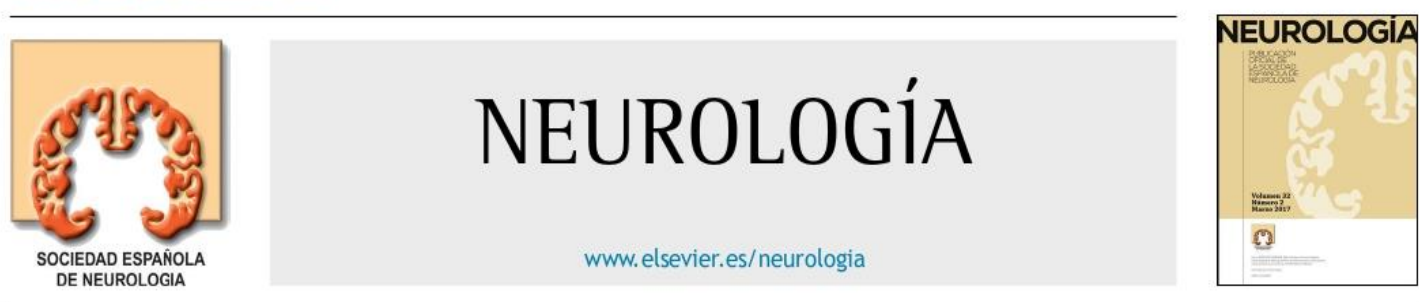

\section{REVISIÓN}

\section{Biomarcadores sanguíneos en la enfermedad de Alzheimer}

\section{Altuna-Azkargorta ${ }^{a, *}$ y M. Mendioroz-Iriarte ${ }^{a, b}$}

a Laboratorio de Neuroepigenética, Navarrabiomed, Complejo Hospitalario de Navarra, Universidad Pública de Navarra (UPNA), IdiSNA, Pamplona, España

b Servicio de Neurología, Complejo Hospitalario de Navarra, Pamplona, España

Recibido el 30 de diciembre de 2017; aceptado el 1 de marzo de 2018

\author{
PALABRAS CLAVE \\ Demencia; \\ Enfermedad de \\ Alzheimer; \\ Diagnóstico precoz; \\ Biomarcadores \\ sanguíneos
}

\begin{abstract}
Resumen
Introducción: El diagnóstico precoz de la enfermedad de Alzheimer mediante la utilización de biomarcadores podría facilitar la instauración y monitorización de intervenciones terapéuticas tempranas con potencial capacidad para modificar significativamente el curso de la enfermedad.

Desarrollo: Los biomarcadores clásicos de líquido cefalorraquídeo y de neuroimagen estruc tural y funcional aprobados tienen una aplicación clínica limitada, dado su carácter invasivo o su elevado coste. La identificación de biomarcadores más accesibles y menos costosos, como los sanguíneos, facilitaría su aplicación en la práctica clínica. Se presenta una revisión bibliográfica de los principales biomarcadores bioquímicos sanguíneos con potencial utilidad para el diagnóstico de la enfermedad de Alzheimer.

Conclusiones: Los biomarcadores sanguíneos son coste y tiempo efectivos con respecto a los marcadores de líquido cefalorraquídeo. Sin embargo, la aplicabilidad inmediata de los biomarcadores bioquímicos sanguíneos en la práctica clínica es poco esperable. Las principales limitaciones estriban en la dificultad para la medición y estandarización de los umbrales entre los diferentes laboratorios y en los fallos de replicación de resultados. Entre todas las moléculas estudiadas, los biomarcadores de apoptosis y neurodegeneración, al igual que los paneles de biomarcadores obtenidos mediante aproximaciones ómicas - como la metabolómica de forma aislada o combinada - ofrecen los resultados más prometedores.

( 2018 Sociedad Española de Neurología. Publicado por Elsevier España, S.L.U. Este es un artículo Open Access bajo la licencia CC BY-NC-ND (http: //creativecommons.org/licenses/bync-nd/4.0/).
\end{abstract}

\footnotetext{
* Autor para correspondencia.

Correo electrónico: mialaz@gmail.com (M. Altuna-Azkargorta).
}

https://doi. org/10.1016/j.nrl.2018.03.006

0213-4853/@ 2018 Sociedad Española de Neurología. Publicado por Elsevier España, S.L.U. Este es un artículo Open Access bajo la licencia CC BY-NC-ND (http://creativecommons.org/licenses/by-nc-nd/4.0/).

Cómo citar este artículo: Altuna-Azkargorta M, Mendioroz-Iriarte M. Biomarcadores sanguíneos en la enfermedad de Alzheimer. Neurología. 2017. https://doi.org/10.1016/j.nrl.2018.03.006 
KEYWORDS

Dementia;

Alzheimer disease;

Early diagnosis;

Blood biomarkers

\section{Blood biomarkers in Alzheimer's disease}

\section{Abstract}

Introduction: The early diagnosis of Alzheimer's disease $(\mathrm{AD})$ via the use of biomarkers could facilitate the implementation and monitoring of early therapeutic interventions with the potential capacity to significantly modify the course of the disease.

Development: Classic cerebrospinal fluid biomarkers and approved structural and functional neuroimaging have a limited clinical application given their invasive nature and/or high cost. The identification of more accessible and less costly biomarkers, such as blood biomarkers, would facilitate application in clinical practice. We present a literature review of the main blood biochemical biomarkers with potential use for diagnosing Alzheimer's disease.

Conclusions: Blood biomarkers are cost and time effective with regard to cerebrospinal fluid biomarkers. However, the immediate applicability of blood biochemical biomarkers in clinical practice is not very likely. The main limitations come from the difficulties in measuring and standardising thresholds between different laboratories and in failures to replicate results. Among all the molecules studied, apoptosis and neurodegeneration biomarkers and the biomarker panels obtained through omics approaches, such as isolated or combined metabolomics, offer the most promising results.

(c) 2018 Sociedad Española de Neurología. Published by Elsevier España, S.L.U. This is an open access article under the CC BY-NC-ND license (http://creativecommons.org/licenses/bync-nd/4.0/).

\section{Introducción}

La enfermedad de Alzheimer (EA) es la enfermedad neurodegenerativa más frecuente, responsable del $50-70 \%$ de los casos de demencia ${ }^{1.7}$, con una previsión de hasta 115 millones de personas afectadas para el año $2050^{8-10}$. En la actualidad, la demencia es la tercera causa de muerte tras las enfermedades cardiovasculares y el cáncer ${ }^{3}$.

A pesar de su gran impacto, la patogénesis de la EA permanece en gran medida desconocida. La hipótesis más aceptada es la de la cascada amiloidea ${ }^{10-13}$, aunque también se han descritos trastornos de la homeostasis del calcio, colesterol y glucosa como factores contribuyentes a la patogenia de la $E A^{4}$. Además, se ha postulado que la enfermedad micro- y macrovascular podría contribuir a la generación de enfermedad amiloidea y neurodegeneración, precediendo al desarrollo de la demencia asociada a la EA ${ }^{11}$.

Por otro lado, se estima que los procesos neurodegenerativos pueden comenzar hasta 20-30 años antes del inicio de los síntomas ${ }^{3,14}$. La detección precoz de la EA en etapas presintomáticas ofrecería una gran oportunidad para establecer intervenciones terapéuticas tempranas y con mayor probabilidad de éxito, puesto que se realizarían antes de que el daño sináptico y la pérdida neuronal estuvieran extendidos. En este escenario, resultaría muy útil la incorporación a la práctica clínica de nuevos biomarcadores, más accesibles y menos costosos que los biomarcadores clásicos ${ }^{15}$.

En este trabajo, se presenta una revisión bibliográfica de los principales biomarcadores bioquímicos sanguíneos con potencial utilidad en la práctica clínica para el diagnóstico de la EA.

\section{Utilidad y limitaciones de los biomarcadores sanguíneos en la enfermedad de Alzheimer}

La principal limitación de los biomarcadores clásicos de la EA -biomarcadores «core» en líquido cefalorraquídeo (LCR),
$A ß$, tau-total (tau-t) y tau fosforilada (tau-p), y PET de metabolismo de glucosa y depósito amiloide ${ }^{4,16-23}$ - es su carácter invasivo y coste excesivo, lo que dificulta su aplicación en la práctica clínica ${ }^{24}$.

La sangre es un fluido accesible que puede utilizarse como origen de potenciales biomarcadores de cribado diagnóstico para EA. Además, los biomarcadores sanguíneos son coste y tiempo efectivos con respecto a los marcadores de $\operatorname{LCR}^{2,18,25,26}$. Los biomarcadores deben estar relacionados con características específicas de la enfermedad, tener gran sensibilidad y especificidad para EA y ser reproducibles, no invasivos, fáciles de realizar y de bajo coste ${ }^{9}$. Cumpliendo los anteriores postulados, los biomarcadores sanguíneos podrían identificar a pacientes en riesgo de presentar EA, de progresión de deterioro cognitivo leve (DCL) a EA y de progresión rápida dentro de la EA clínicamente establecida ${ }^{8}$.

Una de las dificultades para la identificación de biomarcadores sanguíneos en la EA estriba en que es una enfermedad lentamente progresiva y que se desconoce el grado de pérdida de integridad de la barrera hematoencefálica. Sin embargo, se ha descrito la existencia de disfunción de la barrera hematoencefálica en los pacientes con EA, lo que implicaría la existencia de intercambio de proteínas y otras moléculas entre el LCR y la sangre ${ }^{16}$.

Otra limitación es que la sangre es un fluido complejo con múltiples factores de confusión: son necesarios protocolos estandarizados para la preparación de la muestra y su análisis ${ }^{17,25}$. Las diferencias descritas en concentra ciones de analitos específicos podrían deberse a falta de estandarización de los métodos de calibración, a diferentes diluciones de muestras biológicas, a variabilidad en los anticuerpos utilizados y a diferencias de sensibilidad y fiabilidad instrumental ${ }^{2,25}$.

Las aproximaciones para identificar biomarcadores sanguíneos de EA se pueden dividir en dirigidas a identificar moléculas concretas (candidatas) relacionadas con mecanismos patogénicos conocidos y a explorar de forma no sesgada 
un perfil sérico o plasmático de moléculas mediante tecnologías ómicas ${ }^{25}$.

\section{Identificación de biomarcadores sanguíneos en la enfermedad de Alzheimer con aproximación «molécula candidata»}

\section{Péptidos A $\beta$}

Se han intentado identificar marcadores de enfermedad amiloidea en sangre periférica, dada la creencia de que la amiloidogénesis es el centro de la patogenia de la EA (tabla 1).

$\mathrm{La}$ isoforma de $A \beta-42$ es el principal componente de placas seniles ${ }^{1}$. Es un producto de degradación de la proteína precursora de amiloide y puede producir daño en el ácido desoxirribonucleico (ADN) mediante mecanismos de estrés oxidativo. El A $\beta$ circulante tiene origen tanto periférico como central. Se ha observado que diferentes factores bioquímicos, técnicos, clínicos, demográficos y genéticos afectan a los niveles de péptido $A \beta$. Por ejemplo, el $A \beta$ circulante se une a proteínas plasmáticas y a las paredes de los tubos de ensayo, dado su carácter hidrofóbico, e induce enmascaramiento de epítopos e interferencia analítica ${ }^{16}$.

Existe una pobre correlación entre los niveles de $A \beta$ en sangre y el LCR ${ }^{1}$. Aun así, se ha detectado un incremento de $A \beta 1-42$ sérico en pacientes con EA con respecto a controles, que es más llamativo en pacientes con EA familiar o asociada $^{3,17}$ a trisomía 21. Los niveles plasmáticos elevados de $A \beta-42$, bajos de $A \beta-40$ y un ratio $A \beta-42 / A \beta-40$ reducido en pacientes con edad avanzada podrían indicar conversión de normalidad cognitiva a DCL o $E^{3}$.

Sin embargo, debido a la influencia de múltiples factores, la imposibilidad para reproducir muchos de los resultados y su controversia, actualmente no se puede establecer un claro papel de $A \beta$ como biomarcador plasmático ${ }^{3,25}$.

Proteína tau y enzimas relacionadas con su fosforilación La fosforilación de la proteína tau en diferentes residuos regula su capacidad para formar oligómeros y agregados ${ }^{3,9}$ que contribuirán a la formación de ovillos neurofibrilares.
Los métodos basados en la técnica de inmunoanálisis ELISA no tienen suficiente sensibilidad para detectar concentraciones bajas de tau plasmática ${ }^{1,2}$, pero sí una nueva técnica ultrasensible de inmunoanálisis. Mediante esta téc nica se han detectado concentraciones plasmáticas de tau más elevadas en pacientes con EA con respecto a DCL y controles. La correlación entre tau plasmática y tau en LCR es muy débil, prácticamente inexistente ${ }^{27}$.

La detección de proteína tau en plasma se ha asociado con una mayor pérdida longitudinal de volumen hipocámpico y de grosor cortical en regiones específicamente afectas en EA, como la corteza entorrinal, la región inferomedial del lóbulo temporal, el giro fusiforme y el precuneus ${ }^{26,28,29}$

Se ha postulado que los niveles de tau-t y tau-p se correlacionarían con las puntuaciones en test neuropsicológicos y podrían discriminar a pacientes con EA de los de DCL, y estos de los controles ${ }^{1,4,8,25,27}$. Sin embargo, la existencia de un gran solapamiento entre los valores de controles y pacientes dificulta su empleo como biomarcador ${ }^{25,26}$.

La proteína tau plasmática podría ser un marcador inespecífico de neurodegeneración, al objetivarse incrementado en pacientes con ictus isquémico, traumatismo craneoencefálico y prionopatías ${ }^{16}$. Pero la asociación descrita entre niveles de tau plasmático y atrofia en regiones específicamente afectas en la EA permite plantearla como un potencial marcador de cribado de EA precoz ${ }^{17}$.

Algunas proteína-cinasas, entre ellas la cinasa-glicógenosintetasa-3 $\beta$ (GSK-3 $\beta$ ), se han relacionado con la hiperfosforalización de proteína tau ${ }^{3}$. Los niveles plasmáticos de GSK-3 $\beta$ estarian significativamente incrementados en pacientes con EA y DCL frente a controles de la misma edad, lo que lo convierte en un potencial biomarcador ${ }^{17}$.

Por otra parte, DYRK1A (dual specificity tyrosinephosphorylation regulated kinase $A$ ) está implicada en la hiperfosforilación de tau. Esta enzima vincula la enfermedad amiloidea y tau, al regularse los niveles de DYRK1A por los niveles de $A \beta$. Los niveles sanguíneos de DYRK1A son significativamente menores en pacientes con EA respecto a controles, incluso en estadios precoces de la enfermedad ${ }^{9}$,

Tabla 1 Listado de biomarcadores identificados con aproximación molécula candidata con posible finalidad diagnóstica en EA

\begin{tabular}{lll}
\hline Molécula & Vía patogénica & Tendencia en la enfermedad \\
\hline A 1 -42 & Amiloidogénica & Incremento en EA y DCL frente a controles \\
Tau-t y Tau-p & Taupatía & Incremento en EA y DCL frente a controles \\
GSK-3 $\beta$ & Taupatía & Incremento en EA y DCL frente a controles \\
DYRK1A & Taupatía & Disminución en EA y DCL frente a controles \\
& Amiloidogénica & \\
NF-L & Neurodegeneración & Incremento en EA y DCL frente a controles \\
BDNF & Neurodegeneración & Disminución en EA frente a controles, pero no en DCL \\
TNF $\alpha$ & Inflamatoria & Incremento en EA y DCL frente a controles \\
CCL-1 & Inflamatoria & Incremento en EA y DCL frente a controles \\
Monoamino oxidasa B & Daño vascular & Incremento en EA y DCL frente a controles \\
Actividad fosfolipasa 2 & Daño vascular & Incremento en EA frente a controles \\
BACE-1 & Daño vascular & Incremento en EA y DCL frente a controles \\
Homocisteína & Daño vascular & Incremento en EA frente a controles. \\
Ácido fólico & Daño vascular & Disminución en EA frente a controles \\
Cistatina C & Daño vascular & Disminuido en EA y DCL frente a controles \\
Clusterina & Amiloidogénica & \\
\hline
\end{tabular}

BDNF: factor neurotrófico derivado de cerebro

Cómo citar este artículo: Altuna-Azkargorta M, Mendioroz-Iriarte M. Biomarcadores sanguíneos en la enfermedad de Alzheimer. Neurología. 2017. https://doi.org/10.1016/j.nrl.2018.03.006 
lo que lo habilita como potencial biomarcador de diagnóstico precoz. También se ha relacionado DYRK1A con la disregulación de vías neurotróficas, sobre todo, del factor neurotrófico derivado de cerebro, molécula con múltiples funciones en la plasticidad sináptica y la supervivencia neuronal, y cuyos niveles sanguíneos están disminuidos en fases moderadas-avanzadas de la $\mathrm{EA}^{9,30}$.

\section{Neurofilamento ligero}

Los pacientes con EA presentan concentraciones elevadas de neurofilamento ligero (NF-L), marcador de daño neuronal, en el $\mathrm{LCR}^{26}$. Además, existe una excelente correlación entre los niveles plasmáticos y en $\mathrm{LCR}^{1,17}$. Los niveles plasmáticos de NF-L están elevados en pacientes con EA y DCL A $\beta$ positivos y están asociados con el grado de deterioro cognitivo (puntuación en MiniMental Test y Trail Making Test parte B) y con alteraciones descritas en neuroimagen al diagnóstico y evolución de la enfermedad. Sin embargo, la elevación plasmática de NF-L no es específica de la EA: se detecta en otras enfermedades neurodegenerativas y se considera, por tanto, como un marcador de neurodegeneración ${ }^{26}$.

\section{Biomarcadores basados en la hipótesis inflamatoria de la enfermedad de Alzheimer}

En la hipótesis inflamatoria, la neuroinflamación no es consecuencia de la neurodegeneración, sino un factor patogénico en fases iniciales y en la progresión de la enfermedad que perpetuaría el daño neuronal, con activación de microglía y linfocitos $T$ periféricos e implicación del sistema inmune innato ${ }^{10}$. El depósito de tau activaría la microglía y los astrocitos. Además, las formas insolubles de $A \beta$ actuarían sobre los receptores toll-like, mientras que las $A \beta$ solubles serían fagocitadas por la microglía, activando las proteínacinasas-mitógeno-activadas y estimulando la producción de genes proinflamatorios y citocinas, lo que perpeturaría la inflamación. Las citocinas, a su vez, atraerían a células del sistema inmune periférico y producirían alteraciones en la permeabilidad de la barrera hematoencefálica.

Los mediadores inflamatorios presentes en LCR y sangre, y particularmente citocinas y quimocinas, podrían ser utilizados como biomarcadores para el diagnóstico precoz de la EA. En el cerebro de pacientes con EA, como citocinas mediadoras de respuesta inmune, destacan las interleucinas (IL-1, IL-4, IL-6, IL-10), el interferón- $\gamma$ y el factor de necrosis tumoral $\alpha(\mathrm{TNF} \alpha)^{4,22,30}$.

La citocina I-309 es una glicoproteína secretada por linfocitos T activados. Su función principal es atraer linfocitos $\mathrm{B}$ inmaduros, monocitos, células natural killers y dendríticas con receptores CCR8. Se ha postulado como posible predictor de progresión de $\mathrm{DCL}$ a $\mathrm{EA}^{25}$.

\section{Autoanticuerpos}

La presencia de autoanticuerpos en la EA está bien establecida, pero no así su papel patogénico. Su aplicación como posibles biomarcadores es de gran interés, dada su presencia en sangre y LCR.

Se han estudiado anticuerpos anti-A $\beta$ sin concluir su utilidad clínica y se ha planteado el uso de perfiles de autoanticuerpos sanguíneos con prometedores resultados ${ }^{16,31,32}$.
Existe evidencia de que determinados los anticuerpos antifosfólipido obtenidos mediante oxidorreducción están disminuidos en el LCR de pacientes con EA, pero no claramente en sangre. Los niveles de anticuerpos antifosfolípido obtenidos mediante oxidorreducción tienen un incremento inicial en fases de $\mathrm{DCL}$ y posterior disminución con la evolución de la enfermedad. Por tanto, se postulan como marcadores del estadio y no como diagnósticos ${ }^{13}$.

\section{Biomarcadores de apoptosis}

La clusterina está relacionada con procesos de neurodegeneración y sus niveles sanguíneos están incrementados en pacientes con EA. Los niveles de clusterina se correlacionan con el depósito de amiloide objetivado mediante PET y con el grado de atrofia hipocámpica. Se ha postulado que la clusterina podría actuar como transportadora de proteínas extracelulares, entre ellas $A \beta$, y que dicha unión disminuiría su toxicidad ${ }^{25,33}$.

\section{Biomarcadores de plaquetas}

Se ha detectado un incremento de la actividad $\beta$-secretasa1 , expresión elevada de monoamino oxidasa $B$ y actividad fosfolipasa A2 en plaquetas sanguíneas y en el cerebro de pacientes con $\mathrm{EA}^{3,17}$.

\section{Biomarcadores de daño microvascular}

Los factores de riesgo vascular clásicamente se han implicado en el incremento de riesgo de la EA. Se ha detectado una elevación sanguínea del péptido natriurético auricular y la adrenomedulina desde las fases prodrómicas. Además, la adrenomedulina se ha encontrado elevada en el cerebro de pacientes con $\mathrm{EA}^{34}$, confirmándose como potencial biomarcador relacionado con la patogenia de la enfermedad. Por el contrario, no se han detectado diferencias en la expresión de las moléculas de adhesión (VCAM-1 e ICAM-1), ni en selectinas ${ }^{35}$

Los niveles plasmáticos de homocisteína estarían relacionados directamente con los niveles de $A \beta-42$. La hiperhomocisteinemia reduce la neurogénesis mediante un mecanismo que implica el factor del crecimiento de fibroblastos. La homocisteína moderadamente elevada es un factor de riesgo para demencia vascular y EA: se ha objetivado un incremento significativo en los niveles plasmáticos de homocisteína en pacientes con $\mathrm{EA}^{9}$.

Por otra parte, se ha descrito asociación entre EA y niveles plasmáticos bajos de ácido fólico. El ácido fólico es esencial para el metabolismo de la homocisteína. En la EA, la reparación del ADN se encuentra inhibida por el daño oxidativo inducido por $A \beta$ acompañado de deficiencia de ácido fólico. El ácido fólico regula la actividad ADN-metiltransferasa atenuando la producción de $A \beta$. La actividad ADN-metil-transferasa se correlaciona con la formación de la memoria reciente y el mantenimiento de la memoria remota. Se ha postulado que la combinación de niveles de folato, hemoglobina y APOE incrementaría la sensibilidad predictiva respecto al nivel de folato usado de forma aislada como biomarcador diagnóstico de la EA. También se ha documentado que la hemoglobina se uniría a $A \beta$ y favorecería su agregación; por tanto, cifras elevadas de hemoglobina podrían considerarse un factor de riesgo de la $\mathrm{EA}^{12}$. 
La cistatina $C$ es un inhibidor endógeno de cisteína, producida por casi todas las células humanas y disponible prácticamente en todos los fluidos corporales y es considerada como uno de los potenciales marcadores de daño vascular. La cistatina $C$ impide la agregación de $A \beta$ y su depósito de forma concentración-dependiente por su unión a la proteína precursora de amiloide y a los péptidos $A \beta 1-40$ y $A \beta 1-42$. Los niveles séricos y en LCR de cistatina $C$ estarían disminuidos en pacientes con EA desde fases iniciales ${ }^{36}$.

\section{Identificación de biomarcadores sanguíneos en la enfermedad de Alzheimer mediante tecnologias ómicas}

\section{Proteómica plasmática}

Con el objetivo de discriminar pacientes con EA de sujetos sanos, varios estudios han aportado paneles de biomarcadores compuestos por gran cantidad de proteínas con diferentes combinaciones de alta sensibilidad y especificidad. Sin embargo, los resultados muestran un alcance limitado, dada la dificultad de replicarlos ${ }^{17,25,37}$ (tabla 2).

Comparando los perfiles proteómicos en sangre periférica, se ha objetivado desde fases precoces de la EA que los niveles de apolipoproteína A-1 (que inhibe la agregación de oligómeros $A \beta$ disminuyendo su acúmulo extracelular), $\alpha-2$ HS-glicoproteína (con funciones antiinflamatorias y efecto neuroprotector), afamina (proteína de unión específica a vitamina $E$ que permite su transporte por la barrera hematoencefálica con potencial efecto beneficioso sobre el daño ocasionado por $A \beta$ o estrés oxidativo) y plasminógeno están significativamente más bajos en pacientes respecto a controles. Los niveles de apolipoproteína A-4 y cadenas gamma de fibrinógeno, propuestos como responsables de anomalías vasculares en la EA, están significativamente más elevados con respecto a controles $3,16,18$. Por ello, se podrían convertir en biomarcadores para el diagnóstico precoz de EA. Al igual que $\alpha$-1-antitripsina, $\alpha$-2-macroglobulina, apolipoproteína $E$ y complemento $\mathrm{C} 3$, propuestos como biomarcadores diagnósticos de EA tras una revisión sistemática con replicación posterior $^{38}$.

\section{Metabolómica plasmática}

La metabolómica permite identificar alteraciones metabólicas monitorizando simultáneamente una gran variedad de metabolitos, lo que contribuye a comprender mejor la patogenia de la enfermedad. Así, los estudios de perfiles de lipidómica en pacientes con EA esporádica han mostrado la existencia de déficits significativos en 2 categorías importantes de lípidos estructurales: glicerofosfolípidos y esfingolípidos, junto con modificaciones en su metabolismo ${ }^{16,17,39-41}$.

\section{Conclusiones}

En la actualidad, existe un amplio consenso sobre la necesidad de aplicación de terapias anti-A $\beta$ en fases tempranas, posiblemente preclínicas, de la EA. El lento depósito de $A \beta$ enfatiza la existencia de una amplia ventana temporal en la que modificar la acumulación de $A \beta$, pero su identificación clínica requiere el uso de biomarcardores. De elección serían los no invasivos y no excesivamente costosos, como los biomarcadores sanguíneos.

Históricamente, la sensibilidad y especificidad de los biomarcadores sanguíneos ha sido menor que las de los de LCR. La gran dificultad para reproducir y validar con adecuada sensibilidad y especificidad los resultados de biomarcadores sanguíneos ha limitado su aplicación en la práctica clínica hasta la fecha. No obstante, es obvio que existe evidencia creciente sobre la existencia de una especie de firma biológica sanguínea de la $E^{15}$. Los biomarcadores sanguíneos de neurodegeneración, y entre ellos tau y NF-L más que $A B$; de apoptosis como la clusterina; paneles de proteómica $y$ metabolómica probablemente sean los más prometedores. En cambio, es más discutible en la actualidad la utilidad de biomarcadores inflamatorios, de plaquetas o daño microvascular.

La identificación de biomarcadores sanguíneos fiables para el diagnóstico de la EA sigue limitada en la actualidad por problemas técnicos: es muy difícil estandarizar un biomarcador sanguíneo para su uso mundial, dadas las diferencias de muestra, de población estudiada, etc. Pero, gracias a que existen iniciativas globales para superar dichas limitaciones, es probable que, en un futuro próximo, se podrán aplicar en la práctica clínica. Además, dada las limitaciones encontradas en los biomarcadores sanguíneos individuales en cuanto a su sensibilidad, especificidad y valores predictivos, su combinación en paneles de biomarcadores surge como la opción más realista para su aplicación en la práctica clínica.

Por otra parte, nuevos campos del conocimiento están emergiendo como fuentes de potenciales herramientas diagnósticas, como es el caso de los biomarcadores epigenéticos, entre ellos las marcas de metilación del ADN y ciertos ARN no codificantes, como los microARN.

Tabla 2 Listado de biomarcadores identificados con aproximación proteómica con posible finalidad diagnóstica en EA

\begin{tabular}{lll}
\hline Molécula & Vía patogénica & Tendencia en la enfermedad \\
\hline Apolipoproteína A1 & Amiloidogénica & Disminuido en EA y DCL frente a controles \\
Alfa-2-HS-glicoproteína & Inflamatoria & Disminuido en EA y DCL frente a controles \\
Afamina & Amiloidogénica & Disminuido en EA frente a controles \\
Plasminógeno & Daño vascular & Disminuido en EA frente a controles \\
Apolipoproteína A4 & Daño vascular & Aumentado en EA y DCL frente a controles \\
Cadenas gamma fibrinógeno & Daño vascular & Aumentado en EA y DCL frente a controles \\
$\alpha-1$-antitripsina & Amiloidogénica & Incremento en EA frente a controles \\
$\alpha-2$-macroglobulina & Amiloidogénica & Incremento en EA frente a controles \\
Complemento C3 & Inflamatoria & Incremento en EA frente a controles \\
\hline
\end{tabular}

Cómo citar este artículo: Altuna-Azkargorta M, Mendioroz-Iriarte M. Biomarcadores sanguíneos en la enfermedad de Alzheimer. Neurología. 2017. https://doi.org/10.1016/j.nrl.2018.03.006 
En el futuro, los estudios de aproximación ómica permitirán nuevos niveles de conocimiento y análisis. Por ejemplo, mediante la aplicación simultánea de diferentes tecnologías ómicas al mismo conjunto de muestras o por medio de nuevos métodos de análisis de datos, combinando técnicas bioinformáticas, estadísticas y de inteligencia artificial, se podrán identificar nuevas vías biológicas alteradas en la EA. La identificación de nuevos patrones de biomarcadores junto con las cascadas moleculares afectadas podría ser utilizada para el descubrimiento de futuras dianas terapéuticas para tratamiento de la EA.

\section{Conflicto de intereses}

Los autores declaran no tener conflicto de intereses.

\section{Bibliografía}

1. Zetterberg $\mathrm{H}$. Applying fluid biomarkers to Alzheimer's disease Am J Physiol Cell Physiol. 2017 Jul;313:C3-10.

2. Jammeh $E$, Zhao $P$, Carroll C, Pearson S, Ifeachor E. Identification of blood biomarkers for use in point of care diagnosis tool for Alzheimer's disease. Conf Proc IEEE Eng Med Biol Soc. 2016 Aug;2016:2415-8.

3. Jellinger KA, Janetzky B, Attems J, Kienzl E. Biomarkers for early diagnosis of Alzheimer disease: «ALZheimer ASsociated gene»-a new blood biomarker? J Cell Mol Med. 2008 Aug;12:1094-117.

4. Tatebe H, Kasai $T$, Ohmichi $T$, Kishi $Y$, Kakeya T, Waragai $M$, et al. Quantification of plasma phosphorylated tau to use as a biomarker for brain Alzheimer pathology: Pilot case-control studies including patients with Alzheimer's disease and down syndrome. Mol Neurodegener. 2017 Sep;12:63.

5. Doecke JD, Laws SM, Faux NG, Wilson W, Burnham SC, Lam C-P, et al. Blood-based protein biomarkers for diagnosis of Alzheimer disease. Arch Neurol. 2012 Oct;69:1318-25.

6. Lehmann S, Teunissen CE. Biomarkers of Alzheimer's disease: The present and the future. Front Neurol. 2016;7:158.

7. Huynh RA, Mohan C. Alzheimer's disease: Biomarkers in the genome, blood, and cerebrospinal fluid. Front Neurol. 2017;8:102.

8. Shekhar S, Kumar R, Rai N, Kumar V, Singh K, Upadhyay AD, et al. Estimation of tau and phosphorylated tau181 in serum of Alzheimer's disease and mild cognitive impairment patients. PLoS One. 2016;11:e0159099.

9. Janel N, Sarazin M, Corlier F, Corne H, de Souza LC, Hamelin $\mathrm{L}$, et al. Plasma DYRK1A as a novel risk factor for Alzheimer's disease. Transl Psychiatry. 2014 Aug:4:e425.

10. Mietelska-Porowska A, Wojda U. T lymphocytes and inflammatory mediators in the interplay between brain and blood in Alzheimer's disease: Potential pools of new biomarkers. J Immunol Res. 2017;2017:4626540.

11. Ewers M, Mielke MM, Hampel H. Blood-based biomarkers of microvascular pathology in Alzheimer's disease. Exp Gerontol. 2010 Jan;45:75-9.

12. Yoshinaga T, Nishimata H, Kajiya Y, Yokoyama S. Combined assessment of serum folate and hemoglobin as biomarkers of brain amyloid beta accumulation. PLoS One. 2017;12: e0175854.

13. McIntyre JA, Ramsey CJ, Gitter BD, Saykin AJ, Wagenknecht DR, Hyslop PA. Antiphospholipid autoantibodies as blood biomarkers for detection of early stage Alzheimer's disease. Autoimmunity. 2015;48:344-51.
14. Knopman DS. Alzheimer disease biomarkers and insights into mild cognitive impairment. Neurology. 2013;80:978-80, http://dx.doi.org/10.1212/WNL.0b013e31828728ac. Epub 2013 Feb 6.

15. Fiandaca MS, Mapstone ME, Cheema AK, Federoff HJ. The critical need for defining preclinical biomarkers in Alzheimer's disease. Alzheimers Dement. 2014 Jun; 10(3 Suppl):S196-212.

16. Henriksen K, O'Bryant SE, Hampel H, Trojanowski JQ, Montine TJ, Jeromin A, et al. The future of blood-based biomarkers for Alzheimer's disease. Alzheimers Dement. 2014 Jan;10:115-31.

17. Lista S, O'Bryant SE, Blennow K, Dubois B, Hugon J, Zetterberg $\mathrm{H}$, et al. Biomarkers in sporadic and familial Alzheimer's disease. J Alzheimers Dis. 2015;47:291-317.

18. Kitamura Y, Usami R, Ichihara S, Kida H, Satoh M, Tomimoto $\mathrm{H}$, et al. Plasma protein profiling for potential biomarkers in the early diagnosis of Alzheimer's disease. Neurol Res. 2017 Mar;39:231-8.

19. Molinuevo JL, Blennow K, Dubois B, Engelborghs S, Lewczuk P, Perret-Liaudet A, et al. The clinical use of cerebrospinal fluid biomarker testing for Alzheimer's disease diagnosis: A consensus paper from the Alzheimer's Biomarkers Standardization Initiative. Alzheimers Dement. 2014 Nov; 10:808-17.

20. Lleo A, Cavedo E, Parnetti L, Vanderstichele H, Herukka SK, Andreasen $\mathrm{N}$, et al. Cerebrospinal fluid biomarkers in trials for Alzheimer and Parkinson diseases. Nat Rev Neurol. 2015 Jan;11:41-55.

21. Gordon BA, Friedrichsen K, Brier M, Blazey T, Su Y, Christensen $\mathrm{J}$, et al. The relationship between cerebrospinal fluid markers of Alzheimer pathology and positron emission tomography tau imaging. Brain. 2016 Aug;139(Pt 8):2249-60.

22. Sharma N, Singh AN. Exploring biomarkers for Alzheimer's disease. J Clin Diagn Res. 2016 Jul;10:KE01-6.

23. Jack CRJ, Knopman DS, Jagust WJ, Petersen RC, Weiner MW, Aisen PS, et al. Tracking pathophysiological processes in Alzheimer's disease: An updated hypothetical model of dynamic biomarkers. Lancet Neurol. 2013 Feb;12:207-16.

24. De Wilde A, van Maurik IS, Kunneman M, Bouwman F, Zwan M, Willemse EAJ, et al. Alzheimer's biomarkers in daily practice (ABIDE) project: Rationale and design. Alzheimers Dement (Amst). 2017;6:143-51.

25. O'Bryant SE, Mielke MM, Rissman RA, Lista S, Vanderstichele $\mathrm{H}$, Zetterberg $\mathrm{H}$, et al. Blood-based biomarkers in Alzheimer disease: Current state of the science and a novel collaborative paradigm for advancing from discovery to clinic. Alzheimers Dement. 2017 Jan;13:45-58.

26. Mattsson N, Andreasson U, Zetterberg H, Blennow K. Association of plasma neurofilament light with neurodegeneration in patients with Alzheimer disease. JAMA Neurol. 2017 May;74:557-66.

27. Deters KD, Risacher SL, Kim S, Nho K, West JD, Blennow K, et al. Plasma tau association with brain atrophy in mild cog nitive impairment and Alzheimer's disease. J Alzheimers Dis. 2017;58:1245-54.

28. Dage JL, Wennberg AMV, Airey DC, Hagen CE, Knopman DS, Machulda MM, et al. Levels of tau protein in plasma are associated with neurodegeneration and cognitive function in a population-based elderly cohort. Alzheimers Dement. 2016 Dec;12:1226-34.

29. Mielke MM, Hagen CE, Wennberg AMV, Airey DC, Savica R, Knopman DS, et al. Association of plasma total tau level with cognitive decline and risk of mild cognitive impairment or dementia in the Mayo Clinic study on aging. JAMA Neurol. 2017 Sep; 74:1073-80.

30. Gezen-Ak D, Dursun E, Hanagasi H, Bilgic B, Lohman E, Araz OS, et al. BDNF, TNFalpha, HSP90, CFH, and IL-10 serum levels in patients with early or late onset Alzheimer's disease or mild cognitive impairment. J Alzheimers Dis. 2013;37:185-95. 
31. DeMarshall CA, Nagele EP, Sarkar A, Acharya NK, Godsey G, Goldwaser EL, et al. Detection of Alzheimer's disease at mild cognitive impairment and disease progression using autoantibodies as blood-based biomarkers. Alzheimers Dement (Amst). 2016;3:51-62.

32. Gustaw-Rothenberg KA, Siedlak SL, Bonda DJ, Lerner A, Tabaton $M$, Perry $G$, et al. Dissociated amyloid-beta antibody levels as a serum biomarker for the progression of Alzheimer's disease: A population-based study. Exp Gerontol. 2010 Jan; 45:47-52.

33. Gupta VB, Hone E, Pedrini S, Doecke J, O'Bryant S, James I, et al. Altered levels of blood proteins in Alzheimer's disease longitudinal study: Results from Australian Imaging Biomarkers Lifestyle Study of Ageing cohort. Alzheimers Dement (Amst). 2017;8:60-72.

34. Ferrero H, Larrayoz IM, Martisova E, Solas M, Howlett DR, Fran cis PT, et al. Increased levels of brain adrenomedullin in the neuropathology of Alzheimer's disease. Mol Neurobiol. 2017 Sep.

35. Bandaru VVR, Troncoso J, Wheeler D, Pletnikova O, Wang J, Conant K, et al. ApoE4 disrupts sterol and sphingolipid metabolism in Alzheimer's but not normal brain. Neurobiol Aging. 2009 Apr;30:591-9.
36. Sundelof J, Arnlov J, Ingelsson E, Sundstrom J, Basu S, Zethelius B, et al. Serum cystatin C and the risk of Alzheimer disease in elderly men. Neurology. 2008 Sep;71:1072-9.

37. Bjorkgvist M, Ohlsson M, Minthon L, Hansson O. Evaluation of a previously suggested plasma biomarker panel to identify Alzheimer's disease. PLoS One. 2012; 7:e29868.

38. Kiddle SJ, Sattlecker M, Proitsi P, Simmons A, Westman E, Baze net $C$, et al. Candidate blood proteome markers of Alzheimer's disease onset and progression: A systematic review and replication study. J Alzheimers Dis. 2014;38:515-31.

39. Nagaraj S, Laskowska-Kaszub K, Debski KJ, Wojsiat J, Dabrowsk M, Gabryelewicz T, et al. Profile of 6 microRNA in blood plasma distinguish early stage Alzheimer's disease patients from nondemented subjects. Oncotarget. 2017 Mar;8:16122-43.

40. De Leeuw FA, Peeters CFW, Kester MI, Harms AC, Struys EA, Hankemeier T, et al. Blood-based metabolic signatures in Alzheimer's disease. Alzheimers Dement (Amst). 2017;8: 196-207.

41. Han X, Rozen S, Boyle SH, Hellegers C, Cheng H, Burke JR, et al. Metabolomics in early Alzheimer's disease: Identification of altered plasma sphingolipidome using shotgun lipidomics. PLoS One. 2011;6:e21643. 
DNA methylation signature of human hippocampus in Alzheimer's disease is linked to neurogenesis. Altuna, $M$ et al. Clinical Epigenetics 11, 91 (2019) doi:10.1186/s1318-019-0672-7. 


\title{
DNA methylation signature of human hippocampus in Alzheimer's disease is linked to neurogenesis
}

Miren Altuna ${ }^{1,2}$, Amaya Urdánoz-Casado ${ }^{1}$, Javier Sánchez-Ruiz de Gordoa ${ }^{1,2}$, María V. Zelaya ${ }^{3}$, Alberto Labarga ${ }^{4}$, Julie M. J. Lepesant', Miren Roldán', Idoia Blanco-Luquin', Álvaro Perdones ${ }^{4}$, Rosa Larumbe ${ }^{1,2}$, Ivonne Jericó2, Carmen Echavarri ${ }^{1,2}$, Iván Méndez-López ${ }^{1,6}$, Luisa Di Stefano ${ }^{5}$ and Maite Mendioroz ${ }^{1,2^{*}}$ (1)

\begin{abstract}
Background: Drawing the epigenome landscape of Alzheimer's disease (AD) still remains a challenge. To characterize the epigenetic molecular basis of the human hippocampus in $A D$, we profiled genome-wide DNA methylation levels in hippocampal samples from a cohort of pure AD patients and controls by using the Illumina 450K methylation arrays. Results: Up to 118 AD-related differentially methylated positions (DMPs) were identified in the AD hippocampus, and extended mapping of specific regions was obtained by bisulfite cloning sequencing. AD-related DMPs were significantly correlated with phosphorylated tau burden. Functional analysis highlighted that AD-related DMPs were enriched in poised promoters that were not generally maintained in committed neural progenitor cells, as shown by ChiP-qPCR experiments. Interestingly, AD-related DMPs preferentially involved neurodevelopmental and neurogenesisrelated genes. Finally, InterPro ontology analysis revealed enrichment in homeobox-containing transcription factors in the set of AD-related DMPs.
\end{abstract}

Conclusions: These results suggest that altered DNA methylation in the AD hippocampus occurs at specific regulatory regions crucial for neural differentiation supporting the notion that adult hippocampal neurogenesis may play a role in AD through epigenetic mechanisms.

Keywords: DNA methylation, Alzheimer's, Hippocampus, Adult neurogenesis, Poised promoters, Homeobox, Neurodevelopment, Epigenetics

\section{Background}

Alzheimer's disease $(\mathrm{AD})$ is the leading cause of age-related dementia and one of the major global challenges of our time [1]. As knowledge about AD increases, so does the appreciation of the pathogenic complexity of the disorder [2]. Currently, $\mathrm{AD}$ is considered a complex disease that arises from the interaction between environmental and genetic factors [3], modulated through epigenetic mechanisms. Since epigenetics acts as an interface between the environment and the genome, a major focus has been upon

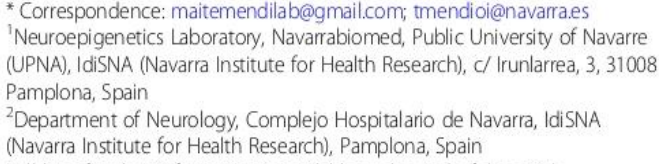

studying epigenetic alterations in $\mathrm{AD}$ to shed some light on the pathogenesis of the disease. DNA methylation is a major epigenetic modification that involves the attachment of a methyl group to the 5-carbon position of a cytosine residue and usually occurs at cytosine-guanine dinucleotides (CpG). These CpG dinucleotides are clustered in the genome constituting $\mathrm{CpG}$ islands, which are enriched in the promoter of more than half of human genes and other important regulatory regions.

DNA methylation is known to be altered in complex diseases including AD. Indeed, a number of gene-specific differences in DNA methylation have been reported so far [4-8]. More recently, genome-wide approaches have uncovered additional gene-specific methylation differences across different brain regions in AD $[9,10]$. By using Illumina Infinium HumanMethylation450K arrays, several 
genes have been found to be differentially methylated in $\mathrm{AD}$ brain autopsy samples, including some genes previously identified as harboring genetic variants for $\mathrm{AD}$, such as ANK1 (ankyrin-1) or BIN1 (amphiphysin II) [11-14]. Importantly, a number of these DNA methylation marks are present in early stages of AD, suggesting that such changes might play a role in the onset of the disorder [12]. On the whole, these reports are providing significant data to enrich our understanding of AD pathogenesis $[15,16]$.

So far, genome-wide DNA methylation studies on $\mathrm{AD}$ have been performed across different brain regions including prefrontal, frontal, and superior temporal neocortex, along with entorhinal cortex. In this study, we have taken a complementary strategy to profile genome-wide DNA methylation in the human hippocampus, a brain region particularly vulnerable to $\mathrm{AD}$ [17-19] and the core of pathological protein tau deposits [20]. We have applied Infinium HumanMethylation450 BeadChip array to hippocampal samples obtained from a homogeneous cohort of pure $A D$ brains and controls. As a result, we report on nove gene-specific DNA methylation changes, recurrent across multiple affected subjects, which occur in the AD hippocampus. This DNA methylation signature of the $\mathrm{AD}$ hippocampus correlates with tau burden and also with specific changes in histone marks. Finally, in silico functional analysis of these changes points to molecular and biological alterations that may be especially relevant to the pathogenesis of $\mathrm{AD}$, including adult brain neurogenesis.

\section{Results}

Hippocampal samples from AD patients and controls DNA methylation changes were evaluated in 36 postmortem hippocampal samples obtained from $26 \mathrm{pa}$ tients with $\mathrm{AD}$ and 12 control subjects. To avoid spurious molecular findings related to multiprotein deposits, only $\mathrm{AD}$ cases with pure deposits of $\mathrm{p}$-tau and $\beta$-amyloid were eligible for the study and controls were free of any protein aggregates. This approach maximizes the chances of finding true molecular associations with $\mathrm{AD}$, even though reducing the number of older controls.

Neuropathological and demographic features of subjects, including age, gender, $\mathrm{ABC}$ score, and postmortem interval (PMI), are listed in Additional file 1: Table S1. $\mathrm{AD}$ subjects were older than controls $(81.2 \pm 12.1$ versus $50.7 \pm 21.5 ; \quad p$ value $<0.01$ ), and no differences were found regarding gender ( $p$ value $=0.16$ ). The PMI ranged from 1.4 to $33 \mathrm{~h}$ and were not significantly different between groups $(8.2 \pm 4.2 \mathrm{~h}$ in controls versus $7.9 \pm 7.1 \mathrm{~h}$ in AD samples; $p$ value $=0.91$ ).

Since DNA methylation may be affected by cellular composition of the brain samples, cell proportions were estimated by using the CETS R package as previously described $[14,21]$. No statistically significant differences were found in cell proportions between the $\mathrm{AD}$ group and the control group (control mean neuronal cell proportion $=0.18$ versus $\mathrm{AD}$ mean neuronal cell proportion $=0.20, p$ value $=0.64$ ) .

\section{Characterization of differentially methylated positions in} the AD hippocampus

Differential methylation analysis between the $A D$ and control hippocampus was performed by using the limma package (R/Bioconductor). After adjusting for age and false discovery rate (FDR) correction, the analysis revealed 118 AD-related differentially methylated positions (DMPs) (absolute $\beta$-difference $\geq 0.1$ and adjusted $p$ value $\leq 0.05$ ) located next to 159 genes (Fig. 1, Table 1). Most of the DMPs, 102 (86.4\%), were hypermethylated in AD cases compared to controls (Fig. 2ac). Inspection of methylation patterns revealed that AD-related DMPs showed a mild-to-moderate effect size, as the average absolute $\beta$-difference was $0.12(\mathrm{SD}=$ 0.02 ) (Fig. 2b). These results are in line with previous AD methylome studies, which showed recurrent gains in DNA methylation of a mild-to-moderate effect size in other brain regions [9-14]. Indeed, up to 17 (10.7\%) differentially methylated genes in our study are found among the top-ranked genes in previous $\mathrm{AD}$ methylome studies performed on frontal, temporal, or entorhinal cortex [11, 12, 14] (Additional file 1: Table S2).

Genomic distribution of AD-related DMPs was next analyzed. We observed that DMPs were more likely to locate in CpG islands, showing a 1.5 -fold enrichment ( $p$ value $<0.001)$ compared with random expectation based on all probes included in the analysis. In addition, significant enrichment was found at first exon (2.4-fold, $p$ value $<0.001)$ and body $(1.2$-fold, $p$ value $<0.05)$ regions (Fig. 2d). Moreover, up to $13(8.1 \%)$ genes were associated with 2 or more AD-related DMPs which would suggest the presence of hotspots of aberrant methylation gain in the human hippocampus affected by AD.

\section{Validation and additional mapping of DMPs}

Among the 118 AD-related DMPs, we selected 7 DMPs to be validated based on their genomic location in or near genes relevant to brain function or AD pathology, including some of the candidate hotspots, i.e., HAND2, HOXA3, HIST1H3E, NXN, PAX3, RBMS1, and RHOB. All the selected genes were successfully validated by bisulfite cloning sequencing since a significant correlation was shown between the $450 \mathrm{~K}$ array data and methylation levels obtained by bisulfite cloning sequencing (Additional file 1: Table S3). Additional mapping of the altered methylation pattern across multiple contiguous CpGs was generated (Fig. 2g and Fig. 3, Additional file 1: 


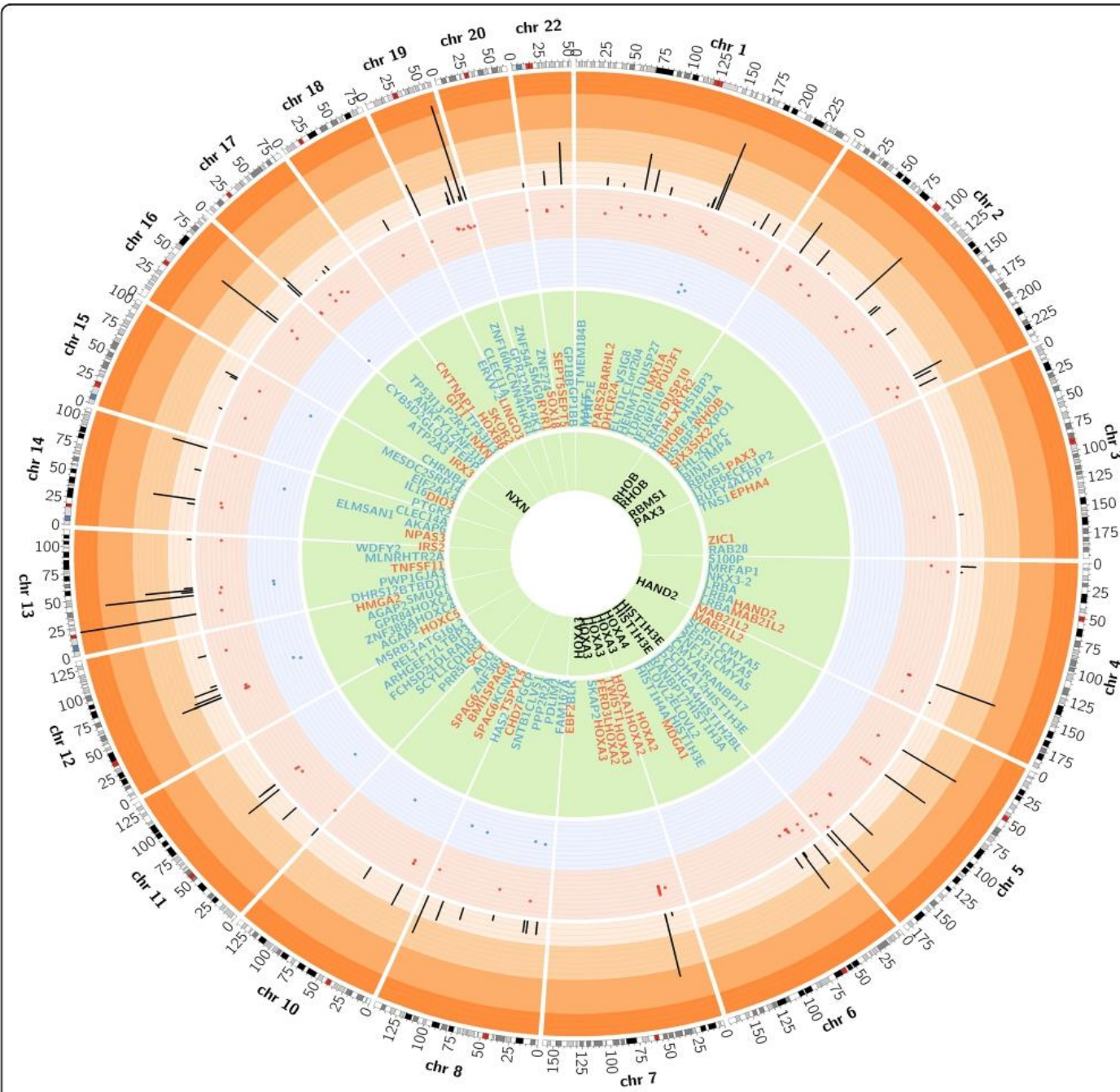

Fig. 1 CIRCOS plot of differentially methylated positions (DMPs) in AD hippocampus. The CIRCOS plot shows a summary of DNA methylation screening results in the AD hippocampus and its validation by bisulfite cloning sequencing. The perimeter of the circular figure represents the human chromosomes, showing the cytogenetic bands and centromeres (in red). Only those chromosomes harboring DMPs are represented in the painted circles. $X$ and $Y$ chromosomes were excluded from the analysis. The orange circle represents $p$ value for each DMP. The inner red and blue dots represent the results of the differential analysis (beta difference) for each DMPs, including gains in methylation (red dots) and losses in methylation (blue dots). The next green circle reports the names of the genes associated to each DMPs. Those genes associated with neurogenesis are highlighted in red font. In black font, those genes that were validated by bisulfite doning sequencing are shown

Figure S1). The results of this mapping support the idea that changes in DNA methylation are not confined to the CpGs queried by the array. On the contrary, alterations of DNA methylation in AD seem to be consistently distributed across discrete regions of the genome and to involve multiple contiguous CpGs.
DNA methylation levels correlate with phosphorylated tau protein burden

The human hippocampus is particularly vulnerable to specific anatomopathological changes in $\mathrm{AD}$ and is considered the region where tau pathology initiates, together with the entorhinal cortex [17-19]. To explore whether 


\section{IDENTIFICACIÓN DE BIOMARCADORES EPIGENÉTICOS EN LA ENFERMEDAD DE ALZHEIMER}

Altuna et al. Clinical Epigenetics

(2019) 11:91

Page 4 of 16

Table 1 Differentially methylated positions (DMPs) in AD hippocampus measured by 450K Illumina BeadChip array

\begin{tabular}{|c|c|c|c|c|c|c|c|c|c|}
\hline \multirow{2}{*}{$\frac{\text { DMPs }}{\text { cg02091185 }}$} & \multicolumn{2}{|c|}{ Genomic coordinates } & \multirow{2}{*}{$\begin{array}{l}\text { Beta. difference } \\
0.198\end{array}$} & \multirow{2}{*}{$\frac{\text { FDR } p \text { value }}{0.003}$} & \multirow{2}{*}{$\frac{\text { GenelD1 }}{\text { RANBP17 }}$} & \multirow[t]{2}{*}{ GenelD2 } & \multirow{2}{*}{$\begin{array}{l}\text { Neurogenesis-related } \\
\text { No }\end{array}$} & \multicolumn{2}{|c|}{ Neurogenesis-related PMID } \\
\hline & 5 & 170288766 & & & & & & & \\
\hline cg07333191 & 4 & 13526769 & 0.168 & 0.002 & RAB28 & $\mathrm{NKX} 3-2$ & No & & \\
\hline cg 14780466 & 2 & 20870812 & 0.150 & 0.011 & GDF7 & $A P O B$ & Yes & 17293457 & 22897442 \\
\hline cg04370442 & 16 & 58019866 & 0.147 & 0.013 & TEPP & ZNF319 & No & & \\
\hline $\operatorname{cg} 16867657$ & 6 & 11044877 & 0.145 & 0.002 & ELOVL2 & & No & & \\
\hline $\operatorname{cg} 04154027$ & 5 & 78985588 & 0.144 & 0.002 & CMYA5 & & No & & \\
\hline cg 19506623 & 2 & 161265259 & 0.143 & 0.036 & RBMS1 & ITGB6 & No & & \\
\hline cg04498198 & 17 & 27899966 & 0.140 & 0.002 & TP53113 & GIT1 & Yes & & 25792865 \\
\hline $\operatorname{cg} 23077820$ & 2 & 223154176 & 0.140 & 0.002 & PAX3 & EPHA4 & Yes & 26287727 & 25978062 \\
\hline cg11015251 & 7 & 27170554 & 0.138 & 0.005 & HOXA4 & & No & & \\
\hline cg 16258854 & 2 & 20648194 & 0.138 & 0.005 & $\mathrm{RHOB}$ & HS1BP3 & Yes & 15306568 & \\
\hline cg01463828 & 8 & 22446721 & 0.137 & 0.007 & PDLIM2 & & No & & \\
\hline cg 13935577 & 12 & 107974897 & 0.136 & 0.008 & BTBD11 & PWP1 & No & & \\
\hline cg 12100751 & 1 & 109203672 & 0.134 & 0.002 & HENMT1 & & No & & \\
\hline cg 19022697 & 1 & 55247140 & 0.133 & 0.004 & PARS2 & DHCR24 & Yes & 29410512 & 24842139 \\
\hline $\operatorname{cg} 25840926$ & 2 & 20647987 & 0.133 & 0.002 & $\mathrm{RHOB}$ & HS1BP3 & Yes & 15306568 & \\
\hline $\operatorname{cg} 22962123$ & 7 & 27153605 & 0.131 & 0.008 & HOXA3 & HOXA2 & Yes & 12954718 & 10230789 \\
\hline cg05637536 & 1 & 154475068 & 0.130 & 0.002 & TDRD10 & & No & & \\
\hline cg01331772 & 2 & 131094827 & 0.129 & 0.002 & IMP4 & & No & & \\
\hline cg23279355 & 5 & 78985592 & 0.128 & 0.002 & CMYA5 & & No & & \\
\hline cg01579024 & 5 & 170288757 & 0.127 & 0.013 & RANBP17 & & No & & \\
\hline cg 15548613 & 22 & 38610795 & 0.127 & 0.002 & MAFF & TMEM184B & No & & \\
\hline cg 13172549 & 7 & 27153636 & 0.125 & 0.019 & HOXA3 & HOXA2 & Yes & 12954718 & 10230789 \\
\hline $\mathrm{cg} 02231404$ & 20 & 62679635 & 0.124 & 0.008 & SOX18 & & Yes & 29666335 & \\
\hline cg 13327545 & 10 & 22623548 & 0.124 & 0.002 & SPAG6 & BMI1 & Yes & 29666335 & 19212323 \\
\hline cg 18247055 & 10 & 22634226 & 0.122 & 0.003 & SPAG6 & & Yes & 26130477 & \\
\hline cg00921266 & 7 & 27153663 & 0.122 & 0.039 & HOXA3 & HOXA2 & Yes & 12954718 & 10230789 \\
\hline cg09490371 & 2 & 233253024 & 0.120 & 0.011 & ECEL 1P2 & ALPP & No & & \\
\hline cg 17448336 & 3 & 147141588 & 0.119 & 0.047 & $\mathrm{ZICl}$ & & Yes & 17507568 & \\
\hline $\operatorname{cg} 16127683$ & 15 & 40268777 & 0.119 & 0.021 & EIF2AK4 & SRP 14 & No & & \\
\hline $\operatorname{cg} 25774643$ & 11 & 627175 & 0.119 & 0.028 & SCT & CDHR5 & Yes & 21159798 & \\
\hline cg 18121224 & 5 & 176559563 & 0.119 & 0.010 & NSD1 & & No & & \\
\hline cg07816556 & 6 & 26017280 & 0.119 & 0.004 & HIST1H4A & HIST1H3A & No & & \\
\hline cg 16308533 & 17 & 40838983 & 0.118 & 0.004 & CNTNAP1 & EZH1 & Yes & 26740489 & 23932971 \\
\hline cg 04533276 & 22 & 19709548 & 0.117 & 0.007 & SEPT5 & GP1BB & Yes & 17935997 & \\
\hline $\operatorname{cg} 22900415$ & 13 & 20736075 & 0.117 & 0.010 & GJA3 & & No & & \\
\hline $\operatorname{cg} 22385702$ & 2 & 45175881 & 0.116 & 0.025 & SIX3 & $\mathrm{S} 1 \times 2$ & Yes & 17576749 & 11401394 \\
\hline cg09655403 & 5 & 78985495 & 0.116 & 0.004 & CMYA5 & & No & & \\
\hline $\operatorname{cg} 22507154$ & 1 & 91185233 & 0.116 & 0.016 & BARHL2 & & Yes & 22307612 & \\
\hline cg 24369989 & 15 & 78933807 & 0.115 & 0.002 & CHRNB4 & & No & & \\
\hline cg 16404157 & 14 & 38724648 & 0.115 & 0.010 & CLEC14A & & No & & \\
\hline cg03146625 & 12 & 54448729 & 0.115 & 0.018 & $\mathrm{HOXC4}$ & SMUG1 & No & & \\
\hline cg04027736 & 7 & 27143403 & 0.115 & 0.011 & HOXA2 & & Yes & 10230789 & \\
\hline cg 12024906 & 19 & 37825679 & 0.115 & 0.005 & HKR1 & & No & & \\
\hline
\end{tabular}




\section{IDENTIFICACIÓN DE BIOMARCADORES EPIGENÉTICOS EN LA ENFERMEDAD DE ALZHEIMER}

Altuna et al. Clinical Epigenetics

(2019) 11:91

Page 5 of 16

Table 1 Differentially methylated positions (DMPs) in AD hippocampus measured by 450K Illumina BeadChip array (Continued)

\begin{tabular}{|c|c|c|c|c|c|c|c|c|c|}
\hline \multirow{2}{*}{$\frac{\text { DMPs }}{\text { cg00303378 }}$} & \multicolumn{2}{|c|}{ Genomic coordinates } & \multirow{2}{*}{$\begin{array}{l}\text { Beta. difference } \\
0.115\end{array}$} & \multirow{2}{*}{$\frac{\text { FDR } p \text { value }}{0.002}$} & \multirow{2}{*}{$\frac{\text { GenelD1 }}{\text { VSIG8 }}$} & \multirow{2}{*}{$\frac{\text { GenelD2 }}{\text { C1orf204 }}$} & \multirow{2}{*}{$\begin{array}{l}\text { Neurogenesis-related } \\
\text { No }\end{array}$} & \multicolumn{2}{|c|}{ Neurogenesis-related PMID } \\
\hline & 1 & 159825552 & & & & & & & \\
\hline cg 17508941 & 7 & 19183280 & 0.114 & 0.002 & TWIST1 & FERD3L & Yes & 23555309 & 23254923 \\
\hline cg24079702 & 2 & 106015771 & 0.114 & 0.005 & FHL2 & & No & & \\
\hline cg 15084543 & 1 & 79472408 & 0.113 & 0.006 & ELTD1 & & No & & \\
\hline $\operatorname{cg} 25738176$ & 17 & 3848506 & 0.113 & 0.033 & ATP2A3 & $P 2 R \times 1$ & No & & \\
\hline $\operatorname{cg} 20864214$ & 11 & 73054121 & 0.113 & 0.018 & RELT & ARHGEF17 & No & & \\
\hline $\operatorname{cg} 06452665$ & 13 & 43148436 & 0.113 & 0.010 & TNFSF11 & & Yes & 24087792 & \\
\hline cg21572722 & 6 & 11044894 & 0.113 & 0.003 & ELOV2 & & No & & \\
\hline $\operatorname{cg} 26092675$ & 6 & 26225258 & 0.112 & 0.002 & HIST1H3E & & No & & \\
\hline cg07336350 & 16 & 54322127 & 0.111 & 0.013 & $\mathbb{R} \times 3$ & & Yes & 10704856 & \\
\hline cg07809484 & 19 & 51231968 & 0.111 & 0.002 & GPR32 & CLEC11A & No & & \\
\hline $\operatorname{cg} 16651126$ & 7 & 27170552 & 0.111 & 0.007 & HOXA4 & & No & & \\
\hline cg05726109 & 22 & 19709755 & 0.111 & 0.007 & SEPT5 & GP1BB & Yes & 17935997 & \\
\hline $\mathrm{cg} 07584855$ & 1 & 221055545 & 0.110 & 0.007 & HLX & DUSP10 & Yes & 7907015 & 19139271 \\
\hline $\operatorname{cg} 14566959$ & 5 & 140772681 & 0.110 & 0.006 & PCDHGA4 & & No & & \\
\hline cg02798280 & 19 & 39087135 & 0.110 & 0.007 & MAP4K1 & RYR1 & No & & 17767953 \\
\hline $\operatorname{cg} 24756378$ & 14 & 33401638 & 0.110 & 0.027 & NPAS3 & AKAP6 & Yes & 21709683 & \\
\hline cg 11864574 & 10 & 22635028 & 0.110 & 0.015 & SPAG6 & & Yes & 29666335 & \\
\hline cg06555959 & 8 & 61835620 & 0.110 & 0.050 & CLVS1 & CHD7 & Yes & & 23827709 \\
\hline cg 12253175 & 12 & 58132093 & 0.110 & 0.029 & AGAP2 & & No & & \\
\hline cg 15834355 & 12 & 54442075 & 0.110 & 0.014 & $\mathrm{HOXC4}$ & $\mathrm{HOXC5}$ & Yes & & 23103965 \\
\hline cg09596958 & 12 & 58132105 & 0.109 & 0.031 & AGAP2 & & No & & \\
\hline $\mathrm{cg} 02267270$ & 6 & 37616410 & 0.109 & 0.047 & MDGA1 & CCDC167 & Yes & 21104742 & \\
\hline cg 18181229 & 1 & 164545699 & 0.109 & 0.016 & $\mathrm{PBX} 1$ & LMX1A & Yes & 27226325 & 24172139 \\
\hline $\operatorname{cg} 01421119$ & 1 & 211555733 & 0.109 & 0.019 & TRAF5 & RD3 & No & & \\
\hline cg03729251 & 4 & 151501035 & 0.108 & 0.012 & LRBA & MAB21L2 & Yes & & 11960703 \\
\hline $\operatorname{cg} 22090150$ & 17 & 4098227 & 0.107 & 0.002 & ANKFY1 & CYB5D2 & No & & \\
\hline cg05877788 & 17 & 27899874 & 0.107 & 0.003 & TP53113 & GIT1 & Yes & & 25792865 \\
\hline cg06396119 & 13 & 49792767 & 0.106 & 0.025 & MLNR & & No & & \\
\hline $\operatorname{cg} 22154659$ & 7 & 27134369 & 0.106 & 0.015 & HOXA1 & SKAP2 & Yes & 14522873 & \\
\hline $\operatorname{cg} 14266527$ & 4 & 151501298 & 0.106 & 0.004 & LRBA & MAB21L2 & Yes & & 11960703 \\
\hline cg 24177393 & 5 & 43037517 & 0.105 & 0.033 & SEPP1 & ZNF131 & No & & \\
\hline cg07942135 & 7 & 27154262 & 0.105 & 0.022 & HOXA3 & HOXA2 & Yes & 12954718 & 10230789 \\
\hline $\operatorname{cg} 22904711$ & 19 & 44278628 & 0.105 & 0.041 & KCNN4 & SMG9 & No & & \\
\hline cg01566965 & 4 & 174447847 & 0.104 & 0.028 & HAND2 & SCRGI & Yes & 22323723 & \\
\hline cg 14557699 & 5 & 140254909 & 0.104 & 0.002 & PCDHA12 & & No & & \\
\hline $\operatorname{cg} 26698460$ & 19 & 58716004 & 0.104 & 0.010 & ZNF274 & ZNF544 & No & & \\
\hline $\mathrm{cg} 02287710$ & 14 & 102027660 & 0.103 & 0.004 & $\mathrm{DlO} 3$ & & Yes & 27707971 & \\
\hline $\operatorname{cg} 21415530$ & 8 & 140715802 & 0.103 & 0.010 & KCNK9 & & No & & \\
\hline cg07589899 & 2 & 62020677 & 0.103 & 0.002 & XPO1 & FAM161A & No & & \\
\hline $\operatorname{cg} 20192747$ & 18 & 44774846 & 0.103 & 0.003 & SKOR2 & & Yes & 24491816 & \\
\hline cg 17179862 & 17 & 46681362 & 0.103 & 0.003 & HOXB6 & LOC404266 & Yes & 10686603 & \\
\hline cg26587870 & 6 & 27730563 & 0.103 & 0.010 & ZNF184 & HIST1H2BL & No & & \\
\hline cg01089914 & 2 & 218843229 & 0.102 & 0.017 & RUFY4 & TNS1 & No & & \\
\hline
\end{tabular}


Table 1 Differentially methylated positions (DMPs) in AD hippocampus measured by 450K Illumina BeadChip array (Continued)

\begin{tabular}{|c|c|c|c|c|c|c|c|c|c|}
\hline \multirow{2}{*}{$\frac{\text { DMPs }}{\operatorname{cg} 14962509}$} & \multicolumn{2}{|c|}{ Genomic coordinates } & \multirow{2}{*}{$\frac{\text { Beta. difference }}{0.102}$} & \multirow{2}{*}{$\frac{\text { FDR } p \text { value }}{0.004}$} & \multirow{2}{*}{$\frac{\text { GenelD1 }}{\text { TFAP2E }}$} & \multirow[t]{2}{*}{ GenelD2 } & \multirow{2}{*}{$\begin{array}{l}\text { Neurogenesis-related } \\
\text { No }\end{array}$} & \multicolumn{2}{|c|}{ Neurogenesis-related PMID } \\
\hline & 1 & 36039655 & & & & & & & \\
\hline $\operatorname{cg} 21869609$ & 19 & 2291613 & 0.102 & 0.018 & LINGO3 & & Yes & 18297755 & \\
\hline cg08865099 & 7 & 27281581 & 0.102 & 0.043 & $\mathrm{EVX} 1$ & & Yes & 10399918 & \\
\hline $\operatorname{cg} 13836098$ & 6 & 26225268 & 0.102 & 0.002 & HIST1H3E & & No & & \\
\hline cg00611789 & 5 & 78985432 & 0.102 & 0.011 & CMYA5 & & No & & \\
\hline cg 13771313 & 11 & 72533295 & 0.102 & 0.017 & ATG16L2 & FCHSD2 & No & & \\
\hline cg21811021 & 4 & 6659346 & 0.101 & 0.015 & S100P & MRFAP1 & No & & \\
\hline cg 11254700 & 19 & 53561386 & 0.101 & 0.020 & ERW-2 & ZNF160 & No & & \\
\hline cg 14557202 & 12 & 54764371 & 0.101 & 0.028 & ZNF385A & GPR84 & No & & \\
\hline cg03422911 & 1 & 237205295 & 0.101 & 0.004 & RYR2 & & Yes & 17767953 & \\
\hline cg 19153828 & 2 & 127782651 & 0.101 & 0.009 & BIN1 & GYPC & No & & \\
\hline cg06867571 & 11 & 65306934 & 0.101 & 0.019 & LTBP3 & SCYL1 & No & & \\
\hline cg09317554 & 4 & 151505084 & 0.101 & 0.014 & LRBA & MAB21L2 & Yes & & 11960703 \\
\hline $\operatorname{cg} 05404236$ & 13 & 110437093 & 0.100 & 0.017 & IRS2 & & Yes & 28833887 & \\
\hline $\operatorname{cg} 02771117$ & 8 & 11279352 & -0.100 & 0.022 & FAM167A & BLK & No & & \\
\hline cg 10373891 & 13 & 52338758 & -0.101 & 0.017 & DHRS 12 & WDFY2 & No & & \\
\hline $\operatorname{cg} 24607755$ & 11 & 36171375 & -0.102 & 0.010 & LDLRAD3 & PRR5L & No & & \\
\hline cg20102280 & 13 & 47470793 & -0.102 & 0.004 & HTR2A & & No & & \\
\hline cg21735068 & 8 & 97975467 & -0.104 & 0.015 & PGCP & TSPYL5 & Yes & & 26911678 \\
\hline $\operatorname{cg} 23907053$ & 12 & 70215816 & -0.107 & 0.015 & RAB3IP & MYRFL & No & & \\
\hline cg 14701867 & 10 & 64193068 & -0.107 & 0.023 & ZNF365 & ADO & No & & \\
\hline cg 14830371 & 8 & 25991602 & -0.108 & 0.027 & PPP2R2A & EBF2 & Yes & & 25762221 \\
\hline $\operatorname{cg} 16668651$ & 15 & 81316319 & -0.110 & 0.035 & IL16 & MESDC2 & No & & \\
\hline cg06688910 & 8 & 122466955 & -0.110 & 0.027 & SNTB1 & HAS2 & No & & \\
\hline $\mathrm{cg} 07463059$ & 1 & 158979810 & -0.119 & 0.010 & $\mathbb{| F | 1 6}$ & & No & & \\
\hline cg05165025 & 14 & 74253312 & -0.119 & 0.046 & PTGR2 & ELMSAN1 & No & & \\
\hline cg07677157 & 12 & 66050928 & -0.133 & 0.026 & HMGA2 & MSRB3 & Yes & 18640244 & \\
\hline $\operatorname{cg} 11236550$ & 1 & 167090757 & -0.138 & 0.012 & DUSP27 & POU2F1 & No & & 18241856 \\
\hline $\operatorname{cg} 20597486$ & 1 & 158979841 & -0.151 & 0.002 & IFl16 & & No & & \\
\hline cg 19987768 & 17 & 750306 & -0.162 & 0.043 & NXN & GLOD4 & Yes & 29037191 & \\
\hline
\end{tabular}

The table shows 118 DMPs with $\beta$-difference $>0.100$, prioritized by beta difference (delta) criteria. FDR false discovery rate, Adj. adjusted, ID identification, PMID PubMed identification. Each probe (CpG site) was annotated by UCSC hg19 build. The last two columns show the PMID of papers supporting the involvement of the genes into neurogenesis or neural development

the altered DNA methylation pattern reflects $\mathrm{AD}$ pathological changes in the hippocampus, we used a semi-automated quantitative method described in detail elsewhere [7] to measure the extension of phosphorylated tau ( $p$-tau) deposits in our set of hippocampal samples. Next, Pearson's coefficient was calculated to evaluate the correlation between DNA methylation levels at each of the identified 118 AD-related DMPs and the extension of p-tau deposits in the hippocampus. We found that DNA methylation levels in 43 (36.4\%) DMPs were significantly correlated with the burden of p-tau deposits (Additional file 1: Table S4). The strongest correlation was observed for differentially methylated CpGs located close to the SOX18, HKR1, PCDHA12, and ATG16L2 genes.

\section{AD-related DMPs overlap bivalent histone marks and} poised promoters

Independent epigenetic mechanisms may play together to coordinately fine-tune gene expression. Therefore, we next asked whether the set of 118 AD-related DMPs was predicted to associate with other epigenetic features such as histone modifications. To this end, we first performed a functional in silico analysis for enrichment in histone marks using ENCODE/Broad data for human brain hippocampus, normal human astrocytes (NH-A), 

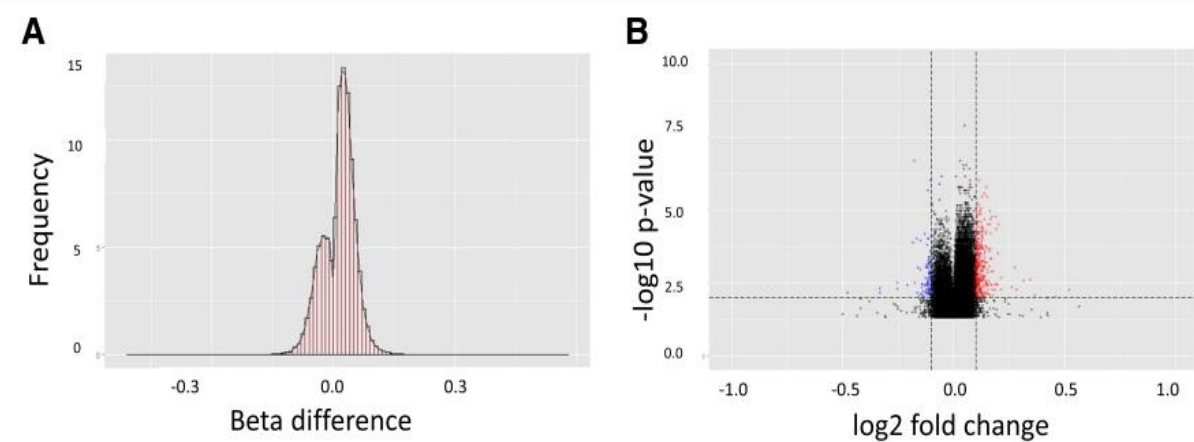

C
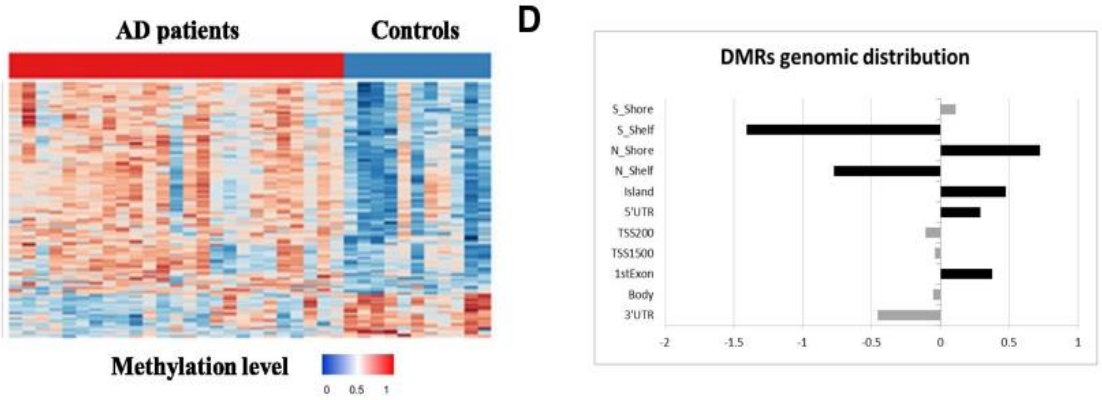

$\mathbf{E}$

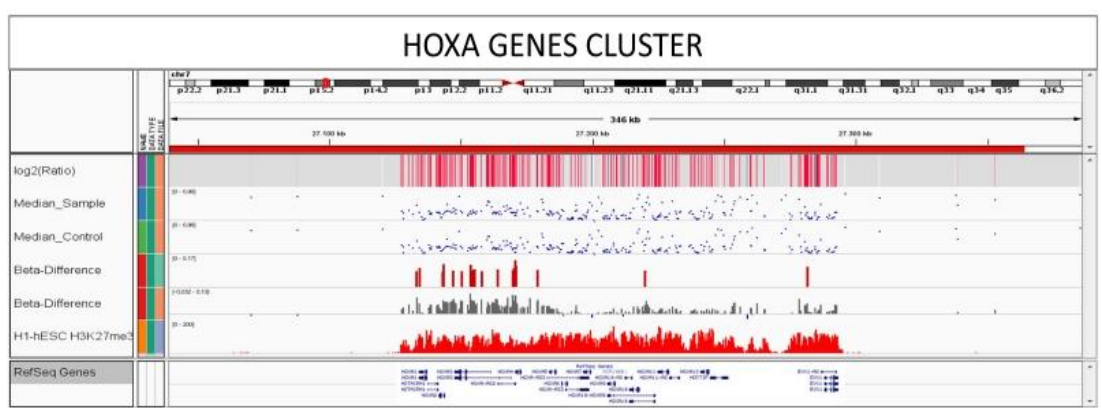

$\mathbf{F}$
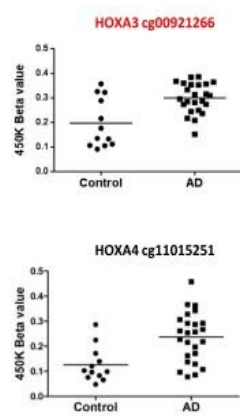

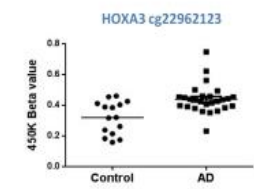

EVX1 C008865099

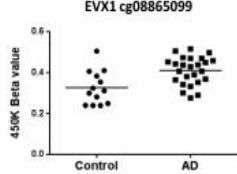

G

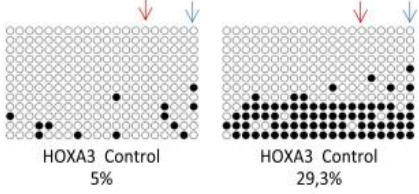

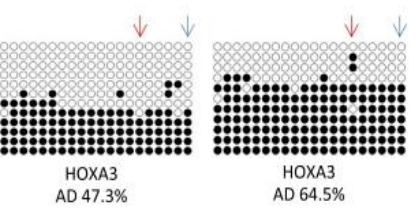
$64.5 \%$ 


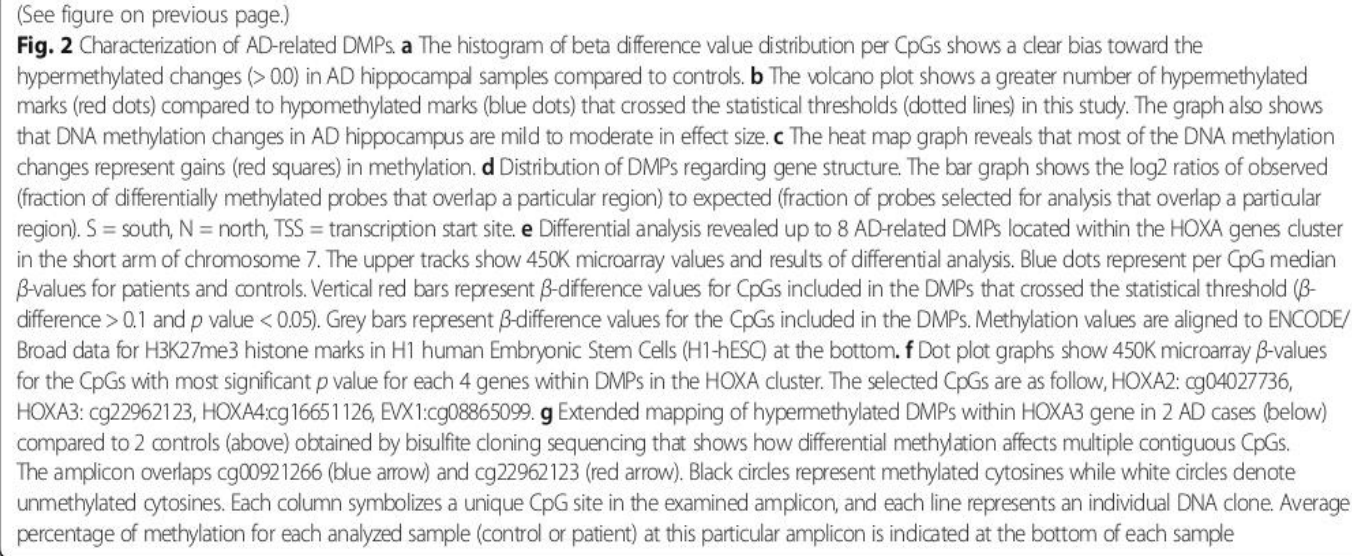

and H1 human Embryonic Stem Cells (H1hESC) identified through the WashU Epigenome Browser [22] and the UCSC Genome Browser [23].

We found that AD-related DMPs were overrepresented in regions of repressive histone marks, particularly in H3K27me3 mark in H1hESCs and H3K9me3 in the human hippocampus (Fig. 4a). We also realized that many of the AD-related DMPs shared both repressive (H3K27me3) and activating (H3K4me2 and H3K4me3) marks in the same locus. In other words, these DMPs overlapped regions of bivalent chromatin that usually characterizes poised promoters. Genes with poised promoters are generally repressed but ready for immediate activation in response to certain signals [24], and are thought to be key developmentally regulated genes not only in stem cells [24-27] but also in differentiated cells [27-29]. In our study, 70 (59.3\%) AD-related DMPs overlapped poised promoters. When taking into account the direction of the methylation change, we observed that up to $68(66.6 \%)$ of the hypermethylated DMPs overlapped bivalent promoters, whereas only $2(12.5 \%)$ of the hypomethylated DMPs overlapped bivalent promoters (Fig. 4b).

\section{ChIP analysis of bivalent promoters in neural human} progenitor cells

Although most of the bivalent modifications in hESC are usually resolved during lineage commitment, a small subset of poised promoters in hESC may remain bivalent during differentiation [24, 27]. Indeed, bivalent promoters may play complex roles in differentiated cells, keeping some genes poised for activation $[24,29,30]$. To explore the fate of bivalent chromatin modifications in our set of AD-related DMPs, we performed a number of chromatin immunoprecipitation-quantitative PCR (ChIP-qPCR) experiments in neural human progenitor cells (NHPCs) which represent a more differentiated state than hESC in the brain tissue. We ran ChIP-qPCR assays on NHPCs using anti-H3K27me3 and antiH3K4me3 antibodies for selected differentially methylated genes, including the HOXA gene cluster. ChIP-qPCR analysis revealed that genes within the HOXA locus resolved to the repressive H3K27me3 status in NHPCs, as was also the case of the DIO3 and TDRD10 genes. On the contrary, ROHB, ELOVL2, and FHL2 resolved to H3K4me3 active status in the committed NHPCs. Only SEPT5 lost both H3K4me3 and H3K27me3 chromatin marks (Fig. 4c). These results illustrate a wide variety of histone marks fates for these differentially methylated genes which are poised in H1hESCs. Although additional research on this issue would be needed, these results suggest that $\mathrm{AD}$-related DMPs are not enriched in genes that retain bivalent marks in lineage-committed cells.

\section{AD-related differentially methylated genes are linked to} neural development and neurogenesis

Next, we wanted to know whether the set of AD-related DMPs was enriched for genes involved in specific diseases, functions, and pathways. To this end, we performed different levels of analysis. First, manually curated search using PubMed revealed that 50 (42.4\%) AD-related DMPs were associated with genes related with neural development and neurogenesis (Table 1, Fig. 1). Consistently, most of these genes overlapped poised promoters (90.9\%), since they are key developmentally regulated genes.

Next, we used the Genomic Regions Enrichment of Annotations Tool (GREAT) [31] to identify enriched ontological terms in our set of AD-related DMPs. The enriched gene ontology (GO) terms in the biological process category revealed a set of different processes consistently associated with embryonic and brain morphogenesis among others (Additional file 1: Figure S2). In addition, our set of AD-related DMPs was enriched in 
A

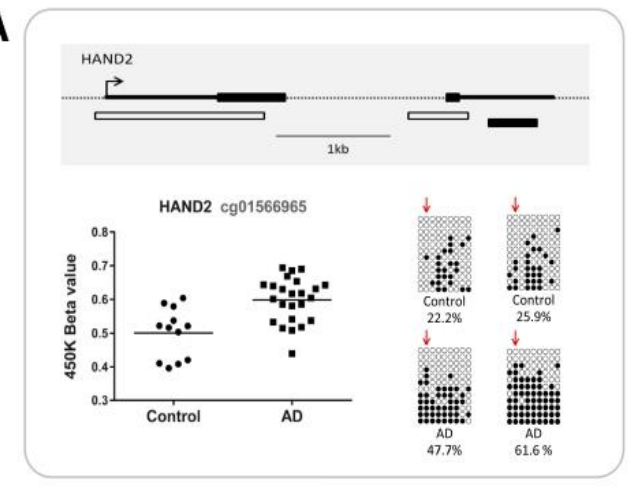

C

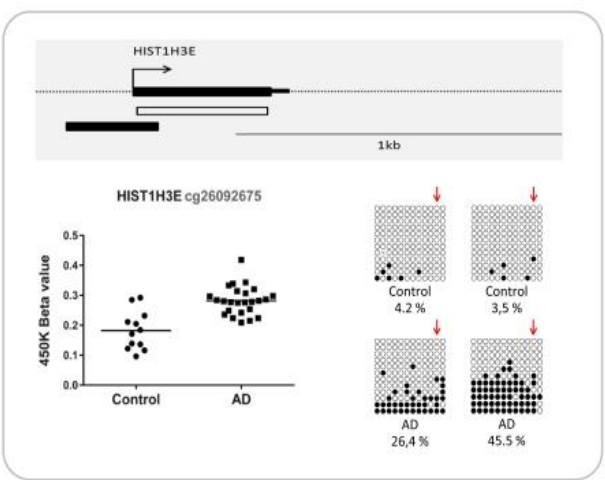

B

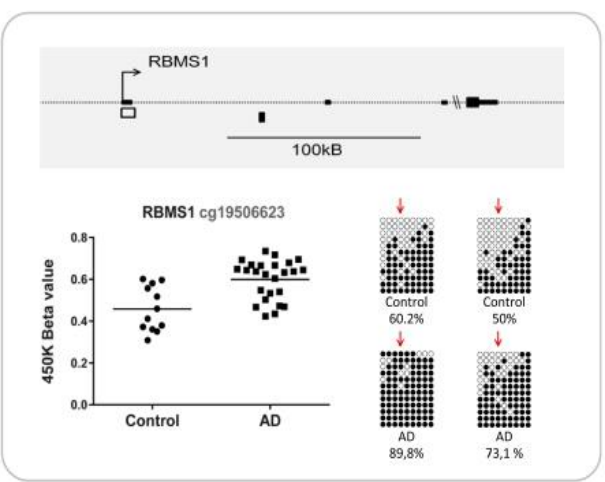

D
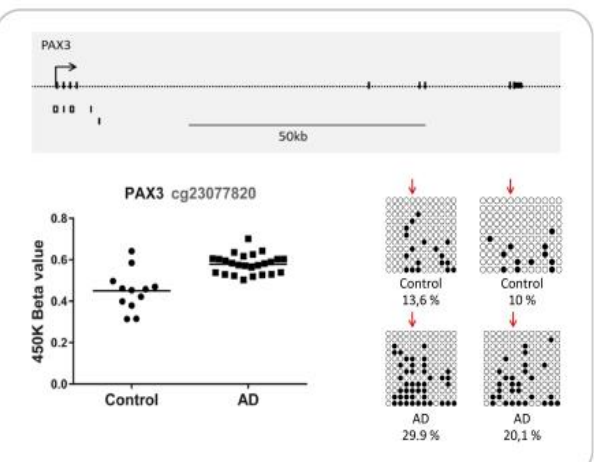

Fig. 3 Validation and extended mapping for the differentially methylated genes HAND2, RBMS1, HISTIH3E, and PAX3. Bisulfite cloning sequencing experiments show that hypemethylation affects multiple contiguous CpGs located in the 3'UTR of HAND2 (a), first exon of RBMS1 (b), the promoter region of HISTTHBE (c), and the body of PAX3 (d). The upper track of each panel shows a genomic map of each gene. White boxes below each gene denote CpG islands, and black boxes represent bisulfite cloning sequencing amplicons. Dot plot graphs show the results of the $450 \mathrm{~K}$ array (beta values) for CpG probes. Validation results are represented by black/white circle-style figures. Each rectangle corresponds to one sample and shows the methylation pattem at a discrete genomic region surrounding the significant $\mathrm{CpG}$ probed by the $450 \mathrm{~K}$ array which is marked by a red arrow. Black circles represent methylated cytosines while white circles denote unmethylated cytosines. Each column symbolizes a unique CpG site in the examined amplicon, and each line represents an individual DNA clone. Average percentage of methylation for each analyzed sample (control or patient) at this particular amplicon is indicated at the bottom of each sample

the "high mobility group (HMG) box domain binding" term in the GO molecular category (fold enrichment = 12.3; FDR Q-value <0.01). HMG is a protein domain which confers proteins the ability to bind DNA and is related to a number of DNA processes, including transcription and DNA repair [32].

Next, an InterPro ontology analysis was performed to test for protein domains, families, and functional sites. The analysis showed enrichment for homeobox domain-related terms in the set of AD-related DMPs (Additional file 1: Table S5). Homeobox transcription factors are crucial in regulating pluripotency and cellular differentiation [33].

\section{Discussion}

In this study, we profiled genome-wide DNA methylation levels to identify novel AD-related methylation changes in the human hippocampus. These results revealed genomic loci hypermethylated in $\mathrm{AD}$ cases compared to controls that largely overlap regulatory regions, mainly bivalent promoters. In addition, the DNA methylation signature was consistently related to genes crucial for neural development or neurogenesis and homeobox-containing transcription factors.

Neuropathological hallmarks of AD tend to occur in particularly vulnerable regions in the human brain $[17,20]$ and are associated to neuronal death and synapse loss from the very early stages of the disease [34]. However, molecular mechanisms underlying the specific brain region pattern of neuropathological changes in $\mathrm{AD}$ are not entirely clear. That was the rationale for selecting the human hippocampus to perform this epigenetic screening since it is a highly vulnerable region to $\mathrm{AD}$ neuropathological 
A

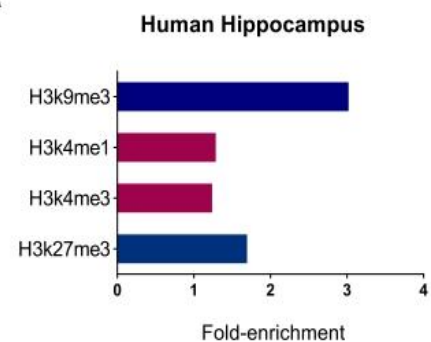

NH-A

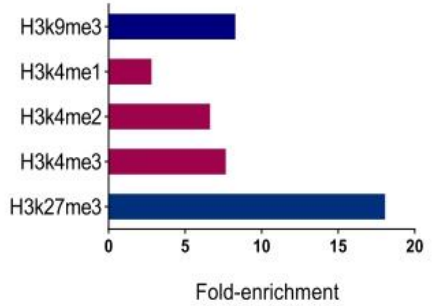

H1hESC

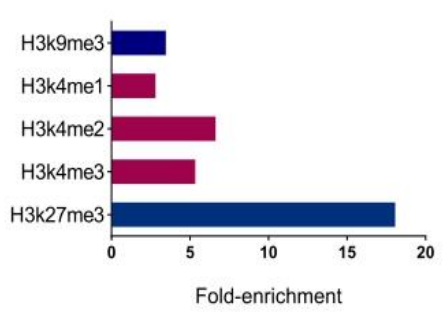

B

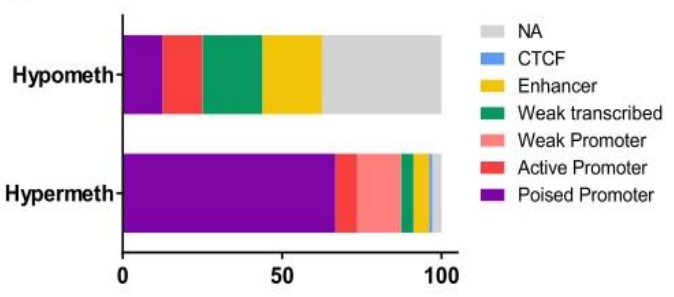

C
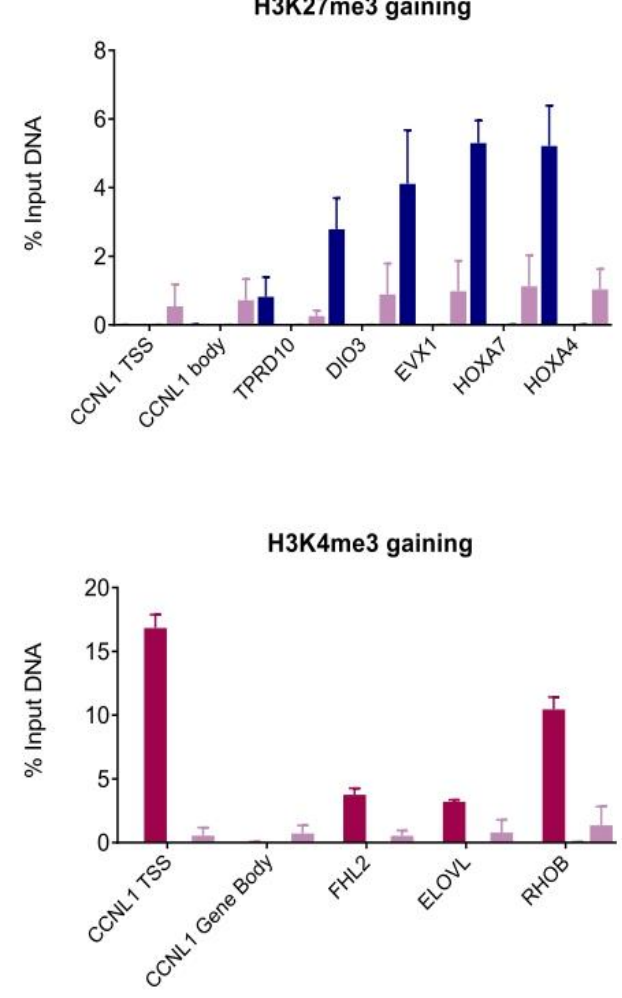

Losing all marks

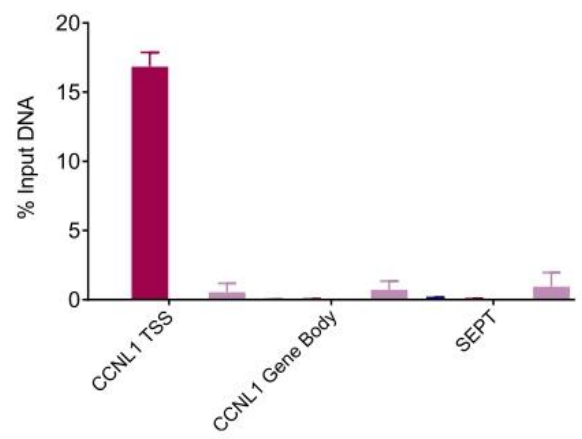

Fig. 4. Histone marks enrichment and ChIP results in NHPCs. a The bar graph shows the strong enrichment in repressive histone marks (blue bars), particularly in H3K27me3 and H3K9me3, in our set of AD-related DMPs. Milder enrichment of active chromatin marks (red bars) is also shown. Only statistically significant results of the hypergeometric test for the available histone marks are shown. b DMPs that were hypermethylated occur preferentially in promoters in a poised or bivalent chromatin state. $\mathbf{c}$ A variety of fates for "poised" genes in committed NHPCs is represented by the results of ChIP experiments. Some of the promoters resolved to repressive (H3K27me3) or active (H3K4me3) promoters while others lost all histone marks. ChIP of the CCNL1 promoter and gene body regions were used as positive control for active promoter histone marks (H3K4me3) and negative control for repressive histone marks (H3K27me3) 
changes. In this regard, our analysis showed a statistically significant positive correlation between DNA methylation levels at $36.4 \%$ of the AD-related DMPs and the hippocampal burden of p-tau. On the other hand, and supporting the robustness of the present study, our results partially overlap those previously reported from methylome studies performed on other $\mathrm{AD}$ brain regions, such as prefrontal, frontal, and superior temporal neocortex or entorhinal cortex [9-14]. The overlap of DMPs among different AD brain regions suggests that a limited number of DMPs may be related to characteristic molecular processes of $\mathrm{AD}$, regardless of the affected brain area. In any case, our complete set of AD-related DMPs extends and complements the current epigenomic landscape of the AD brain.

Interestingly, the functional analysis showed that a significant percentage of the differentially methylated genes were related to neural development and neurogenesis. It was astounding that other biological, cellular, and molecular processes generally associated with neurodegeneration such as apoptosis, autophagy, inflammation, oxidative stress, and mitochondrial or lysosomal dysfunction were not overrepresented in the set of AD-related DMPs. Though strongly related to brain development, neurogenesis is also maintained in the adult human brain, mainly in two distinct areas, i.e., the subventricular zone and the subgranular zone of the dentate gyrus in the hippocampus. There is substantial neurogenesis throughout life in the human hippocampus as it is estimated that up to one third of human hippocampal neurons are subject to constant turnover [35]. Adult neurogenesis is linked to hippocampal-dependent learning and memory tasks [36-38] and is reduced during aging $[35,39]$. Recent evidence suggests that adult neurogenesis is altered in the neurodegenerative process of AD [40-42], but it is still controversial with some authors reporting increased neurogenesis [43, 44], whereas others show reduced neurogenesis $[39,42,45,46]$. In the human hippocampus, a sharp drop in adult neurogenesis has been observed in subjects with $\mathrm{AD}$ [42]. Remarkably, protein tau has been also involved in the modulation of adult hippocampal neurogenesis exerted by external stimuli [47] and impairs proliferation of neuronal precursors in the hippocampal dentate gyros in a tauopathy mouse model [48]. Definitely, the molecular mechanisms involved in defective neurogenesis in $A D$ remain to be elucidated [41].

In this scenario, the results of the present study point to neurogenesis-related genes as targets of epigenetic changes in the hippocampus affected by AD. Enrichment of AD-related DNA methylation marks in neurodevelopmental and neurogenesis-related genes may reflect changes in epigenetic regulation of the neuronal population subjected to exchange in the hippocampus, whose function and balance could be relevant to $\mathrm{AD}$ pathogenesis. These methylation changes might be built throughout life due to external and internal cues and would represent an example of epigenetic interaction between environmental and genetic factors in developing $\mathrm{AD}$. As an alternative explanation, these epigenetic marks might also represent the trace of DNA methylation alterations induced during early developmental stages of the hippocampus, which would remain as a fingerprint in the larger proportion of hippocampal neurons that are not exchanged. This second hypothesis would link AD to early life stages, in concordance with recent studies that revealed abnormal p-tau deposits (pre-tangles) in brains of young individuals under $30[49,50]$ suggesting AD pathology would start earlier in life than it was previously thought. The influence of the genetic risk for $\mathrm{AD}$ has also been postulated to begin in early life [51], and other AD risk factors may be influenced by in utero environment [52].

We also observed that AD-related DMPs overlap relevant regulatory regions in the genome, such as $\mathrm{CpG}$ islands and bivalent histone marks corresponding to poised promoters. This result is in line with previous studies that found hypermethylated DMPs in the AD superior temporal gyrus to be enriched in poised promoters [14]. Promoters may be found in three distinct states: active, repressed, and poised. In the poised state, promoters are repressed but may be rapidly activated in response to certain cues [24]. Interestingly, poised promoters are very often associated with genes critical to the development and, as such, are characteristic of stem cells [24-27]. A number of poised promoters can also be maintained in lineage-committed and differentiated cells [29-31]. In our study, ChIP-qPCR analysis suggests that the bivalent promoters enriched in the set of $\mathrm{AD}$-related DMPs resolve to a variety of states in committed NPCs and therefore are not enriched in genes retaining bivalent marks in lineage-committed cells.

The functional in silico analysis showed enrichment for the homeobox domain-containing family of genes in the set of AD-related DMPs. Homeobox domain-containing genes encode transcription factors (TFs) that result crucial during early embryonic development and morphogenesis [33]. Some homeobox TFs act by inducing cellular differentiation while other homeobox TFs are involved in maintaining pluripotency. Homeobox genes are known to be tightly regulated by DNA methylation and modifications of the chromatin state. Notably, homeobox domain-containing TFs are being closely connected to neurogenesis [53-55] and specific homeobox TFs, such as Dbx2, are involved in age-related neurogenic decline [56]. Most interestingly, Dbx2 is involved in the molecular changes that characterize the aged phenotype of neural stem/progenitor cells from the subventricular zone in mice, and 
it has been proposed as a player in promoting age-related neurogenic decline [56].

Deregulation of homeobox genes is related to certain diseases, such as cancer. However, the relationship with $\mathrm{AD}$ and neurodegenerative disorders has been barely assessed. Only a few reports are found in the literature regarding $\mathrm{AD}$ and homeobox domain-containing genes, e.g., low expression of GAX gene, a regulator of vascular differentiation, in brain endothelial cells in $\mathrm{AD}$ [57], or GTX gene, a homeobox gene with neuroprotective properties [58]. Therefore, these findings open a new avenue for research to better understand the role of homeobox TFs in the $\mathrm{AD}$ pathogenesis.

At any rate, we want to be cautious with our conclusions. There was a significant difference in age between controls and $\mathrm{AD}$ patients, being the latter group older than the former group. Although we adjusted for age in the statistical differential methylation analysis, the accuracy of this correction may be limited as there is little overlap in the age ranges of both groups. For the sake of external validity, these findings should be replicated in an independent cohort of human hippocampal samples.

\section{Conclusions}

On the whole, our results suggest that altered DNA methylation in the $\mathrm{AD}$ hippocampus occurs at specific regulatory regions that are crucial for neural differentiation and support the notion that adult hippocampal neurogenesis may play a role in the development of $\mathrm{AD}$. However, we are far from understanding how DNA methylation changes, interacting with other epigenetic mechanisms, modulate relevant molecular pathways in developing the disease. In addition, other topics such as the role of non-CpG methylation or hydroxymethylation would be interesting to address in the AD hippocampus. Therefore, further research on the alterations of epigenetic mechanisms in $\mathrm{AD}$ is guaranteed.

\section{Methods}

\section{Aim, design, and setting of the study}

The aim of this study was to profile genome-wide DNA methylation in the human hippocampus, a brain region particularly vulnerable to $\mathrm{AD}$ and the core of pathological protein tau deposits. This is an observational, transversal, case-control study to identify differentially methylated positions among AD cases and controls.

Human brain samples and neuropathological examination We evaluated postmortem hippocampal samples from 38 subjects ( $26 \mathrm{AD}$ patients and 12 controls), provided by the Navarrabiomed Brain Bank. After death, half brain specimens from donors were cryopreserved at $-80^{\circ} \mathrm{C}$. Neuropathological examination was performed following the usual recommendations [59]. Assessment of $\beta$-amyloid deposit was carried out by immunohistochemical staining of paraffin-embedded sections (3-5 $\mu \mathrm{m}$ thick) with a mouse monoclonal (S6F/3D) anti- $\beta$-amyloid antibody (dilution 1/50) (Leica Biosystems Newcastle Ltd, Newcastle upon Tyne, UK). Evaluation of neurofibrillary pathology was performed with a mouse monoclonal antibody anti-human PHF-TAU, clone AT-8 (Tau AT8) (dilution 1/ 1000) (Innogenetics, Gent, Belgium), which identifies p-tau [19]. The reaction product was visualized using an automated slide immunostainer (Leica Bond Max) with Bond Polymer Refine Detection (Leica Biosystems Newcastle Ltd). AD staging was performed by using the $A B C$ score according to the updated National Institute on Aging-Alzheimer's Association guidelines [60]. Agreement for any diagnosis was reached by members of a panel composed of two neuropathologists (VZ, CE) and two neurologists (JS, MM).

Genome-wide DNA methylation profiling and differentia methylation analysis

CpG methylation levels were profiled genome-wide by using Infinium HumanMethylation450 BeadChip array (Illumina, Inc., San Diego, CA, USA) [61] at the Roswell Park Cancer Institute Genomics Shared Resource (Buffalo, NY, USA). Briefly, $500 \mathrm{ng}$ of genomic DNA from each brain sample was bisulfite treated and hybridized to the BeadChip according to the manufacturer's protocol. A total of 485,577 cytosine positions were interrogated throughout the human genome, covering the $99 \%$ of RefSeq genes and $96 \%$ of CpG islands.

\section{Quality control and data processing}

In order to minimize the potential bias introduced by batch effects, we performed samples-to-batch allocation using the OSAT tool [62]. Microarray image processing was carried out using Genome Studio Methylation Module (v1.8.5). Background was corrected, and adjustment was performed to avoid type I/II assay chemistry bias. So as to minimize technical variation and improve data quality, the Dasen method [63] was used as a normalization tool.

Before performing differential methylation analysis, we removed probes that overlapped common single nucleotide polymorphisms (SNPs) and also those probes classified as internal controls of the Illumina microarray. Additionally, probes located on the $\mathrm{X}$ and $\mathrm{Y}$ chromosomes were discarded along with those probes previously described to hybridize to multiple locations in the genome $[64,65]$. Probes that technically did not pass the Illumina quality threshold (1188 probes with bead count $<3$ in $>5 \%$ of samples and 378 probes having $1 \%$ of samples with a detection $p$ value $>0.05$ ) were also removed. In the end, a total of 264,031 probes (representing individual CpG sites) were further analyzed for differential methylation (Additional file 1: Figure S3). 


\section{Differential methylation analysis}

Our aim was to identify differentially methylated positions (DMPs), that is to say, differentially methylated CpGs related with $\mathrm{AD}$ status. Linear model of microarray analysis (LIMMA) adjusted for age was performed to fit a linear regression model for each $\mathrm{CPG}$ site (R/Bioconductor package) [66]. Percentage of methylation ( $\beta$-value) at each surveyed $\mathrm{CpG}$ site was calculated and ranged from 0 to 1 . Benjamini and Hochberg false discovery rate (FDR) correction was used $(p$ value $<0.05)$. Methylation differences were prioritized by lowest adjusted $p$ values to ensure the most consistent DMPs between $\mathrm{AD}$ patients and controls. This analysis identified sets of candidate loci with consistent differences in methylation in AD versus control hippocampus. Gene annotation was obtained using the Genomic Regions Enrichment of Annotations Tool (GREAT) [31].

\section{Bisulfite sequencing validation of DMPs}

Next, $500 \mathrm{ng}$ of genomic DNA was bisulfite converted using the EpiTect Bisulfite Kit (QIAGEN, Redwood City, CA, USA) according to the manufacturer's instructions. Primer pair sequences were designed by MethPrimer [67] and are listed in Additional file 1: Table S6. PCR products were cloned using the TopoTA Cloning System (Invitrogen, Carlsbad, CA, USA), and between 12 and 24 independent clones were sequenced for each examined subject and region by Sanger sequencing [68]. Methylation graphs were obtained by using QUMA software [69], and maps of genes were drawn by using IGV software.

\section{Quantitative assessment of $\mathrm{p}$-tau deposits in the hippocampus}

In order to quantitatively assess p-tau burden in the hippocampal samples of AD subjects, we applied a method described in detail elsewhere [7]. Briefly, sections of the hippocampus were examined after performing immunostaining with anti-p-tau antibody (clone AT-8) (dilution 1/ 1000), and representative images were analyzed with ImageJ software to obtain an average quantitative measure of the global p-tau deposit for each section and patient. Examples of AT-8 staining for control and different AD stages are shown in Additional file 1: Figure S4.

\section{Chromatin immunoprecipitation in Normal Human Neural Progenitor Cells}

Normal Human Neural Progenitor (NHNP) cells (Lonza) were grown in $75 \mathrm{~cm}^{2}$ culture flasks in NPBM medium (Neural Progenitor Basal Medium, Lonza) with the addition of hFGF, hEGF, NSF-1, and GA. NHNP cells were fixed in $1 \%$ formaldehyde for $10 \mathrm{~min}$ at room temperature; the reaction was stopped by addition of $1.25 \mathrm{M}$ glycine solution, and cells were washed in PBS and harvested in IP buffer (1 volume of SDS buffer to 0.5 volume of Triton dilution buffer and protease inhibitors).
For each ChIP, $100 \mu \mathrm{g}$ of DNA was used. Chromatin was sonicated to an average size of $750 \mathrm{bp}$. Sonicated sample was then blocked by incubating with Protein G and A sepharose beads at $4^{\circ} \mathrm{C}$ for $1 \mathrm{~h}$. Ten percent of the sample was kept aside as INPUT, and $1 \mu \mathrm{g}$ of antibody or IgG was added to the remaining sample and incubated overnight at $4^{\circ} \mathrm{C}$. The next day Protein $\mathrm{G}$ and $\mathrm{A}$ sepharose beads were added and incubated for $2 \mathrm{~h}$ at $4{ }^{\circ} \mathrm{C}$. After extensive washes, immunocomplexes were eluted from the beads and cross-links were reversed. The DNA was recovered by phenol-chloroform extraction and ethanol precipitation. DNA was resuspended in $150 \mu \mathrm{l}$ of water, and $3.75 \mu \mathrm{l}$ were used for real-time qPCRs in a final volume of $10 \mu \mathrm{l}$. The antibodies used in this study were anti-H3 (ab1791, Abcam), anti-H3K27me3 (ab6002, Abcam), and antiH3K4me3 (ab8580, Abcam). ChIP of the CCNL1 promoter and gene body regions were used as a positive control for active promoter histone marks (H3K4me3) and negative control for repressive histone marks (H3K27me3).

\section{Functional in silico analysis of DMPs}

We performed a systematic manual curation of the literature using PubMed to identify whether AD-related differentially methylated genes were enriched in nervous system functions, including neurogenesis and neural development.

In order to determine the biological significance of AD-related DMPs, gene ontology analysis and pathway analysis were performed using the Genomic Regions Enrichment of Annotations Tool (GREAT) [31]. To define gene regulatory domains, each gene was assigned a basal regulatory domain of a minimum distance upstream (5.0 $\mathrm{kb})$ and downstream of the transcription start site (TSS) (1 Kb plus distal up to $1000 \mathrm{~Kb}$ ). The gene regulatory domain was extended in both directions to the nearest gene's basal domain but no more than the maximum extension in one direction. By using GREAT, we got InterPro ontology which contains data on protein domains, families, and functional sites. InterPro annotations give information about the function, structure, and evolution of the domains by combining several other databases (PROSITE, PRINTS, Pfam, ProDom, SMART, TIGRFAMs, PIRSF, SUPERFAMILY, PANTHER, and Gene3D). Only those terms with a FDR-corrected $p$ value less than 0.05 were reported.

\section{Additional file}

Additional file 1: Table S1. Brain sample set analyzed by $450 \mathrm{~K}$ Illumina BeadChip array. Table S2. Differentially methylated genes in previous AD methylome studies. Table $\mathbf{S 3}$. Correlation between $450 \mathrm{~K}$ array data and DNA methylation levels obtained by bisulfite cloning sequencing. Table $\mathrm{S} 4$. Correlation between DNA methylation levels at each DMPs and tau burden Table S5. InterPro Gene Ontology enrichment analysis. Table S6. Bisulfite PCR primers. Figure S1. Validation and extended mapping for the differentially methylated genes RHOB and NXN. Figure $\mathbf{S 2}$. Functional in silico study of 
DMPs. Figure S3. Bioinformatics pipeline. Figure S4. Representative examples of tau staining (AT8) for control and AD stages. (PDF $886 \mathrm{~kb}$ )

\section{Abbreviations}

AD: Altheimer's disease; bp: Base pair; ChlP: Chromatin immunoprecipitation; CpG: Cytosine-phosphate-guanine dinucleotide; DMPs: Differentially methylated positions; GO: Gene ontology; GREAT: Genomic Regions Enrichment of Annotations Tool; GWAS: Genome-wide association studies; H1hESC: H1 human Embryonic Stem Cells: NH-A: Normal human astrocytes: NHNP. Normal Human Neural Progenitor Cells; NPBM: Neural Progenitor Basal Medium; OSAT: Optimal Sample Assignment Tool; PM: Postmortem interval; $p$-tau: Hyperphosphorylated tau; SD: Standard deviation; SNPs: Single nudeotide polymorphisms; STRING: Search Tool for the Retrieval of Interacting Genes; TF: Transcription factor; TSS: Transcription start site; UCSC: University of California, Santa Cruz

\section{Acknowledgements}

We want to kindly thank Isabel Gil M.D., Ph.D., Ana Purroy, Valle Coca, and Ana Aramendia from the Navarrabiomed BrainBank for their technical support and help and Genomics Shared Resource of the Roswell Park Cancer Institute (Buffalo, NY, USA). We are very thankful to Teresa Tuñón MD., Ph.D., and Federico García Bragado M.D., Ph.D., for their encouragement and anatomopathological support. We also want to thank Pitu Manubens † M.D., Ph.D., for invaluable mentoring and inspiration. Finally, we are very grateful to the patients and relatives that generously donor the brain tissue to the Navarrabiomed Brain Bank

\section{Funding}

This work was supported by the Spanish Government through grants from the Institute of Health Carlos III (FIS PI13/02730 and P117/02218), jointly funded by European Regional Development Fund (ERDF), European Union "A way of shaping Europe"; the Regional Basque Govemment through a grant from The Basque Foundation for Health Innovation and Research (BIOEF) (BIO12/ALZ/007): a grant from Fundación Caja-Navarra and the Trans-Pyrenean Biomedical Research Network (REFBIO); crowdfunding through the PRECIPITA platform (Spanish foundation for science and technology-FECYT; and funding from "LaCaixa Foundation". In addition, AUC received a grant "Doctorados industriales 20182020 " founded by Government of Navarra and MM received a grant "Programa de intensificación" founded by Fundación Bancaria "la Caixa" and Fundación Caja-

\section{Availability of data and materials}

All relevant data generated or analyzed during this study are included in this published article and its supplementary information files.

\section{Authors' contributions}

MA contributed to study design, acquisition of data, subject recruitment data analysis and characterization, and drafting/revising the manuscript for content. AUC contributed to developing epigenetic experiments, analysis, and drawing figures. JSR contributed to drafting/revising the manuscript for content, analysis and interpretation of data (p-tau), and acquisition of image data. MVZ participated in acquiring data, revising subject diagnosis, and classifying patients and contributed to drafting/revising the manuscript for content. AL contributed to bioinformatics analysis and drafting the manuscript. JML performed ChIP experiments and statistical analysis. MR contributed to drawing figures, performed bisulfite experiments, and was involved in interpretation of data. IBL contributed to data analysis and to draft the manuscript for content. AP contributed to bioinformatics analysis. RL contributed to subject recruitment and characterization. IJ was involved in interpretation of data and contributed to drafting/revising the manuscript for content. CE participated in acquiring data, revising subject diagnosis, and classifying patients and contributed to the drafting/revising the manuscript for content. IML contributed to the study concept and design, obtaining funding, analysis of data and drafting/revising the manuscript for content. LDS contributed to ChIP experiments and drafting/revising the manuscript for content. MM contributed to study concept and design, subject recruitment and characterization, obtaining funding, study supervision, data analysis, and drafting/revising the manuscript for content. All authors read and approved the final manuscript.

\section{Ethics approval and consent to participate}

This study was camied out in accordance with the principles of the Declaration of Helsinki, and handling of human brain samples was performed according to the current Spanish national legislation (Royal Decree RD1716/2011). Written informed consent was obtained from all subjects or next of kin. The study was approved by the Ethics Committee of the Complejo Hospitalario de Navarra (90/2014) and the Scientific Committee of Navarrabiomed Brain Bank, Spain.

\section{Consent for publication}

Not applicable.

Competing interests

The authors declare that they have no competing interests.

\section{Publisher's Note}

Springer Nature remains neutral with regard to jurisdictional claims in published maps and institutional affiliations.

\section{Author details}

'Neuroepigenetics Laboratory, Navarrabiomed, Public University of Navarre (UPNA), IdiSNA (Navarra Institute for Health Research), c/ Irunlarrea, 3, 31008 Pamplona, Spain. ${ }^{2}$ Department of Neurology, Complejo Hospitalario de Navarra, IdiSNA (Navarra Institute for Health Research), Pamplona, Spain. ${ }^{3}$ Department of Pathology, Complejo Hospitalario de Navarra- IdiSNA (Navarra Institute for Health Research), Pamplona, Spain. ${ }^{4}$ Bioinformatics Unit, Navarrabiomed, Public University of Navarre (UPNA), IdiSNA (Navarra Institute for Health Research), Pamplona, Spain. ${ }^{5}$ Laboratoire de biologie cellulaire et moléculaire du contrôle de la prolifération (LBCMCP), Université Paul Sabatier, CNRS, Toulouse, France. ${ }^{6}$ Department of Intemal Medicine, Hospital García-Orcoyen, Estella, Spain.

Received: 14 February 2019 Accepted: 25 April 2019

Published online: 19 June 2019

\section{References}

1. Winblad B, Amouyel P, Andrieu S, Ballard C, Brayne C, Brodaty H, et al. Defeating Altheimer's disease and other dementias: a priority for European science and society, Lancet Neurol. 2016;15(5):455-532. https//doi.org/10. 1016/51474-4422(16)00062-4.

2. Blennow K, de Leon MJ, Zetterberg H. Alzheimer's disease. Lancet. 2006; 368(9533):387-403. https//doi.org/10.1016/50140-6736(06)69113-7.

3. Reitz C, Brayne C, Mayeux R. Epidemiology of Alzheimer disease. Nat Rev Neurol. 2011;7(3):137-52. https:/doi.org/10.1038/nrneurol.2011.2.

4. Sanchez-Mut JV, Graff J. Epigenetic alterations in Alzheimer's disease. Front Behav Neurosci. 2015;9:347. https://doi.org/10.3389/fnbeh.2015.00347.

5. Rao JS, Keleshian VL, Klein S, Rapoport SI. Epigenetic modifications in frontal cortex from Alzheimer's disease and bipolar disorder patients. Transl Psychiatry. 2012;2:e132. https://doi.org/10.1038/tp.2012.55.

6. Siegmund KD, Connor CM, Campan M, Long TI, Weisenberger DJ, Biniszkiewicz D, et al. DNA methylation in the human cerebral cortex is dynamically regulated throughout the life span and involves differentiated neurons. PLoS One. 2007;2(9):e895. https:/doi.org/10.1371/journal.pone. 0000895

7. Celarain N, Sanchez-Ruiz de Gordoa J, Zelaya MV, Roldan M, Larumbe R, Pulido $L$, et al. TREM2 upregulation correlates with 5-hydroxymethycytosine enrichment in Altheimer's disease hippocampus. Clin Epigenetics. 2016:8:37. https:/doi.org/10.1186/s13148-016-0202-9.

8. Mendioroz M, Celarain N, Altuna M, Sanchez-Ruiz de Gordoa J, Zelaya MV, Roldan $\mathrm{M}$, et al. CRTCl gene is differentially methylated in the human hippocampus in Altheimer's disease. Alzheimers Res Ther. 2016;8(1):15. https//doi.org/10.1186/s13195-016-0183-0.

9. Bakulski KM, Dolinoy DC, Sartor MA, Paulson HL, Konen JR, Lieberman AP, et al. Genome-wide DNA methylation differences between late-onset Alzheimer's disease and cognitively normal controls in human fronta cortex. J Alzheimers Dis. 2012;29(3):571-88. https://doi.org/10.3233/jad-2012 111223.

10. Sanchez-Mut JV, Aso E, Heyn H, Matsuda T, Bock C. Ferrer I, et al. Promoter hypermethylation of the phosphatase DUSP22 mediates PKA-dependent TAU phosphorylation and CREB activation in Alzheimer's disease. Hippocampus. 2014;24(4):363-8. https://doi.org/10.1002/hipo.22245. 
11. Lunnon K Smith R. Hannon E De Jager PL Srivastava G Volta M et al. Methylomic profiling implicates cortical deregulation of ANK1 in Alzheimer's disease. Nat Neurosci. 2014;17(9):1164-70. https//doi.org/10.1038/nn.3782

12. De Jager PL, Srivastava G, Lunnon K, Burgess J, Schalkwyk LC, Yu L, et al. Alzheimer's disease: early alterations in brain DNA methylation at ANK1, BIN1, RHBDF2 and other loci. Nat Neurosci. 2014;17(9):1156-63. https:/doi. org/10.1038/nn.3786.

13. Yu L, Chibnik LB, Srivastava GP, Pochet N, Yang J, Xu J, et al. Association of Brain DNA methylation in SORL1, ABCA7, HLA-DRB5, SLC24A4, and BIN1 with pathological diagnosis of Alzheimer disease. JAMA Neurol. 2015;72(1): 15-24. https//doi.org/10.1001/jamaneurol.2014.3049.

14. Watson CT, Roussos P, Garg P, Ho DJ, Azam N, Katsel PL, et al. Genomewide DNA methylation profiling in the superior temporal gyrus reveals epigenetic signatures associated with Alzheimer's disease. Genome Med. 2016:8(1):5. https://doi.org/10.1186/513073-015-0258-8

15. Klein HU, Bennett DA, De Jager PL. The epigenome in Alzheimer's disease: current state and approaches for a new path to gene discovery and understanding disease mechanism. Acta Neuropathol. 2016. https://doi.org/ 10.1007/s00401-016-1612-7.

16. Delgado-Morales R, Esteller M. Opening up the DNA methylome of dementia. Mol Psychiatry. 2017. https://doi.org/10.1038/mp.2016.242

17. Wenk GL. Neuropathologic changes in Altheimer's disease. I Clin Psychiatry. 2003,64(Suppl 9):7-10.

18. Braak $\mathrm{H}$, Braak E. Neuropathological stageing of Alzheimer-related changes. Acta Neuropathol. 1991;82(4):239-59.

19. Braak H, Alafuzoff I, Arzberger T, Kretzchmar H, Del Tredici K. Staging of Alzheimer disease-associated neurofibrillary pathology using paraffin sections and immunocytochemistry. Acta Neuropathol. 2006;112(4):389-404 https:/doi.org/10.1007/s00401-006-0127-z

20. Lace G, Savva GM, Forster G, de Silva R, Brayne C, Matthews FE, et a. Hippocampal tau pathology is related to neuroanatomical connections: an ageing population-based study. Brain. 2009;132(Pt 5):1324-34. https://doi. org/10.1093/brain/amp059.

21. Guintivano J, Aryee M, Kaminsky ZA. A cell epigenotype specific model for the correction of brain cellular heterogeneity bias and its application to age brain region and major depression. Epigenetics. 2013;8(3):290-302. https// doi.org/10.4161/epi.23924.

22. Zhou X, Maricque B, Xie M, Li D, Sundaram V, Martin EA, et al. The human epigenome browser at Washington University. Nat Methods. 2011;8(12): 989-90. https//doi.org/10.1038/nmeth.1772.

23. Kent WJ, Sugnet CW, Furey TS, Roskin KM, Pringle TH, Zahler AM, et al. The human genome browser at UCSC. Genome Res. 2002;12(6):996-1006. https// doi.org/10.1101/gr.229102 Article published online before print in May 2002

24. Harikumar A, Meshorer E. Chromatin remodeling and bivalent histone modifications in embryonic stem cells. EMBO Rep. 2015;16(12):1609-19. https:/doi.org/10.15252/embr.201541011.

25. Bernstein BE, Mikkelsen TS, Xie X, Kamal M, Huebert DJ, Cuff J, et al. A bivalent chromatin structure marks key developmental genes in embryonic stem cells. Cell. 2006;125(2):315-26. https//doi.org/10.1016/j.cell.2006.02.041.

26. Zhao XD, Han X, Chew JL, Liu J, Chiu KP, Choo A, et al. Whole-genome mapping of histone $\mathrm{H} 3 \mathrm{Lys} 4$ and 27 trimethylations reveals distinc genomic compartments in human embryonic stem cells. Cell Stem Cell. 2007;1 (3):286-98. https//doi.org/10.1016/.stem.2007.08.004

27. Abraham BJ, Cui K, Tang Q, Zhao K. Dynamic regulation of epigenomic landscapes during hematopoiesis. BMC Genomics. 2013;14:193. https://do org/10.1186/1471-2164-14-193.

28. Mikkelsen TS, Ku M, Jaffe DB, Issac B, Lieberman E Giannoukos G, et al. Genome-wide maps of chromatin state in pluripotent and lineage-committed cells. Nature. 2007;448(7 153):553-60. https//doi.org/10.1038/nature06008.

29. Maupetit-Méhouas S, Montibus B, Nury D, Tayama C, Wassef M, Kota SK, al. Imprinting control regions (ICRs) are marked by mono-allelic bivalent chromatin when transcriptionally inactive. Nucleic Acids Res. 2016;44(2):621 35. https//doi.org/10.1093/nar/gkv960.

30. Yoo S, Bieda MC. Differences among brain tumor stem cell types and fetal neural stem cells in focal regions of histone modifications and DNA methylation, broad regions of modifications, and bivalent promoters. BMC Genomics. 2014;15:724. https://doi.org/10.1186/14712164-15-724.

31. McLean CY, Bristor D, Hiller M, Clarke SL, Schaar BT, Lowe CB, et al. GREAT improves functional interpretation of cis-regulatory regions. Nat Biotechnol. 2010;28(5):495-501. https://doi.org/10.1038/nbt.1630.
32. Thomas JO. HMG1 and 2: architectural DNA-binding proteins. Biochem Soc Trans. 2001;29(Pt 4):395-401.

33. Corsetti MT, Briata P, Sanseverino L, Daga A, Airoldi I, Simeone A, et al. Differential DNA binding properties of three human homeodomain proteins. Nucleic Acids Res. 1992;20(17):4465-72.

34. Serrano-Pozo A, Frosch MP, Masliah E, Hyman BT. Neuropathologica alterations in Alzheimer disease. Cold Spring Harb Perspect Med. 2011;1(1. a006189. https://doi.org/10.1101/cshperspect.a006189.

35. Spalding KL, Bergmann O, Alkass K, Bernard S, Salehpour M, Huttner HB, et al. Dynamics of hippocampal neurogenesis in adult humans. Cell. 2013; 153(6):1219-27. https//doi.org/10.1016/j.cell.2013.05.002.

36. Dokter $\mathrm{M}$, von Bohlen und Halbach $\mathrm{O}$. Neurogenesis within the adult hippocampus under physiological conditions and in depression. Neural Regen Res. 2012:7(7):552-9. https:/doi.org/10.3969/.issn.1673-5374.2012.07.013.

37. Ming GL, Song H. Adult neurogenesis in the mammalian brain: significant answers and significant questions. Neuron. 2011;70(4);687-702. https://dol. org/10.1016/.jneuron.2011.05.001.

38. Drapeau E, Mayo W, Aurousseau C, Le Moal M, Piazza PV, Abrous DN. Spatia memory performances of aged rats in the water maze predict levels of hippocampal neurogenesis. Proc Natl Acad Sci U S A. 2003;100(24):1438590. https://doi.org/10.1073/pnas.2334169100.

39. Mathews KI, Allen KM, Boerrigter D, Ball H, Shannon Weickert C, Double KL. Evidence for reduced neurogenesis in the aging human hippocampus despite stable stem cell markers. Aging Cell. 2017. https//doi.org/10.1111/ acel.12641.

40. Mu Y, Gage FH. Adult hippocampal neurogenesis and its role in Alzheimer's disease. Mol Neurodegener. 2011;6:85. https://doi.org/10.1186/1750-1326-6-85.

41. Crews L, Masliah E. Molecular mechanisms of neurodegeneration in Alzheimer's disease. Hum Mol Genet. 2010;19(R1):R12-20. https://doi.org/10 1093/hmg/ddq160.

42. Moreno-Jimenez EP, Flor-Garcia M, Terreros-Roncal J, Rabano A, Cafini F, PallasBazarra N, et al. Adult hippocampal neurogenesis is abundant in neurologically healthy subjects and drops shardly in patients with Altheimer's disease. Nat Med. 2019. https:// doi.org/10.1038/541591-019-0375-9.

43. Jin K, Peel AL, Mao XO, Xie L, Cottrell BA, Henshall DC, et al. Increased hippocampal neurogenesis in Alzheimer's disease. Proc Natl Acad Sci U S A. 2004;101(1):343-7. https://doi.org/10.1073/pnas.2634794100.

44. Gomez-Nicola D, Suzzi S, Vargas-Caballero M, Fransen NL, Al-Malki H Cebrian-Silla A, et al. Temporal dynamics of hippocampal neurogenesis in chronic neurodegeneration. Brain. 2014;137(Pt 8):2312-28. https://doi.org/10 1093/brain/awuls5

45. Boekhoorn K, Joels M. Lucassen PJ. Increased proliferation reflects glial and vascular-associated changes, but not neurogenesis in the presenile Alzheimer hippocampus. Neurobiol Dis. 2006;24(1):1-14. https://doi.org/10 1016/.j.nbd.2006.04.017

46. Li B, Yamamori H, Tatebayashi Y, Shafit-Zagardo B, Tanimukai H, Chen S, et al. Failure of neuronal maturation in Alzheimer disease dentate gyrus. Neuropathol Exp Neurol, 2008;67(1):78-84. https://doi.org/10.1097/nen. $0 \mathrm{~b} 013 \mathrm{e} 318160 \mathrm{cSdb}$

47. Pallas-Bazarra N, Jurado-Arjona J, Navarrete M, Esteban JA, Hernández F, Ávila J, et al. Novel function of Tau in regulating the effects of external stimuli on adult hippocampal neurogenesis. EMBO J. 2016:35(13):1417-36. https:/doi.org/10.15252/embj.201593518.

48. Houben S, Leroy K, Ando K, Yilmaz Z, Widomski C, Buee L, et al. Genetic ablation of tau in postnatal neurons rescues decreased adult hippocampa neurogenesis in a tauopathy model. Neurobiol Dis. 2019;127:131-41. https:/ doi.org/10.1016/.nbd.2019.02.021.

49. Braak H, Del Tredici K. The pathological process underlying Alzheimer's disease in individuals under thirty. Acta Neuropathol. 2011;121(2):171-81. https:/doi.org/10.1007/s00401-010-0789-4.

50. Braak H, Thal DR, Ghebremedhin E, Del Tredici K. Stages of the pathologic process in Alzheimer disease: age categories from 1 to 100 years. J Neuropathol Exp Neurol. 2011;70(11):960-9. https://doi.org/10.1097/NEN. Ob013e318232a379.

51. Mormino EC, Sperling RA, Holmes AJ, Buckner RL, De Jager PL, Smoller IW, et al. Polygenic risk of Alzheimer disease is associated with early-and latelife processes. Neurology. 2016:87(5):481-8. https//doi.org/10.1212 WNL. 0000000000002922

52. Ross MG, Desai M, Khorram O, McKnight RA, Lane RH, Torday J. Gestational programming of offspring obesity: a potential contributor to Alzheimer's disease. Curr Alzheimer Res. 2007:4(2):213-7. 
53. Estacio-Gomez A, Diaz-Benjumea FJ. Roles of Hox genes in the patterning of the central nervous system of Drosophila. Fly. 2014;8(1):26-32. https:/doi. org/10.4161/fly.27424

54. Karalay O, Doberauer K, Vadodaria KC, Knobloch M, Berti L, Miquelajauregui $A$, et al. Prospero-related homeobox 1 gene (Prox1) is regulated by canonical Wnt signaling and has a stage-specific role in adult hippocampa neurogenesis. Proc Nat Acad Sci U S A. 2011;108(14):5807-12. https:/doi. org/10.1073/pnas. 1013456108

55. Technau GM, Rogulja-Ortmann A, Berger C, Birkholz O, Rickert C. Composition of a neuromere and its segmental diversification under the control of Hox genes in the embryonic CNS of Drosophila. J Neurogenet. 2014;28(3-4):171-80. https//doi.org/10.3109/01677063.2013. 868459 .

56. Lupo G, Nisi PS, Esteve P, Paul YL, Novo CL, Sidders B, et al, Molecular profiling of aged neural progenitors identifies $\mathrm{Db} \times 2$ as a candidate regulator of age-associated neurogenic decline. Aging Cell. 2018;17(3):e12745. https:// doi.org/10.1111/acel.12745.

57. Wu Z, Guo H, Chow N, Sallstrom J, Bell RD, Deane R, et al. Role of the MEOX2 homeobox gene in neurovascular dysfunction in Alzheimer disease. Nat Med. 2005:11(9):959-65. https://doi.org/10.1038/nm1287.

58. Hashimoto $Y$, Tsuji O, Kanekura K, Aiso S, Nikura T, Matsuoka M, et al. The Gox homeodomain transcription factor exerts neuroprotection using its homeodomain. J Biol Chem. 2004;279(16):16767-77. https://doi.org/10.1074/ jbc.M313630200.

59. Bell JE, Alafuzoff I, Al-Sarraj S, Arzberger T, Bogdanovic N, Budka H, et al. Management of a twenty-first century brain bank: experience in the BrainNet Europe consortium. Acta Neuropathol. 2008;115(5):497-507. https:/doi.org/10.1007/500401-008-0360-8.

60. Montine TJ, Phelps CH, Beach TG, Bigio EH, Caims NJ, Dickson DW, et al. National Institute on Aging-Alzheimer's Association guidelines for the neuropathologic assessment of Alzheimer's disease: a practical approach. Acta Neuropathol. 2012;123(1):1-11. https://doi.org/10.1007/ s00401-011-0910-3.

61. Sandoval J, Heyn H, Moran S, Serra-Musach J, Pujana MA Bibikova M, et al. Validation of a DNA methylation microarray for $450,000 \mathrm{CpG}$ sites in the human genome. Epigenetics. 2011;6(6):692-702.

62. Yan L, Ma C, Wang D, Hu Q, Qin M, Conroy JM, et al. OSAT: a tool for sample-to-batch allocations in genomics experiments. BMC Genomics. 2012; 13.689. https:/doi.org/10.1186/1471-2164-13-689.

63. Pidsley R, Y Wong CC, Volta M, Lunnon K, Mill J, Schalkmyk LC. A datadriven approach to preprocessing Illumina $450 \mathrm{~K}$ methylation array data. BMC Genomics. 2013;14:293.

64. Chen YA, Lemire M, Choufani S, Butcher DT, Grafodatskaya D, Zanke BW, et al. Discovery of cross-reactive probes and polymorphic CpGs in the Illumina Infinium HumanMethylation450 microarray. Epigenetics. 2013:8(2):203-9. https//doi.org/10.4161/epi.23470.

65. Price ME, Cotton AM, Lam LL, Farre P, Emberly E, Brown CJ, et al. Additional annotation enhances potential for biologically-relevant analysis of the Illumina Infinium HumanMethylation450 BeadChip array. Epigenetics Chromatin. 2013;6(1):4. https//doi.org/10.1186/17568935-6-4.

66. Ritchie ME, Phipson B, Wu D, Hu Y, Law CW, Shi W, et al. Limma powers differential expression analyses for RNA-sequencing and microarray studies. Nucleic Acids Res. 2015:43(7):e47. https//doi.org/10. 1093/nar/gkv007.

67. Li LC, Dahiya R. MethPrimer: designing primers for methylation PCRs. Bioinformatics. 2002;18(11):1427-31.

68. Sanger F, Nicklen S, Coulson AR. DNA sequencing with chain-terminating inhibitors. Proc Natl Acad Sci U S A. 1977;74(12):5463-7.

69. Kumaki Y, Oda M, Okano M. QUMA: quantification tool for methylation analysis. Nucleic Acids Res. 2008;36(Web Server issue):W170-5. doi:10.1093/ nar/gkn294.

Ready to submit your research? Choose BMC and benefit from:

- fast, convenient online submission

- thorough peer review by experienced researchers in your field

- rapid publication on acceptance

- support for research data, including large and complex data type

- gold Open Access which fosters wider collaboration and increased citations

- maximum visibility for your research: over 100M website views per year

At BMC, research is always in progress.

Learn more biomedcentral.com/submission 


\section{Supplemental Table S1. Brain sample set analyzed by $450 \mathrm{~K}$ Illumina BeadChip array.}

\begin{tabular}{|c|c|c|c|c|c|c|c|c|}
\hline No. & Status & ABC score & $\begin{array}{c}\text { Braak \& } \\
\text { Braak stage }\end{array}$ & APS & $\begin{array}{l}\text { Age at death } \\
\text { (years) }\end{array}$ & Gender & PMI (h) & $\begin{array}{c}\text { Region } \\
\text { hippocampus }\end{array}$ \\
\hline 1 & Control & control & NA & NPD & 61 & male & 8 & yes \\
\hline 2 & Control & control & NA & NPD & 81 & male & 10.5 & yes \\
\hline 3 & Control & control & $\mathrm{NA}$ & NPD & 43 & female & 3 & yes \\
\hline 4 & Control & control & NA & NPD & 88 & male & 9 & yes \\
\hline 5 & Control & control & $\mathrm{NA}$ & NPD & 53 & male & 7 & yes \\
\hline 6 & Control & control & NA & NPD & 41 & male & 3.5 & yes \\
\hline 7 & Control & control & NA & NPD & 28 & male & 6 & yes \\
\hline 8 & Control & control & NA & NPD & 46 & female & 7 & yes \\
\hline 9 & Control & control & $\mathrm{NA}$ & NPD & 69 & male & 12 & yes \\
\hline 10 & Control & control & NA & NPD & 19 & female & NA & yes \\
\hline 11 & Control & control & $\mathrm{NA}$ & NPD & 26 & male & 6.2 & yes \\
\hline 12 & Control & control & NA & NPD & 54 & male & 18 & yes \\
\hline 13 & $A D$ & A1B1C1 & 1 & 0.00 & 60 & male & 15.3 & yes \\
\hline 14 & $A D$ & A1B1C1 & 1 & 2.00 & 85 & male & 3.2 & yes \\
\hline 15 & $A D$ & A1B1C1 & II & 0.00 & 66 & female & 1.4 & yes \\
\hline 16 & $A D$ & A1B2C1 & III & 0.00 & 88 & female & 33 & yes \\
\hline 17 & $A D$ & A1B2C1 & III & 3.00 & 96 & female & 1.5 & yes \\
\hline 18 & $A D$ & $\mathrm{~A} 1 \mathrm{~B} 2 \mathrm{C} 2$ & III & 0.33 & 79 & female & 13 & yes \\
\hline 19 & $A D$ & A1B2C2 & III & 1.00 & 81 & female & 9 & yes \\
\hline 20 & $A D$ & A1B2C3 & IV & 2.33 & 84 & female & 13 & yes \\
\hline 21 & $A D$ & $\mathrm{~A} 2 \mathrm{~B} 2 \mathrm{C} 2$ & III & 5.00 & 88 & male & 3.5 & yes \\
\hline 22 & $A D$ & $\mathrm{~A} 2 \mathrm{~B} 2 \mathrm{C} 2$ & IV & 2.33 & 91 & female & 10 & yes \\
\hline 23 & $A D$ & $\mathrm{~A} 2 \mathrm{~B} 2 \mathrm{C} 2$ & IV & 1.33 & 84 & male & 3.3 & yes \\
\hline 24 & $A D$ & $\mathrm{~A} 2 \mathrm{~B} 2 \mathrm{C} 2$ & IV & 3.00 & 97 & female & NA & yes \\
\hline 25 & $A D$ & $\mathrm{~A} 2 \mathrm{~B} 2 \mathrm{C} 3$ & IV & 1.33 & 78 & male & 5 & yes \\
\hline 26 & $A D$ & $\mathrm{~A} 2 \mathrm{~B} 3 \mathrm{C} 3$ & $\mathrm{~V}$ & 5.67 & 77 & female & 4 & yes \\
\hline 27 & $A D$ & A3B2C1 & IV & 1.33 & 90 & female & 3 & yes \\
\hline 28 & $A D$ & A3B2C3 & III & 6.67 & 98 & female & 3 & yes \\
\hline 29 & $A D$ & $\mathrm{~A} 3 \mathrm{~B} 2 \mathrm{C} 3$ & III & 2.67 & 85 & female & $\mathrm{NA}$ & yes \\
\hline 30 & $A D$ & A3B3C2 & $\mathrm{V}$ & 3.00 & 92 & female & 14 & yes \\
\hline 31 & $A D$ & A3B3C2 & $\mathrm{V}$ & 7.00 & 82 & female & 9 & yes \\
\hline 32 & $A D$ & A3B3C2 & V & 8.00 & 91 & male & 5 & yes \\
\hline 33 & $A D$ & A3B3C 3 & $\mathrm{~V}$ & 4.00 & 77 & female & 11 & yes \\
\hline 34 & $A D$ & A3B3C 3 & $\mathrm{VI}$ & 3.33 & 93 & female & 3 & yes \\
\hline 35 & $A D$ & АЗВ3С 3 & $\mathrm{VI}$ & 4.33 & 61 & male & 10 & yes \\
\hline 36 & $A D$ & АЗВ3С 3 & $\mathrm{VI}$ & 9.67 & 70 & male & 2.35 & yes \\
\hline 37 & $A D$ & A3B3C 3 & $\mathrm{VI}$ & 8.33 & 59 & male & 4 & yes \\
\hline 38 & $A D$ & A3B3C3 & $\mathrm{VI}$ & 8.33 & 59 & male & 4 & yes \\
\hline
\end{tabular}

The table shows the characteristic of the samples included in the study. No.: Number; AD: Alzheimer's disease; APS: amyloid plaque score; NPD: no protein deposit; PMI: post mortem interval; h: hours; NA: not applicable. 
Additional File: Altuna et al.

Supplemental Table S2. Differentially methylated genes in previous AD methylome studies.

\begin{tabular}{|l|l|}
\hline Genes & AD methylome study \\
\hline ATG16L2 & De Jager et al. \\
\hline BIN1 & De Jager et al.; Yu et al. \\
\hline CMYA5 & Watson et al.; Bakulski et al. \\
\hline DUSP27 & Lunnon el al. \\
\hline GP1BB & Lunnon el al. \\
\hline HOTAIRM1 & De Jager et al. \\
\hline HOXA1 & De Jager et al. \\
\hline HOXA2 & Lunnon el al.; De Jager et al. \\
\hline HOXA3 & Lunnon el al. \\
\hline HOXA4 & De Jager et al. \\
\hline KCNN4 & De Jager et al. \\
\hline MAP4K1 & Lunnon el al. \\
\hline NXN & De Jager et al. \\
\hline PARS2 & De Jager et al. \\
\hline SEPT5 & Lunnon el al. \\
\hline SIX3 & De Jager et al. \\
\hline SMG9 & De Jager et al. \\
\hline
\end{tabular}

The table shows the genes that have been previously found associated with $A D$ in methylome studies performed on human brain samples. 
Additional File: Altuna et al.

Supplemental Table S3. Correlation between 450K array data and DNA methylation levels obtained by bisulfite cloning sequencing

\begin{tabular}{|c|c|c|c|}
\hline Gene & Array Probes & Pearson's Coefficient & p-value \\
\hline HOXA3 & $\begin{array}{r}\text { cg22962123, } \\
\text { cg13172549, } \\
\text { cg00921266 }\end{array}$ & 0.784 & 0.002 \\
\hline HAND2 & $\begin{array}{c}\text { cg01566965, } \\
\text { cg1967399 }\end{array}$ & 0.855 & 0.007 \\
\hline RBMS1 & $\begin{array}{c}\text { cg19506623, } \\
\text { cg03157115, } \\
\text { cg18852574 }\end{array}$ & 0.777 & 0.003 \\
\hline HIST1H3E & $\begin{array}{r}\text { cg26092675, } \\
\text { cg13836098 }\end{array}$ & 0.847 & 0.008 \\
\hline PAX3 & $\begin{array}{r}\text { cg23077820, } \\
\text { cg04688351, } \\
\text { cg22989843 }\end{array}$ & 0.934 & $<0.0001$ \\
\hline NXN & cg19987768 & 0.982 & 0.017 \\
\hline RHOB & cg16258854 & 0.986 & 0.013 \\
\hline
\end{tabular}


Additional File: Altuna et al.

Supplemental Table S4. Correlation between DNA methylation levels at each DMPs and tau burden.

\begin{tabular}{|c|c|c|c|c|c|c|c|}
\hline Probe ID & & $\begin{array}{l}\text { Genomic } \\
\text { pordinates }\end{array}$ & GenelD1 & GenelD2 & $\begin{array}{l}\text { Pearson's } \\
\text { correlation } \\
\text { coefficient }\end{array}$ & $p$-value & $\begin{array}{c}\text { FDR } \\
\text { corrected } \\
\text { p-value }\end{array}$ \\
\hline $\operatorname{cg} 12253175$ & 12 & 58132093 & $A G A P 2$ & & $0.350 *$ & 0.037 & 0.045 \\
\hline cg09596958 & 12 & 58132105 & $A G A P 2$ & & $0.370 *$ & 0.026 & 0.045 \\
\hline cg22090150 & 17 & 4098227 & $A N K F Y 1$ & CYB5D2 & $0.404 *$ & 0.015 & 0.042 \\
\hline cg13771313 & 11 & 72533295 & ATG16L2 & FCHSD2 & $0.436 * *$ & 0.008 & 0.042 \\
\hline cg19153828 & 2 & 127782651 & BIN1 & GYPC & $0.353^{*}$ & 0.035 & 0.045 \\
\hline cg13935577 & 12 & 107974897 & BTBD11 & PWP1 & $0.389 *$ & 0.019 & 0.042 \\
\hline cg24369989 & 15 & 78933807 & CHRNB4 & & $0.407^{*}$ & 0.014 & 0.042 \\
\hline cg04154027 & 5 & 78985588 & CMYA5 & & $0.406^{*}$ & 0.014 & 0.042 \\
\hline $\operatorname{cg} 23279355$ & 5 & 78985592 & CMYA5 & & $0.348 *$ & 0.038 & 0.045 \\
\hline cg00611789 & 5 & 78985432 & CMYA5 & & $0.350 *$ & 0.037 & 0.045 \\
\hline cg09490371 & 2 & 233253024 & ECEL1P2 & $A L P P$ & $0.349 *$ & 0.037 & 0.045 \\
\hline cg16127683 & 15 & 40268777 & EIF $2 A K 4$ & SRP14 & $0.414 *$ & 0.012 & 0.042 \\
\hline cg13836098 & 6 & 26225268 & HIST1H3E & & $0.392 *$ & 0.018 & 0.042 \\
\hline cg12024906 & 19 & 37825679 & $H K R 1$ & & $0.517^{* *}$ & 0.001 & 0.020 \\
\hline cg07584855 & 1 & 221055545 & $H L X$ & DUSP10 & $0.379 *$ & 0.023 & 0.045 \\
\hline cg22962123 & 7 & 27153605 & HOXA3 & HOXA2 & $0.349 *$ & 0.037 & 0.045 \\
\hline $\operatorname{cg} 13172549$ & 7 & 27153636 & НOXАЗ & HOXA2 & $0.400 *$ & 0.016 & 0.042 \\
\hline cg00921266 & 7 & 27153663 & HOXA3 & HOXA2 & $0.355^{*}$ & 0.034 & 0.045 \\
\hline $\operatorname{cg} 17179862$ & 17 & 46681362 & HOXB6 & LOC404266 & $0.344 *$ & 0.040 & 0.045 \\
\hline cg20597486 & 1 & 158979841 & IFI16 & & $-0.397 *$ & 0.017 & 0.042 \\
\hline cg01331772 & 2 & 131094827 & IMP4 & & $0.335^{*}$ & 0.046 & 0.048 \\
\hline cg09317554 & 4 & 151505084 & $\angle R B A$ & MAB21L2 & $0.346^{*}$ & 0.039 & 0.045 \\
\hline
\end{tabular}


Additional File: Altuna et al.

\begin{tabular}{|c|c|c|c|c|c|c|c|}
\hline cg02798280 & 19 & 39087135 & MAP4K1 & $R Y R 1$ & $0.394^{*}$ & 0.018 & 0.042 \\
\hline cg02267270 & 6 & 37616410 & MDGA1 & $C C D C 167$ & $0.373^{*}$ & 0.025 & 0.045 \\
\hline $\operatorname{cg} 06396119$ & 13 & 49792767 & MLNR & & $0.422^{*}$ & 0.010 & 0.042 \\
\hline $\operatorname{cg} 24756378$ & 14 & 33401638 & NPAS3 & AKAPG & $0.378^{*}$ & 0.023 & 0.045 \\
\hline cg19022697 & 1 & 55247140 & PARS2 & DHCR24 & $0.409 *$ & 0.013 & 0.042 \\
\hline $\operatorname{cg} 14557699$ & 5 & 140254909 & PCDHA12 & & $0.444^{* *}$ & 0.007 & 0.042 \\
\hline cg01463828 & 8 & 22446721 & PDLIM2 & & $0.360 *$ & 0.031 & 0.045 \\
\hline cg20864214 & 11 & 73054121 & RELT & ARHGEF17 & $0.418^{*}$ & 0.011 & 0.042 \\
\hline $\operatorname{cg} 25840926$ & 2 & 20647987 & $R H O B$ & HS1BP3 & $0.404^{*}$ & 0.015 & 0.042 \\
\hline cg03422911 & 1 & 237205295 & $R Y R 2$ & & $0.340^{*}$ & 0.043 & 0.047 \\
\hline cg21811021 & 4 & 6659346 & S100P & MRFAP1 & $0.330 *$ & 0.049 & 0.049 \\
\hline cg05726109 & 22 & 19709755 & SEPT5 & $G P 1 B B$ & $0.335^{*}$ & 0.046 & 0.048 \\
\hline cg22385702 & 2 & 45175881 & $S I X 3$ & $S I X 2$ & $0.330^{*}$ & 0.049 & 0.049 \\
\hline cg02231404 & 20 & 62679635 & SoX18 & & $0.550 * *$ & 0.001 & 0.020 \\
\hline cg05637536 & 1 & 154475068 & TDRD10 & & $0.362^{*}$ & 0.030 & 0.045 \\
\hline cg14962509 & 1 & 36039655 & TFAP2E & & $0.354^{*}$ & 0.034 & 0.045 \\
\hline cg04498198 & 17 & 27899966 & TP53/13 & GIT1 & $0.357^{*}$ & 0.032 & 0.045 \\
\hline cg05877788 & 17 & 27899874 & TP53/13 & GIT1 & $0.399^{*}$ & 0.016 & 0.042 \\
\hline cg01421119 & 1 & 211555733 & TRAF5 & $R D 3$ & $0.403^{*}$ & 0.015 & 0.042 \\
\hline cg00303378 & 1 & 159825552 & VSIG8 & C1orf204 & $0.359 *$ & 0.031 & 0.045 \\
\hline cg07589899 & 2 & 62020677 & XPO1 & FAM161A & $0.345^{*}$ & 0.039 & 0.045 \\
\hline
\end{tabular}

ID: identification; Genomic coordinates according to GRCh37/hg19 Assembly; GeneID1 \& GenelD2: gene aliases of overlapping genes; * p-value<0.05; ** $p$ value $<0.01$ 


\section{IDENTIFICACIÓN DE BIOMARCADORES EPIGENÉTICOS EN LA ENFERMEDAD DE ALZHEIMER}

Additional File: Altuna et al.

Supplemental Table S5. InterPro Gene Ontology enrichment analysis.

\begin{tabular}{|c|c|c|c|c|c|c|c|c|c|}
\hline Ontology & \# Term Name & $\begin{array}{l}\text { Hyper } \\
\text { Rank }\end{array}$ & $\begin{array}{l}\text { Hyper FDR } \\
\text { Q-Val }\end{array}$ & $\begin{array}{l}\text { Hyper Fold } \\
\text { Enrichment }\end{array}$ & $\begin{array}{l}\text { Hyper } \\
\text { Foregr ound } \\
\text { Region Hits } \\
\end{array}$ & $\begin{array}{l}\text { Hyper } \\
\text { Total } \\
\text { Regions }\end{array}$ & $\begin{array}{c}\text { Hyper } \\
\text { Reglon Set } \\
\text { Coverage }\end{array}$ & $\begin{array}{l}\text { Hyper } \\
\text { Foreground } \\
\text { Gene Hits }\end{array}$ & $\begin{array}{c}\text { Total } \\
\text { Genes } \\
\text { Annotated }\end{array}$ \\
\hline \multirow{8}{*}{ InterPro } & Homeodomain-like & 4 & $1.34044 \mathrm{e}-4$ & 3.6792 & 23 & 14059 & $19.49 \%$ & 21 & 327 \\
\hline & Homeobox domain & 5 & $2.95230 e-4$ & 3.9476 & 20 & 11394 & $16.95 \%$ & 18 & 243 \\
\hline & $\begin{array}{l}\text { Homeobox, } \\
\text { conserved site }\end{array}$ & 3 & $3.24527 e-5$ & 4.6678 & 20 & 9636 & $16.95 \%$ & 17 & 188 \\
\hline & $\begin{array}{l}\text { Homeodomain, } \\
\text { metazoa }\end{array}$ & 2 & $2.74152 e-5$ & 6.8887 & 15 & 4897 & $12.71 \%$ & 11 & 92 \\
\hline & B30.2/SPRY domain & 10 & $2.48293 e-2$ & 10.5090 & 6 & 1284 & $5.08 \%$ & 3 & 91 \\
\hline & $\begin{array}{l}\text { SPIa/RYanadine } \\
\text { receptar SPRY }\end{array}$ & 9 & $2.52847 e-2$ & 10.6753 & 6 & 1264 & $5.08 \%$ & 3 & 89 \\
\hline & $\begin{array}{l}\text { Homeobox protein, } \\
\text { antennapedia type }\end{array}$ & 7 & $6.26551 e-3$ & 21.0968 & 5 & 533 & $4.24 \%$ & 4 & 12 \\
\hline & $\begin{array}{l}\text { Homeobox protein, } \\
\text { antennapedia type, } \\
\text { conserved site }\end{array}$ & 1 & $1.01380 e-8$ & 32.3586 & 10 & 695 & $8.47 \%$ & 6 & 20 \\
\hline
\end{tabular}

Additional File: Altuna et al.

\begin{tabular}{|c|c|c|c|c|c|c|c|c|}
\hline $\begin{array}{l}\text { Domain of unknown } \\
\text { function DUF } 4074\end{array}$ & 6 & $7.82430 e-4$ & 65.6620 & 4 & 137 & $3.39 \%$ & 1 & 3 \\
\hline Mab-21-like & 8 & $1.31348 \mathrm{e}-2$ & 71.7742 & 3 & 94 & $2.54 \%$ & 1 & 2 \\
\hline HIN-200/IF120x & 11 & $2.55725 \mathrm{e}-2$ & 249.8804 & 2 & 18 & $1.69 \%$ & 1 & 4 \\
\hline
\end{tabular}

The table shows the top-ranked categories obtained by using the InterPro Ontology set. 
Supplemental Table S6. Bisulfite PCR primers.

\begin{tabular}{|c|c|c|c|c|c|c|c|}
\hline Gene ID & Probe & $\begin{array}{l}\text { Amplicon } \\
\text { size }\end{array}$ & $\operatorname{Tm} 1$ & Forward Primer & $\operatorname{Tm} 2$ & Reverse Primer & $\begin{array}{l}\text { CpGs in } \\
\text { amplicon }\end{array}$ \\
\hline HAND2 & cg01566965 & 397 & 56.59 & TTITTTGAGGTATTAGTTATTAAAAGATT & 56.36 & TCCCTCTTAACTATATAAACACCAAC & 9 \\
\hline HIST1H3E & cg13836098 & 279 & 57.65 & GAGTTGTTTTAGTGGTTAGTTGTTTG & 59.94 & AAAAAAACCAATTCTCTATCCAAATTTA & 12 \\
\hline НОХАЗ & cg00921266 & 327 & 54.30 & AGTAAGAGAGTTTTTTGTGAGAGT & 50.30 & AACTCTACCTAAACTAATAACACC & 20 \\
\hline NXN & cg19987768 & 263 & 50.72 & GTTTTAAATGTTATTATAAATTTTAAGT & 58.26 & ATTCTACCAAAAAACAAAACTTTCC & 12 \\
\hline PAX3 & $\operatorname{cg} 23077820$ & 190 & 57.58 & GGGTTTTTATTGAGTAATAATTATTGAAG & 52.99 & ACATTCATAAATACTAAAACCATTC & 12 \\
\hline RBMS1 & cg19506623 & 179 & 59.62 & ATAAAGGGAGGAGGGATTIIIIT & 58.37 & TCCCAATAACTTATCCAAAAACC & 9 \\
\hline RHOB & cg16258854 & 216 & 59.73 & TTGGGTITITTATTGAGTGTTAAGG & 57.76 & TACAAACAAAAAATATCAAACTCCC & 12 \\
\hline
\end{tabular}

ID: identification; Tm1: Melting Temperature Forward Primer; Tm2: Melting Temperature Reverse Primer 
Additional File: Altuna et al.

\title{
Supplemental Figure S1
}

A.
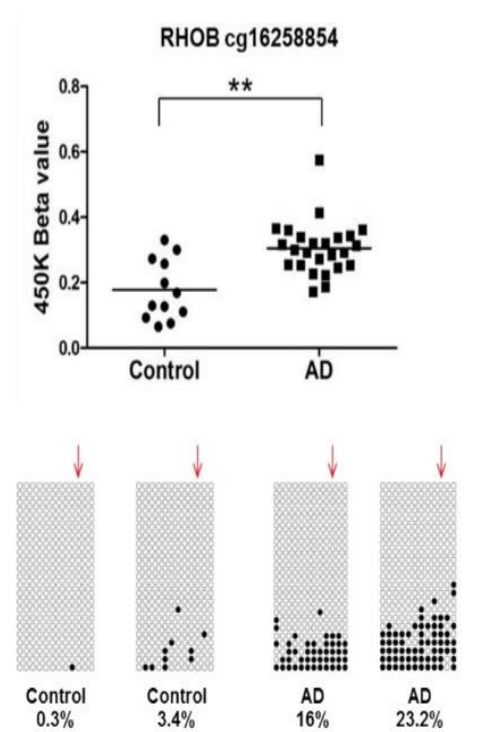

B.
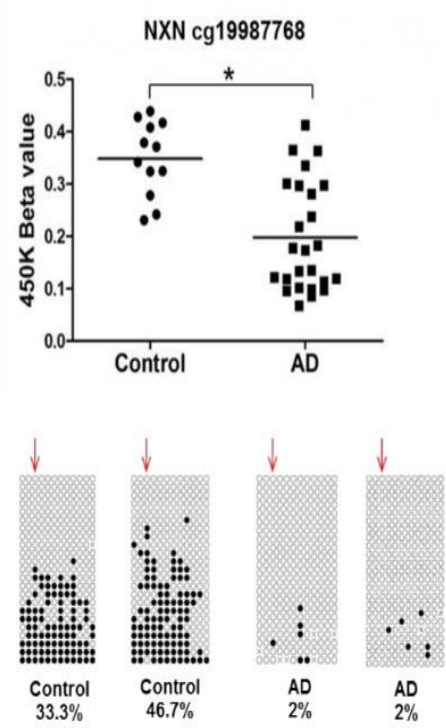

Additional File: Altuna et al.

\begin{abstract}
Validation and extended mapping for the differentially methylated genes RHOB and NXN. Bisulfite cloning sequencing shows that hypermethylation affects multiple contiguous $\mathrm{CpGs}$ within $\mathrm{RHOB}$ gene $(\mathrm{A})$ and hypomethylation affects multiple contiguous CpGs within NXN gene (B). White boxes below each gene denote CpG islands and black boxes represent bisulfite cloning sequencing amplicons. Dot-plot graphs show the results of the $450 \mathrm{~K}$ array (beta values) for CpG probes. Validation results are represented by black/white circle-style figures. Each rectangle corresponds to one sample and shows the methylation pattern at a discrete genomic region surrounding the significant $\mathrm{CpG}$ probed by the $450 \mathrm{~K}$ array which is denoted by a red arrow. Black circles represent methylated cytosines while white circles denote unmethylated cytosines. Each column symbolizes a unique CpG site in the examined amplicon and each line represents an individual DNA clone. Average percentage of methylation for each analyzed sample (control or patient) at this particular amplicon is indicated at the bottom of each sample.
\end{abstract}




\section{Additional File: Altuna et al.}

\section{Supplemental Figure S2}

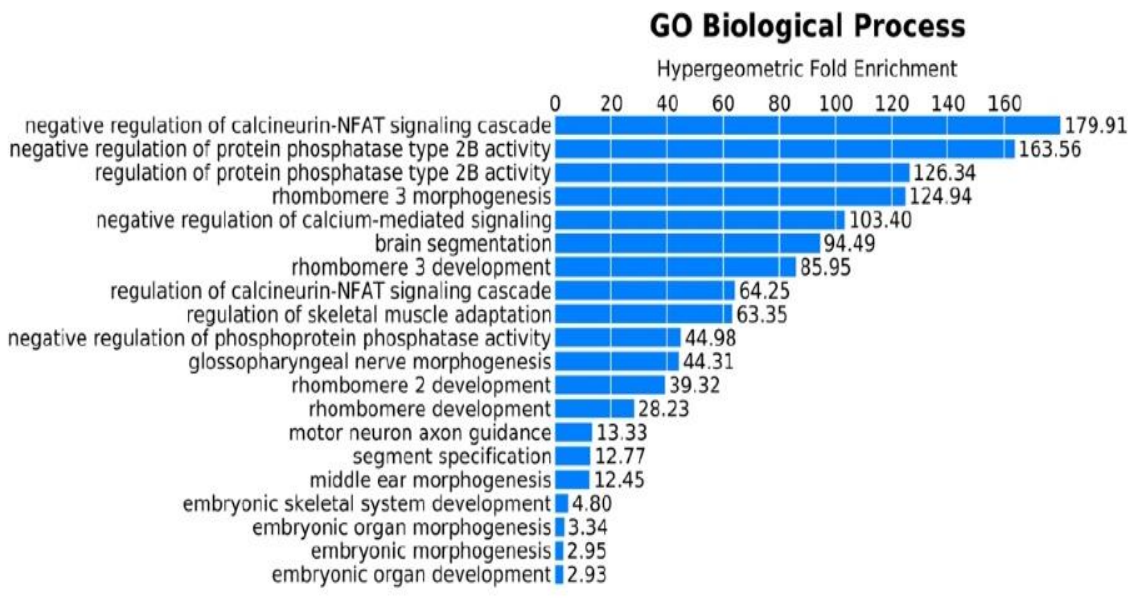

Functional in silico study of DMPs. The bar graph shows the results of the InterPro ontology analysis that revealed strong enrichment in processes consistently associated with embryonic and brain morphogenesis among others in our set of DMPs in the hippocampus of AD patients. 
Additional File: Altuna et al.

\section{Supplemental Figure S3}

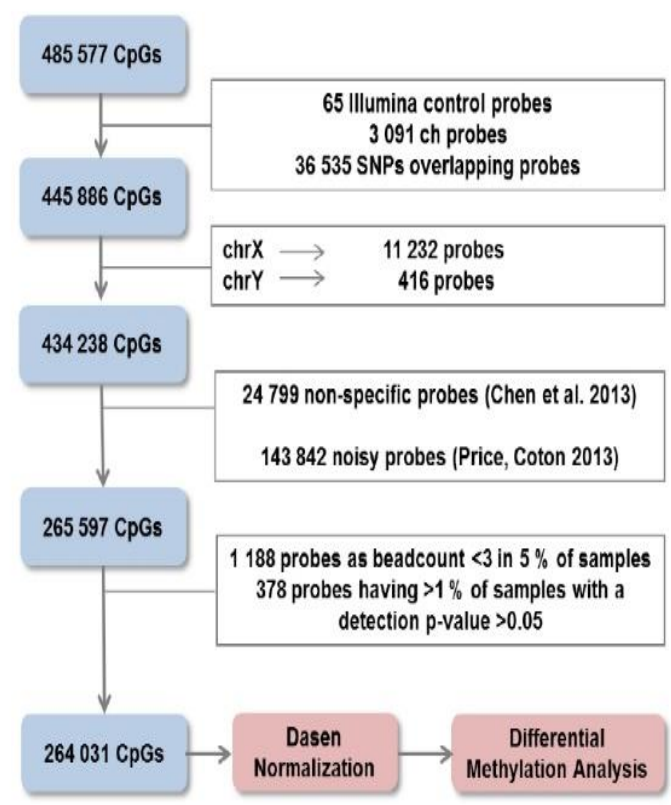

The diagram shows the bioinformatics pipeline used in this study: procedures for $450 \mathrm{~K}$ methylation data quality control and normalization analysis. 
Additional File: Altuna et al.

\section{Supplemental Figure $\$ 4$}
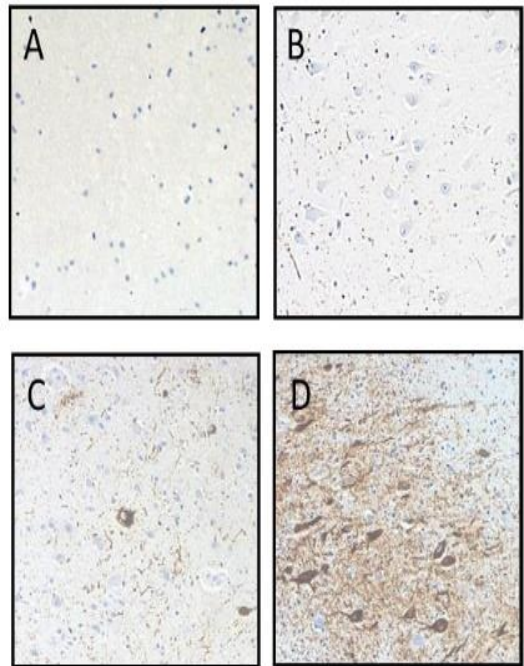

Representative examples of tau staining (AT8) for control and AD stages. Pictures were obtained at $10 \mathrm{x}$ from cases showing different degree of protein tau deposit. A-D: AT-8 staining. Density degree of neurophil threads and tangles (A, control; B, low; C, intermediate; D, high). 
PLD3 epigenetic changes in the hippocampus of Alzheimer's disease. Blanco-Luquin I, Altuna M. et al. Clinical Epigenetics 11, 2018; 10: 116. doi: 10.1186/s13148-018-0547-3 


\title{
PLD3 epigenetic changes in the hippocampus of Alzheimer's disease
}

Idoia Blanco-Luquin', Miren Altuna 1,2, Javier Sánchez-Ruiz de Gordoa 1,2, Amaya Urdánoz-Casado ', Miren Roldán', María Cámara ${ }^{2}$, Victoria Zelaya ${ }^{3}$, María Elena Erro ${ }^{1,2}$, Carmen Echavarri ${ }^{1,4}$ and Maite Mendioroz ${ }^{1,2^{*}}$

\begin{abstract}
Background: Whole-exome sequencing has revealed a rare missense variant in PLD3 gene (rs145999145) to be associated with late onset Alzheimer's disease (AD). Nevertheless, the association remains controversial and little is known about the role of PLD3 in AD. Interestingly, PLD3 encodes a phospholipase that may be involved in amyloid precursor protein (APP) processing. Our aim was to gain insight into the epigenetic mechanisms regulating PLD3 gene expression in the human hippocampus affected by AD.

Results: We assessed PLD3 mRNA expression by qPCR and protein levels by Western blot in frozen hippocampal samples from a cohort of neuropathologically confirmed pure AD cases and controls. Next, we profiled DNA methylation at cytosine-phosphate-guanine dinucleotide $(\mathrm{CpG})$ site resolution by pyrosequencing and further validated results by bisulfite cloning sequencing in two promoter regions of the PLD3 gene. A 1.67-fold decrease in PLD3 mRNA levels ( $p$ value $<0.001$ ) was observed in the hippocampus of AD cases compared to controls, and a slight decrease was also found by Western blot at protein level. Moreover, PLD3 mRNA levels inversely correlated with the average area of $\beta$-amyloid burden (tau- $b=-0,331 ; p$ value $<0.01$ ) in the hippocampus. A differentially methylated region was identified within the alternative promoter of $P L D 3$ gene showing higher DNA methylation levels in the AD hippocampus compared to controls $(21.7 \pm 4.7 \%$ vs. $18.3 \pm 4.8 \%$; $p$ value $<0.05)$.

Conclusions: PLD3 gene is downregulated in the human hippocampus in AD cases compared to controls. Altered epigenetic mechanisms, such as differential DNA methylation within an alternative promoter of PLD3 gene, may be involved in the pathological processes of AD. Moreover, PLD3 mRNA expression inversely correlates with hippocampal $\beta$-amyloid burden, which adds evidence to the hypothesis that PLD3 protein may contribute to AD development by modifying APP processing.
\end{abstract}

Keywords: PLD3, Alzheimer's disease, Epigenetics, DNA methylation, Gene and protein expression, Hippocampus, APP, Lysosome

\section{Background}

Alzheimer's disease (AD) is a genetically complex process where $\varepsilon 4$ allele of the $A P O E$ gene (APOE4) is by far the best-established genetic susceptibility risk factor. In addition, genome-wide association studies have revealed a considerable number of small-effect common variants in genes related to $\mathrm{AD}[1-3]$. However, those

\footnotetext{
*Correspondence: maitemendilab@gmail.com

${ }^{1}$ Neuroepigenetics Laboratory-Navarrabiomed, Complejo Hospitalario de Navarra, Universidad Pública de Navarra (UPNA), IdiSNA (Navarra Institute for Health Research), C/ Irunlarrea, 3, 31008 Pamplona, Navarra, Spain ${ }^{2}$ Department of Neurology, Complejo Hospitalario de Navarra- IdiSNA (Navarra Institute for Health Research), C/ Irunlarrea, 3, 31008 Pamplona, Navarra, Spain

Full list of author information is available at the end of the article
}

variants do not explain the full heritability of this disease. More recently, novel sequencing technologies are enabling the identification of other rare genetic variants that could potentially contribute to the development of sporadic AD. Notable recent discoveries in this area include rare disease variants in TREM2, UNC5C, AKAP9, TM2D3, ADAM10, and PLD3 genes [2, 4, 5].

PLD3 (phospholipase D family, member 3) (OMIM * 615698) gene is located at chromosome 19q13.2 and encodes a lysosomal protein that belongs to the phospholipase D (PLD) superfamily, which catalyzes the hydrolysis of membrane phospholipids. However, PLD3 catalytic function has not yet been demonstrated $[6,7]$. PLD3 gene is highly expressed in the brain of healthy

O The Author(s). 2018 Open Access This article is distributed under the terms of the Creative Commons Attribution 4.0 International License (http://creativecommons.org/licenses/by/4.0), which permits unrestricted use, distribution, and reproduction in any medium, provided you give appropriate credit to the original author(s) and the source, provide a link to the Creative Commons license, and indicate if changes were made. The Creative Commons Public Domain Dedication waiver (http $/ /$ creativecommons.org/publicdomain/zero/1.0/) applies to the data made available in this article, unless otherwise stated. 
controls, particularly in several brain regions vulnerable to $\mathrm{AD}$ pathology, such as frontal, temporal, and occipital cortices and hippocampus, but reduced in neurons from AD brains $[3,8]$. Nevertheless, little is known on the regulation, the function, and the involvement of PLD3 in AD pathogenesis.

Interestingly, controversial association exists about this gene conferring increased risk for the development of AD. Cruchaga et al. performed whole-exome sequencing on $\mathrm{AD}$ patients and identified a rare missense variant (rs145999145) in exon 7 of the PLD3 gene which resulted in a val232-to-met (V232M) substitution [8]. Their results revealed that carriers of the PLD3 coding variant had a twofold increased risk for late onset $A D$. Moreover, they showed that PLD3 influences amyloid precursor protein (APP) processing, acting as a negative regulator, since PLD3 overexpression in cultured neuroblastoma cells correlated with lower intracellular APP, extracellular $A \beta 42$, and $A \beta 40$ levels and that PLD3 protein could be co-immunoprecipitated with APP. In that regard, Satoh et al. showed an accumulation of PLD3 on neuritic plaques in $\mathrm{AD}$ brains and suggested a key role for PLD3 in the pathological processes of AD [9].

Other authors confirmed that PLD3 gene variant V232M was associated with $A D$ risk and significantly lower cognitive function [10] providing a systematic view of the involvement of PLD3 in $\mathrm{AD}$ at genetic, mRNA, and protein level expression. However, additional studies were not able to define an essential role of PLD3 rare variants in $\mathrm{AD}$ [11], neither to support an important contribution of PLD3 rare variants in the etiology of $\mathrm{AD}$, given the high variability of the frequency of PLD3 Val232Met variant across populations [12]. Indeed, follow-up studies have questioned the role of PLD3 rare variants in $\mathrm{AD}$, obtaining negative replication data [13-15] and suggesting a more complex role of PLD3 in the etiology of the disease.

Keeping in mind the results mentioned above, we wanted to gain insight into the epigenetic mechanisms regulating PLD3 expression in order to add evidence to the potential contribution of PLD3 to AD. Further knowledge on these mechanisms may provide opportunities for new AD therapeutic strategies. Here, we profiled $P L D 3$ gene expression and methylation in the human hippocampus, one of the most vulnerable brain regions to $\mathrm{AD}$. To that end, we selected a cohort of neuropathologically defined "pure" AD cases and controls to measure hippocampal PLD3 expression by quantitative PCR and Western blot. Next, we explored the correlation of PLD3 expression with AD neuropathological changes. Finally, DNA methylation levels at two distinct promoter regions of the PLD3 gene were assessed by pyrosequencing and bisulfite cloning sequencing.

\section{Methods \\ Human hippocampal samples and neuropathological examination}

Brain hippocampal samples from $30 \mathrm{AD}$ patients and 12 controls were provided by Navarrabiomed Brain Bank. After death, half brain specimens from donors were cryopreserved at $-80{ }^{\circ} \mathrm{C}$. Neuropathological examination was completed following the usual recommendations [16] and according to the updated National Institute on Aging-Alzheimer's Association guidelines [17]. Assessment of $\beta$-amyloid deposition was carried out by immunohistochemical staining of paraffin-embedded sections $(3-5 \mu \mathrm{m}$ thick) with a mouse monoclonal (S6F/3D) anti $\beta$-amyloid antibody (Leica Biosystems Newcastle Ltd., Newcastle upon Tyne, UK). Evaluation of neurofibrillary pathology was performed with a mouse monoclonal antibody anti-human PHF-TAU, clone AT-8, (Tau AT8) (Innogenetics, Gent, Belgium), which identifies hyperphosphorylated tau (p-tau) [18]. The reaction product was visualized using an automated slide immunostainer (Leica Bond Max) with Bond Polymer Refine Detection (Leica Biosystems, Newcastle Ltd.).

To avoid spurious findings related to multiprotein deposits, "pure" AD cases with deposits of only p-tau and $\beta$-amyloid were eligible for the study and controls were free of any pathological protein aggregate. This approach maximizes chances of finding true associations with $\mathrm{AD}$, even though reducing the final sample size. A summary of characteristics of subjects included in this study is shown in Additional file 1: Table S1. AD subjects were older than controls $(82.3 \pm 11.3$ versus $50.7 \pm 21.5 ; p$ value $<0.01)$, and no differences were found regarding gender ( $p$ value $=0.087$ ). The postmortem interval (PMI) were not significantly different between groups $(8.2 \pm 4.4 \mathrm{~h}$ in the control group versus $7.9 \pm 7.1 \mathrm{~h}$ in the $\mathrm{AD}$ group; $p$ value $=0.91$ ).

\section{PLD3 mRNA expression analysis by RT-qPCR}

Total RNA was isolated from hippocampal homogenates using RNeasy Lipid Tissue Mini kit (QIAGEN, Redwood City, CA, USA), following the manufacturer's instructions. Genomic DNA was removed with recombinant DNase (TURBO DNA-free ${ }^{\mathrm{Tw}}$ Kit, Ambion, Inc., Austin, TX, USA). RNA integrity was checked by $1.25 \%$ agarose gel electrophoresis under denaturing conditions. Concentration and purity of RNA were both evaluated with NanoDrop spectrophotometer. Only RNA samples showing a minimum quality index $(260 \mathrm{~nm} / 280 \mathrm{~nm}$ absorbance ratios between 1.8 and 2.2 and $260 \mathrm{~nm} / 230 \mathrm{~nm}$ absorbance ratios higher than 1.8) were included in the study. Complementary DNA (cDNA) was reverse transcribed from $1500 \mathrm{ng}$ total RNA with SuperScript ${ }^{\circ}$ III First-Strand Synthesis Reverse Transcriptase (Invitrogen, Carlsbad, CA, USA) after priming with oligo-d (T) and random primers. RT-qPCR reactions were performed in 
triplicate with Power SYBR Green PCR Master Mix (Invitrogen, Carlsbad, CA, USA) in a QuantStudio 12K Flex Real-Time PCR System (Applied Biosystems, Foster City, CA, USA) and repeated twice within independent cDNA sets. Sequences of primer pair were designed using Real Time PCR tool (IDT, Coralville, IA, USA) and are listed in Additional file 1: Table S2. Relative expression level of PLD3 mRNA in a particular sample was calculated as previously described [19] and $A C T B$ gene was used as the reference gene to normalize expression values.

\section{PLD3 protein expression analysis by Western blot}

Human hippocampus tissue from patients and control samples was lysed with $100 \mu \mathrm{L}$ lysis buffer containing urea, thiourea, and DTT. After centrifugation at $35.000 \mathrm{rpm}$ for $1 \mathrm{~h}$ at $15^{\circ} \mathrm{C}$, extracted proteins were quantified following the Bradford-Protein Assay (Bio-Rad, Hercules, CA, USA) by using a spectrophotometer.

Next, $5 \mu$ g of protein per sample were resolved in $4-20 \%$ Criterion TGX stain-free gels (Bio-Rad) and electrophoretically transferred onto nitrocellulose membranes using a Trans-blot Turbo transfer system ( $25 \mathrm{~V}, 7 \mathrm{~min})$ (Bio-Rad). Equal loading of the gel was assessed by stain-free digitalization and by Ponceau staining. Membranes were probed with rabbit anti-human PLD3 primary antibody (Sigma-Aldrich; 1:250) in 5\% nonfat milk and incubated with peroxidase-conjugated anti-rabbit secondary antibody (Cell Signaling; 1:2000). Immunoblots were then visualized by exposure to an enhanced chemiluminescence Clarity Western ECL Substrate (Bio-Rad) using a ChemidocMP Imaging System (Bio-Rad). Expression levels of PLD3 were standardized by the corresponding band intensity of GAPDH (Calbiochem; 1:10000).

\section{Quantitative assessment of $\beta$-amyloid and $p$-tau deposits} in hippocampal samples

In order to quantitatively assess the $\beta$-amyloid and $\mathrm{p}$-tau burden for further statistical analysis, we applied a method to quantify protein deposits, as described in detail elsewhere [20]. In brief, hippocampal sections were examined after performing immunostaining with anti $\beta$-amyloid and anti p-tau antibodies. Focal deposit of $\beta$-amyloid, including neuritic, immature, and compact plaques [21], was analyzed with the Image J software. Moreover, $\beta$-amyloid plaque count, referred to as amyloid plaque score (APS), was measured. Finally, p-tau deposit was also analyzed with ImageJ software in order to obtain an average quantitative measure of the global p-tau deposit for each section.

\section{PLD3 methylation measurement by pyrosequencing}

Genomic DNA was isolated from frozen hippocampal tissue by phenol-chloroform method [22]. Next, $500 \mathrm{ng}$ of genomic DNA was bisulfite converted using the
EpiTect Bisulfite Kit (Qiagen, Redwood City, CA, USA) according to the manufacturer's protocol. Primers to amplify and sequence two promoter regions of PLD3 were designed with PyroMark Assay Design version 2.0.1.15 (Qiagen) (Additional file 1: Table S2), and PCR reactions were carried out on a VeritiTM Thermal Cycler (Applied Biosystems, Foster City, CA, USA). Next, $20 \mu \mathrm{l}$ of biotinylated PCR product was immobilized using streptavidin-coated sepharose beads (GE Healthcare Life Sciences, Piscataway, NJ, USA) and $0.3 \mu \mathrm{M}$ sequencing primer was annealed to purified DNA strands. Pyrosequencing was performed using the PyroMark Gold Q96 reagents (Qiagen) on a PyroMark ${ }^{\text {mi }}$ Q96 ID System (Qiagen). For each particular cytosine-phosphate-guanine dinucleotide $(\mathrm{CpG})$, methylation levels were expressed as percentage of methylated cytosines over the sum of total cytosines. Unmethylated and methylated DNA samples (EpiTect PCR Control DNA Set, Qiagen) were used as controls for the pyrosequencing reaction.

\section{PLD3 methylation validations by bisulfite cloning} sequencing

Bisulfite-converted genomic DNA was used to validate pyrosequencing results. Primer pair sequences were designed by MethPrimer [23] and are listed in Additional file 1: Table S2. PCR products were cloned using the TopoTA Cloning System (Invitrogen, Carlsbad, CA, USA), and a minimum of 10-12 independent clones were sequenced for each examined subject and region. Methylation graphs were obtained with QUMA software [24].

\section{Statistical data analysis}

Statistical analysis was performed with SPSS 21.0 (IBM, Inc., USA). Before performing differential analysis, we checked that all continuous variables showed a normal distribution, as per one-sample Kolgomorov-Smirnov test and the normal quantil-quantil (QQ) plots. Data represents the mean \pm standard deviation (SD). Significance level was set at $p$ value $<0.05$. Statistical significance for PLD3 mRNA levels and pyrosequecing intergroup differences was assessed by $T$ test. One-way analysis of variance (ANOVA) followed by Games-Howell post hoc analysis was used to analyze differences in the expression levels of PLD3 mRNA between Braak and Braak stage groups. A logistic regression model (ENTER method) was fit to assess the independent association of PLD3 mRNA levels with $\mathrm{AD}$ status, using gender and age as covariates. Kendall's tau-b correlation coefficient was used to determine correlation between AD-related pathology and PLD3 mRNA expression levels. Difference between two bisulfite cloning sequencing groups was evaluated with Mann-Whitney $U$ test. GraphPad Prism version 6.00 for Windows (GraphPad Software, La Jolla, CA, USA) 
was used to draw graphs except for methylation figures that were obtained by QUMA software.

\section{Results}

PLD3 expression is downregulated in Alzheimer's disease hippocampus

As the first step in this study, we measured PLD3 mRNA expression levels by real-time quantitative PCR (RT-qPCR) in the hippocampus of AD patients compared to controls. Five samples did not pass the RNA quality threshold (see the "Methods" section) and so were not included in the experiments. Eventually, $26 \mathrm{AD}$ cases were compared to 11 controls. As shown in Fig. 1a, PLD3 mRNA levels were significantly decreased by 1.67-fold in the hippocampus of AD cases compared to controls $[p$ value $<0.001]$. Next, a disease-staging analysis was performed to investigate changes of PLD3 mRNA levels depending on the AD severity measured by Braak \& Braak staging [21]. We found that PLD3 mRNA levels were significantly reduced across Braak \& Braak stages $[p$ value $<0.005$; Fig. 1b]. Games-Howell post hoc analysis revealed that PLD3 mRNA expression was significantly different between control and Braak stages III-IV [ $p$ value $<0.05$ ] and between control and Braak stages V-VI $[p$ value $<0.05]$ (Fig. 1).
Then, to identify adjusted estimates of the association of PLD3 mRNA levels with $\mathrm{AD}$ status (control $=0$; $\mathrm{AD}$ $=1$ ), a logistic regression model was designed. Age and gender were included into the model to adjust for potentially confounding variables. As shown in Table 1, PLD3 mRNA expression levels remained as an independent predictor of AD status after adjusting for age and gender [ $p$ value $<0.05$ ] (Table 1$)$.

In order to examine whether the decrease in PLD3 mRNA levels in the AD hippocampus extended to the protein level, a Western blot analysis was performed. Protein extracts from frozen hippocampal samples that were included in the qPCR experiment were obtained, and a polyclonal antibody against a recombinant protein epitope signature tag (PrEST) of PLD3 was used. GAPDH protein detection was used as housekeeping. In line with the PLD3 mRNA expression results, we observed that PLD3 protein expression tends to be decreased in samples from hippocampus of AD patients as compared to controls (Fig. 1c).

Correlation of PLD3 mRNA expression levels with $\mathrm{p}$-tau and amyloid deposits

Next, we aimed to correlate PLD3 mRNA levels with AD-related neuropathological changes in hippocampal
A

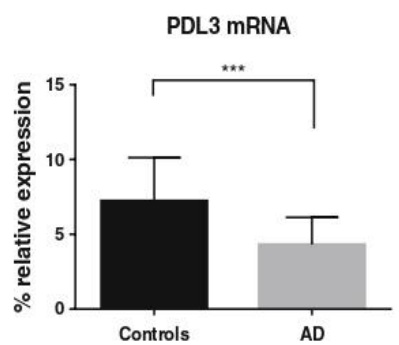

C

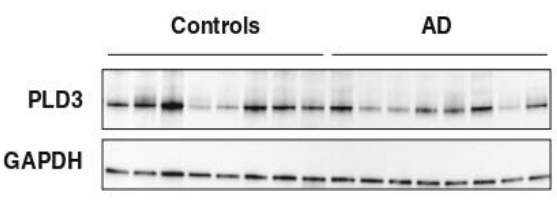

B
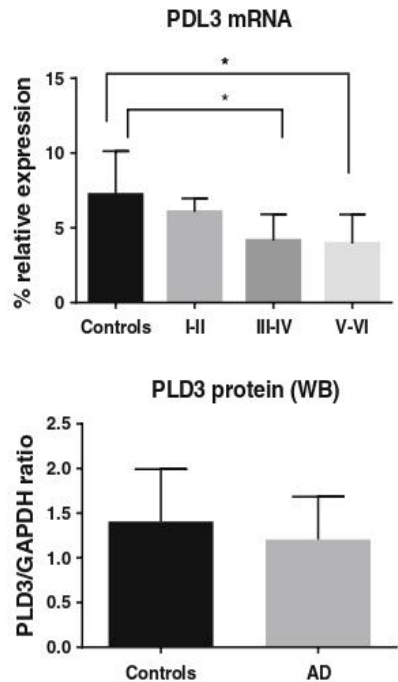

Fig. 1 PLD3 expression is decreased in human hippocampus in Alzheimer's disease (AD). a The graph shows a significant 1.67-fold decrease in PLD3 mRNA levels in AD hippocampal samples compared to control hippocampal samples. b PLD3 mRNA expression decreased across AD stages, as shown when PLD3 mRNA expression levels are sorted by Braak and Braak stages. Bars represent percentage of PLD3 mRNA expression relative to $A C T B$ housekeeping gene expression. Vertical lines represent the standard error of the mean. ${ }^{*} p$ value $<0.05 ;{ }^{* * *} p$ value $<0.001$. c Western blot analysis of PLD3 shows a mild protein expression decrease in AD. Human hippocampus samples from controls or AD patients were loaded as labeled on top of lanes. GADPH expression is shown as reference control. The bar chart represents the quantitative measurement of the PLD3 protein relative to GAPDH protein expression 
Table 1 Adjusted logistic regression model to predict AD status

\begin{tabular}{lllll}
\hline Variable & $B$ & Wald & $p$ value & OR \\
\hline PLD3 mRNA levels & -0.544 & 4.212 & $0.040^{*}$ & 0.581 \\
Gender (female) & 0.613 & 0.286 & 0.593 & 1.847 \\
Age $<65$ years old & 2.774 & 5.981 & $0.014^{*}$ & 16.02 \\
Constant & -1.494 & 0.254 & 0.614 & 0.224 \\
\hline
\end{tabular}

Alzheimer status (control $=0 ; A D=1$ ) was considered as the dependent variable and PLD3 mRNA expression levels, gender, and age were included as covariates

$B$ regression coefficient, $O R$ odds ratio

${ }^{*} p$ value $<0.05$

sections. In brief, $\beta$-amyloid and hyperphosphorylated tau (p-tau) burden were measured and averaged for each subject by a semi-automated quantitative method by using the ImageJ software (see the "Methods" section). The amyloid plaque score (APS) was also recorded. As $\beta$-amyloid and p-tau data were not normally distributed, the non-parametric Kendall's tau-b correlation coefficient was used. We found that the average area of $\beta$-amyloid burden in the hippocampus was inversely correlated with PLD3 mRNA levels [tau-b $=-0,331 ; p$ value $<0.01$ ], and accordingly, an inverse association was found between APS and PLD3 mRNA levels [tau-b $=-0,319 ; p$ value $<0.01$ ] Regarding p-tau deposits, a statistically significant correlation was found for an inverse correlation [tau-b $=-0,306$; $p$ value $<0.01]$.

DNA methylation in PLD3 is increased in hippocampus of AD cases compared to controls

DNA methylation levels of regulatory regions in the genome modulate the expression of related or nearby genes. Thus, we tested whether DNA methylation levels in PLD3 gene were also altered in the AD hippocampus. PLD3 gene is located in the long arm of chromosome 19 (19q13.2) and has two distinct CpG island-containing promoter regions as shown by the UCSC Genome Browser website [25] (Fig. 2a). The principal promoter, which is placed at the $5^{\prime}$ end of the gene, contains a 553 bp CpG island (chr19:40854181-40854733; GRCh37/ hg19) while an alternative promoter overlapping exon 2 contains a smaller 207 bp CpG island (chr19:40871 618-40871824; GRCh37/hg19). Pyrosequencing primers were designed to amplify and sequence specific CpGs within both promoters regions (P_prom CpG1 and CpG2 for the principal promoter and A_prom CpG1 and CpG2 for the alternative promoter) (Fig. 2a).

We observed that the principal promoter of PLD3 was mostly demethylated [mean $\pm \mathrm{SD}, 1.8 \pm 2.9 \%$ ], as it corresponds to the constitutive promoter of an actively expressed gene. Average DNA methylation levels were slightly higher in $\mathrm{AD}$ cases compared to controls only for P_prom CpG2 $[2.6 \pm 3.13 \%$ vs. $0 \pm 0 \% ; p$ value $<0.001]$. The alternative promoter showed intermediate levels of
DNA methylation [20.5 $\pm 4.91 \%]$. A_prom CpG1 showed a statistical trend to be highly methylated in $\mathrm{AD}$ cases compared to controls $[23 \pm 7.8 \%$ vs. $18.4 \pm$ $6.2 \% ; p$ value $=0.09]$ and a statistically significant difference in DNA methylation levels was observed for A_prom CpG2 in AD cases compared to controls [21.5 $\pm 5.8 \%$ vs. $15.3 \pm 3.8 \% ; p$ value $<0.01]$.

Next, we sought to replicate pyrosequencing results by extending the initial cohort with additional $\mathrm{AD}$ and control hippocampal samples for which DNA was available. These samples came from Navarrabiomed Brain Bank and were used to increase the sample size for the methylation experiments. Eventually, $36 \mathrm{AD}$ patients and 18 controls were analyzed by pyrosequencing. In the principal promoter, average DNA methylation levels showed a trend to be higher in $\mathrm{AD}$ cases compared to controls at P_prom CpG2 [2.3 $\pm 2 \%$ vs. $1 \pm 2.4 \% p$ value $=0.094]$. In the alternative promoter, no differences were found for A_prom CpG1 between AD cases and controls $[p$ value $>0.05]$. However, we observed a statistically significant difference in DNA methylation levels for A_prom CpG2 between $\mathrm{AD}$ cases and controls $[21.7 \pm 4.7 \%$ vs. $18.3 \pm$ $4.8 \%$; $p$ value $<0.05$ ], pointing to a differentially methylated region located within the alternative promoter of PLD3 in the AD hippocampus (Fig. 2b). In order to test whether A_prom CpG2 methylation was an independent predictor of $\mathrm{AD}$ status (control $=0 ; \mathrm{AD}=1$ ), a binary logistic regression model was performed. After adjusting for age and gender, A_prom CpG2 methylation levels remain as an independent predictor of $\mathrm{AD}$ (Additional file 1: Table S3).

We validated the pyrosequencing results and extended the methylation local mapping by using bisulfite cloning sequencing in two independent amplicons overlapping both PLD3 promoter regions. DNA methylation percentage was measured at $\mathrm{CPG}$ site resolution and further averaged across all the $\mathrm{CPG}$ sites for each amplicon. In line with the previous pyrosequencing results, we found that average DNA methylation levels of the amplicon at PLD3 principal promoter were very low and showed no differences between $\mathrm{AD}$ patients and controls (Fig. 2c). On the contrary, average DNA methylation levels of the amplicon at PLD3 alternative promoter were increased in AD patients compared to controls $[19.1 \pm 7.8 \%$ vs. $6 \pm$ $4 \% ; p$ value $<0.05$ ] (Fig. 2c).

Since DNA methylation is one of the major mechanisms to regulate gene expression, we analyzed the correlation between PLD3 mRNA expression and PLD3 DNA methylation in our sample set. No significant correlation was found between expression and DNA methylation measured by pyrosequencing [A_prom CpG1 $r=-0.264, p$ value $=0.114 ;$ A_prom CpG2 $r=-0.275, p$ value $=0.110]$. However, a significant inverse correlation was observed between expression and DNA methylation 


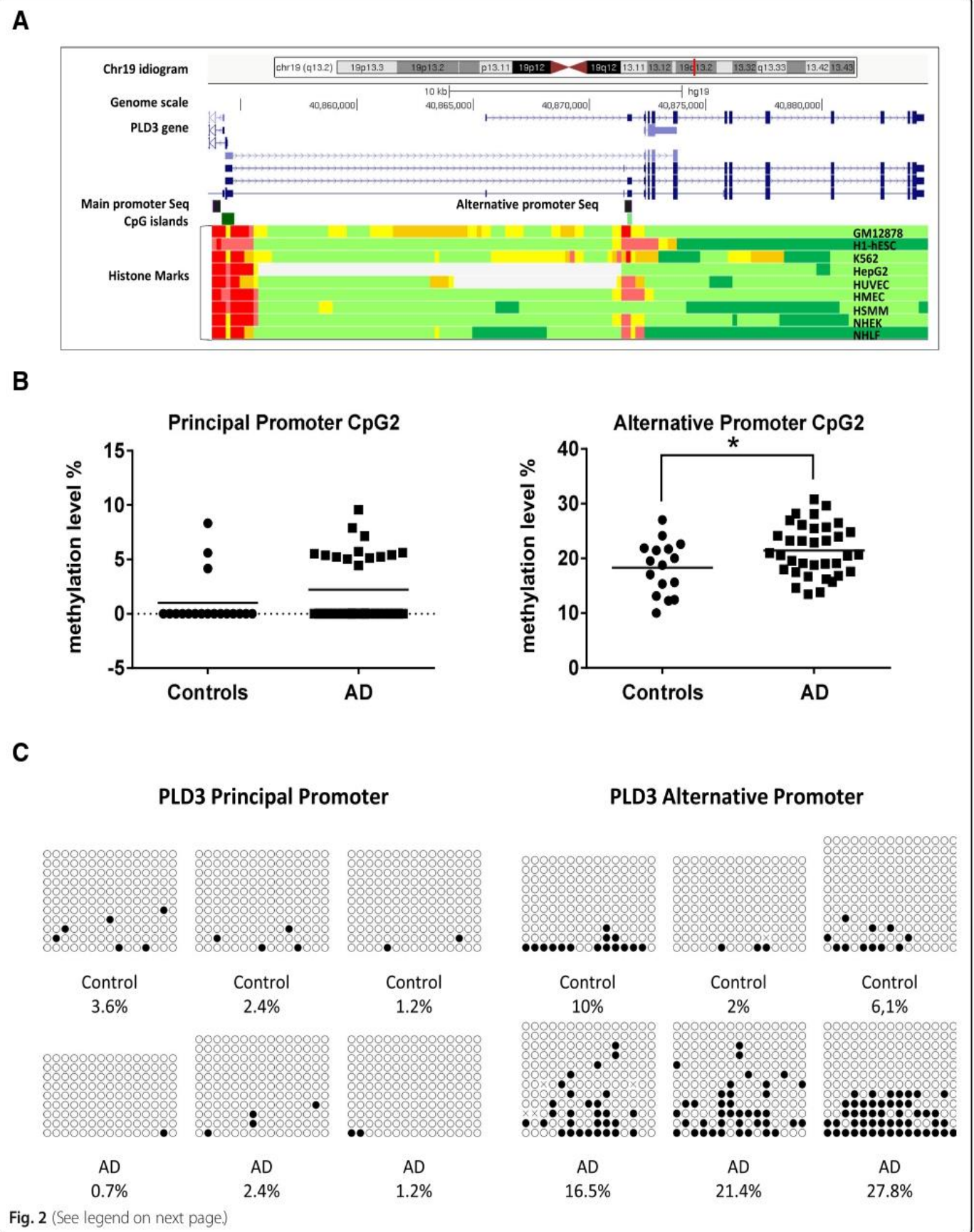




\begin{abstract}
See figure on previous page.
Fig. 2 PLD3 DNA methylation levels in human hippocampal samples. a The graph shows genomic position of the amplicons (black boxes) validated by bisulfite cloning sequencing which contain the cytosines assayed by pyrosequencing (CpG1 and CpG2) within the promoter regions (principal and alternative) of the PLD3 gene. PLD3 is located on the long am of chromosome 19 (chr 19:40,854,332-40,884,390 -GRchr19/hg19 coordinates). CpG islands are represented by isolated green boxes. At the bottom of the graph, predicted functional elements are shown for each of nine human cell lines explored by chromatine imunoprecipitation (ChlP) combined with massively parallel DNA sequencing. Boxes represent promoter regions (red), enhancers (yellow), transcriptional transition and elongation (dark green), and weak transcribed regions (light green). The track was obtained from the Chromatin State Segmentation by HMM from ENCODE/Broad track shown at the UCSC Genome Browser. b Dot-plot charts representing methylation levels for principal and alternative promoter of PLD3 by pyrosequencing. Horizontal lines represent median methylation values for each group." $p$ value $<0.05$. c Representative examples of bisulfite cloning sequencing validation for the two independent amplicons (principal and alternative promoter regions). Black and white circles denote methylated and unmethylated cytosines respectively. Each column symbolizes a unique CPG site in the examined amplicon, and each line represents an individual DNA clone
\end{abstract}

in the PLD3 alternative promoter measured by bisulfite cloning sequencing $[r=-0.683 ; p$ value $<0.05]$.

\section{Discussion}

We report PLD3 gene to be downregulated at both transcript and protein level in the human hippocampus affected by $\mathrm{AD}$. In addition, we show that the decrease in PLD3 mRNA expression inversely correlates with $\beta$-amyloid burden in the hippocampus. An important finding of this study is that an alternative promoter of PLD3 gene is differentially methylated in the hippocampus of $\mathrm{AD}$ patients compared to controls suggesting that epigenetic disturbances in PLD3 may occur in the pathological process of $\mathrm{AD}$

Our results showing a reduction in PLD3 expression in the $\mathrm{AD}$ hippocampus add to previous evidence supporting the idea that PLD3 gene is downregulated in brain areas affected by $\mathrm{AD}$ processes $[8,9]$. Cruchaga et al. [8] used data from genome-wide transcriptomics in laser-captured neurons from $33 \mathrm{AD}$ cases and 16 controls (GEO dataset GSE5281) [26] to reveal that PLD3 gene expression was significantly lower in $\mathrm{AD}$ cases compared to controls. In addition, Satoh et al. found a marginal reduction in PLD3 mRNA levels in the frontal cortex of $7 \mathrm{AD}$ cases compared to 14 non-AD subjects, including other neurodegenerative disorders such as amyotrophic lateral sclerosis and Parkinson disease [9]. In agreement with the previous results, we observed a statistically significant decrease in PLD3 mRNA expression in the hippocampus, a vulnerable region to $\mathrm{AD}$ pathology, and also show that $P L D 3$ is reduced across Braak \& Braak stages indicating that PLD3 is somehow related to the progressive neurodegenerative processes of $\mathrm{AD}$.

A number of different mechanisms could explain the decrease in PLD3 gene expression in the AD hippocampus, including the progressive loss of neuronal populations, changes in cellular composition with increasing astrogliosis in late stages of $\mathrm{AD}$, or cell-type-specific decrease in PLD3 gene expression. A limitation of the present study is that it has been designed on a tissue-specific basis, and therefore, changes in gene expression at cell-specific level, including neuron-specific level, cannot be assessed. In fact, the ratio of cellular components in the human hippocampus may change across different stages of $\mathrm{AD}$. In this case, and if the expression of PLD3 were cell type specific, the gene expression changes observed globally in the hippocampus could be attributed to the loss of a given cell population and not reflect actual PLD3 expression changes. However, the fact of having found epigenetic modifications in the same sample set would support the existence of a true alteration in the regulation of PLD3 gene expression. To know whether the difference in PLD3 gene expression is driven by a decreased expression in neurons or by changes in the ratio of cell populations in the brain of $\mathrm{AD}$ patients, other technologies, such as the emerging single-cell techniques, should be used.

The reduction in PLD3 expression is in line with the classical $\beta$-amyloid cascade hypothesis of $\mathrm{AD}$, since PLD3 protein seems to act as a negative regulator of APP processing [8]. It has been shown that knockdown of PLD3 expression in cells results in higher levels of extracellular $\mathrm{A} \beta 42$ and $\mathrm{A} \beta 40$ levels, and conversely, overexpression of PLD3 is associated with reduced extracellular $A \beta 42$ and $A \beta 40$ levels [8]. Furthermore, PLD3 protein is accumulated in neuritic plaques in human $A D$ brains [9]. Indeed, it has been demonstrated that PLD3 protein can be co-immunoprecipitated with APP in cultured cells [8]. Even more, PLD3 protein has been recently characterized as a novel endosome-to-Golgi retrieval gene that regulates the endosomal protein sorting, whose loss of function results in increased processing of APP [27]. Accordingly, we have found an inverse correlation between PLD3 mRNA expression levels and the burden of hippocampal $\beta$-amyloid assessed by two measurements, averaged deposit of $\beta$-amyloid and amyloid plaque score (APS). All these data supports the notion that PLD3 protein could display a protective effect against $\mathrm{AD}$ pathology through its role in APP trafficking, as other authors have previously suggested [27].

Interestingly, PLD3 protein is co-expressed with other lysosomal proteins [9], including progranulin, which regulates lysosomal functioning and is also accumulated in neuritic plaques $[9,28]$. Moreover, PLD3 protein is 
required to preserve the structure of lysosomes in vivo and, therefore, impairment of the endosomal-lysosomal systems has been proposed as an alternative mechanism by which PLD3 could contribute to the development of $\mathrm{AD}$ [29]. Most interestingly, another genetic variant in PLD3, p.Leu308Pro, was recently found to cause autosomal dominant spinocerebellar ataxia [30], a neurodegenerative condition where lysosomal disturbances are thought to be crucial [31, 32]. As an additional alternative explanation, PLD3 might also influence AD pathological processes by altering adult neurogenesis since PLD3 gene expression seems to be turned on at late stages of neurogenesis [33].

Finally, we describe an altered pattern of DNA methylation within an alternative promoter of the PLD3 gene in the human hippocampus affected by AD. To our knowledge, no previous reports on altered DNA methylation in PLD3 gene have been published and very little is known about regulation of $P L D 3$ gene expression. The alternative promoter of PLD3 is placed $\sim 17,500$ bp downstream the principal promoter overlapping exon 2 . It contains a small CpG island and is conserved across several cell types (Fig. 2a). In our study, it was found to be differentially methylated showing higher DNA methylation levels in AD patients than in controls. Since DNA methylation of CpG islands is one of the major epigenetic mechanisms that influence gene expression, our results indicate that altered DNA methylation at this particular regulatory region might contribute to downregulate PLD3 expression in AD.

In this regard, we also show a significant correlation between PLD3 mRNA expression and DNA methylation in our dataset when measured by bisulfite cloning sequencing, while the pyrosequencing results did not show correlation with expression. It is intriguing why the significant correlation is found only for the bisulfite cloning sequencing results. First of all, although not significant, an inverse correlation appears in the statistical analysis for the pyrosequencing results. However, it is only a statistical trend. One possible explanation would be that DNA methylation levels measured by bisulfite cloning sequencing average the methylation levels of an extended genomic region (15 CpGs), and therefore, this result may be more close to the real functional effect of methylation on gene expression than the result of individual CpGs.

Epigenetic disturbances are increasingly being described for a number of genes related to $A D$, including genes harboring rare variants that contribute to developing $\mathrm{AD}$ [34-40]. In this sense, our work provides new knowledge about the epigenetic alterations involved in gene transcription regulation in key brain regions for the development of $\mathrm{AD}$. Additionally, our results support the involvement of PLD3 in the pathology of AD.

\section{Conclusions}

To sum up, this study confirms that PLD3 gene is downregulated in the hippocampus of $\mathrm{AD}$ patients. Moreover, PLD3 expression inversely correlates with $\beta$-amyloid burden, which adds evidence to the hypothesis that PLD3 protein may contribute to $\mathrm{AD}$ development through modifying APP processing. Having identified a differentially methylated region in an alternative promoter of $P L D 3$, our study suggests that epigenetic disturbances in PLD3 gene may be involved in the pathological processes of $\mathrm{AD}$.

\section{Additional file}

Additional file 1: Table S1. Brain sample set analyzed in our study Table S2. RT-qPCR and bisulfite PCR primers. Table S3. Adjusted logistic regression model to predict AD status. (PDF $465 \mathrm{~kb}$ )

\section{Abbreviation}

AD: Alzheimer's disease; ANOVA: Analysis of variance; APOE4: $\varepsilon 4$ allele of the APOE gene; APP: Amyloid precursor protein; APS: Amyloid plaque score; CDNA: Complementary DNA; CpG: Cytosine-phosphate-guanine dinucleotide GEO: Gene Expression Omnibus: PLD3: Phospholipase D family, member 3: PrEST: Protein epitope signature tag; p-tau: Hyperphosphorylated tau; QQ: Quantil-quantil plots; RT-qPCR: Real-time quantitative PCR; Tau AT8: Mouse monoclonal antibody anti-human PHF-TAU, clone AT-8; UCSC: University of California, Santa Cruz; V232M: Val232-to-met substitution

\section{Acknowledgements}

We want to kindly thank Teresa Tunón M.D., Ph.D (Department of Pathology, Complejo Hospitalario de Navarra, technical support), Federico García-Bragado M.D. Ph.D (Department of Pathology, Complejo Hospitalario de Navarra, technical support), Iván Méndez M.D. (Department of Internal Medicine, Hospital García Orcoyen, technical editing), and Isabel Gil M.D. (Navarrabiomed BrainBank, technical support) for their help. Finally, we are very grateful to the patients and relatives that generously donor the brain tissue to the Navarrabiomed Brain Bank.

\section{Funding}

This work was supported by the Spanish Government through grants from the Institute of Health Carlos III (FIS PI13/02730 \& PI17/02218), jointly funded by the European Regional Development Fund (ERDF), European Union, "A way of shaping Europe"; the Regional Basque Government through a grant from The Basque Foundation for Health Innovation and Research (BIOEF) (BIO12/ALZ) 007), a grant from Fundación Caja-Navarra; and the Trans-Pyrenean Biomedical Research Network (REFBIO). In addition, AUC received a grant "Doctorados industriales 2018-2020" founded by the Govemment of Navarra and MM received a grant "Programa de intensificación" funded by Fundación Bancaria "la Caixa" and Fundación Caja-Navarra.

\section{Availability of data and materials}

The datasets generated and analyzed during the current study are available from the corresponding author on reasonable request.

\section{Authors' contributions}

IBL contributed to the acquisition of the data, analysis and interpretation of the data, and drafting/revising of the manuscript for content. MR contributed to the acquisition of the data and drafting/revising of the manuscript for content. JSR contributed to the analysis and interpretation of the data ( $\mathrm{p}$-tau and amyloid deposits), sorting of the patients into different stages, and acquisition of the image data. AU contributed to the analysis of the data, figure drawing, and drafting/revising of the manuscript for content. MR contributed to the running of the experiments and was involved in the interpretation of the data. MC contributed to the acquisition of the data and drafting/revising of the manuscript for content. MVZ participated in the revision of the subject diagnosis and classification of patients and 
contributed to the drafting/revising the manuscript for content. MEE contributed to the analysis of the results and drafting/revising of the manuscript for content. CE contributed to the acquisition of the data diagnosis of the subjects, and drafting/revising of the manuscript for content. MM contributed to the drafting/revising of the manuscript for content, study concept and design, analysis and interpretation of the data, acquisition of the data, statistical analysis, study supervision, and obtaining the funding. All authors read and approved the final manuscript.

\section{Ethics approval and consent to participate}

The Ethics Committee of the "Complejo Hospitalario de Navarra" approved the use of human subjects for this study (Pyto 90/2014). Written informed consent was obtained from all subjects or next of kin.

\section{Consent for publication}

Not applicable.

\section{Competing interests}

The authors declare that they have no competing interests.

\section{Publisher's Note}

Springer Nature remains neutral with regard to jurisdictional claims in published maps and institutional affiliations.

\section{Author details}

'Neuroepigenetics Laboratory-Navarrabiomed, Complejo Hospitalario de Navarra, Universidad Pública de Navarra (UPNA), IdiSNA (Navarra Institute for Health Research), C/ Irunlarrea, 3, 31008 Pamplona, Navarra, Spain. Department of Neurology, Complejo Hospitalario de Navarra- IdiSNA (Navarra Institute for Health Research), C/ Inunlarrea, 3, 31008 Pamplona, Navarra, Spain. ${ }^{3}$ Department of Pathology, Complejo Hospitalario de NavarraIdiSNA (Navarra Institute for Health Research), 31008 Pamplona, Navarra, Spain. ${ }^{4}$ Hospital Psicogeriátrico Josefina Arregui, 31800 Alsasua, Navarra,

Received: 23 June 2018 Accepted: 27 August 2018 Published online: 12 September 2018

References

1. Bettens K, Sleegers K, Van Broeckhoven C. Genetic insights in Alzheimer's disease. Lancet Neurol. 2013;12(1):92-104. https://doi.org/10.1016/514744422(12)70259-4.

2. Zhu JB, Tan CC, Tan L, Yu JT. State of play in Alzheimer's disease genetics I Alzheimers Dis. 2017:58(3):631-59. https://doi org/10.3233/JAD-170062

3. Humphries C, Kohli MA. Rare variants and transcriptomics in Altheimer disease Curr Genet Med Rep. 2014;2(2):75-84. https//doi.org/10.1007/s40142-014-0035-9.

4. Giri M, Zhang M, Lü Y. Genes associated with Alzheimer's disease: an overview and current status. Clin Interv Aging. 2016:11:665-81. https:/do org/10.2147/CIA.S105769.

5. Guimas Almeida C, Sadat Mirfakhar F, Perdigăo C, Burrinha T. Impact of lateonset Alzheimer's genetic risk factors on beta-amyloid endocytic production. Cell Mol Life Sci. 2018; https://doi.org/10.1007/s00018-018-2825-9.

6. Munck A, Böhm C, Seibel NM, Hashemol Hosseini Z. Hampe W. Hu-K4 is a ubiquitously expressed type 2 transmembrane protein associated with the endoplasmic reticulum. FEBS J. 2005;272(7):1718-26. https://doi.org/10.1111/ j.1742-4658.2005.04601.x.

7. Gonzalez AC, Schweizer M, Jagdmann S, Bernreuther C, Reinheckel T, Saftig $P$. et al. Unconventional trafficking of mammalian phospholipase D3 to lysosomes. Cell Rep. 2018;22(4):1040-53. https//doi.org/10.1016/j.celrep. 2017.12.100.

8. Cruchaga C, Karch CM, Jin SC, Benitez BA, Cai Y, Guerreiro R, et al. Rare coding variants in the phospholipase D3 gene confer risk for Alzheimer's disease Nature 2014:505(7484):550-4 https//doiorg/101038/nature12825.

9. Satoh J, Kino Y, Yamamoto Y, Kawana N, Ishida T, Saito Y, et al. PLD3 is accumulated on neuritic plaques in Alzheimer's disease brains. Altheimers Res Ther. 2014;6(9):70. https//doi.org/10.1186/s13195-014-0070-5.

10. Engelman CD, Darst BF, Bilgel M, Vasilievic E, Koscik RL, Jedynak BM, et al. The effect of rare variants in TREM2 and PLD3 on longitudinal cognitive function in the Wisconsin Registry for Alzheimer's Prevention. Neurobiol Aging. 2018;66: 177.el-5. https//doi.org/10.1016/..neurobiolaging.2017.12.025
11. Zhang DF, Fan Y, Wang D, Bi R, Zhang C, Fang Y, et al. PLD3 in Alzheimer's disease: a modest effect as revealed by updated association and expression analyses. Mol Neurobiol. 2016;53(6):4034-45. https://doi.org/10.1007/512035015-9353-5.

12. van der Lee $\mathrm{SJ}$, Holstege $\mathrm{H}$, Wong $\mathrm{TH}$, Jakobsdottir J, Bis JC, Chouraki V, et al. PLD3 variants in population studies. Nature. 2015;520(7545):E2-3. https:// doi.org/10.1038/nature14038.

13. Cacace R, Van den Bossche T, Engelborghs S, Geerts N, Laureys A, Dillen L, et al. Rare variants in PLD3 do not affect risk for early-onset Altheimer disease in a European Consortium Cohort. Hum Mutat. 2015;36(12):1226-35. https:/doi.org/10.1002/humu.22908.

14. Lambert JC, Grenier-Boley B, Bellenguez C, Pasquier F, Campion D, Dartigues IF, et al. PLD3 and sporadic Altheimer's disease risk. Nature. 2015;520(7545): E1. https://doi.org/10.1038/nature 14036

15. Heilmann S, Drichel D, Clarimon J, Fernández V, Lacour A, Wagner H, et al PLD3 in non-familial Alzheimer's disease. Nature. 2015;520(7545):E3-5. https:/doi.org/10,1038/nature14039.

16. Bell JE, Alafuzoff I, Al-Sarraj S, Arzberger T, Bogdanovic N, Budka $\mathrm{H}$, et Management of a twenty-first century brain bank: experience in the BrainNet Europe consortium. Acta Neuropathol. 2008;115(5):497-507. https:/doi.org/10.1007/s00401-008-0360-8.

17. Montine TJ, Phelps CH, Beach TG, Bigio EH, Cairns NJ, Dickson DW, et al. National Institute on Aging-Alzheimer's Association quidelines for the neuropathologic assessment of Alzheimer's disease: a practical approach. Acta Neuropathol. 2012;123(1):1-11. https://doi.org/10.1007/ 500401-011-0910-3.

18. Braak H, Alafuzoff I, Arzberger T, Kretzschmar H, Del Tredici K. Staging of Alzheimer disease-associated neurofibrillary pathology using paraffin sections and immunocytochemistry. Acta Neuropathol. 2006;1 12(4):389-404 https:/doi.org/10.1007/500401-006-0127-z.

19. Livak KJ, Schmittgen TD. Analysis of relative gene expression data using real-time quantitative PCR and the 2(-Delta Delta C(T)) Method. Methods (San Diego, Calif). 2001;25(4):402-8. https://doi.org/10.1006/meth.2001.1262.

20. Celarain N, Sánchez-Ruiz de Gordoa J, Zelaya MV, Roldán M, Larumbe R, Pulido L, et al. TREM2 upregulation correlates with 5 -hydroxymethycytosine enrichment in Altheimer's disease hippocampus. Clin Epigenetics. 2016;8:37. https:/doi.org/10.1186/s13148-016-0202-9.

21. Braak H, Braak E. Neuropathological stageing of Alzheimer-related changes. Acta Neuropathol. 1991;82(4):239-59.

22. Miller SA, Dykes DD, Polesky HF. A simple salting out procedure for extracting DNA from human nudeated cells. Nucleic Acids Res. 1988;16(3):1215.

23. Li LC, Dahiya R. MethPrimer: designing primers for methylation PCR Bioinformatics. 2002;18(11):1427-31.

24. Kumaki Y, Oda M, Okano M. QUMA: quantification tool for methylation analysis. Nucleic Acids Res. 2008;36(Web Server issue):W170-5. https//doi. org/10.1093/nar/gkn294.

25. Kent WJ, Sugnet CW, Furey TS, Roskin KM, Pringle TH, Zahler AM, et al. The human genome browser at UCSC. Genome research. 2002;12(6):996-1006. https:/doi.org/10.1101/gr.229102. Article published online before print in May 2002

26. Liang WS, Reiman EM, Valla J, Dunckley T, Beach TG, Grover A, et al. Alzheimer's disease is associated with reduced expression of energy metabolism genes in posterior cingulate neurons. Proc Natl Acad Sci U S A. 2008;105(11):4441-6. https://doi.org/10.1073/pnas.0709259105.

27. Mukadam AS, Breusegem SY, Seaman MNJ. Analysis of novel endosome-toGolgi retrieval genes reveals a role for PLD3 in regulating endosoma protein sorting and amyloid precursor protein processing. Cell Mol Life Sci. 2018; https://doi.org/10.1007/s00018-018-2752-9.

28. Tanaka Y, Suzuki G, Matsuwaki T. Hosokawa M, Serrano G, Beach TG, et a. Progranulin regulates lysosomal function and biogenesis through acidification of lysosomes. Hum Mol Genet. 2017;26(5):969-88. https:/doi. org/10.1093/hmg/ddx011.

29. Fazzari P, Horre K, Arranz AM, Frigerio CS, Saito T, Saido TC, et al. PLD3 gene and processing of APP. Nature. 2017;541(7638):E1-2. https//doi.org/10.1038 nature 21030

30. Nibbeling EAR, Duarri A, Verschuuren-Bemelmans CC, Fokkens MR Karjalainen JM, Smeets CLM, et al. Exome sequencing and network analysis identifies shared mechanisms underlying spinocerebellar ataxia. Brain. 2017; 40(11):2860-78. https://doi.org/10.1093/brain/awx251

31. Unno T, Wakamori M, Koike M, Uchiyama Y, Ishikawa K, Kubota $\mathrm{H}$, et al. Development of Purkinje cell degeneration in a knockin mouse mode 
reveals lysosomal involvement in the pathogenesis of SCA6. Proc Natl Acad Sci U S A. 2012;109(43):17693-8. https//doi.org/10.1073/pnas.1212786109.

32. Alves $S$, Cormier-Dequaire F, Marinello M, Marais T, Muriel MP, Beaumatin F, et al. The autophagy/lysosome pathway is impaired in SCA7 patients and SCA7 knock-in mice. Acta Neuropathol. 2014;128(5):705-22. https//doi.org/ 10.1007/500401-014-1289-8.

33. Pedersen KM, Finsen B, Celis JE, Jensen NA. Expression of a novel murine phospholipase D homolog coincides with late neuronal development in the forebrain. J Biol Chem. 1998:273(47):31494-504.

34. Bakulski KM, Dolinoy DC, Sartor MA, Paulson HL, Konen JR, Lieberman AP, et al. Genome-wide DNA methylation differences between late-onset Alzheimer's disease and cognitively normal controls in human frontal cortex. J Alzheimers Dis. 2012;29(3):571-88. https://doi.org/10.3233//ad-2012-111223

35. Sanchez-Mut JV, Aso E, Heyn H, Matsuda T, Bock C, Ferrer I, et al. Promoter hypermethylation of the phosphatase DUSP22 mediates PKA-dependent TAU phosphorylation and CREB activation in Altheimer's disease. Hippocampus. 2014;24(4):363-8. https:/doi.org/10.1002/hipo.22245.

36. Lunnon K, Smith R, Hannon E, De Jager PL, Srivastava G, Volta M, et al. Methylomic profiling implicates cortical deregulation of ANK1 in Alzheimer's disease. Nat Neurosci. 2014;17(9):1164-70. https//doi.org/10.1038/nn.3782.

37. De Jager PL, Srivastava G, Lunnon K, Burgess J, Schalkwyk LC, Yu L, et al. Alzheimer's disease: early alterations in brain DNA methylation at ANK1, BIN1, RHBDF2 and other loci. Nat Neurosci. 2014;17(9):1156-63. https//doi. org/10.1038/nn.3786.

38. Yu L, Chibnik LB, Srivastava GP, Pochet N, Yang J, Xu J, et al. Association of Brain DNA methylation in SORLI, ABCA7, HLA-DRBS, SLC24A4, and BIN 1 with pathological diagnosis of Alzheimer disease. JAMA Neurol. 2015;72(1): 15-24. https//doi.org/10.1001/jamaneurol.2014.3049.

39. Watson CT, Roussos P, Garg P. Ho DJ, Azam N, Katsel PL, et al. Genome wide DNA methylation profiling in the superior temporal gyrus reveals epigenetic signatures associated with Alzheimer's disease. Genome Med. 2016;8(1):5. https://doi.org/10.1186/s13073-015-0258-8.

40. Celarain N, Sanchez-Ruiz de Gordoa J, Zelaya MV, Roldan M, Larumbe R, Pulido $L$, et al. TREM2 upregulation correlates with 5 -hydroxymethycytosine enrichment in Alzheimer's disease hippocampus. Clinical Epigenetics. 2016; 8:37. https://doi.org/10.1186/s13148-016-0202-9. 


\section{Additional File 1}

Supplemental Table S1. Brain sample set analyzed in our study.

No. Diagnosis Braak stage APS Age at death (years) Gender PMI (h) Cohort type

\begin{tabular}{|llll}
\hline 1 & Control & 0 & NA \\
\hline 2 & Control & 0 & NA \\
\hline 3 & Control & 0 & NA \\
\hline 4 & Control & 0 & NA \\
\hline 5 & Control & 0 & NA \\
\hline 6 & Control & 0 & NA \\
\hline 7 & Control & 0 & NA \\
\hline 8 & Control & 0 & NA \\
\hline
\end{tabular}

\begin{tabular}{rlll}
\hline 9 & Control & 0 & NA \\
\hline 10 & Control & 0 & NA \\
\hline 11 & Control & 0 & NA \\
\hline 12 & Control & 0 & NA \\
\hline 13 & Control & 0 & NA
\end{tabular}

$\begin{array}{lllll}13 & \text { Control } & 0 & \text { NA } & 5 \\ 14 & \text { Control } & 0 & \text { NA } & 66 \\ 15 & \text { Control } & 0 & \text { NA } & 88\end{array}$

16 Control $\quad 0 \quad$ NA $\quad 76$

\begin{tabular}{lllll}
17 & Control & 0 & NA & 65 \\
\hline 18 & Control & 0 & NA & 69
\end{tabular}

\begin{tabular}{|ccccc}
\hline 19 & $A D$ & I & 0,00 & 60 \\
\hline 20 & $A D$ & I & 2,00 & 85 \\
\hline 21 & $A D$ & I & NA & 85 \\
\hline
\end{tabular}

\begin{tabular}{|ccccc}
\hline 22 & AD & I & NA & 80 \\
\hline 23 & AD & II & 0,00 &
\end{tabular}

\begin{tabular}{lllll}
\hline 24 & AD & II & NA & 80 \\
\hline 25 & AD & II & NA & 71 \\
\hline 26 & AD & & NA
\end{tabular}

$\begin{array}{lllll}26 & \text { AD } & \text { II } & \text { NA } & 71 \\ 27 & \text { AD } & \text { II } & \text { NA } & 74\end{array}$

$\begin{array}{ccccc}28 & \text { AD } & \text { III } & 0 & 85 \\ 29 & \text { AD } & \text { III } & 0,00 & 88\end{array}$

\begin{tabular}{|c|c|c|c|}
\hline 30 & $A D$ & III & 3,00 \\
\hline 31 & $A D$ & III & 0,33 \\
\hline
\end{tabular}

\begin{tabular}{|c|c|c|c|c|c|c|c|}
\hline J1 & $A D$ & III & 0,00 & 19 & Temale & 15 & original \\
\hline 32 & $A D$ & III & 2,33 & 84 & female & 13 & original \\
\hline 33 & $A D$ & III & 2,00 & 98 & female & 23 & original \\
\hline 34 & $A D$ & III & 2,67 & 85 & female & NA & original \\
\hline 35 & $A D$ & III & 3,67 & 83 & male & 9 & original \\
\hline 36 & $A D$ & III & 6,67 & 69 & female & 4,3 & original \\
\hline 37 & $A D$ & III-IV & 1,00 & 81 & female & 9 & original \\
\hline 38 & $A D$ & III-IV & 6,67 & 98 & female & 3 & original \\
\hline 39 & $A D$ & IV & 5,00 & 88 & male & 3,5 & original \\
\hline
\end{tabular}


PLD3 in AD hippocampus 2

\begin{tabular}{|cccccccc|}
\hline 40 & $\mathrm{AD}$ & IV & 2,33 & 91 & female & 10 & original \\
\hline 41 & $\mathrm{AD}$ & $\mathrm{IV}$ & 1,33 & 84 & male & 3,3 & original \\
\hline 42 & $\mathrm{AD}$ & $\mathrm{IV}$ & 3,00 & 97 & female & $\mathrm{NA}$ & original \\
\hline 43 & $\mathrm{AD}$ & $\mathrm{IV}$ & 1,33 & 78 & male & 5 & original \\
\hline 44 & $\mathrm{AD}$ & $\mathrm{IV}$ & 1,33 & 90 & female & 3 & original \\
\hline 45 & $\mathrm{AD}$ & $\mathrm{V}$ & 3,00 & 92 & female & 14 & original \\
\hline 46 & $\mathrm{AD}$ & $\mathrm{V}$ & 4,00 & 77 & female & 11 & original \\
\hline 47 & $\mathrm{AD}$ & $\mathrm{V}$ & 7,00 & 82 & female & 9 & original \\
\hline 48 & $\mathrm{AD}$ & $\mathrm{V}$ & 8,00 & 91 & male & 5 & original \\
\hline 49 & $\mathrm{AD}$ & $\mathrm{V}$ & 5,67 & 77 & female & 4 & original \\
\hline 50 & $\mathrm{AD}$ & $\mathrm{VI}$ & 3,33 & 93 & female & 3 & original \\
\hline 51 & $\mathrm{AD}$ & $\mathrm{VI}$ & 8,00 & 86 & female & 2,3 & original \\
\hline 52 & $\mathrm{AD}$ & $\mathrm{VI}$ & 4,33 & 61 & male & 10 & original \\
\hline 53 & $\mathrm{AD}$ & $\mathrm{VI}$ & 9,67 & 70 & male & 2,35 & original \\
\hline 54 & $\mathrm{AD}$ & $\mathrm{VI}$ & 8,33 & 59 & male & 4 & original \\
\hline
\end{tabular}

The table shows the characteristic of the samples included in the study $(n=54)$. No.: Number; APC: amyloid plaque score; h: hours; AD: Alzheimer's disease; PMI: post mortem interval; $\mathrm{NA}=$ not applicable. 
$P L D 3$ in AD hippocampus 3

Supplemental Table S2. RT-qPCR and Bisulfite PCR primers.

\begin{tabular}{|c|c|c|c|c|c|c|c|}
\hline ID & Accesion number & Purpose & Amplicon Size & $\mathrm{Tm}$ & Primer $F$ & $\operatorname{Tm} 2$ & Primer $\mathrm{R}$ \\
\hline PLD3 bis & \multirow{2}{*}{ NA } & \multirow{2}{*}{ Bisulfite PCR } & 269 & 59.6 & TTTTTTITTTTTTATTGGGGTTT & 59.09 & AACCCCAACTTCTATCTAAACAAACTA \\
\hline PLD3_prom bis & & & 318 & 59.1 & TGGGATTATTTGTTTTATTGTATAGATG & 59.37 & АTTTCTTTAAАCCTCAATTTCCTCC \\
\hline PLD3 pyro & \multirow{2}{*}{ NA } & \multirow{2}{*}{ Pyrosequencing } & 240 & 60.1 & ATTTTAGGGTGGAATGTAGTAAAGT & 61 & AACTACCTCCCATAAACCCCCAACTTCTA \\
\hline PLD3 seq & & & & 40.7 & GTGAGTTAGGATTGGG & & \\
\hline PLD3_prin pyro & \multirow{2}{*}{ NA } & \multirow{2}{*}{ Pyrosequencing } & 112 & 55.5 & ATGAGAAAGGAGTATGTTTGGT & 58.3 & СCCACACCCACCTTCCAAACTATA \\
\hline PLD3_prin seq & & & & 42.1 & TTGGTTTTAGTAGGTTTGTAGTTTA & & \\
\hline PLD3_q & NM_012268 & QPCR & 141 & 61.8 & TTCTATGACACCCGCTACAAC & 62.1 & CACGTTGAGTAGAGCCTTCAG \\
\hline
\end{tabular}

qPCR

14161.8 TTCTATGACACCCGCTACAAC

The table shows the primer pairs used in the study. Amplified transcripts are identified by RefSeq Accession or GeneBank accesion number. qPCR: quantitative PCR; bp: base pair; Tm: Melting Temperature; NA: not applicable. 


\section{IDENTIFICACIÓN DE BIOMARCADORES EPIGENÉTICOS EN LA ENFERMEDAD DE ALZHEIMER}

PLD3 in AD hippocampus 4

Supplemental Table S3. Adjusted Logistic Regression Model to predict AD status.

\begin{tabular}{|cccccc|}
\hline Variable & B & Wald & p-value & OD & CI 95\% for OD \\
\hline A_prom CpG2 methylation levels & 0.085 & 6.104 & $0.013^{*}$ & 0.92 & $0.86-0.98$ \\
\hline Gender (Female) & -0.271 & 0.113 & 0.737 & 1.31 & $0.27-6.37$ \\
\hline Age $<65$ yo & -2.671 & 10.027 & $0.002^{* *}$ & 14.45 & $2.77-75.50$ \\
\hline
\end{tabular}

Alzheimer status (Control=0; $A D=1$ ) was considered as the dependent variable and PLD3 A_prom CpG2 methylation levels, gender and age were included as covariates. B: regression coefficient; OD: odds ratio; IC: confidence interval; yo: year-old; ${ }^{*}$ : p-value $<0.05 ;{ }^{* *}$ : p-value $<0.01$ 
